\author{
Universidade de Brasília \\ Faculdade de Tecnologia \\ Departamento de Engenharia Florestal
}

\title{
TRATAMENTO TERMOMECÂNICO \\ UNILATERAL EM MADEIRA TROPICAL \\ PARA PRODUÇÃO DE PISO: EFEITOS SOBRE AS PROPRIEDADES FÍSICAS, MECÂNICAS E SUPERFICIAIS
}

\author{
ANA CAROLINA SALGADO DE FREITAS \\ Orientador: Prof. Dr. Cláudio Henrique S. Del Menezzi
}

Dissertação de mestrado em Ciências Florestais

Publicação: PPGEFL.DM - 246/2015

Brasília/DF: Fevereiro/2015 
UNIVERSIDADE DE BRASÍLIA

FACULDADE DE TECNOLOGIA

DEPARTAMENTO DE ENGENHARIA FLORESTAL

PROGRAMA DE PÓS-GRADUAÇÃO EM CIÊNCIAS FLORESTAIS

"TRATAMENTO TERMOMECÂNICO UNILATERAL EM MADEIRA TROPICAL PARA PRODUÇÃO DE PISO: EFEITOS SOBRE AS PROPRIEDADES FÍSICAS, MECÂNICAS E SUPERFICIAIS"

ANA CAROLINA SALGADO DE FREITAS

DISSERTAÇÃO DE MESTRADO ACADÊMICO SUBMETIDA AO PROGRAMA DE PÓS-GRADUAÇÃO EM CIÊNCIAS FLORESTAIS, DO DEPARTAMENTO DE ENGENHARIA FLORESTAL, DA FACULDADE DE TECNOLOGIA DA UNIVERSIDADE DE BRASÍLIA, COMO PARTE DOS REQUISITOS NECESSÁRIOS PARA A OBTENÇÃO DO GRAU DE MESTRE.

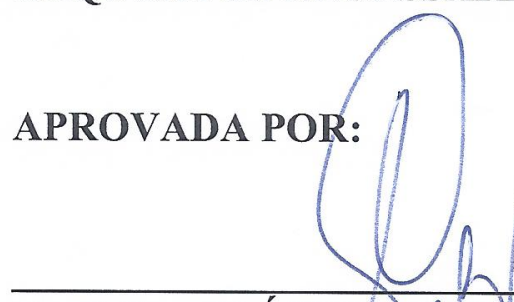

Prof $^{\circ}$ Dr. CLÁUDIO HÉNRIQUE SOARES DEL MENEZZI (Departamento de Engenharia Florestal-EFL, UnB);

(Orientador)

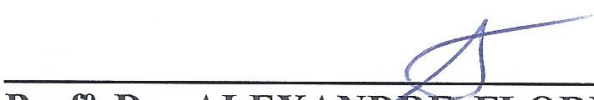

Prof $^{\circ}$ Dr. ALEXANDRE FLORIAN DA COSTA (Departamento de Engenharia Florestal-EFL, UnB);

(Examinador Intermo)

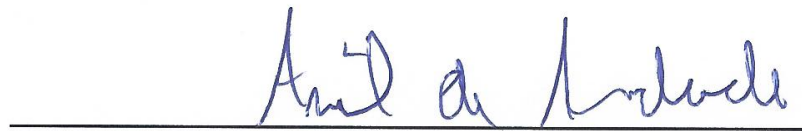

Dr. ARIEL DE ANDRADE (Associação Nacional dos Produtores de Pisos de Madeira Maciça - ANPM/SP);

(Examinador Externo)

Profo Dr. AILTON TEIXEIRA DO VALE (Departamento de Engenharia Florestal-EFL, UnB).

(Examinador Suplente)

Brasília-DF, 20 de fevereiro de 2015. 
Ficha catalográfica elaborada pela Biblioteca Central da Universidade de Brasília. Acervo 1020808.

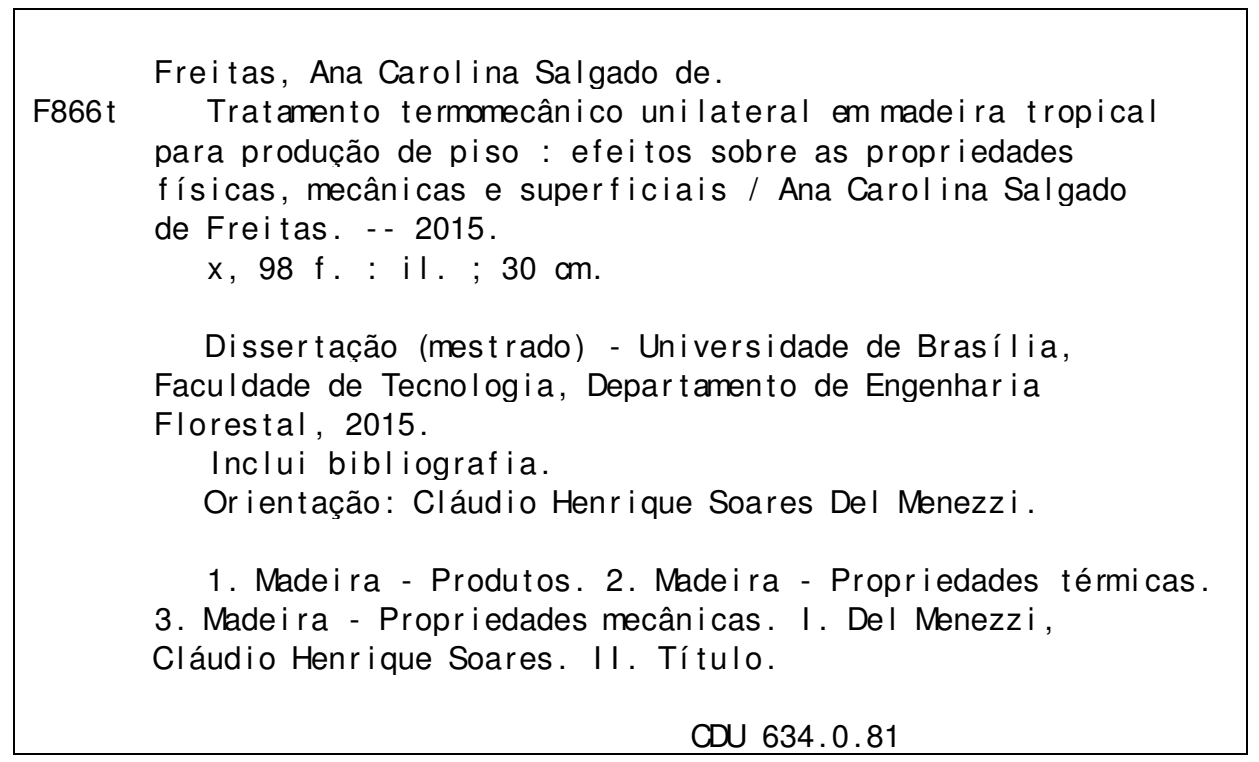




\section{AGRADECIMENTOS}

Agradeço primeiramente a Deus pelo dom da vida e pela oportunidade do meu mestrado.

Agradeço especialmente a minha mãe Lourdes e meu padrasto Jurandir por sempre me darem apoio nos momentos mais difíceis e acreditarem no meu potencial.

Ao Douglas pelos incentivos e dedicação que foram fundamentais nessa jornada e por compartilhar comigo planos de uma vida futura.

Ao meu orientador Cláudio pela ideia do projeto e por estar comigo nessa longa caminhada prestando o apoio necessário na realização deste trabalho.

Gostaria de agradecer também aos meus amigos pelo carinho e por sempre me incentivaram e compartilharem comigo momentos especiais. Em especial agradeço a Rebeca, amiga de longa estrada e que me prestou apoio nos momentos mais importantes, e a Ana Carolina companheira de curso e momentos de descontração.

Aos meus familiares que são a minha e estão sempre presentes em todas as etapas da minha vida.

Aos funcionários do LPF e do Departamento de Engenharia Florestal os quais sem o auxílio não seria possível a conclusão desse trabalho.

A todos os professores da Engenharia Florestal na construção do conhecimento e amadurecimento acadêmico. Agradeço em especial a cadeira de tecnologia.

Ao professor Mário Tomasselo e toda a sua equipe do laboratório de anatomia florestal da Esalq que me recebeu com tanto carinho e se mostrou tão solicito em me ajudar no nos testes de densitometria.

Agradeço a todas as pessoas que me ajudaram na realização deste trabalho, seja direta ou indiretamente. Em especial a amiga Dione. 


\title{
Resumo
}

\section{TRATAMENTO TERMOMECÂNICO UNILATERAL EM MADEIRA TROPICAL PARA PRODUÇÃO DE PISO: EFEITOS SOBRE AS PROPRIEDADES FÍSICAS, MECÂNICAS E SUPERFICIAIS}

\begin{abstract}
A floresta amazônica possui uma grande biodiversidade, na tentativa de garantir que todas as espécies tenham o seu melhor aproveitamento, existem várias técnicas que buscam melhorar as propriedades das madeiras e consequentemente ampliar suas possibilidades de uso, principalmente para produtos de alto valor agregado como o piso de madeira. Entre eles destacase o tratamento termomecânico unilateral que é uma técnica que combina tratamento térmico com a compressão mecânica em apenas uma das faces da madeira, visando obter um produto com menor efeito das tensões internas da compressão e maior resistência mecânica. Em virtude disso, o objetivo do trabalho foi avaliar o efeito do tratamento termomecânico em apenas umas das superfícies da Simarouba amara nas propriedades físicas, mecânicas e superficiais. O tratamento foi realizado utilizando uma prensa hidráulica com resistência elétrica nas temperaturas de $180^{\circ} \mathrm{C}$ e $200^{\circ} \mathrm{C}$, pressão de $7,94 \mathrm{MPa}(50 \%)$ e $11,90 \mathrm{MPa}(75 \%)$ e tempo de 30 minutos, formando quatro tratamentos e a testemunha. Todos os quatro tratamentos realizados foram comparados com a testemunha para verificar o efeito do tratamento termomecânico. $O$ tratamento mostrou que houve um aumento na densificação, o que explica o aumento na densidade final. Nas propriedades superficiais também foram observados ganhos significativos com o escurecimento da madeira e a diminuição da molhabilidade. Os resultados dos ensaios mecânicos também foram positivos com o aumento da taxa de dureza, resistência à compressão paralela e módulo de ruptura. Em relação à estabilidade dimensional, apenas o material tratado com maior pressão $(75 \%)$ apresentou maior inchamento em espessura. Comportamento semelhante foi observado na taxa de não retorno em espessura e na taxa de retração. Houve diminuição do teor de umidade de equilíbrio para a maioria dos tratamentos, mostrando que o tratamento foi eficiente em reduzir a higroscopicidade da madeira e deixando o material mais estável a condições atmosféricas variáveis. A combinação da maior temperatura e menor pressão $\left(200^{\circ} \mathrm{C}\right.$ e $\left.50 \%\right)$ se mostrou mais eficaz para uso que requer maior estabilidade dimensional e o uso da maior pressão e menor temperatura $\left(180^{\circ} \mathrm{C} \mathrm{e}\right.$ $75 \%$ ) o mais indicado em demandas de maior resistência mecânica.
\end{abstract}

Palavra-chave: tratamento termomecânico unilateral, madeira tropical e tensões de compressão 


\section{Abstract \\ UNILATERAL THERMOMECHANICAL TREATMENT IN TROPICAL WOOD FOR FLOOR PRODUCTION: EFFECTS ON PHYSICAL, SURFACE AND MECHANICAL PROPERTIES}

The Amazon forest has a great biodiversity, in an attempt to ensure that all species have their best use, there are several techniques that seek to improve the properties of wood and consequently increase their possibilities of use, especially for high value-added products such as floor wood. Among them stands out the unilateral thermomechanical treatment which is a heat treatment technique that combines with mechanical compression on only one side of the wood obtains a product with less effect of the internal stresses of compression and greater mechanical strength. With a focus on this type of treatment, the objective of this work was to evaluate the effects of thermomechanical treatment in only one of the surfaces of the Simarouba amara (marupá) and its results on the wood's physical, mechanical and surface properties. The treatment was performed using a hydraulic press with electrical resistance at temperatures of $180^{\circ} \mathrm{C}$ and $200^{\circ} \mathrm{C}$, pressure of 7.94 $\mathrm{MPa}(50 \%)$ and $11,90 \mathrm{MPa}(75 \%)$ and time period of 30 minutes. Throughout the tests four treatments 'witnesses' were designated. All four treatments made were compared with the 'witnesses' samples to verify the effect of thermomechanical treatment. The treatment showed an increase in the densification which explains the increase in the final density. The surface properties were also observed significant gains with the darkening of the wood and the reduction of wettability. The results of the mechanical tests were also positive when it comes to the increase of the hardness ratio, parallel compression resistance and modulus of rupture. Regarding the dimensional stability, only the high-pressure $(75 \%)$ treated material showed higher thickness swelling. Similar behavior was observed in the rate of no return in thickness and shrinkage. There was a decrease of the equilibrium moisture content for most treatments, showing that the treatment was effective in reducing the hygroscopicity of wood and achieving a more stable material to variable atmospheric conditions. The combination of higher temperature and lower pressure $\left(200^{\circ} \mathrm{C}\right.$ e $\left.50 \%\right)$ proved to be more effective for uses that require greater dimensional stability. The combination of higher pressure and lower temperature $\left(180^{\circ} \mathrm{C}\right.$ e $\left.75 \%\right)$ proved to be more effective for uses that demand greater mechanical strength.

Keywords: unilateral thermomechanical treatment, tropical wood and compressive stress 


\section{Sumário}

1

INTRODUÇÃO

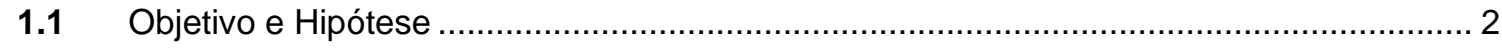

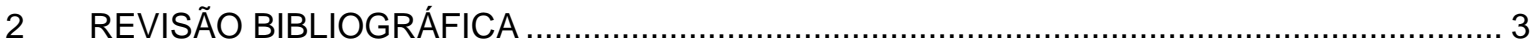

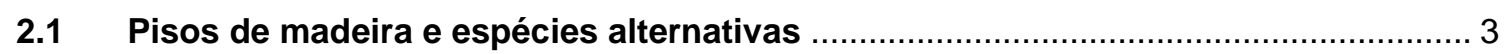

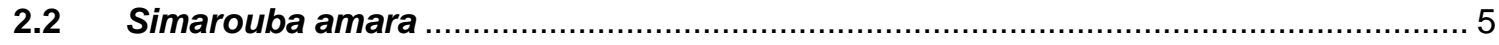

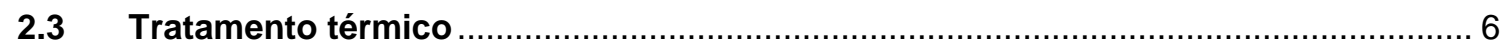

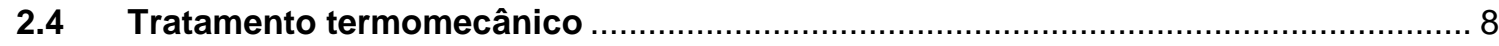

2.5 Efeito do tratamento termomecânico nas propriedades da madeira ....................... 10

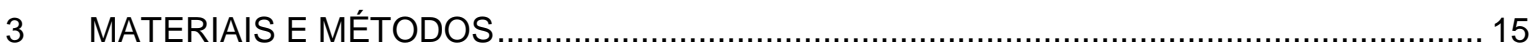

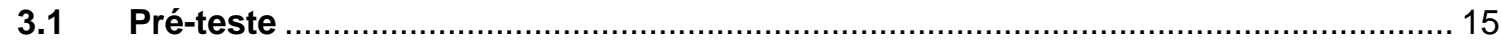

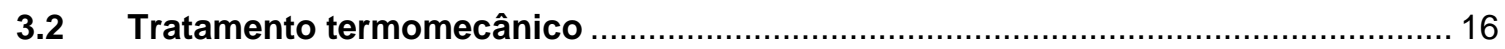

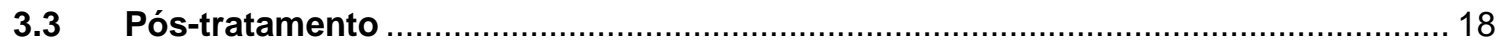

3.4 Confecção dos corpos de prova

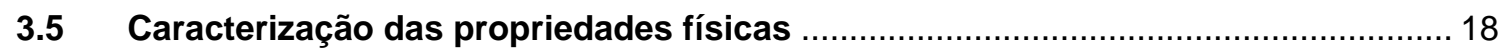

3.6 Caracterização das propriedades mecânicas ………................................................. 23

3.7 Caracterização das propriedades de superfície ………....................................... 25

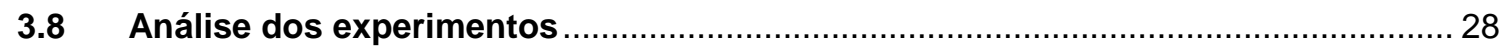

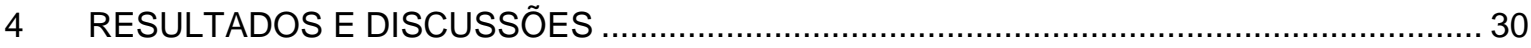

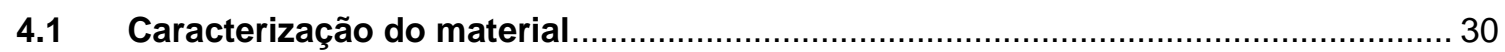

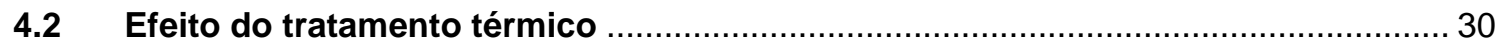

4.2.1 Efeito nas propriedades físicas ……............................................................. 30

4.2.2 Efeito nas propriedades mecânicas …….................................................... 49

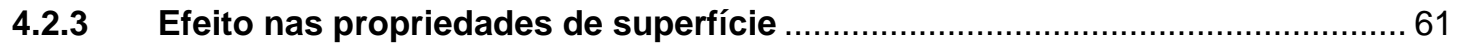

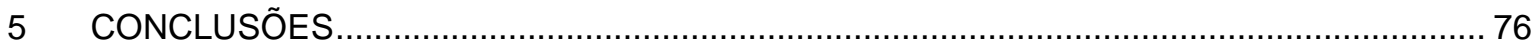

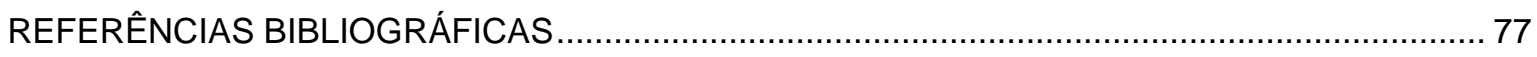

APÊNDICE I - ESTATÍSTICA DESCRITIVA E ANÁLISES DE VARIÂNCIA PARA AS

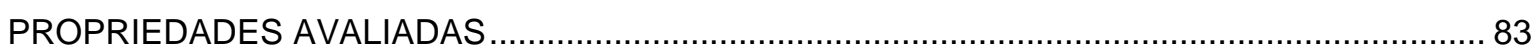




\section{Lista de Figuras}

Figura 1 - Visão microscópica da superfície densificada (a) e da não densificada (b) que passou pelo tratamento termomecânico.

Figura 2 - Prensa hidráulica com resistência elétrica utilizada no tratamento termomecânico unilateral

Figura 3 - Croqui da confecção dos corpos de prova sendo 1, 2 e 3: Flexão estática e Stress Wave, 4:Molhabilidade; 5: Colorimetria; 6:TUE e Estabilidade dimensional; 7: Compressão Paralela; 8: Dureza; 9: Densitometria; 10: Abrasão

Figura 4 - Esquema do teste de inchamento em espessura onde En, Ec e Ef representam espessura natural da amostra, espessura comprimida e espessura final respectivamente e IE, TNRE e TR representam inchamento em espessura, taxa de não retorno em espessura e taxa de retração respectivamente.

Figura 5 - Teste de densitometria de raio-x na face transversal das amostra submetidas ao

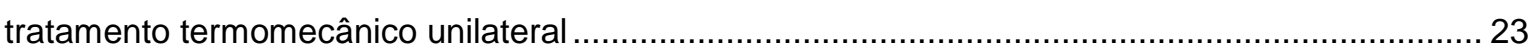

Figura 6 - Ensaio de flexão estática (a); Ensaio de compressão paralela (b); Ensaio de dureza (c)

Figura 7 - Goniômetro - Kruss DSA30 e software DSA30 e marcações sobre a superfície densificada para orientar a deposição da gota séssil 26

Figura 8 - Taber aparelho para ensaio de abrasão e amostra termodensificada passando pelo ensaio de abrasão.

Figura 9 - Resultados da perda de massa (PM) e perda de massa definitiva (PMDAT) dos quatro tratamentos termomecânicos e suas respectivas análises fatoriais com o efeito dos fatores temperatura e pressão isolados

Figura 10 - Resultados da taxa de compressão (TC) para os quatro tratamentos termomecânicos

Figura 11 - Análise fatorial com efeito da temperatura e pressão isolados na taxa de compressão do tratamento termomecânico realizado.

Figura 12 - Interação entre o fator temperatura e pressão na taxa de compressão no tratamento termomecânico...

Figura 13 - Resultados da taxa de densificação (TD) para os quatro tratamentos termomecânicos e análise fatorial com o efeito dos fatores temperatura e pressão isolados.

Figura 14 - Resultados da densidade final dos quatro tratamentos termomecânicos e da testemunha.

Figura 15 - Análise fatorial com o efeito dos fatores temperatura e pressão isolados na densidade final dos tratamentos termomecânicos

Figura 16 - Perfil da densidade da espessura dos quatro tratamentos e da testemunha dividido em três zonas de comportamento

Figura 17 - Imagens da anatomia macroscópica das três zonas do perfil de densidade dos quatro tratamentos e da testemunha. 
Figura 18 - Resultados do teor de umidade de equilíbrio (TUE) dos quatro tratamentos termomecânicos e a testemunha

Figura 19 - Análise fatorial com efeito isolado dos fatores temperatura e pressão no TUE dos tratamentos termomecânicos

Figura 20 - Resultados do inchamento em espessura após duas e vinte e quatro horas para os quatro tratamentos termomecânicos e a testemunha e análise fatorial com efeito dos fatores temperatura e pressão isolados

Figura 21 - Resultados da absorção em espessura após duas e 24 horas para os quatro tratamentos termomecânicos e a testemunha e análise fatorial com efeito dos fatores temperatura e pressão isolados

Figura 22 - Resultados da taxa de não retorno em espessura para os quatro tratamentos termomecânicos e a testemunha

Figura 23 - Análise fatorial com efeito dos fatores temperatura e pressão isolados na taxa de não retorno em espessura nos tratamentos termomecânicos

Figura 24 - Resultados da taxa de retração em espessura para os quatro tratamentos termomecânicos e a testemunha e análise fatorial com efeito dos fatores temperatura e pressão isolados

Figura 25 - Comparação entre a taxa de não retorno em espessura, taxa de compressão e inchamento em espessura dos quatro tratamentos termomecânicos analisados.

Figura 26 - Interação entre os fatores temperatura e pressão para AB2H, AB24H e TNRE dos quatros tratamentos termomecânicos analisados.

Figura 27 - Resultados da dureza para os quatro tratamentos termomecânicos e a testemunha e análise fatorial com efeito da temperatura e pressão isolados

Figura 28 - Resultados da resistência à compressão paralela para os quatro tratamentos e a

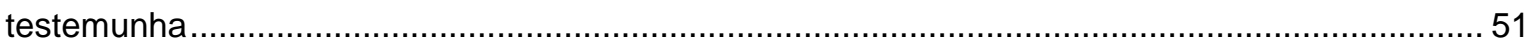

Figura 29 - Análise fatorial com efeito dos fatores temperatura e pressão isolados . 52 Figura 30 - Resultados do $\mathrm{f}_{\mathrm{M}}$ lado não densificado e lado densificado para os quatro tratamentos termomecânicos e a testemunha

Figura 31 - Análise fatorial com efeito dos fatores temperatura e pressão isolados no $f_{M}$ dos tratamentos termomecânicos

Figura 32 - Interação entre os fatores temperatura e pressão para $f_{M}$ lado densificado dos quatros tratamentos termomecânicos analisados.

Figura 33 - Resultados do $E_{m}$ do lado não densificado e lado densificado para os quatro tratamentos termomecânicos e a testemunha

Figura 34 - Análise fatorial com efeito do fator temperatura isolados no $E_{m}$ do tratamento termomecânicos

Figura 35 - Análise fatorial com efeito do fator pressão isolados no $E_{m}$ do tratamento

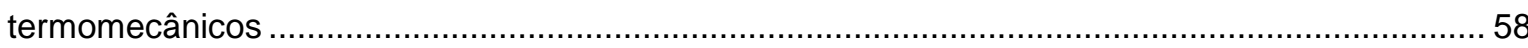

Figura 36 - Resultados da $E_{d}$ para os quatro tratamentos termomecânicos e a testemunha ..........58 
Figura 37 - Análise fatorial com efeito dos fatores temperatura e pressão isolados no $E_{d}$ dos tratamentos termomecânicos

Figura 38 - Resultados da velocidade de propagação da onda para os quatro tratamentos termomecânicos e a testemunha e análise fatorial com efeito dos fatores temperatura e pressão isolados 60

Figura 39 - Resultados do ângulo de contato para os quatro tratamentos termomecânicos e a testemunha.

Figura 40 - Análise fatorial com efeito dos fatores temperatura e pressão isolados no ângulo de contato nos tratamentos termomecânicos

Figura 41 - Corpos de prova com o desgaste do teste de abrasão.

Figura 42 - Resultados da taxa de desgaste para os quatro tratamentos termomecânicos e a testemunha e análise fatorial com efeito da temperatura e pressão isolados

Figura 43 - Resultados da perda de massa para os quatro tratamentos termomecânicos e a testemunha e análise fatorial com efeito da temperatura e pressão isolados 65

Figura 44 - Resultados da claridade $L^{*}$ para os quatro tratamentos termomecânicos e a testemunha. 66

Figura 45 - Resultados do parâmetro $a^{*}$ para os quatro tratamentos termomecânicos e a testemunha.

Figura 46 - Resultados do parâmetro $b^{*}$ para os quatro tratamentos termomecânicos e a testemunha.

Figura 47 - Resultados do parâmetro C para os quatro tratamentos termomecânicos e a testemunha. 69

Figura 48 - Resultados do parâmetro $h^{*}$ para os quatro tratamentos termomecânicos e a testemunha...... 69

Figura 49 - Análise fatorial com efeito dos fatores temperatura e pressão isolados para os parâmetros $L^{*}$ e $a^{*}$ dos tratamentos termomecânicos . 70 Figura 50 - Análise fatorial com efeito dos fatores temperatura e pressão isolados para os parâmetro b* e C dos tratamentos termomecânicos. 71 Figura 51 - Análise fatorial com efeito dos fatores temperatura e pressão isolados para 0

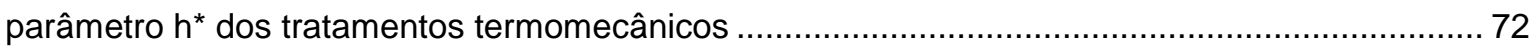
Figura 52 - Resultados para $\Delta \mathrm{E}$ nos quatros tratamentos termomecânicos .................................... 73 Figura 53 - Variação da cor entre os tratamentos e a testemunha 73 


\section{Lista de Tabelas}

Tabela 1 - Consumo energético para produção de materiais 3

Tabela 2 - Principais espécies de madeira utilizadas na confecção de pisos 4

Tabela 3- Temperatura e pressão utilizadas no pré-teste para determinação das temperaturas definitivas nos tratamentos termomecânicos 16

Tabela 4 - Delineamento experimental do tratamento termomecânico unilateral nas tábuas de marupá 16

Tabela 5 - Classificação da variação total da cor $(\Delta \mathrm{E})$ de madeiras 28

Tabela 6 -Resultados do desvio padrão, densidade aparente e do coeficiente de variação dos quatro tratamentos termomecânicos unilateral realizados e a testemunha 30 Tabela 7 - Resultados das médias, valores máximos e mínimos para a densitometria de raio-x dos quatro tratamentos termomecânicos e da testemunha 37 Tabela 8 - Características físicas e mecânicas de espécies madeireiras utilizadas na produção de piso 52

Tabela 9 - Resultados para as variações dos paramentos colorimétricos entre os tratamentos e a testemunha. 72

Tabela 10 - Tabela resumo com efeito da temperatura e da pressão do tratamento termomecânico nas propriedades físicas, superficiais e mecânicas 


\section{LISTA DE SÍMBOLOS, NOMENCLATURAS E ABREVIAÇÕES}

\begin{tabular}{|c|c|}
\hline$a^{*}$ & - Matiz vermelha \\
\hline $\mathrm{AB} 2 \mathrm{H}$ & - Absorção de água após duas horas \\
\hline $\mathrm{AB} 24 \mathrm{H}$ & - Absorção de água após vinte e quatro horas \\
\hline$A C$ & - Ângulo de contato \\
\hline$b^{*}$ & - Matiz amarela \\
\hline C & - Saturação \\
\hline $\mathrm{CP}$ & - Corpo-de-prova \\
\hline$\rho f$ & - Densidade final \\
\hline $\mathrm{Em}$ & - Módulo de elasticidade \\
\hline$f_{c}, 0^{\circ}$ & - Resistência à compressão paralela \\
\hline $\mathrm{fH}, 90^{\circ}$ & - Dureza Janka \\
\hline$f_{M}$ & - Resistência na flexão estática \\
\hline$h^{*}$ & - Ângulo de tinta \\
\hline $\mathrm{IE} 2 \mathrm{H}$ & - Inchamento em espessura após duas horas \\
\hline IE24H & - Inchamento em espessura após vinte e quatro horas \\
\hline$L^{*}$ & - Claridade \\
\hline MOE & - Módulo de elasticidade \\
\hline MOR & - Módulo de ruptura \\
\hline PM & - Perda de massa \\
\hline \multicolumn{2}{|c|}{ PMdaA - Perda de massa da abrasão } \\
\hline \multicolumn{2}{|c|}{ PMDAT - Perda de massa definitiva após o tratamento } \\
\hline TC & - Taxa de compressão \\
\hline TD & - Taxa de densificação \\
\hline TNRE & - Taxa de não retorno em espessura \\
\hline TR & - Taxa de retração \\
\hline TUE & - Teor de umidade de equilíbrio \\
\hline$v_{0}$ & - Velocidade \\
\hline$\Delta \mathrm{E}$ & - Variação da cor \\
\hline
\end{tabular}




\section{INTRODUÇÃO}

A Floresta Amazônica é a maior floresta tropical da Terra, que cobre $40 \%$ do continente sulamericano e com uma vasta biodiversidade que chega até trezentas diferentes espécies de plantas produtoras de madeira por hectare (MONGABAY 2013; SOUZA, 1997). Na visão de Souza (1997), para que essa grande variedade não seja um fator negativo para o desenvolvimento sustentável, é preciso que a exploração aproveite todos os materiais possíveis. Loureiro et al., (1977) afirmam que das duas mil espécies conhecidas, apenas algumas dezenas têm mercado firmado. Isto torna necessário promover no mercado as espécies regionais aptas aos mais diversos usos industriais.

Essa grande exploração concentrada em uma reduzida gama de espécies amazônicas acarreta o uso não sustentável desse recurso natural, de modo a levar a redução da biodiversidade. Pode se atribuir parte da responsabilidade dessa situação à falta de investimento em estudos para caracterização tecnológica de novas espécies. Esses estudos podem viabilizar a utilização de outras espécies tropicais que possam se tornar competitivas e consequentemente tornar essa cadeia de produção mais sustentável.

É nesse cenário que surge a necessidade de investimentos em espécies que muitas vezes são subaproveitadas pela falta de conhecimento do seu real potencial de uso como, por exemplo, elementos de piso, que são produtos florestais de alto valor agregado.

O mercado de piso de madeira no Brasil tem ganho força ao longo dos últimos anos, mas ainda é muito pequeno considerando o grande potencial florestal do país. Segundo a Associação Nacional de Produtores de Pisos de Madeira (ANPM) em 2009 e 2010, o Brasil produziu aproximadamente 10 milhões de $\mathrm{m}^{2}$ de piso de madeira sólida, número pouco expressivo quando comparado com a produção em 2009 da Europa e dos EUA, que chega aos 80 milhões de $\mathrm{m}^{2}$. Essa utilização vem crescendo, mas a matéria prima se concentra em madeiras de ipê, cumaru, maçaranduba e jatobá.

Entre as espécies tropicais alternativas existem várias que podem ser citadas como exemplo de madeira com baixa densidade e de coloração mais clara e são subaproveitadas na área da tecnologia da madeira. Para o presente trabalho, o marupá (Simarouba amara) com densidade variando entre 0,45 a $0,55 \mathrm{~g} / \mathrm{cm} 3$, que é considerado uma madeira leve e clara, foi escolhido por apresentar características que geralmente são evitadas na produção de piso de madeira. Esse comércio possui preferência por madeiras mais escuras e com maior densidade, pois são mais resistentes às deteriorações físicas e biológicas.

A madeira, em aspectos gerais, e apesar de ser um material com excelentes propriedades, possui características que podem dificultar o seu uso como instabilidade dimensional e degradação 
biológica. Isso se deve principalmente ao fato da madeira ser um material com alta higroscopicidade e anisotropia (MODES, 2010). A partir disso, a variação dimensional da madeira é uma característica que pode limitar ou até mesmo desqualificá-la para algumas utilizações, devido às grandes alterações em sua estrutura. Com isso, o tratamento térmico surge como uma possível solução para esse problema.

O tratamento térmico tem o objetivo de melhorar algumas propriedades da madeira, como a resistência biológica a estabilidade dimensional, e a resistência à radiação ultravioleta, entre outras, produzindo um material que, no fim do ciclo de vida do produto, não apresenta um perigo ambiental superior ao da madeira não tratada, ou seja, atribui um maior valor agregado à madeira com baixo custo e sem a utilização de produtos químicos. Outra vantagem citada por Stamm (1964) é que a madeira estabilizada dimensionalmente pelo tratamento térmico adquire considerável resistência ao apodrecimento.

Apesar disso, a estabilização da madeira relativa à redução da higroscopicidade é sempre acompanhada pela perda de massa e de uma diminuição da resistência mecânica. Para tentar amenizar essa perda, técnicas de densificação são utilizadas concomitantemente, resultando no tratamento termomecânico. Nesse tratamento, a densificação ocorre através da deformação da parede celular, o que reduz o volume de espaços vazios (KUTNAR et al., 2009). No entanto, a fim de garantir as propriedades adequadas da madeira tratada, é importante que o tratamento ocorra a uma temperatura ideal que seja responsável pela transição vítrea, conferindo, às cadeias poliméricas, maior mobilidade. De acordo com Kultikova (1999), a compressão da madeira sem o colapso celular é o fator mais importante no aumento das propriedades mecânicas e físicas do material densificado. Estudos utilizando modificação termomecânica em madeira são recentes e escassos, especialmente com madeira tropical.

\subsection{Objetivo e hipótese}

O presente trabalho tem como objetivo avaliar o efeito do tratamento termomecânico em apenas uma das superfícies da Simarouba amara nas propriedades físicas, mecânicas e superficiais

Diante de todas as colocações expostas acima, espera-se que a madeira da Simarouba amara aumente sua resistência mecânica e adquira uma cor mais escura após a densificação e ganhe estabilidade dimensional com a diminuição das pressões internas causadas pela compressão. Dessa forma podendo se tornar uma boa alternativa para o mercado de piso de madeira. 


\section{REVISÃo BIBLIOGRÁFICA}

\subsection{Pisos de madeira}

Segundo Silva e Bittencourt (2002), piso pode ser definido como uma superfície qualquer, contínua ou descontínua, construída com a finalidade de permitir o trânsito pesado ou leve. Os mesmos autores destacam alguns aspectos importantes na qualidade de um piso, como: resistência ao desgaste ao trânsito, econômico, inalterabilidade da cor e fácil manutenção. Portanto, o uso e o ambiente em que será inserido determinam a escolha de um piso. Atualmente, existem vários tipos de matérias que são utilizados na produção de pisos, como cerâmica, pedras, resina, vidro e madeira.

A madeira, por ser um produto ecologicamente correto, ou seja, natural, reciclável e renovável, agrega valor ao produto final em tempos em que o desenvolvimento sustentável vem ganhando elevada importância. Além disso, quando são utilizados produtos de madeira durável, como o piso maciço, há uma contribuição para redução do efeito estufa. De forma geral, uma tonelada de madeira representa 1,4 tonelada de gás carbônico $\left(\mathrm{CO}_{2}\right)$ absorvido pelas árvores. São as árvores jovens, em pleno crescimento, que consomem mais carbono e liberam mais oxigênio. Assim, quando se extrai da floresta as árvores maduras e a madeira é utilizada de forma perene, duplicase a eficiência da cadeia de $\mathrm{CO}_{2}$ criada pela fotossíntese (REMADE, 2006).

Andrade (2014) destaca que a agregação de valor que os pisos de madeira trazem aos produtos madeireiros incentiva o manejo sustentável das florestas, pois o retorno econômico dos recursos florestais contribui para a manutenção das florestas em pé. Na atual necessidade de economia de energia, a madeira também ganha vantagens por apresentar consumo muito menor do que outros materiais, conforme mostra a Tabela 1 (ANPM 2014).

Tabela 1 - Consumo energético para produção de materiais

\begin{tabular}{cc}
\hline Produto & kg E. C. por tonelada* \\
\hline Alumínio & 4200 \\
Cal & 1800 \\
Aço & 1000 \\
Cimento & 260 \\
Tijolo Cerâmico & 140 \\
Bloco de Concreto & 25 \\
Madeira & 0,8 \\
\hline
\end{tabular}

${ }^{*} \mathrm{~kg}$ E. C.: quilograma equivalente de carvão $=3000$ kcal. Fonte: ANPM (2014)

O piso de madeira maciça é aquele em que há apenas o beneficiamento da madeira, sem combinações com outros tipos de produtos processados. Segundo ANPM (2006), para escolher a madeira para a produção de piso, algumas características devem ser levadas em consideração 
como: disponibilidade de volume ofertado pelo mercado, ferramentas exigidas para trabalhar durante a produção, cor e tonalidade da madeira, resistência física e mecânica, densidade de média a alta e resistência natural ao ataque de xilófagos.

As principais espécies utilizadas para a produção de piso de madeira maciça no Brasil (ANPM, 2014) estão apresentadas na Tabela 2. A escolha da espécie florestal depende do uso e do tipo de peça a ser confeccionada, e, obviamente, da estética do produto requerido.

Tabela 2 - Principais espécies de madeira utilizadas na confecção de pisos

\begin{tabular}{cc}
\hline Nome Popular & Nome Científico \\
\hline Amendoim & Pterogyne nitens \\
Cabreúva-vermelha & Miroxylon balsamum \\
Cumaru & Dipteryx odorata \\
Ipê & Tabebuia sp. \\
Jatobá & Hymenaea sp. \\
Muiracatiara & Astronium lecointei \\
Pau-marfim & Balfourodendron riedelianum \\
Perobinha & Aspidosperma sunbincanum \\
Roxinho & Peltogyne recifensis \\
Sucupira & Diplotropis purpurea \\
\hline
\end{tabular}

Fonte: ANPM (2014)

Segundo Silva e Souza (1992), dentre as propriedades físicas da madeira, as de extrema importância para as aplicações na produção de pisos são a densidade e a retratibilidade. Devido às relações água-madeira, a umidade é um importante fator a ser observado no piso de madeira, devendo verificar a umidade de equilíbrio antes de ser instalado o piso, para reduzir as contrações e expansões.

Pela forte relação da densidade com a resistência da madeira, algumas espécies tropicais sofrem grande pressão na exploração da cadeia produtiva. No Brasil há uma alta biodiversidade e a falta de conhecimento das propriedades de outras espécies ou até mesmo conhecimento em tecnologias para melhoramento tem representado entraves no crescimento do setor madeireiro.

Paralelamente, vem sendo observada a conscientização da necessidade de um melhor aproveitamento dos recursos naturais provenientes das florestas tropicais, em particular no que concerne à floresta Amazônica, com a disseminação dos conceitos de manejo sustentado e comercialização de material certificado. Cada vez menos se compactua com a exploração seletiva e predatória, que conduziu à exaustão diversas espécies de uso consagrado (ZANGIÁCOMO E LAHR, 2007). 


\subsection{Simarouba amara}

A Simarouba amara Aubl., também conhecida como caixeta ou marupá, é uma espécie pioneira que pertence à família Simaroubaceae. Ocorre por toda a Região Amazônica, como também na região Centro-Oeste e Sudeste do Brasil. Na Região Amazônica desenvolve-se tanto em matas de várzea quanto de terra firme, sendo que é mais comum atingirem maior porte na primeira região (LOUREIRO, 1977).

A madeira caracteriza-se por apresentar coloração branco-amarelada, sendo o cerne e alburno indistintos, bem como os anéis de crescimento. Além disso, configura-se como moderadamente lisa ao tato, com pouco brilho e com grã direita (STANGERLIN, 2012).

A madeira é leve $\left(0,435\right.$ a $\left.0,55 \mathrm{~g} / \mathrm{cm}^{3}\right)$, clara e fácil de trabalhar (LOUREIRO, 1977). Quanto à fenologia, é uma espécie de padrão regular, com plena floração no mês de dezembro, no início da estação chuvosa e a frutificação na estação chuvosa (PINTO et al., 2005). Em relação às propriedades biológicas, Marcondes (2011) e Paula; Alves (2007) destacam que a madeira de marupá é suscetível ao ataque de cupins e brocas, bem como por fungos xilófagos.

A madeira de marupá é muito utilizada na indústria de móveis, para fabricação de brinquedos e caixas para guardar documentos, entre outros objetos de valor (CRUZ et al.,2006). De acordo com Cavalcante (2006), a madeira é fácil de serrar, aplainar, pregar e aparafusar, recebendo bom acabamento.

Segundo Slooten e Souza (1993), o marupá é indicado para ser utilizado como tampo de instrumento de corda, uma vez que suas propriedades como a densidade, o módulo de elasticidade, o decremento logarítmico e a frequência de vibração são semelhantes àquelas da madeira de spruce (Picea abies), tradicionalmente utilizada para essa finalidade. Além disso, Longwood (1962) também menciona que, nos Estados Unidos, a madeira de marupá é utilizada para tubos de órgãos e teclas de pianos, devido, principalmente, à sua baixa contração e boa trabalhabilidade. Além disso, citam-se vários usos do marupá como para lenha e carvão, madeira comercial, cerca viva, planta medicinal, paisagismo e artesanal (FRANKE, 1999).

Com relação às características dendrométricas, o marupá apresenta fuste cilíndrico com diâmetro de até $80 \mathrm{~cm}$ e altura próxima a $35 \mathrm{~m}$, sendo o comprimento de toras comerciais variável entre 5 a 22 m (PAULA E ALVES, 2007; JANKOWSKY et al., 1990).

Em relação à composição química, os estudos realizados por Santana e Okino (2007) afirmam que o marupá possui $19,5 \%$ de hemicelulose, $48,5 \%$ de celulose, $32 \%$ de lignina, $0,3 \%$ de cinzas e $2,1 \%$ de extrativos. 


\subsection{Tratamento térmico}

Os estudos envolvendo tratamento térmico tiveram suas primeiras publicações na década de quarenta com 0 trabalho de Stamm que patenteou esse processo de madeira tratada de staybwood ou madeira estável. Contudo, somente nas últimas décadas esse processo foi sistematicamente pesquisado e aplicado industrialmente em alguns países da Europa (ESTEVES et al., 2008).

Atualmente os métodos utilizados em escala industrial em países como Finlândia, Holanda, Alemanha e França são: Thermowood, Plato Wood, Bois-Perdure e OHT-Oil Heat Treatment (ESTEVES, et al., 2008). Rousset (2004) afirma que a Finlândia junto à França são os países mais avançados em processos industriais de tratamento térmico.

No processo Finlandês Thermowood, a madeira é seca a $100^{\circ} \mathrm{C}$ por até dois dias e é aquecida com vapor d'água em uma faixa de temperatura de 150 a $240^{\circ} \mathrm{C}$ em um período de tempo de $0,5 \mathrm{a}$ 4 horas. $\mathrm{O}$ processo holandês Plato divide-se em três estágios: hidrotermólise, secagem e cura 170 a $190^{\circ} \mathrm{C}$. A hidrotermólise dura de 4 a 5 horas, a secagem de 3 a 5 dias e a cura de 14 a 16 horas. Já o método francês, Bois-Perdure, consiste no aquecimento lento da madeira pré-seca a $12 \%$ de teor de umidade em 210 a $240^{\circ} \mathrm{C}$, em atmosfera com nitrogênio. Por fim, o alemão baseiase no aquecimento da madeira com óleo quente dentro da autoclave com o controle da temperatura $\left(180\right.$ a $\left.260^{\circ} \mathrm{C}\right)$ e da pressão (2 e 14 bar) e posterior aquecimento $\left(60\right.$ a $\left.220^{\circ} \mathrm{C}\right)$ ao ar (ROUSSET, 2004).

Segundo Esteves e Pereira (2009), o processo de Thermwood é possivelmente o mais bem sucedido da Europa. Segundo os mesmos autores, dos cerca de $130.000 \mathrm{~m}^{3}$ de madeira tratada termicamente em 2007, cerca de 50\% foi tratada pelo método Thermwood. O maior consumidor dessa madeira tratada é a Europa, onde foram comprados $92 \%$ de todo o material tratado termicamente.

No Brasil, os primeiros estudos sobre a termorretificação ocorreram na década de oitenta e desde então os estudos com a associação da madeira com elevadas temperaturas tem apresentado resultados promissores na melhoria de suas propriedades tecnológicas. Segundo Brito (2006), a termorretificação ou modificação térmica é um processo em que o calor é aplicado na madeira utilizando altas temperaturas $\left(100\right.$ a $\left.250^{\circ} \mathrm{C}\right)$ que provocam o início da degradação de seus componentes químicos fundamentais. Conforme Byrne e Nagle (1997), a madeira começa a ser degradada a temperaturas próximas de $200^{\circ} \mathrm{C}$, com o início da decomposição da hemicelulose, componente que mais contribui para higroscopicidade da madeira, por apresentar elevada quantidade de grupamentos hidroxílicos e estrutura completamente amorfa.

A celulose, por sua vez, apresenta resistência moderada, em função da presença de regiões cristalinas. A lignina é o componente da madeira mais resistente à degradação térmica. Apesar 
disso, ocorrem modificações significativas em sua estrutura, que podem ser constatadas pelo aumento na concentração de compostos fenólicos na madeira tratada termicamente (ESTEVES et al., 2008).

Uma das consequências das modificações químicas, principalmente a degradação da hemicelulose, é o aumento na estabilidade dimensional. Vital et al., (2014) avaliaram o efeito da termorretificação em painéis confeccionados com diferentes proporções de partículas de Pinus sp. submetidas a três temperaturas $\left(180,200\right.$ e $\left.220^{\circ} \mathrm{C}\right)$. Os autores constataram que a estabilidade dimensional dos painéis aumentou com a adição de partículas modificadas termicamente, enquanto as propriedades mecânicas foram reduzidas.

Mendes (2010), avaliando o efeito térmico sobre as propriedades de painéis OSB submetidos a temperaturas variando de 200 a $240^{\circ} \mathrm{C}$, também identificou que os painéis atingem melhor grau de estabilidade quando submetida a elevadas temperaturas. Dirol e Guyonnet (1993) relatam que a estabilidade dimensional alcançada quando a madeira é submetida a altas temperaturas pode estar relacionada à formação de novos polímeros menos higroscópicos derivados da degradação da hemicelulose.

Além da estabilidade dimensional, o tratamento térmico apresenta algumas outras propriedades que também sofrem alterações como as citadas por Jones e Hill (2007): mudança na coloração, a qual transita entre escura e marrom; redução do conteúdo de umidade de equilíbrio em até $50 \%$; aumento da durabilidade natural; ganho na resistência a deterioração por organismos xilófagos; e redução nas propriedades mecânicas em até $30 \%$.

Muitos autores têm relatado os benefícios do tratamento térmico sobre a resistência ao apodrecimento da madeira. Welzbacher e Rapp (2002) fazendo uma comparação entre várias técnicas de tratamentos térmicos submetidos ao ataque da podridão parda (Coriolus versicolor) constataram que todos obtiveram sucesso, tendo uma perda de massa variando entre $1 \%$ a $12 \%$.

No que se refere à resistência ao ataque de cupins, Pessoa (2006) constatou que o tratamento térmico não é suficiente para oferecer total imunidade a esses agentes, apesar dos menores danos à madeira, bem como a mortalidade desses insetos, à medida da elevação da temperatura do tratamento.

Em relação à variação na cor da madeira, Lopes et al., (2014) trabalhando com teca, classificaram a cor original dessa madeira como branco acizentado, segundo a classificação proposta por Camargos (1999). Utilizando o tratamento térmico, a coordenada $L^{*}$ (claridade) teve significativa diminuição nas duas temperaturas utilizadas $\left(180^{\circ} \mathrm{C}\right.$ e $\left.200^{\circ} \mathrm{C}\right)$, mas o tratamento mais severo foi 0 que apresentou a maior diminuição nessa variável. Esteves et al., (2008) atribuem a alteração da cor original da madeira após o tratamento térmico a alguns fatores como: formação de produtos 
oxidativos (por exemplo, quinonas) e produtos da degradação das hemiceluloses e da lignina, os quais migram às superfícies da madeira; remoção ou migração dos extrativos e compostos nutritivos, tais como açúcares de baixo peso molecular e aminoácidos, em direção às superfícies da madeira; e aumento no teor de lignina.

É interessante salientar que os resultados referentes ao tratamento térmico dependem de um conjunto de fatores, como: taxa de aquecimento, temperatura final e tempo de tratamento, uso de atmosfera redutora ou oxidante, pressão e a espécie de madeira tratada.

\subsection{Tratamento termomecânico}

Devido ao fato de várias propriedades da madeira estarem correlacionadas com a densidade, muitos processos de densificação têm sido desenvolvidos a fim de aumentar a densidade da madeira, reduzindo os espaços vazios internos pelo uso da compressão, impregnação dos espaços vazios com substâncias fluidas (resinas naturais, ceras fundidas, enxofre e metais fundidos) e até mesmo a combinação dos dois processos. No entanto, o uso de produtos químicos no método de impregnação da madeira afeta suas características naturais e sustentáveis além de ser um processo com alto custo (HEGER, et al., 2004).

Tendo em vista essas desvantagens, os tratamentos termomecânicos surgem como a principal alternativa para o aumento da densidade em madeiras. Esses tratamentos são a associação do tratamento térmico com a densificação da madeira. O principal objetivo desses é combinar os benefícios que a retificação térmica traz para a madeira em suas propriedades físicas, associado aos benefícios do ganho das propriedades mecânicas decorrentes do aumento da densidade no tratamento mecânico (BUSTOS et al., 2011).

De acordo com Wang (2007), durante o tratamento termomecânico ocorrem modificações químicas simultaneamente à compressão da madeira, devido às altas temperaturas. A perda de massa da madeira é uma das principais características dos tratamentos termomecânicos. Essa pode ser atribuída à perda de água livre e higroscópica e à degradação parcial da madeira.

Outra característica e principal problema associado á densificação da madeira é a manutenção da compressão aplicada após o tratamento (KUTNAR; KAMKE, 2012; BUSTOS et al., 2011). Essa instabilidade se deve ao fato da densificação gerar tensões internas decorrentes das alterações estruturais na parede da celular. Assim, quando exposta a condições de umidade, as tensões são liberadas, levando ao inchamento ou empenamento das peças de madeira. Pós-tratamentos têm sido testados, a fim de levar á liberação dessas tensões internas.

Kutnar e Kamke (2012) utilizaram um pós-tratamento consistindo no resfriamento do material tratado sobre pressão, para uma eficiente estabilização das tensões internas e fixação da forma final. Porém, ao considerar o rendimento industrial, a logística do processo deve ser avaliada, levando em conta a quantidade de material tratado por vez, o tamanho das amostras 
(normalmente pequenas amostras), o gasto energético e de tempo de cada tratamento, que são muito longos e complexos limitam-nos.

Para melhorar essa limitação da estabilidade dimensional, técnicas que usam a compressão associada com umidade e calor vêm recebendo maior atenção nos últimos tempos. Entre elas, pode-se destacar os tratamentos termohidromecânicos e o termohigromecânico. Ambos usam a umidade como forma de promover o amolecimento dos polímeros rígidos da madeira e comprimir a madeira com o mínimo de rachaduras (KOLLMANN, 1975).

Navi e Girardet (2000) desenvolveram o processo termohidromecânico ou THM que consiste em pré-tratar a madeira com vapor saturado de $150^{\circ} \mathrm{C}$ e em seguida aplicar pressão $\left(130 \mathrm{~kg} / \mathrm{cm}^{2}\right)$. A pressão e o vapor são mantidos após a densificação constituindo um pós-tratamento. Os resultados mostram que o material densificado, por esse processo é menos higroscópico e mais estável.

Kamke e Sizemore (2005) patentearam o tratamento termomecânico VTC (Viscoelastic Thermal Compression). Segundo Kutnar e Sernek (2007), esse processo é capaz de aumentar a densidade da madeira entre $100 \%$ e $300 \%$. A compressão é feita em um sistema de vapor e alta pressão que são condições que impedem o rompimento das paredes celulares durante o processo. A madeira tratada pelo VTC primeiro é aquecida e acondicionada sob altas temperaturas e umidade para que os polímeros atinjam o estado de transição vítrea. O segundo passo é a rápida retirada de vapor e águas das paredes celulares e em seguida a madeira passa pela compressão perpendicular à grã enquanto ainda está em um estado mais viscoso. Depois a madeira é reaquecida para as liberações das tensões da compressão. Por fim, há o resfriamento do material para abaixo da temperatura de transição vítrea e o aumento do teor de umidade com acondicionamento da madeira em local com umidade e temperatura ambiente.

Welzbacher (2007) em seus estudos também testou a combinação do tratamento mecânico com o térmico, mas sem utilizar a umidade durante o processo de densificação. A proposta era usar apenas o calor produzido pelo contato da madeira com os pratos da prensa. Para mitigar a limitação da instabilidade dimensional e degradar os polímeros higroscópicos, os autores utilizaram um pós-tratamento térmico que consiste na aplicação de óleo quente (Oil-Heart Treatment, $\mathrm{OHT}$ ). Esse tratamento foi testado em escala laboratorial e industrial. No primeiro, os autores usaram madeira sólida de Spruce (Picea abies) e temperatura entre $140^{\circ} \mathrm{C}$ e $200^{\circ} \mathrm{C}$, variando o tempo entre 30 minutos e 240 minutos. Em escala industrial, a temperatura utilizada foi de $160^{\circ} \mathrm{C}$, pressão de $5,0 \mathrm{~N} / \mathrm{mm}^{2}$ aplicada na velocidade de $1 \mathrm{~mm} / \mathrm{min}$ até a espessura das amostras ser reduzida de $46 \mathrm{~mm}$ para $24 \mathrm{~mm}$. A pressão foi aplicada por $30 \mathrm{~min}$ e depois reduzida para $0,5 \mathrm{~N} / \mathrm{mm}^{2}$ até o resfriamento do material a $80^{\circ} \mathrm{C}$. 
No Brasil também pode-se observar alguns exemplos de experimentos nessa área. Del Menezzi (2004), em seu estudo sobre tratamento termomecânico em painéis de pinus do tipo OSB, verificou que a temperatura foi o fator mais importante para as alterações nas propriedades do material, enquanto o fator tempo foi significativo principalmente para as propriedades físicas. Esse autor analisou duas temperaturas $\left(190^{\circ} \mathrm{C}\right.$ e $\left.220^{\circ} \mathrm{C}\right)$ e três tempos (12, 16, 20 minutos), num total de seis tratamentos. Além disso, verificou o aparecimento da taxa de não retorno de espessura (TNRE), a qual representa o inchamento definitivo do painel oriundo da liberação das tensões internas de compressão. Quando o painel entra em contato com a água, ele incha devido ao intumescimento próprio da madeira e também pela liberação das tensões de compressão. Juntos determinam o inchamento total do painel. Quando o painel é seco, a madeira contrai, retornando em espessura apenas até o ponto referente ao inchamento próprio da madeira. No entanto, a madeira não volta à sua espessura inicial devido à liberação das tensões de compressão. Esse inchamento residual ou definitivo é representado pela TNRE.

Arruda et al., (2011) analisaram alguns efeitos da modificação termomecânica nas propriedades de compensados produzidos com lâminas de Paricá (Schizolobium amazonicum). Para isso utilizaram tratamentos com temperatura $\left(150^{\circ} \mathrm{C}\right)$, tempo (10 e $15 \mathrm{~min}$.) e pressão $\left(1 \mathrm{~N} / \mathrm{mm}^{2}\right)$, fatores usados para modificação termomecânica, porém não obtiveram resultados significativos nas propriedades analisadas, devido à insuficiência dos tratamentos em alterar as propriedades dos compensados. Os efeitos sob as propriedades mecânicas e de estabilidade dimensional não foram eficientes e significativos, pois se esperava uma melhora com a compressão. Além disso, os tratamentos levaram a um leve escurecimento da madeira com a variação do tempo, entretanto não significativos.

Entre os vários métodos citados acima, todos visam aumentar a densidade da madeira e, consequentemente, a redução dos espaços vazios (porosidade). Os principais fatores que afetam esses tratamentos são a taxa de aquecimento, temperatura final, tempo de tratamento, o uso de uma atmosfera oxidante ou redutora, pressão e as características da própria espécie (BORGES E QUIRINO, 2004).

Apesar dos inúmeros benefícios do tratamento termomecânico, a limitação da instabilidade dimensional continua sendo a maior preocupação dos pesquisadores. Em decorrência desse fato, vários métodos de pós-tratamentos que visam diminuir a liberação das tensões internas surgiram, e entre os mais economicamente viáveis e mais eficazes até hoje estudados podem ser citados: 0 simples calor por contato em prensa quente, uso do vapor d'água saturado e óleo quente.

\subsection{Efeito do tratamento termomecânico nas propriedades da madeira}

A densificação afeta várias propriedades físicas e mecânicas da madeira. A principal modificação é a redução dos espaços vazios entre as células e o lume celular, como pode ser observado na Figura 1. Devido ao efeito do calor sobre os polímeros viscoelásticos da madeira, os vasos se 
achatam e há uma distorção dos raios (KUTNAR et al., 2009). Para que se obtenha bons resultados nas propriedades físicas e mecânicas, com o processo de compressão, é essencial que haja nenhum ou o mínimo possível de colapsos das paredes celulares.

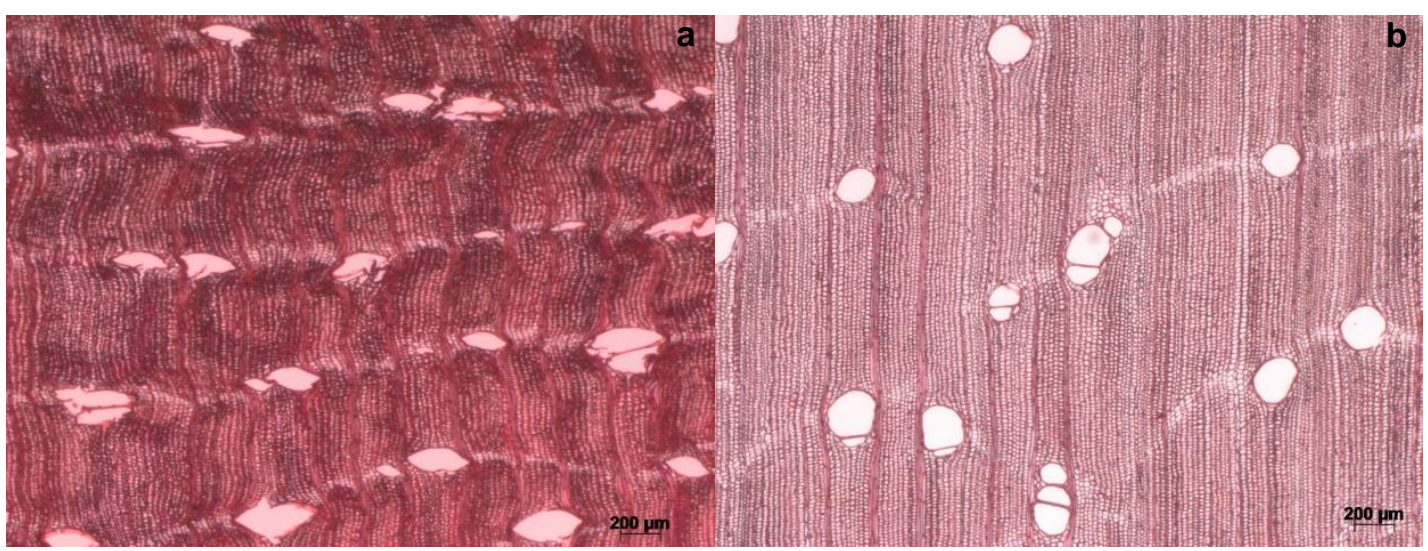

Figura 1 - Visão microscópica da superfície densificada (a) e da não densificada (b) que passou Fonte: Autora pelo tratamento termomecânico

Segundo Cowie (1991), o achatamento celular ocorre por flambagem elástica, plastic yielding ou esmagamento, dependendo das características da espécie e condições do ensaio. A flambagem elástica pode ser definida como flambagem sem fratura celular e ocorre quando os polímeros da parede celular estão em fase elástica. Esse estado resultará em certa recuperação da deformação após a retirada da carga. Plastic yielding ocorre quando os polímeros estão entre a fase vítrea e a fase elástica. Nesse caso, a deformação permanecerá mesmo após a retirada da carga. E o esmagamento acontece quando os polímeros estão na fase vítrea.

A modificação da densificação também pode ser observada pela superfície da madeira. Tanto o calor como a compressão concomitantemente agem deixando a superfície mais lisa e menos porosa, características que afetam diretamente na molhabilidade e na rugosidade da madeira.

Bekhta et al., (2012) comentam que a rugosidade de lâminas tratadas termomecanicamente ocorre principalmente em função da temperatura e da pressão de compressão. Os autores usaram temperaturas de aquecimento entre $100^{\circ} \mathrm{C}$ e $210^{\circ} \mathrm{C}$ e pressões entre 1,0 e $9,0 \mathrm{~N} / \mathrm{mm}^{2}$. Nos dois estudos, foi observada uma redução da rugosidade à medida que aumentou a temperatura e a pressão.

A diminuição dos espaços vazios exerce forte influência na higroscopicidade da madeira resultando em um material menos poroso e com menos espaços vazios internamente. $\mathrm{O}$ calor age na degradação da hemicelulose, como já foi dito anteriormente, constituinte mais hidrófilo desse material, reduzindo sua capacidade de permutar água com o meio e diminuindo problemas de contração e inchamento. De acordo com Weiland e Guyonnet (2003), peças de madeira tratadas termicamente são menos higroscópicas em comparação com as não tratadas, fato verificado pelo ângulo de contato formado entre a água, ou outro solvente orgânico, e a superfície da madeira. 
Arnold (2010) afirma que o ângulo de contato está diretamente relacionado com a rugosidade, onde quanto maior a rugosidade menor o ângulo de contato e, consequentemente, maior a molhabilidade. Esse comportamento foi observado por Vasconcelos (2012), que também atribuiu seus resultados à vitrificação e inativação da superfície causada pelo calor e pressão do tratamento. Utilizando temperatura de $180^{\circ} \mathrm{C}$ e $210^{\circ} \mathrm{C}$ e pressão de $2,5 \mathrm{MPa}$, o ângulo de contato passou de $36^{\circ}$ para uma média de $90^{\circ}$.

Outros benefícios bem significativos ocorrem como consequência da redução dos espaços vazios e o aumento na densidade da madeira, o que resulta no aumento das propriedades mecânicas. Welzbacher et al., (2008) conseguiram aumentar a densidade de Picea abies Karst de 0,42 g/cm para $0,74 \mathrm{~g} / \mathrm{cm}^{3}$ tratando as peças termomecanicamente a $200^{\circ} \mathrm{C}$ por 4 horas. Heger et al., (2004) observaram o fechamento dos lumens de Spruce (Picea sp.) e o aumento da densidade de 0,45 $\mathrm{g} / \mathrm{cm}^{3}$ para $1,28 \mathrm{~g} / \mathrm{cm}^{3}$ quando as amostras foram densificadas no sentido radial, em reator sob vapor saturado.

Gardner et al., (1993), quando investigaram as alterações na estrutura dos polímeros da parede celular, observaram que o aumento da cristalinidade da celulose em condições de prensagem a quente resultou no aumento do módulo de elasticidade. No estudo de Narayanamurti e Kaul (1966), as propriedades mecânicas foram melhoradas com o aumento da taxa de compressão e densidade básica. O MOE, na tração e na flexão das madeiras termomecanicamente tratadas a $200{ }^{\circ} \mathrm{C}$, foi quase duas vezes maior que as não tratadas, segundo o estudo de Cloutier et al., (2008). Esse valor só diminuiu para as madeiras tratadas em $220^{\circ} \mathrm{C}$ e $240^{\circ} \mathrm{C}$. O mesmo comportamento pôde ser observado para o MOR na tração e flexão, sendo esse aumento mais importante para a flexão do que para a tração. A dureza também aumentou: passou de $17 \mathrm{~N} / \mathrm{mm}^{2}$ nas madeiras não tratadas, para $45 \mathrm{~N} / \mathrm{mm}^{2}$ nas madeiras tratadas a $200{ }^{\circ} \mathrm{C}$. A dureza só reduziu nas tratadas em $220^{\circ} \mathrm{C}$ e $240^{\circ} \mathrm{C}$, provavelmente devido à maior degradação dos polímeros da parede celular.

Assim como no tratamento térmico, o tratamento termomecânico também passa por alterações nas propriedades colorimétricas devido à ação do calor. Em espécies de madeira de cor clara, que são geralmente consideradas menos atrativas, o escurecimento é uma importante vantagem desses tratamentos, dando à madeira um tom tropical, que é valorizado em muitos países (SILVA, 2012).

As variações de cor das amostras de madeiras dependem dos componentes químicos que interagem com luz dentro do comprimento de onda entre $380-780 \mathrm{~nm}$. Típicas estruturas moleculares que apresentam grupos cromóforos na madeira são a lignina, abaixo do comprimento de onda de $500 \mathrm{~nm}$, e os extrativos fenólicos, como taninos, flavonóides, estilbenos, acima de 500 $\mathrm{nm}$, sendo que os extrativos parecem participar menos do que a lignina na formação da cor da 
madeira tratada com calor. Subprodutos da degradação das hemiceluloses podem levar a madeira a uma tonalidade escura, ou seja, redução de sua claridade. A formação de produtos de oxidação, tais como quinonas, também é referida como a razão para a mudança de cor (ESTEVES et al., 2008)

As mudanças de cor para as espécies Pinus pinaster Aiton e Eucalyptus globulus Labill, tratadas termicamente em forno e em autoclave, com temperatura e tempo variando entre 170 e $200^{\circ} \mathrm{C}$, e entre 2 e $24 \mathrm{~h}$ foram estudadas por Esteves et al., (2008). A madeira de eucalipto tratada termicamente revelou uma cor uniforme, sendo escurecida com o aumento da intensidade do tratamento.

Para o pínus, a extensão da cor é menos uniforme, sendo que a cor depende da relação entre lenho inicial e lenho tardio na superfície das amostras. Também, em alguns casos, há a formação de manchas escuras na superfície devido à exsudação de algum tipo de resina. Os parâmetros de cores foram determinados pelo método CIELAB, sendo que se constatou que o tratamento com calor, na presença e ausência de ar, escurece a madeira de pínus e eucalipto e, de maneira geral, reduz os componentes das cores vermelho $\left(+a^{*}\right)$ e amarelo $\left(-b^{*}\right)$. Quanto maior a perda de massa, maior a alteração na cor, e mudanças de cor já são obtidas para pequena perda de massa, da ordem de $2 \%$. Estas alterações de cores na madeira tratada termicamente também foram observadas nos trabalhos de Gouveia (2008) e Sundqvist (2004).

Os benefícios do tratamento térmico sobre a resistência ao ataque de organismos xilófagos são amplamente relatados em trabalhos científicos, no entanto, estudos sobre o efeito do tratamento termomecânico são escassos na literatura. Unsal et al., (2009) trabalharam com Pinus sylvestris tratado termomecanicamente (5 ou $7 \mathrm{MPa}$ e 120 ou $150^{\circ} \mathrm{C}$ ) e não encontraram melhora na resistência natural da madeira tratada. Em relação ao fungo Trametes versicolor, o tratamento não afetou a resistência quando comparado com a madeira não tratada e ainda reduziu a resistência ao ataque do Gloeophyllum trabeum. Os mesmos autores afirmam que resultados mais interessantes foram encontrados em testes de resistência a cupins em laboratório, usando os cupins subterrâneos orientais, flavipes Reticulitermes.

Vaz (2013), quando submeteu painéis compensados confeccionados com lâminas de Trattinnickia burseraefolia tratados termomecanicamente em uma prensa hidráulica a temperaturas de $140^{\circ} \mathrm{C} \mathrm{e}$ $180^{\circ} \mathrm{C}$, tempos de um e dois minutos e pressão constante de 2,7 MPa ao ataque de fungos causadores de podridão parda (Gloeophyllum trabeum) e de podridão branca (Trametes versicolor), verificou que tanto a temperatura quanto o tempo tiveram influência significativa quanto à resistência biológica dos painéis. No entanto, a combinação da maior temperatura com o maior tempo se mostrou mais eficiente no aumento da resistência ao G. trabeum. 
Para Silva et al., (2008), a melhora na resistência da madeira tratada contra ataque de fungos está relacionada a quatro motivos distintos: aumento na característica hidrofóbica da madeira, que reduz a absorção de água, o que não favorece o desenvolvimento de certos organismos; modificação química dos polissacarídeos e lignina da madeira, que leva a uma inibição das enzimas digestivas dos fungos, decorrente da perda de capacidade dessas enzimas reconhecer seu substrato; significante degradação das hemiceluloses, e por fim geração de novas substâncias que podem atuar como fungicidas para madeira. 


\section{MATERIAIS E MÉTODOS}

A madeira de Simarouba amara foi obtida no comércio de madeira serrada do Distrito Federal, foram adquiridas 30 amostras de madeira $(15,0 \mathrm{~cm}$ de largura $\times 2,5 \mathrm{~cm}$ de espessura $\times 45,0 \mathrm{~cm}$ de comprimento). Foi realizada uma análise visual a fim de selecionar as tábuas com as menores quantidades de defeitos, visando obter as tábuas de melhor qualidade. Após esta etapa, as tábuas foram colocadas em câmara climatizada $\left(20 \pm 3^{\circ} \mathrm{C} ; 65 \pm 1 \%\right.$ de umidade relativa do ar) no laboratório do departamento de Engenharia Florestal da Universidade de Brasília, até alcançarem massa constante, condição essencial para o início dos tratamentos termomecânicos.

Foram obtidas a densidade aparente de cada amostra, conforme a norma ASTM D2395 (2007), com o objetivo de selecioná-las por tratamento, eliminando a densidade como fonte de variação, a fim de não haver diferença significativa de densidade inicial entre os tratamentos.

Para que a escolha fosse completamente aleatória, as amostras foram numeradas de 1 a 30 e seus respectivos dados tabulados utilizando as planilhas do Excel. Depois, seguindo a ordem crescente, as amostras foram novamente numeradas de 1 a 5 de forma aleatória. Por fim, as amostras que receberam a mesma numeração formaram o mesmo tratamento. Assim todas as amostras que receberam o número um foram designadas para o tratamento 1 e assim sucessivamente. Após a distribuição, foi feita uma Análise de Variância fator único a $5 \%$ de significância para identificar a existência de diferença entre os tratamentos. Como não foi verificado nenhum tipo de distinção, essa distribuição foi mantida.

\subsection{Pré-teste}

Para determinar as temperaturas que seriam usadas no trabalho, foram adquiridas dez tábuas de marupá (15,0 cm de largura x 2,5 cm de espessura $\times 45,0 \mathrm{~cm}$ de comprimento) que foram tratadas nas temperaturas de $140^{\circ} \mathrm{C}, 180^{\circ} \mathrm{C}, 200^{\circ} \mathrm{C}$ e $210^{\circ} \mathrm{C}$. A primeira e a última temperaturas foram descartadas: aquela não apresentou nenhuma alteração aparente no material, e a temperatura de $210^{\circ} \mathrm{C}$ carbonizou a superfície da madeira, não atingindo a aparência desejada.

O tempo de 30 minutos já havia sido pré-estabelecido, assim como a pressão de $50 \%$ e $75 \%$ pressão correspondente a $7,94 \mathrm{MPa}(50 \%)$ e $11,90 \mathrm{MPa}(75 \%)$ da resistência a compressão perpendicular da madeira da Simarouba amara (4,41 MPa). Essas condições foram escolhidas baseadas no referencial teórico. Ao todo foram realizados cinco tratamentos, conforme a Tabela 3 , que determinaram a escolha das temperaturas de $180^{\circ} \mathrm{C}$ e $200^{\circ} \mathrm{C}$ combinadas com as pressões de $50 \%$ e $75 \%$. 
Tabela 3- Temperatura e pressão utilizadas no pré-teste para determinação das temperaturas definitivas nos tratamentos termomecânicos

\begin{tabular}{ccc}
\hline Tratamento & Temperatura & Pressão \\
\hline 1 & $140^{\circ} \mathrm{C}$ & $50 \%$ \\
2 & $180^{\circ} \mathrm{C}$ & $75 \%$ \\
3 & $180^{\circ} \mathrm{C}$ & $75 \%$ \\
4 & $200^{\circ} \mathrm{C}$ & $75 \%$ \\
5 & $210^{\circ} \mathrm{C}$ & $75 \%$ \\
\hline
\end{tabular}

\subsection{Tratamento termomecânico}

Para o tratamento termomecânico, utilizou-se a prensa hidráulica, do laboratório de tecnologia da Fazenda Água Limpa da UnB - FAL, equipada com dois pratos aquecidos por resistência elétrica, com controle de temperatura, tempo e pressão.

Para analisar o efeito do tratamento térmico tendo como fonte de variação a temperatura e a pressão, foram testadas as duas temperaturas $180^{\circ} \mathrm{C}$ e $200^{\circ} \mathrm{C}$; e as duas pressões $50 \%$ e $75 \%$ determinadas no pré-teste e tempo de $30 \mathrm{~min}$ de acordo com a Tabela 4. Para calcular as pressões citadas que foram ajustadas na prensa foi utilizada a Equação 1.

$$
\mathrm{PM}=\frac{\mathrm{Pe} \times \mathrm{Ac}}{551,55}
$$

Onde:

$\mathrm{PM}=$ pressão na prensa $\left(\mathrm{kgf} / \mathrm{cm}^{2}\right)$;

$\mathrm{Pe}=$ pressão pretendida $\left(\mathrm{kgf} / \mathrm{cm}^{2}\right)$;

$\mathrm{Ac}=$ área que será comprimida $\left(\mathrm{cm}^{2}\right)$

$551,55=$ área da prensa $\left(\mathrm{cm}^{2}\right)$

Tabela 4 - Delineamento experimental do tratamento termomecânico unilateral nas tábuas de marupá

\begin{tabular}{c|c|c|c}
\hline Tratamentos & $\begin{array}{c}\text { Temperatura, Pressão e } \\
\text { Tempo }\end{array}$ & Pós-Tratamento & No de Tábuas \\
\hline Testemunha & - & - & 6 \\
1 & $180^{\circ} \mathrm{C}, 50 \%$ e $30 \mathrm{~min}$ & Sem pressão (30 min) & 6 \\
2 & $180^{\circ} \mathrm{C}, 75 \%$ e $30 \mathrm{~min}$ & Sem pressão (30 min) & 6 \\
3 & $200^{\circ} \mathrm{C}, 50 \%$ e $30 \mathrm{~min}$ & Sem pressão (30 min) & 6 \\
4 & $200^{\circ} \mathrm{C}, 75 \%$ e $30 \mathrm{~min}$ & Sem pressão (30 min) & 6 \\
\hline
\end{tabular}


Foram realizados quatro tratamentos termomecânicos e a testemunha, com seis repetições cada, totalizando trinta tábuas. A temperatura interna da madeira foi acompanhada ao longo do tratamento. Para isso, com o auxilio de uma furadeira, foi feito um orifício de 1,5 a $2 \mathrm{~cm}$ de comprimento e $3 \mathrm{~mm}$ de diâmetro na parte radial dos CPs, onde foi introduzido um termopar tipo $\mathrm{K}$ conectado a um termômetro. Outros dois termopares foram introduzidos na placa de aço e em um dos pratos da prensa, a fim de acompanhar a temperatura desses elementos.

A dinâmica dos tratamentos consistiu em aquecer os pratos da prensa até atingir a temperatura dos tratamentos $\left(180^{\circ} \mathrm{C}\right.$ e $\left.200^{\circ} \mathrm{C}\right)$. Após os pratos estarem devidamente aquecidos, as madeiras foram colocadas na prensa, permanecendo por um período de 30 minutos sob as devidas condições de temperatura e pressão de cada tratamento.

Para que houvesse a densificação de apenas uma das superfícies, entre as seis madeiras foi colocada uma placa de aço com as seguintes dimensões: 50,0 x 5,0 x 50,0 cm com o intuito de isolar uma das superfícies da madeira. A Figura 2 ilustra melhor a dinâmica do procedimento.

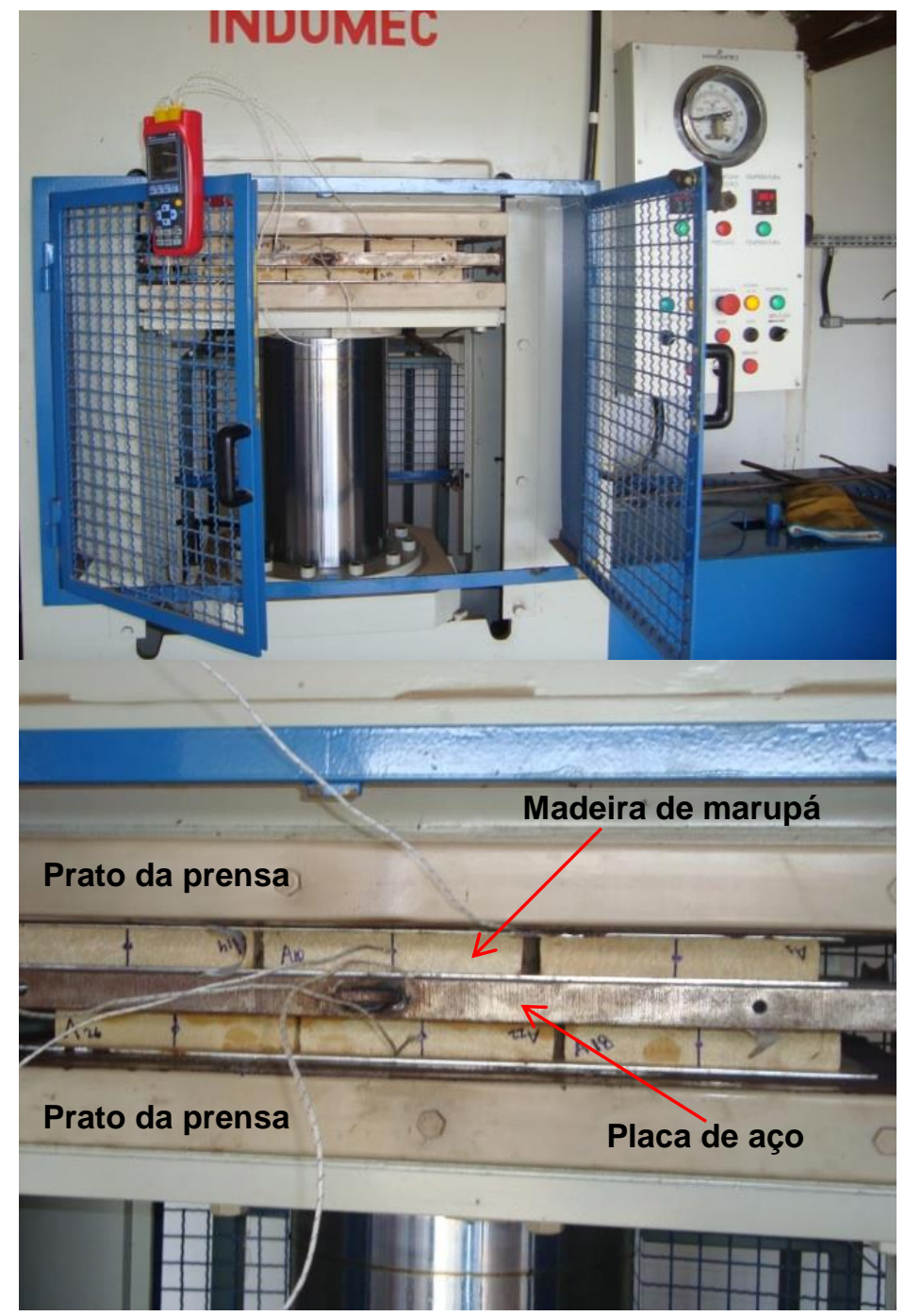

Figura 2 - Prensa hidráulica com resistência elétrica utilizada no tratamento termomecânico unilateral 


\subsection{Pós-tratamento}

Após os pratos atingirem a temperatura definida nos tratamentos $\left(180^{\circ} \mathrm{C}\right.$ e $\left.200^{\circ} \mathrm{C}\right)$ e o material permanecer nessas condições por $30 \mathrm{~min}$, a pressão foi retirada e as tábuas permaneceram em contato com os pratos aquecidos da prensa, ou seja, sem pressão, durante 30 minutos, de modo que as tensões internas da madeira pudessem ser liberadas levemente, estabilizando as novas condições internas das tábuas. Todos os quatro tratamentos receberam o pós-tratamento.

\subsection{Confecção dos corpos de prova}

Depois de submetidos aos tratamentos termomecânicos, as tábuas tratadas retornaram à câmara de climatização $\left(20 \pm 3^{\circ} \mathrm{C} ; 65 \pm 1 \%\right.$ URA) e permaneceram sob tal condição até novo equilíbrio higroscópico com o meio, para início da caracterização de suas propriedades. As propriedades estudadas foram classificadas como físicas, mecânicas e superficiais.

As tábuas climatizadas foram cortadas de acordo com o croqui apresentado na Figura 3 . Todo o material seguiu o padrão demostrado a seguir de modo a contemplar todos os ensaios realizados.

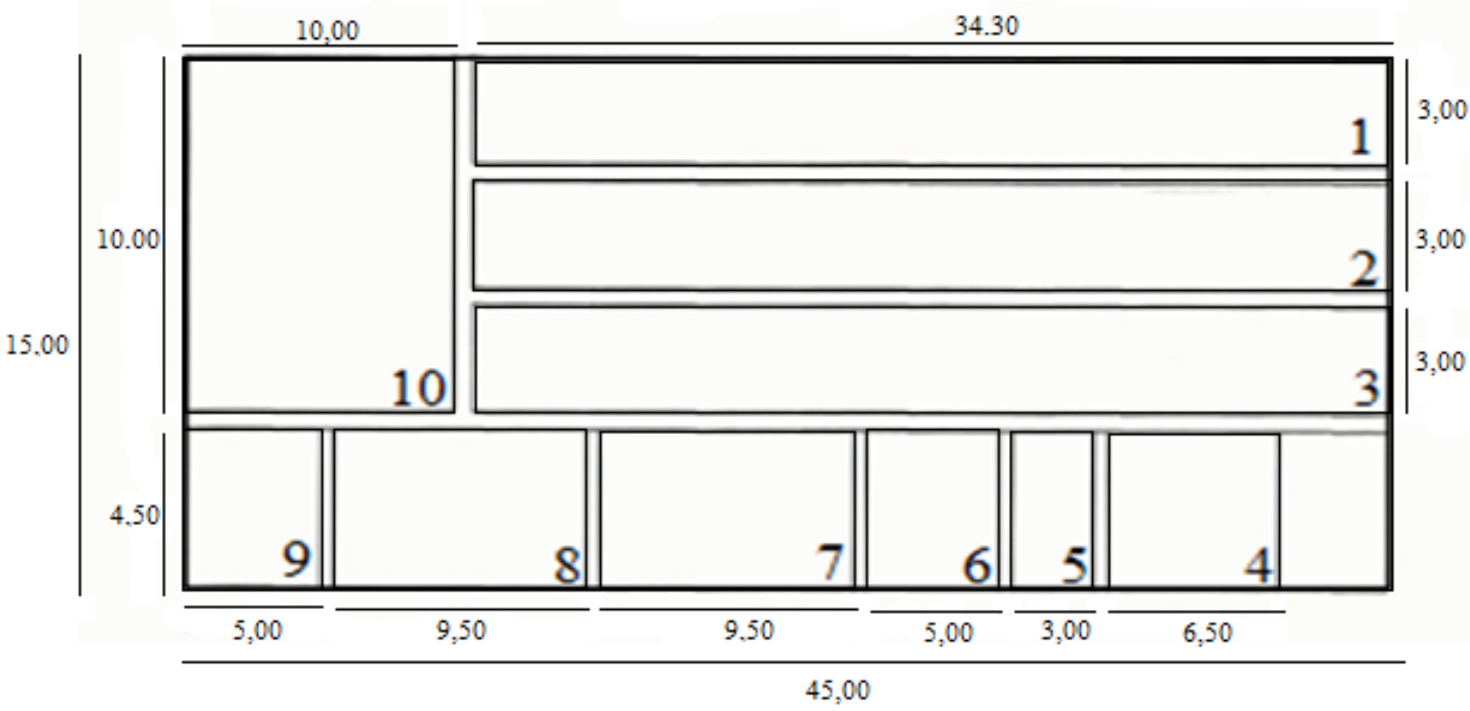

Figura 3 - Croqui da confecção dos corpos de prova sendo 1, 2 e 3: Flexão estática e Stress Wave, 4:Molhabilidade; 5: Colorimetria; 6:TUE e Estabilidade dimensional; 7: Compressão Paralela; 8: Dureza; 9: Densitometria; 10: Abrasão

\subsection{Caracterização das propriedades físicas}

Nas propriedades físicas foram calculadas: a perda de massa (PM) (Equação 2), perda de massa definitiva após o tratamento (PMDAT) (Equação 3), taxa de compactação da madeira (TC) (Equação 4), a qual representa o quanto a tábua reduziu em espessura; taxa de densificação (TD) (Equação 5) que considera o quanto a densidade da madeira aumentou após o tratamento, teor de 
umidade de equilíbrio (TUE) (Equação 6) e densidade aparente final (Df) (Equação 7), (SANTOS, 2011).

$$
\mathrm{PM}=\frac{(\mathrm{Mi}-\mathrm{Mf})}{\mathrm{Mi}} \times 100
$$

Onde:

$\mathrm{PM}=$ perda de massa após o tratamento (\%);

$\mathrm{Mi}=$ massa da tábua antes do tratamento $(\mathrm{g})$;

$\mathrm{Mf}=$ massa da tábua após o tratamento $(\mathrm{g})$;

$$
\text { PMDAT }=\frac{(\text { Mi }- \text { Mf })}{\text { Mi }} \times 100
$$

Onde:

PMDAT $=$ perda de massa definitiva após o tratamento (\%);

$\mathrm{Mi}=$ massa da tábua antes do tratamento $(\mathrm{g})$;

$\mathrm{Mf}=$ massa da tábua após a climatização $(\mathrm{g})$;

$$
\mathrm{TC}=\frac{(\mathrm{Ei}-\mathrm{Ef})}{\mathrm{Ef}} \times 100
$$

Onde:

TC = taxa de compactação (\%);

$\mathrm{Ei}=$ espessura da tábua antes do tratamento $(\mathrm{cm})$;

$\mathrm{Ef}=$ espessura da tábua após o tratamento $(\mathrm{cm})$;

$$
\mathrm{TD}=\frac{(\mathrm{Df}-\mathrm{Di})}{\mathrm{Di}} \times 100
$$

Onde:

TD = taxa de densificação (\%);

$\mathrm{Di}=$ densidade inicial antes do tratamento $\left(\mathrm{g} / \mathrm{cm}^{3}\right)$; 
$\mathrm{Df}=$ densidade final após o tratamento $\left(\mathrm{g} / \mathrm{cm}^{3}\right)$;

$$
\mathrm{TUE}=\frac{(\mathrm{Mi}-\mathrm{Mf})}{\mathrm{Mf}} \times 100
$$

Onde:

TUE = teor de umidade de equilíbrio (\%);

$\mathrm{Mi}=$ massa inicial $(\mathrm{g})$;

$\mathrm{Mf}$ - massa final $(\mathrm{g})$;

$$
\rho_{\mathrm{f}}=\frac{\mathrm{M}}{\mathrm{V}}
$$

Onde:

$\rho_{\mathrm{f}}=$ densidade aparente final após o tratamento $\left(\mathrm{g} / \mathrm{cm}^{3}\right)$;

$\mathrm{M}=$ massa da tábua após o tratamento $(\mathrm{g})$;

$\mathrm{V}=$ volume da tábua após o tratamento $\left(\mathrm{cm}^{3}\right)$;

No ensaio de estabilidade dimensional foram utilizados seis CPs de 5,0 x 4,5 cm (c x I) de cada tratamento, totalizando trinta amostras. A caracterização dessa propriedade seguiu a metodologia sugerida por Arruda (2012). A madeira em seu estado inicial sofreu compressão pelo tratamento termomecânico e a partir daí passou pelo processo de imersão em água para obtenção do inchamento em espessura após $2 \mathrm{H}$ e $24 \mathrm{H}$ (IE2H e IE24H). Depois de saturada, a madeira foi submetida a secagem em estufa para a obtenção da TR e TNRE (Figura 4).

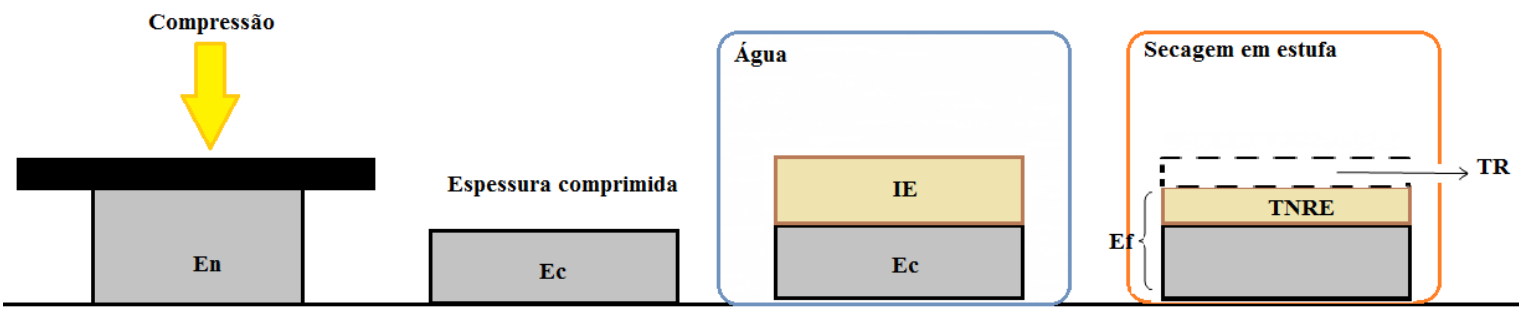

Figura 4 - Esquema do teste de inchamento em espessura onde En, Ec e Ef representam espessura natural da amostra, espessura comprimida e espessura final respectivamente e IE, TNRE e TR representam inchamento em espessura, taxa de não retorno em espessura e taxa de Fonte: Baseada em ARRUDA, 2012. retração respectivamente.

Para caracterização dessas variáveis foi calculado o inchamento em espessura e absorção de água após duas horas de imersão em água (IE2H, AB2H) (Equações 8 e 9 respectivamente), inchamento em espessura e absorção de água após vinte e quatro horas de imersão (IE24H, 
$A B 24 H)$ (Equações 10 e 11 respectivamente), taxa de não retorno em espessura (TNRE) (Equação 12) e taxa de retração (TR) (Equação 13).

$$
\mathrm{IE} 2 \mathrm{H}=\frac{\left(\mathrm{E}_{2} \mathrm{H}-\mathrm{Ei}\right)}{\mathrm{Ei}} \times 100
$$

Onde:

$\mathrm{IE} 2 \mathrm{H}$ = inchamento em espessura após 2 horas de imersão em água (\%);

$\mathrm{E} 2 \mathrm{H}$ = espessura após 2 horas de imersão em água $(\mathrm{cm})$;

$\mathrm{Ei}=$ espessura inicial do corpo de prova $(\mathrm{cm})$;

$$
\mathrm{AB} 2 \mathrm{H}=\frac{(\mathrm{M} 2 \mathrm{H}-\mathrm{Mi})}{\mathrm{Mi}} \times 100
$$

Onde:

$\mathrm{AB} 2 \mathrm{H}=$ absorção de água após 2 horas de imersão (\%);

$\mathrm{M} 2 \mathrm{H}$ = massa após 2 horas de imersão em água $(\mathrm{g})$;

$\mathrm{Mi}=$ massa inicial do corpo de prova $(\mathrm{g})$;

$$
\mathrm{IE} 24 \mathrm{H}=\frac{\left(\mathrm{E}_{24 \mathrm{H}}-\mathrm{Ei}_{\mathrm{i}}\right)}{\mathrm{Ei}} \times 100
$$

Onde:

IE24H = inchamento em espessura após 24 horas de imersão em água (\%);

$\mathrm{E} 24 \mathrm{H}$ = espessura após 24 horas de imersão em água $(\mathrm{cm})$;

$\mathrm{Ei}=$ espessura inicial do corpo de prova $(\mathrm{cm})$;

$$
\mathrm{AB} 24 \mathrm{H}=\frac{(\mathrm{M} 24 \mathrm{H}-\mathrm{Mi})}{\mathrm{Mi}} \mathrm{x} 100
$$

Onde: 
AB24H = absorção de água após 24 horas de imersão (\%);

$\mathrm{M} 24 \mathrm{H}$ = massa após 24 horas de imersão em água (g);

$\mathrm{Mi}=$ massa inicial do corpo de prova $(\mathrm{g})$;

$$
\mathrm{TNRE}=\frac{(\mathrm{Ee}-\mathrm{Ei})}{\mathrm{Ei}} \times 100
$$

Onde:

TNRE = taxa de não retorno em espessura (\%);

$\mathrm{Ee}=$ espessura após secagem na estufa $(\mathrm{cm})$;

$\mathrm{Ei}=$ espessura inicial do corpo de prova $(\mathrm{cm})$

$$
\mathrm{TR}=\frac{(\mathrm{E} 24 \mathrm{H}-\mathrm{Ee})}{\mathrm{E}_{24 \mathrm{H}}} \times 100
$$

Onde:

TR = Taxa de retração (\%);

$\mathrm{E} 24 \mathrm{H}$ = espessura após 24 horas de imersão em água $(\mathrm{cm})$;

$\mathrm{Ee}=$ espessura após secagem na estufa $(\mathrm{cm})$;

A fim de verificar como ocorreu a densificação ao longo da espessura, foi realizado o ensaio de densitometria de raio-x no laboratório de anatomia florestal da Escola Superior de Agricultura Luiz de Queiroz da Universidade de São Paulo - Esalq. Foram utilizados três CPs medindo 5,0 cm x 4,5 $\mathrm{cm}(\mathrm{c} \times \mathrm{I})$ e espessura variável, as amostras antes do ensaio ficaram acondicionadas em câmara climática $\left(20 \pm 3^{\circ} \mathrm{C} ; 65 \pm 1 \%\right.$ URA). O aparelho utilizado foi o de densitometria de raio-x modelo QDP-01X da Quintek Measurement Systems e os valores da densidade foram determinados a cada $4 \mu \mathrm{m}$, ao longo da espessura da madeira, que foi analisada na face transversal . $O$ aparelho determinou o perfil individual de cada amostra e a média para cada tratamento (Figura 5). 


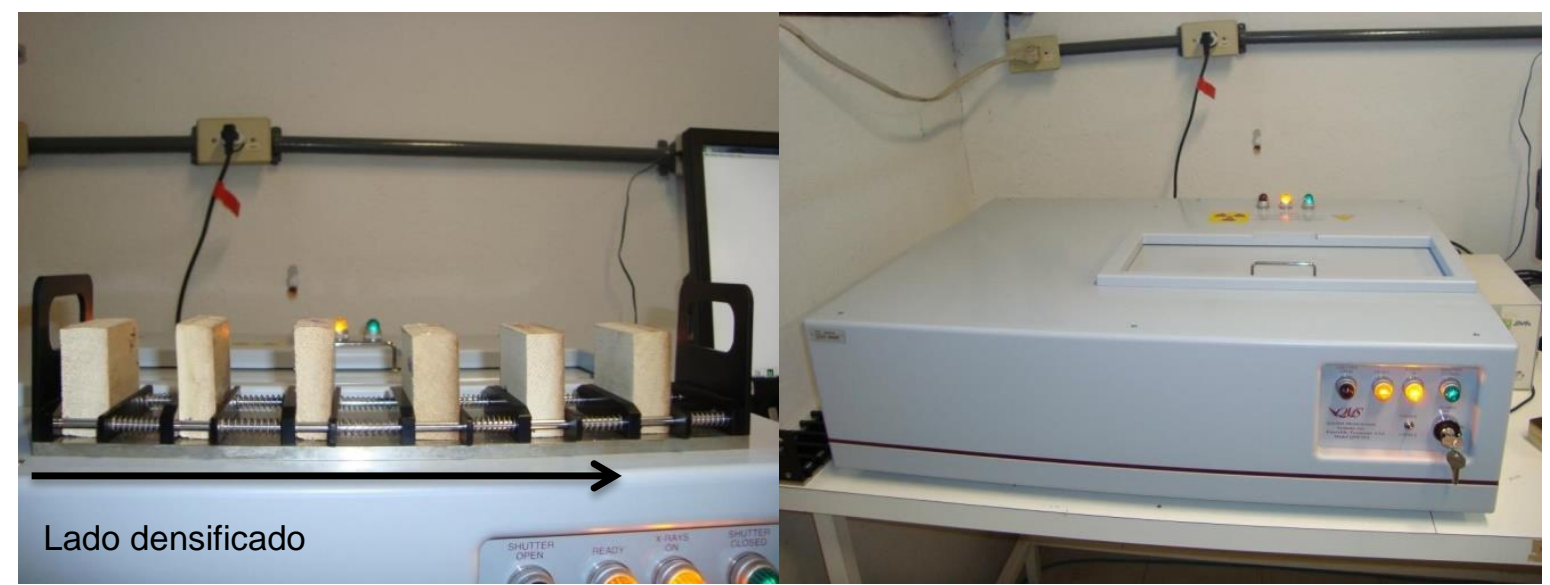

Figura 5 - Teste de densitometria de raio-x na face transversal das amostra submetidas ao tratamento termomecânico unilateral

Após a obtenção dos dados, foram confeccionados gráficos com o comportamento da densidade ao longo da espessura das três amostras analisadas por tratamento. Foi possível dividir os gráficos em três zonas com comportamentos distintos. A primeira zona tem densidade semelhante à apresentada pela testemunha; na zona II ocorre o aumento da densidade e a zona III é onde ocorre o decréscimo da densidade. Por meio da análise dos gráficos, foi possível identificar nas amostras as três zonas e, com o auxílio da anatomia macroscópica, pequenas amostras de cada zona foram ampliadas com o intuito de elucidar o comportamento dos raios e vasos.

\subsection{Caracterização das propriedades mecânicas}

As propriedades mecânicas consistiram em ensaios destrutivos como a avaliação da flexão estática com obtenção do módulo de elasticidade $\left(E_{m}\right)$ e módulo de ruptura $\left(f_{M}\right)$, conduzidos segundo a norma ASTM D143 (2000) para corpos reduzidos. Também foi avaliada a resistência máxima à compressão paralela $\left(\mathrm{f}_{\mathrm{c}, 0^{\circ}}\right)$, dureza Janka $\left(\mathrm{f}_{\mathrm{H}}, \mathrm{N}\right)$. Em relação aos ensaios não destrutivos utilizou-se o aparelho de stress wave para obter as variáveis velocidade e módulo de elasticidade dinâmico Todos os ensaios destrutivos foram realizados em uma Máquina Universal de Ensaios (EMIC DL 30000) como mostra a Figura 6. 


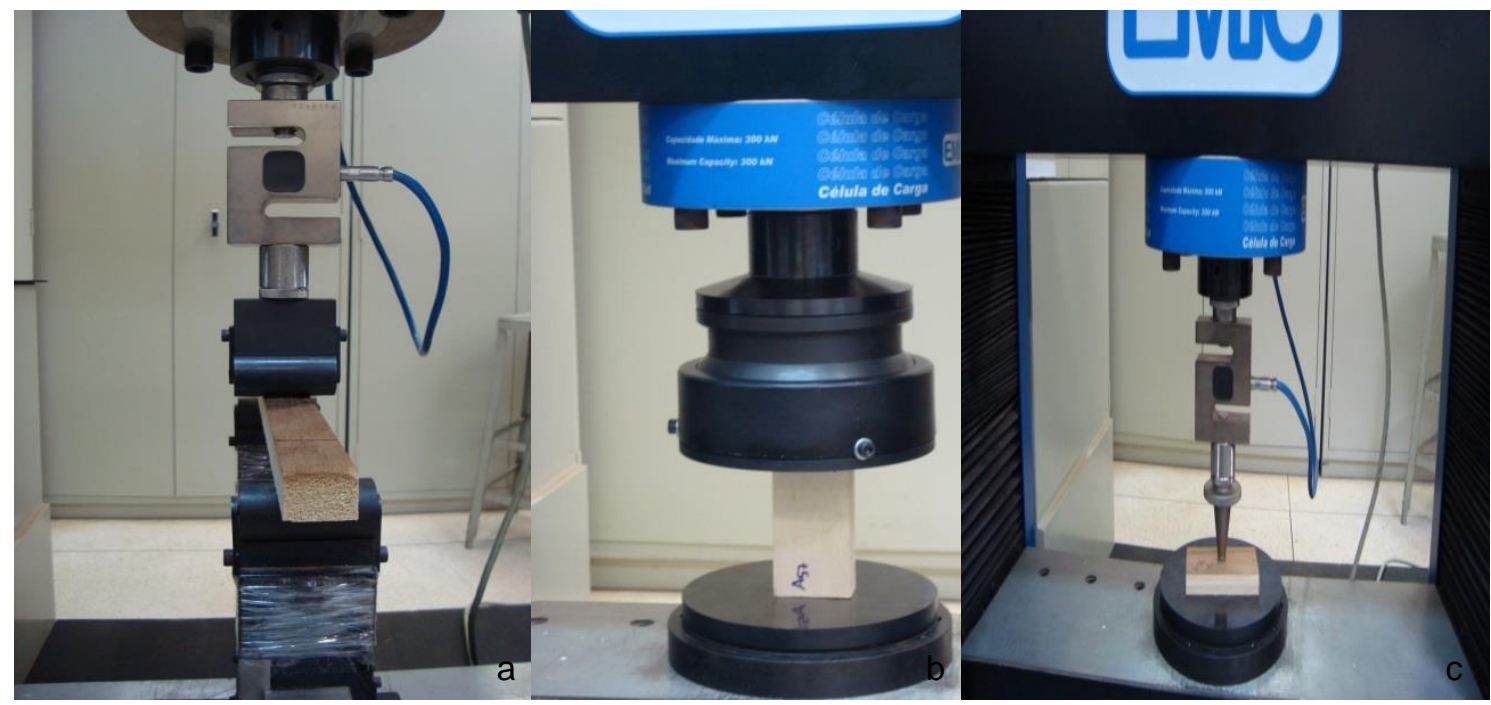

Figura 6 - Ensaio de flexão estática (a); Ensaio de compressão paralela (b); Ensaio de dureza

(c)

Para o ensaio de flexão estática, foram utilizados dezoito CPs por tratamento medindo $34,30 \mathrm{~cm} \times$ $3,00 \mathrm{~cm}(\mathrm{c} \times \mathrm{l})$. Durante os ensaios, conforme as dimensões dos corpos de prova, o vão e a velocidade do ensaio foram modificados para atender a norma ASTM 143 (2000). O vão correspondeu a doze vezes a média da espessura de cada tratamento.

Para verificar o efeito da densificação em apenas uma das superfícies para cada tábua, dois corpos de prova foram ensaiados de modo que a tração ocorresse no lado não densificado e um corpo de prova com tração na superfície densificada. Esse ensaio caracterizou principalmente a rigidez e a resistência da madeira e serviu para avaliar o efeito da densificação unilateral nessas propriedades.

O ensaio de resistência a compressão paralela foi realizado com seis CPs medindo $9,5 \mathrm{~cm} \times 4,5$ $\mathrm{cm}(\mathrm{c} \times \mathrm{I})$ em cada tratamento e testemunha. A avaliação da dureza Janka foi realizada somente na superfície que durante o tratamento termomecânico esteve em contato direto com os pratos da prensa. Os corpos de prova utilizados para este ensaio foram confeccionados com as dimensões de $9,5 \mathrm{~cm} \times 5,0 \mathrm{~cm}(\mathrm{c} \times \mathrm{I})$ e espessura variando de acordo com o tratamento termomecânico utilizado.

O "Stress Wave Timer" (SWT) da marca Metriguard modelo 239-A foi utilizado nesse trabalho e é um equipamento composto por dois transdutores acelerômetros, dispostos sobre o material a ser medido, e um relógio registrador da velocidade da onda. O processo de medição por meio desse equipamento consistiu na disposição do corpo de prova $(34,30 \times 3,00 \mathrm{~cm}$ e com espessura variando de acordo com o tratamento) entre os dois sensores com vão de 12x a espessura do material; zerando-se o relógio registrador e liberando um pêndulo metálico que entra em choque com o sensor que emite a onda na face transversal do material, fazendo que a onda percorra a madeira longitudinalmente até o receptor. Cada tratamento teve dezoito repetições, sendo que 
cada corpo de prova passou por três medições. Dessa forma, determinou-se a velocidade de propagação da onda (Equação 14) e o módulo de elasticidade dinâmico - $E_{d}$, (Equação 15) com as médias das repetições.

$$
V=\frac{D}{t \times 10^{-6}}
$$

Onde:

$\mathrm{V}=$ velocidade $(\mathrm{m} / \mathrm{s})$;

$\mathrm{D}=$ vão $(\mathrm{m})$;

$\mathrm{t}=$ tempo $(\mathrm{s})$.

$$
\mathrm{Ed}=\mathrm{V}^{2} \times \rho \times 10^{-6}
$$

Onde:

Ed= Módulo de Elasticidade Dinâmico (MPa);

$\mathrm{V}=$ velocidade $(\mathrm{m} / \mathrm{s})$;

$\rho=$ densidade $\left(\mathrm{kg} / \mathrm{m}^{3}\right)$.

\subsection{Caracterização das propriedades de superfície}

A avaliação da superfície da madeira foi realizada por meio da determinação da molhabilidade, abrasão e colorimetria da face que esteve em contato com o prato da prensa durante 0 tratamento.

A molhabilidade foi avaliada pelo método da medição do ângulo de contato (AC) da gota séssil com o uso do Goniômetro - Kruss DSA30 e do software DSA30 (Figura 7). Esse equipamento mede o AC entre um líquido depositado sobre um sólido ou entre um líquido e um gás. As imagens foram captadas e analisadas pelo software que faz uma média entre os ângulos da direita e da esquerda. Para medir AC, foram utilizados seis CPs por tratamento medindo $6,5 \times 4,5 \mathrm{~cm}$ (c $\mathrm{x}$ I). As amostras receberam três marcações no intuito de orientar as três repetições de cada CP. Foi depositada uma gota d'água destilada de $10 \mu \mathrm{l}$ na superfície densificada e o AC medido uma vez a cada seis segundos durante sessenta segundos. 


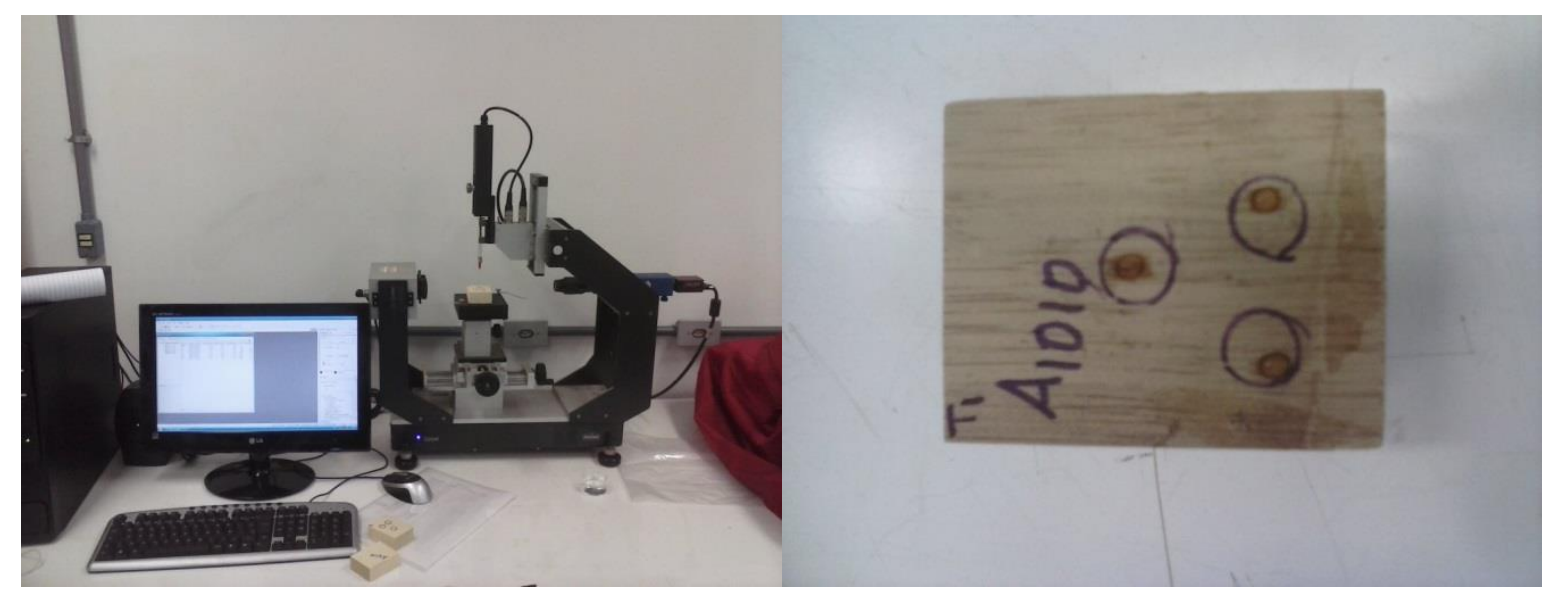

Figura 7 - Goniômetro - Kruss DSA30 e software DSA30 e marcações sobre a superfície densificada para orientar a deposição da gota séssil

O teste de abrasão foi realizado no Laboratório de Produtos Florestais (LPF) com o auxílio do abrasímetro da marca Taber (Figura 8) que é um abrasímetro que possui dois discos rotativos, o que permite o ensaio de dois corpos de prova simultaneamente. Cada disco rotativo possui dois suportes para rebolos, que podem ser carregados com pesos de 250 ou $750 \mathrm{~g}$, e, somados ao peso do suporte, totalizam 500 ou $1000 \mathrm{~g}$ de carga sobre o corpo de prova em cada rebolo. Os rebolos são discos de superfície áspera que ficam em contato com o corpo de prova gerando o atrito e, consequentemente, perda de massa.

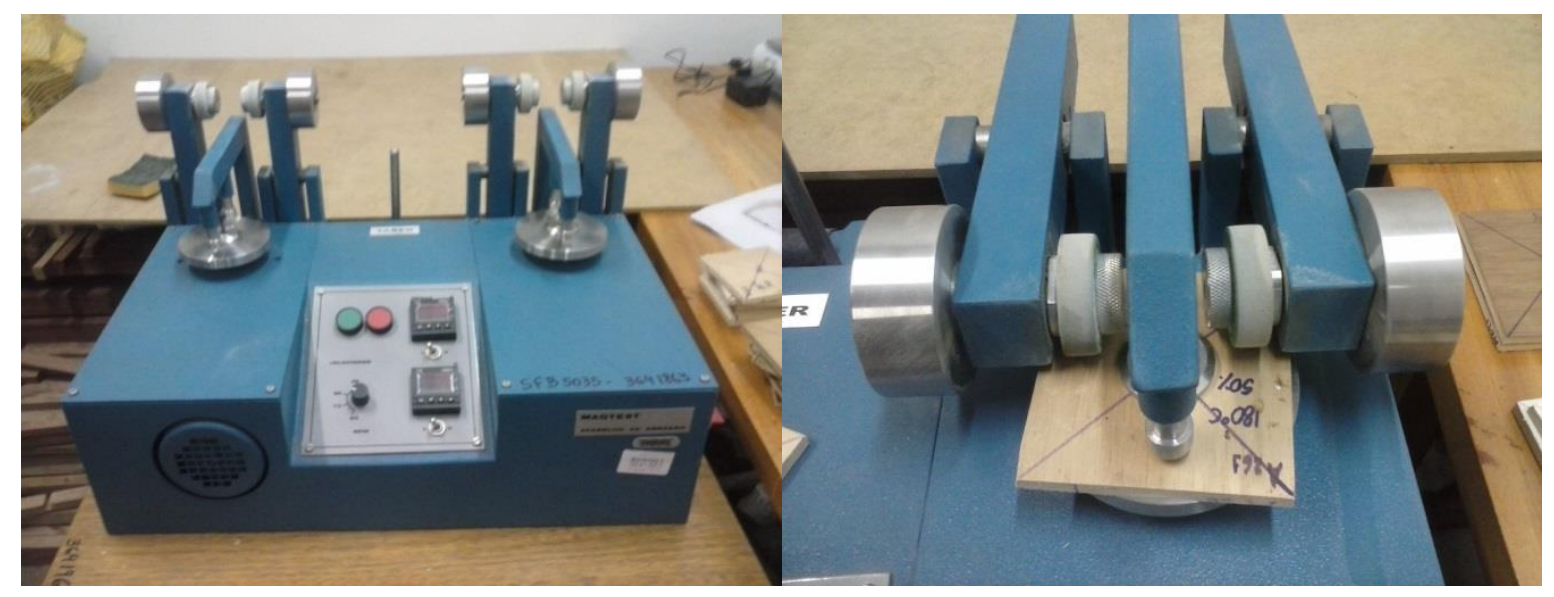

Figura 8 - Taber aparelho para ensaio de abrasão e amostra termodensificada passando pelo ensaio de abrasão

Para que durante o tratamento não ocorra esse empastamento dos rebolos e, consequentemente, a distorção dos dados, braços de sucção aspiram as partículas que vão se desprendendo da amostra enquanto o ensaio é realizado. Os rebolos utilizados no teste foram do tipo H18, compostos de partículas abrasivas e vitrificadas, de abrasividade média. A carga escolhida foi de $1000 \mathrm{~g}$, com 60 rotações por minuto (rpm) de velocidade e 600 ciclos, metodologia sugerida por Lopes (2012). 
Para análise da variação da resistência à abrasão em função da face ensaiada, cada tratamento teve seis repetições com CPs medindo $10 \mathrm{~cm} \times 10 \mathrm{~cm}$ (c $\times$ I). Inicialmente foi determinada a massa das amostras em uma balança analítica e, em seguida, fixadas nos discos rotativos do Taber e submetidas ao número de ciclos predeterminados. Durante esse processo, ocorre um "empastamento" do rebolo, fazendo-se necessária uma limpeza periódica do mesmo. Essa limpeza foi feita a cada duzentos ciclos, utilizando uma lixa e pincel. Após a finalização dos ciclos, quaisquer resíduos presentes nas amostras foram removidos utilizando um pincel, e as mesmas tiveram as massas determinadas novamente.

A variação de massa observada entre a pesagem inicial e final permitiu calcular a perda de massa da abrasão (PMdaA) e taxa de desgaste em função à abrasão das amostras como mostra a Equações 16 e 17 respectivamente.

$$
\mathrm{PMdaA}=\frac{(\mathrm{Mi}-\mathrm{Mf})}{\mathrm{Mf}} \times 100
$$

Onde:

PMdaA = perda de massa da abrasão (\%);

$\mathrm{Mi}=$ massa da amostra antes do ensaio $(\mathrm{g})$;

$\mathrm{Mf}=$ massa da amostra após do ensaio $(\mathrm{g})$;

Taxa de Desgaste $=100 \times \frac{(\mathrm{Mi}-\mathrm{Mf}}{\mathrm{N}}$

Onde:

Taxa de Desgaste $=$ taxa de desgaste $(\%)$;

$\mathrm{Mi}=$ massa da amostra antes do ensaio $(\mathrm{mg})$;

$\mathrm{Mf}=$ massa da amostra após o ensaio $(\mathrm{mg})$;

$\mathrm{N}$ = número de ciclos de abrasão realizados;

Para avaliação colorimétrica foram obtidas trinta amostras medindo $5,0 \times 4,5 \mathrm{~cm}(\mathrm{c} \times \mathrm{I})$ para as quais foram avaliados os parâmetros colorimétricos da testemunha em relação aos tratamentos termomecânicos. Em cada amostra, foram tomadas dez medidas na face que esteve em contato com a prensa, cada tratamento teve seis repetições. 
A avaliação dos parâmetros colorimétricos foi realizada de acordo com o sistema CIELAB (1972). Utilizou-se um espectrofotômetro Color Eye XTH-X-Rite, iluminante D65 conectado a um microcomputador. Foram determinados os parâmetros colorimétricos $\mathrm{L}^{*}$ (claridade), $\mathrm{a}^{*}$ (coordenada do eixo vermelho-verde) e $b^{*}$ (coordenada do eixo azul-amarelo), C (saturação) e $\mathrm{h}^{*}$ (ângulo de tinta). Para determinar as alterações na cor da madeira, após o tratamento utilizou-se a variação total da cor $\left(\Delta \mathrm{E}^{*}\right)$, metodologia que leva em consideração as diferenças das coordenadas cromáticas e de luminosidade, fornecendo uma visão mais ampla sobre o desempenho das madeiras submetidas ao tratamento termomecânico. A utilização desse parâmetro é adotada por diversos autores como Barreto e Pastore (2009) e Gouveia (2008), sendo expressa pela Equação 18.

$$
\Delta \mathrm{E}^{*}=\sqrt{\Delta \mathrm{L}^{* 2}+\Delta \mathrm{a}^{* 2}+\Delta \mathrm{b}^{* 2}}
$$

Onde:

$\Delta \mathrm{E}^{*}=$ variação da cor;

$\Delta \mathrm{L}^{*}=$ variação da luminosidade (amostra tratada menos testemunha);

$\Delta a^{*}$ e $\Delta b^{*}=$ variação das coordenadas cromáticas (amostra tratada menos testemunha);

Os valores de variação de cor foram utilizados por Barreto e Pastore (2009) para classificar a diferença da cor (Tabela 5) elaborada por Hikita et al., (2001), que se basearam em níveis de percepção. As médias das coordenadas cromáticas também serviram para determinar a cor que cada tratamento alcançou, utilizando a tabela proposta por Camargos e Gonçalez (2001).

Tabela 5 - Classificação da variação total da cor $(\Delta \mathrm{E})$ de madeiras

\begin{tabular}{c|c}
\hline Variação da cor $\left(\boldsymbol{\Delta} \mathbf{E}^{*}\right)$ & Classificação \\
\hline $0,0-0,5$ & Desprezível \\
$0,6-1,5$ & Ligeiramente perceptível \\
$1,6-3,0$ & Notável \\
$3,1-6,0$ & Apreciável \\
$6,1-12,0$ & Muito apreciável \\
\hline
\end{tabular}

\subsection{Análise dos experimentos}

A análise do experimento foi realizada por meio da análise de variância (ANOVA), teste de média, comparações descritivas e análise fatorial no programa estatístico SPSS 21. Para comparar e verificar a existência de diferença significativa dos quatro tratamentos e a testemunha, foi utilizado o teste Dunnett a $5 \%$ de significância, analisando assim o efeito de cada tratamento em relação às 
propriedades estudadas. Para identificar o efeito do aumento da temperatura ou da pressão ou a interação entre os fatores nas propriedades, foi realizada uma Análise de Variância Fatorial, a 5\% de significância, com dois fatores (temperatura e pressão) sendo dois níveis cada $\left(180^{\circ} \mathrm{C} \mathrm{e} 200^{\circ} \mathrm{C}\right.$; $50 \%$ e $75 \%)$. 


\section{RESULTADOS E DISCUSSÕES}

\subsection{Caracterização do material}

A Tabela 6 apresenta a caracterização das madeiras antes do tratamento, mostrando que as condições de densidade eram semelhantes para todos os tratamentos. A densidade média foi de $0,437 \mathrm{~g} / \mathrm{cm}^{3}$. A homogeneidade dessas características pôde ser comprovada por meio da análise estatística que não mostrou nenhuma diferença significativa entre os tratamentos.

Tabela 6 - Resultados do desvio padrão, densidade aparente e do coeficiente de variação dos quatro tratamentos termomecânicos unilateral realizados e a testemunha

\begin{tabular}{cccc}
\hline Tratamento & \multicolumn{3}{c}{ Densidade } \\
\cline { 2 - 4 } & Densidade aparente $\left(\mathrm{g} / \mathrm{cm}^{3}\right)$ & Desvio Padrão & CV $(\%)$ \\
\hline Testemunha & 0,44 & 0,018 & 3,998 \\
T1 $\left(180^{\circ} \mathrm{C} 50 \%\right)$ & 0,440 & 0,013 & 2,885 \\
T2 $\left(180^{\circ} \mathrm{C} 75 \%\right)$ & 0,434 & 0,007 & 1,513 \\
T3 $\left(200^{\circ} \mathrm{C} 50 \%\right)$ & 0,439 & 0,017 & 3,954 \\
T4 $\left(200^{\circ} \mathrm{C} 75 \%\right)$ & 0,433 & 0,009 & 1,995 \\
\hline Média & 0,437 & 0,013 & 2,869 \\
\hline
\end{tabular}

\subsection{Efeito do tratamento térmico}

\subsubsection{Efeito nas propriedades físicas}

A Figura 9 mostra que o efeito do tratamento termomecânico aumentou a PM e PMDAT ao longo dos tratamentos, ou seja, como esperado a maior PM ocorreu no T4 $\left(200^{\circ} \mathrm{C}\right.$ e $\left.75 \%\right)$ que foi o mais severo e a menor no $\mathrm{T} 1\left(180^{\circ} \mathrm{C}\right.$ e $\left.50 \%\right)$, o mesmo ocorreu para a variável PMDAT. Como após os tratamentos o material foi acondicionado em câmara climatizadora, processo pelo qual a madeira volta a ganhar umidade resultando no PMDAT, foi possível concluir que a madeira, ao longo do tratamento, sofreu não apenas a perda de água, mas também a degradação de polímeros, reduzindo a disponibilidade dos sítios de hidroxila da região amorfa das paredes celulares. Allegretti et al., (2012) afirmam que a partir de $160^{\circ} \mathrm{C}$ a temperatura já é responsável pela modificação térmica e pela perda de massa, a qual indica degradação dos constituintes da madeira e redução da higroscopicidade. 


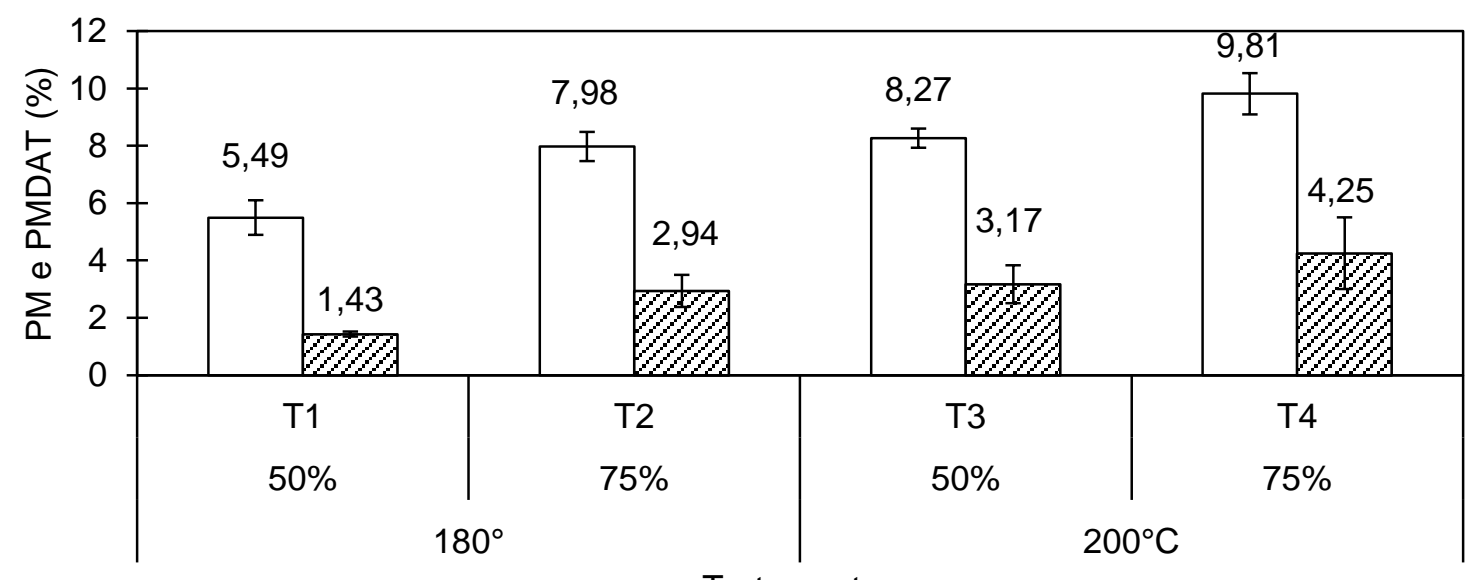

Tratamentos
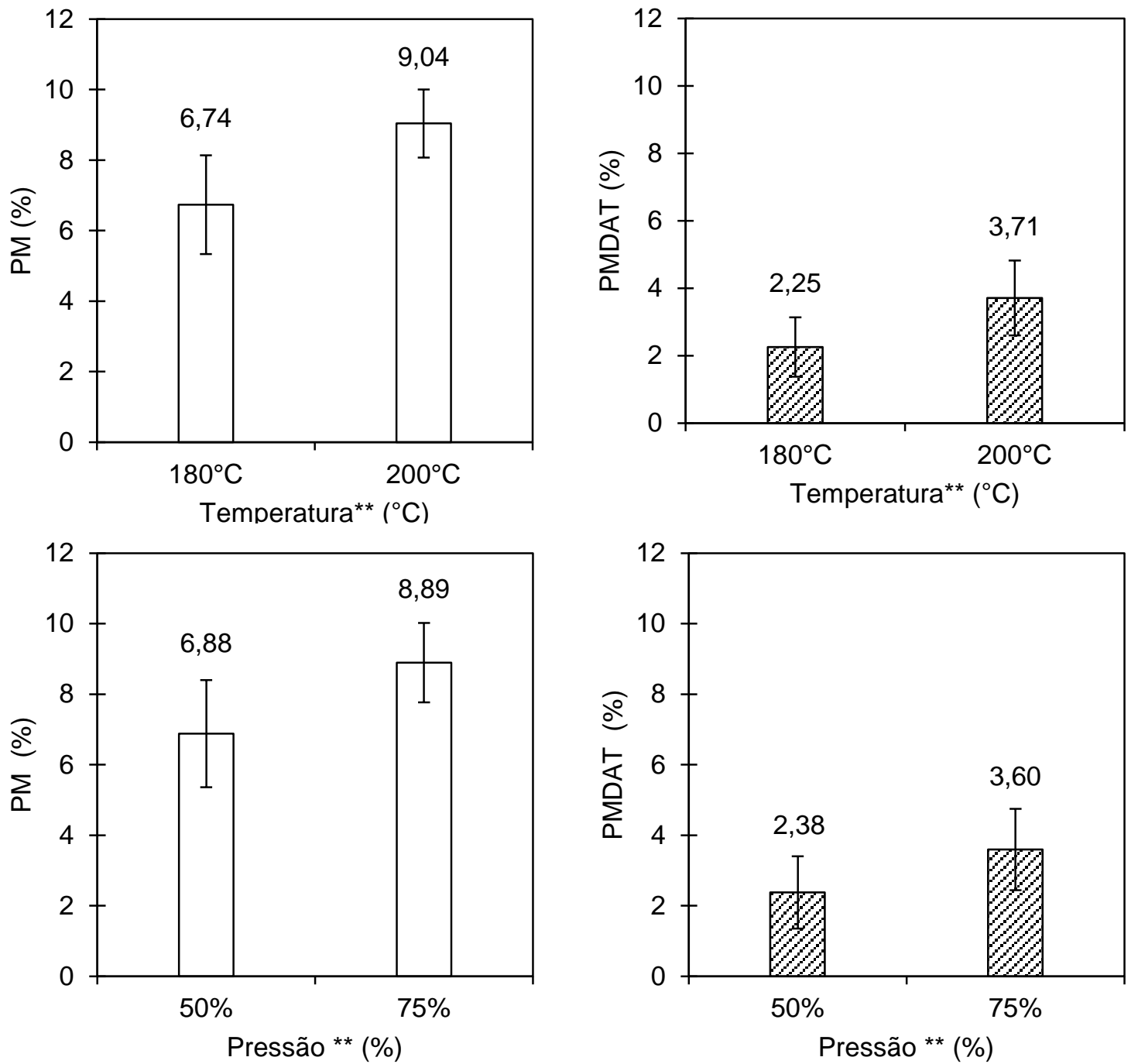

Figura 9 - Resultados da perda de massa (PM) e perda de massa definitiva (PMDAT) dos quatro tratamentos termomecânicos e suas respectivas análises fatoriais com o efeito dos fatores temperatura e pressão isolados

** fator significativo na análise fatorial a $5 \%$ de significância. As barras acima das colunas indicam o desvio padrão.

Através da análise fatorial, também foi possível constatar a interferência da pressão nos resultados. Assim como foi observado, na temperatura com o aumento da pressão a PM e PMDAT 
são maiores. A PM na pressão de $75 \%$ teve resultado $29,22 \%$ maior quando comparado com a madeira submetida a 50\%. Para esse fator, a PMDAT apresentou valores menores, porém a diferença entre as pressões aumentou para $51,26 \%$. Esses resultados ratificam a ideia que durante o tratamento a madeira sofreu não apenas perda de água, mas também degradação interna.

Alguns autores utilizam a taxa de compressão para expressar a magnitude da mudança na espessura final em relação à inicial do material. Dessa forma, a Figura 10 ilustra a taxa de compressão (TC) sofrida pela madeira ao longo dos tratamentos. T2 e T4 submetidos à pressão de $75 \%$ alcançaram os maiores valores com $37,99 \%$ e $37,08 \%$ respetivamente. Porém, é possível observar uma diferença muito pequena no resultado desses dois tratamentos, mesmo sendo tratados com temperaturas diferentes. Já nos tratamentos $\mathrm{T} 1$ e T3 submetidos à mesma pressão (50\%), a diferença dos resultados já é maior, mostrando a influência da temperatura nesse nível de pressão.

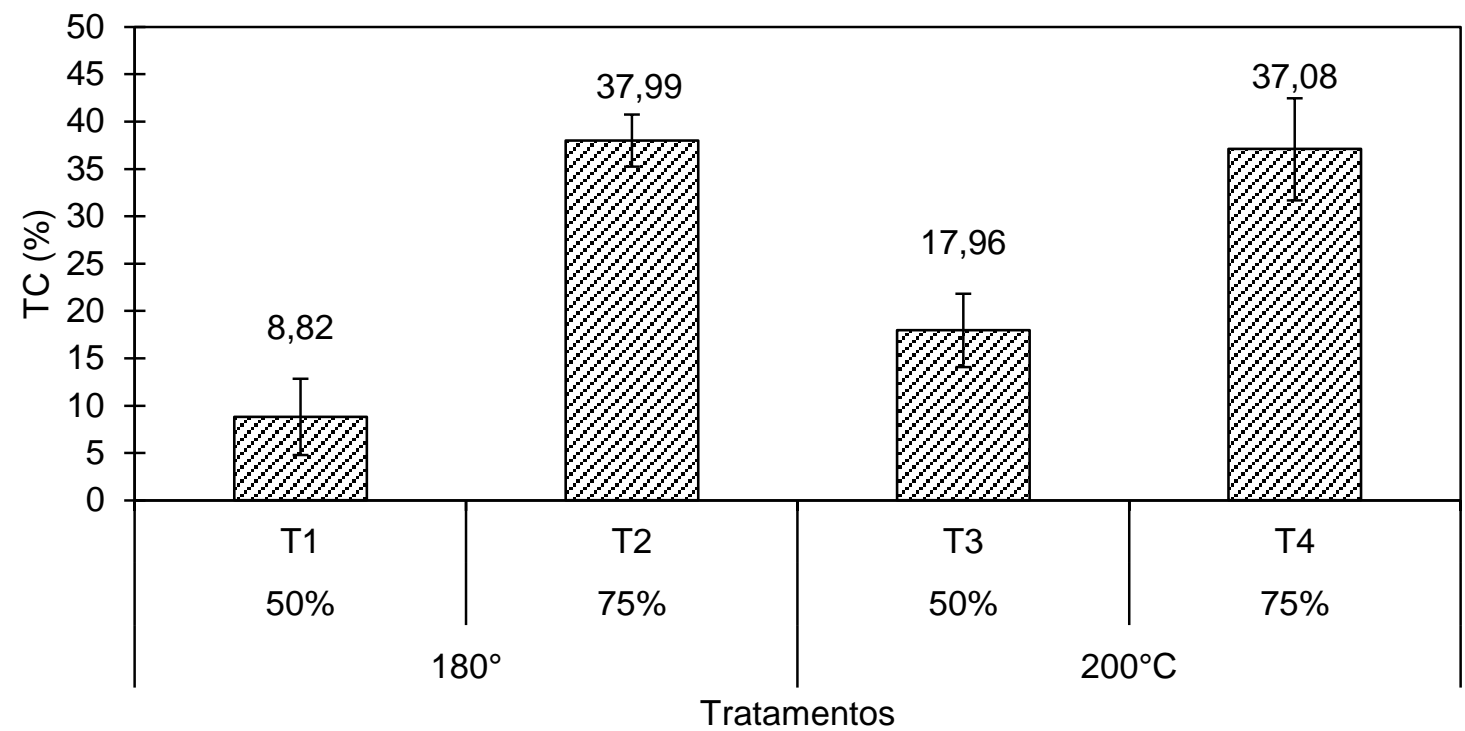

Figura 10 - Resultados da taxa de compressão (TC) para os quatro tratamentos termomecânicos

A análise fatorial vem corroborar com as afirmativas acima, mostrando que tanto a temperatura como a pressão exercem influência na TC como mostra a Tabela A.7 do apêndice I. Na Figura 11 percebe-se que, com a elevação da temperatura, ocorre o aumento de $17,61 \%$ da TC. A temperatura age nos polímeros viscoelásticos da madeira facilitando a deformação da parede celular de forma que essa ocorra sem rompimento ou fratura.

Na Figura 11 também é possível observar que a diferença é de 180,28\% entre as duas pressões, ou seja, mesmo os dois fatores sendo significativos, pode-se atribuir, nesse caso, a pressão a maior responsabilidade pela elevação na TC. 

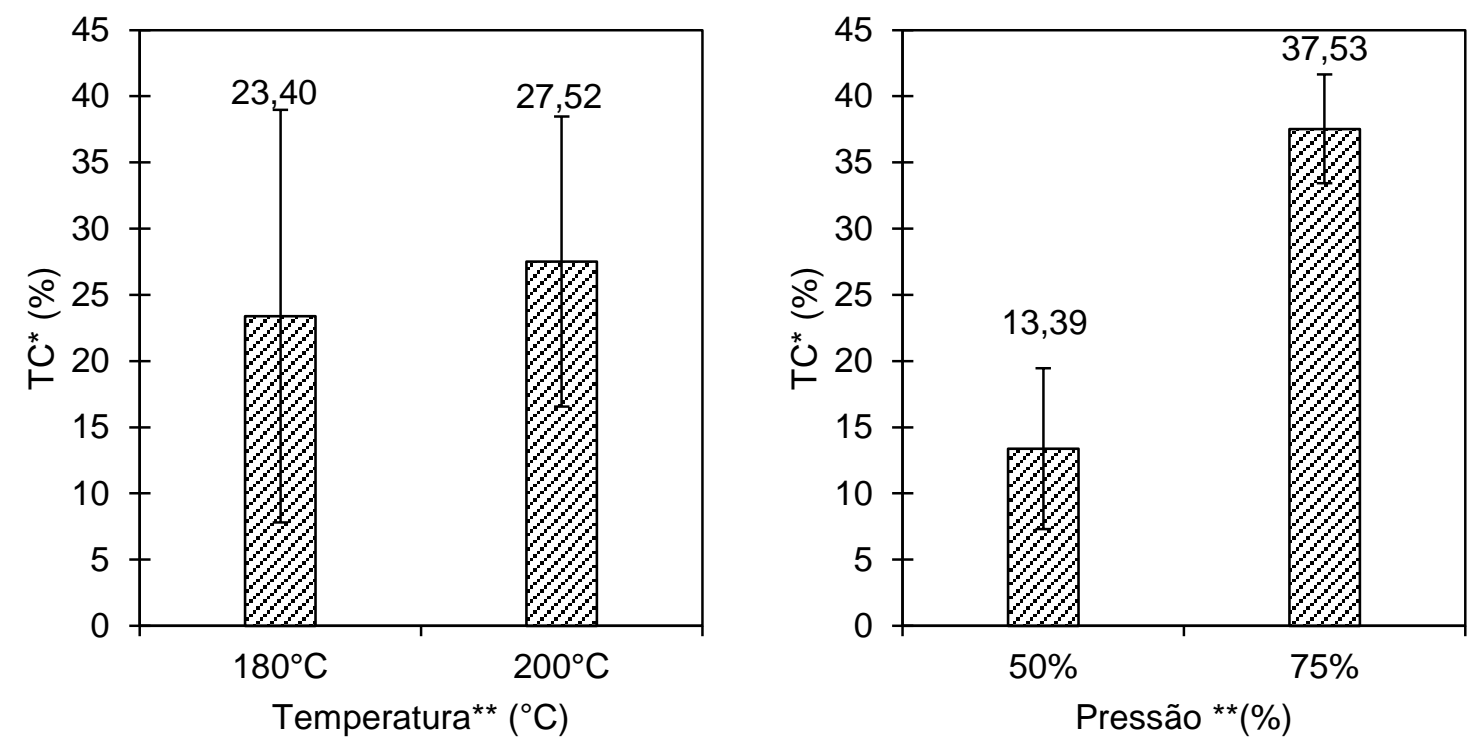

Figura 11 - Análise fatorial com efeito da temperatura e pressão isolados na taxa de compressão do tratamento termomecânico realizado

** fator significativo na análise fatorial a $5 \%$ de significância. As barras acima das colunas indicam o desvio padrão.

Segundo Naraynamurti e Kaul (1966) geralmente a taxa de compressão está mais relacionada ao aumento da pressão. Já os autores Bekhta et al., (2012), afirmam que TC é mais sensível à mudança da temperatura do que à pressão e ao tempo.

A análise estatística também mostrou que ocorre uma interação entre o efeito da temperatura e pressão, como se observa na Figura 12. A pressão $75 \%$ nas duas temperaturas possui valores superiores à pressão de $50 \%$. Mesmo com os valores mais baixos, a menor pressão sofreu aumento significativo com aumento da temperatura. Em outras palavras, a pressão de $50 \%$ foi mais sensível ao aumento da temperatura do que à pressão de $75 \%$. Com base nos dados apresentados, pode-se afirmar que a melhor taxa de compressão é obtida no T2 e T4 com a pressão de $75 \%$. 


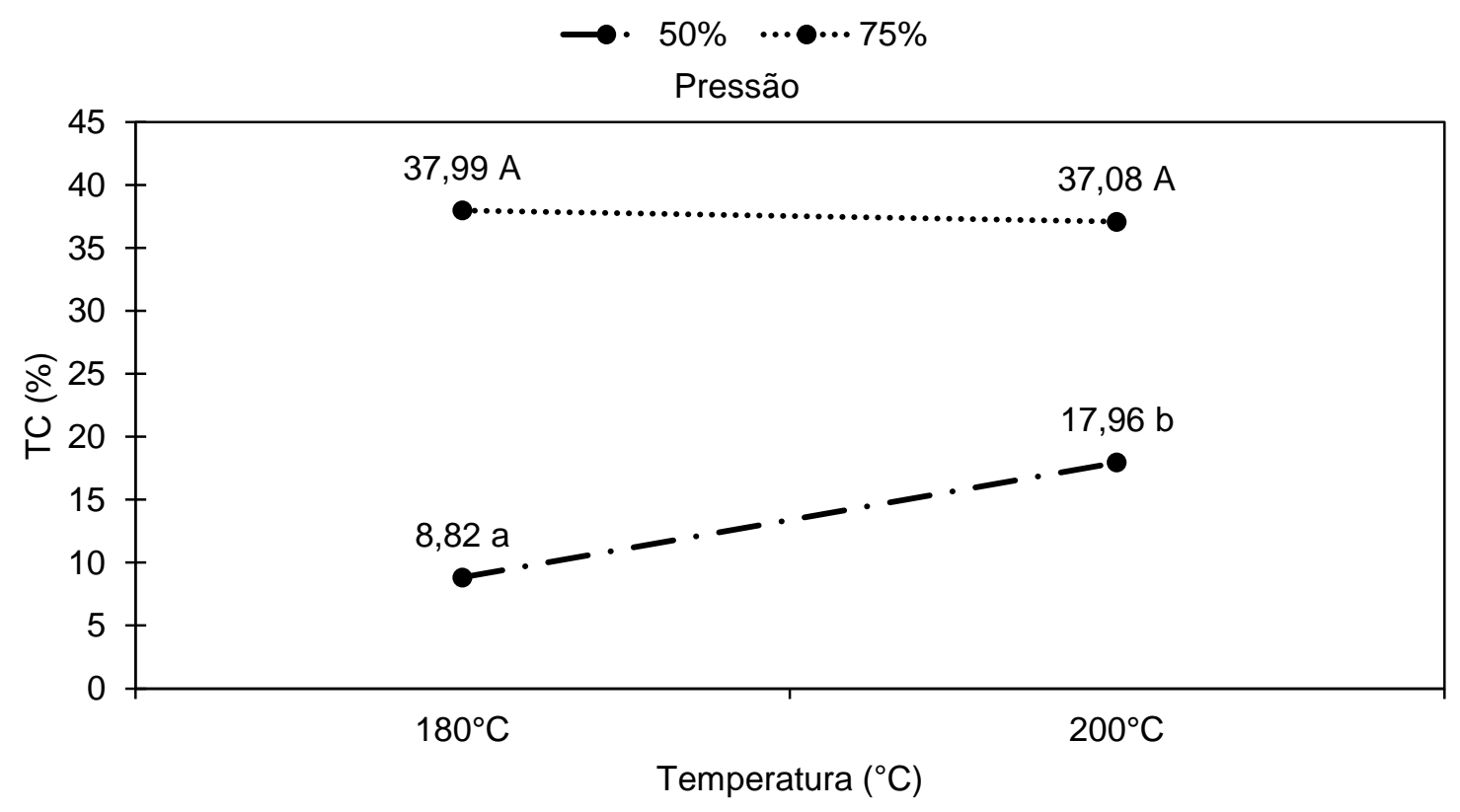

Figura 12 - Interação entre o fator temperatura e pressão na taxa de compressão no tratamento termomecânico

Nota: letras distintas maiúsculas e minúsculas indicam diferença significativa pela análise de variância a 5\% de significância.

Outra variável importante de se observar foi a Taxa de Densificação - TD que leva em conta a diferença da densidade inicial e a final. Com o uso da pressão, há uma redução nos espaços entre as células e do lume celular, resultando no aumento da densidade. Os tratamentos 2 e 4 obtiveram maior TD com $48,63 \%$ e $44,15 \%$, respectivamente.

A Figura 13 apresenta o resultado da análise fatorial (Tabela A.7 apêndice I) que atribui influência significativa para a mudança na TD, apenas à pressão. Os resultados mostram que o aumento na pressão aumenta a taxa de densificação, ou seja, a diferença entre a densidade inicial e final aumenta. 

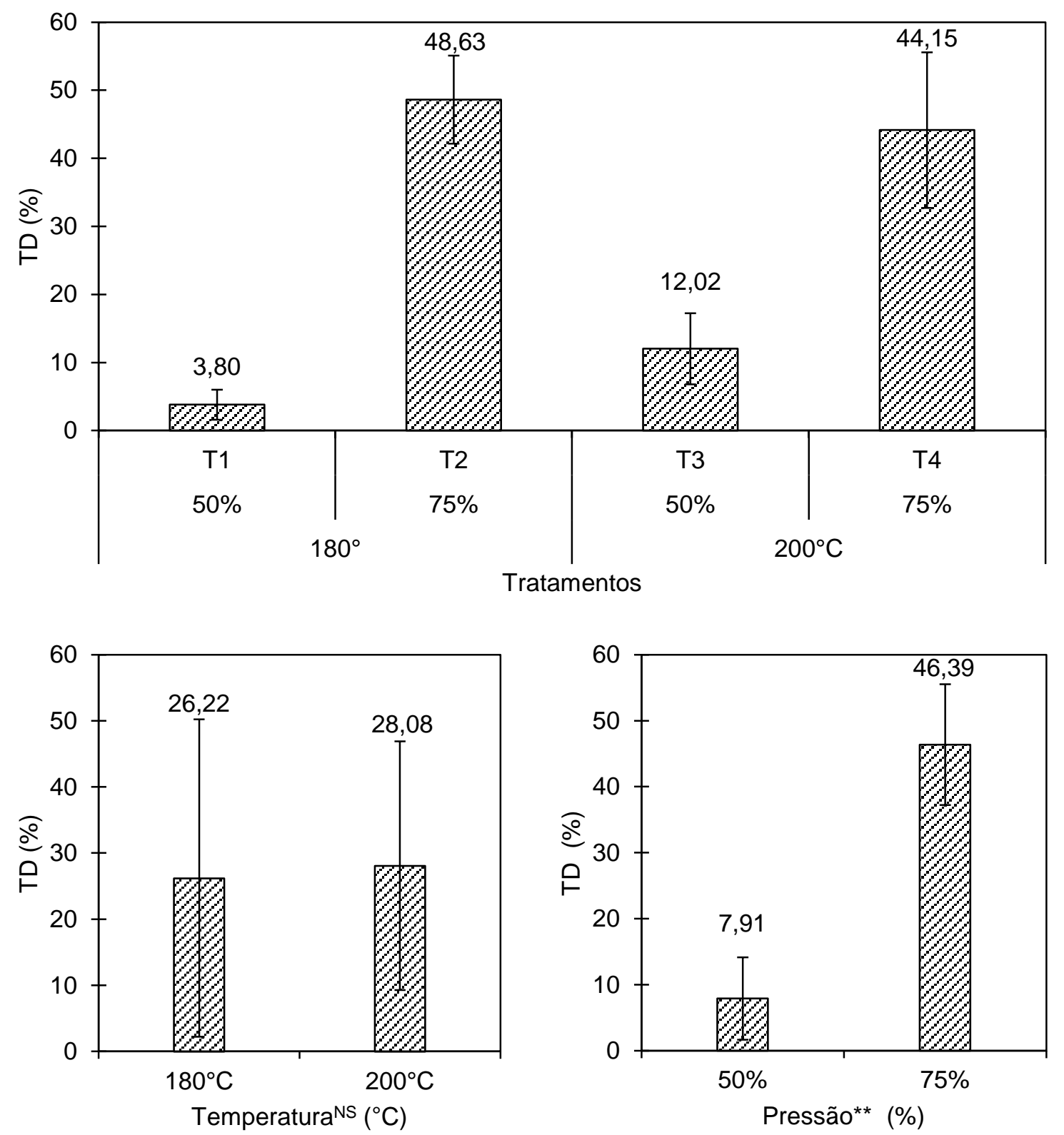

Figura 13 - Resultados da taxa de densificação (TD) para os quatro tratamentos termomecânicos e análise fatorial com o efeito dos fatores temperatura e pressão isolados.

** fator significativo na análise fatorial a $5 \%$ de significância ${ }^{\text {NS }}$ fator não significativo na análise fatorial a 5\% de significância. As barras acima das colunas indicam o desvio padrão.

Em relação à densidade final, a Figura 14 mostra os valores médios dos quatro tratamentos e da testemunha. Como já esperado, pelos resultados apresentadas na Figura 13, a densidade final aumentou, sendo que os maiores valores foram atingidos pelas condições dos tratamentos 2 e 4 $0,65 \mathrm{~g} / \mathrm{cm}^{3}$ e $0,62 \mathrm{~g} / \mathrm{cm}^{3}$ respectivamente. Já os tratamentos 1 e 3 alcançaram densidades menores $0,45 \mathrm{~g} / \mathrm{cm}^{3}$ e $0,49 \mathrm{~g} / \mathrm{cm}^{3}$ respectivamente. A diferença média entre os maiores e os menores valores foi de $35,10 \%$ podendo inferir a maior sensibilidade para alteração na pressão. 


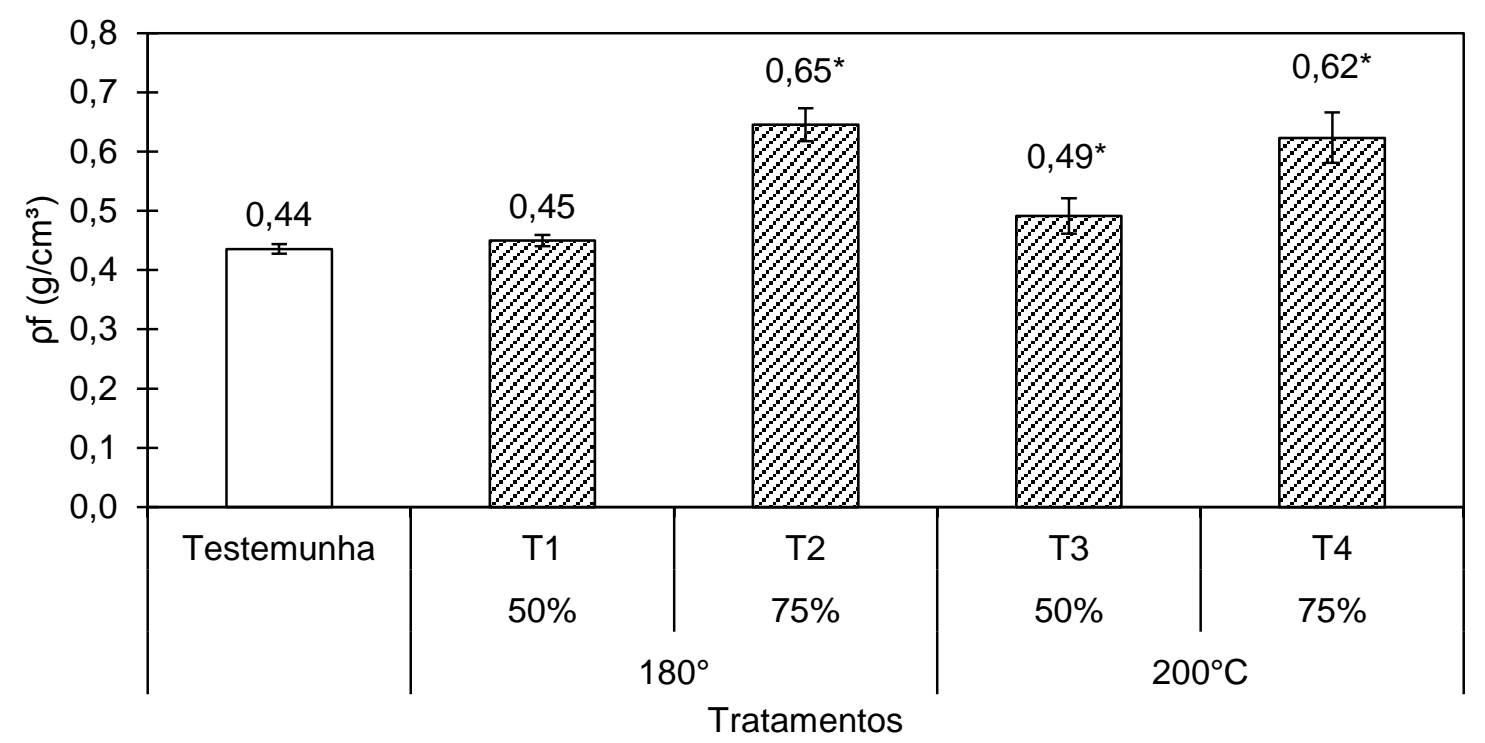

Figura 14 - Resultados da densidade final dos quatro tratamentos termomecânicos e da testemunha

* diferença significativa a 5\% de significância pelo teste de Dunnett.

O teste de Dunnett (Tabela A.4 apêndice I) apresenta os tratamentos 2, 3 e 4 significativamente diferentes da testemunha. Em relação ao $\mathrm{T} 1$, não foi encontrada diferença estatística quando comparado com a testemunha.

Ulker et al., (2012), utilizando pressão de $6 \mathrm{MPa}$ e temperatura de $120^{\circ} \mathrm{C}, 140^{\circ} \mathrm{C}$ e $160^{\circ} \mathrm{C}$, observaram que, depois do processo de densificação da madeira de Pinus sylvestris, a densidade aumentou de $0,42 \mathrm{~g} / \mathrm{cm}^{3}$ para $0,81 \mathrm{~g} / \mathrm{cm}^{3} \mathrm{em}$ todos os três tratamentos, ou seja, um aumento de $93 \%$ na densidade foi conseguido.

A análise fatorial explica esse resultado mostrando que apenas a pressão foi fator relevante nos valores da densidade final, assim como na TD. Pela Figura 15, nota-se que quanto maior a pressão maior é a densidade final. Assim, observa-se uma forte relação entre a taxa de compressão e a densidade básica. Inoue et al., (1993) corroboram com essa afirmação. Em seus estudos, esses autores constataram que a densidade aumentou de $0,36 \mathrm{~g} / \mathrm{cm}^{3}$ para $0,50 \mathrm{~g} / \mathrm{cm}^{3}$ com o grau de compressão de $30 \%$ e com uma taxa de compressão de $60 \%$ a densidade aumentou para $0,9 \mathrm{~g} / \mathrm{cm}^{3}$. Santos (2011) verificou influência da duração nos tratamentos na tendência de melhorar as propriedades da madeira, porém deve-se levar em consideração que nesse trabalho o autor usou temperatura de no máximo $170^{\circ} \mathrm{C}$. 

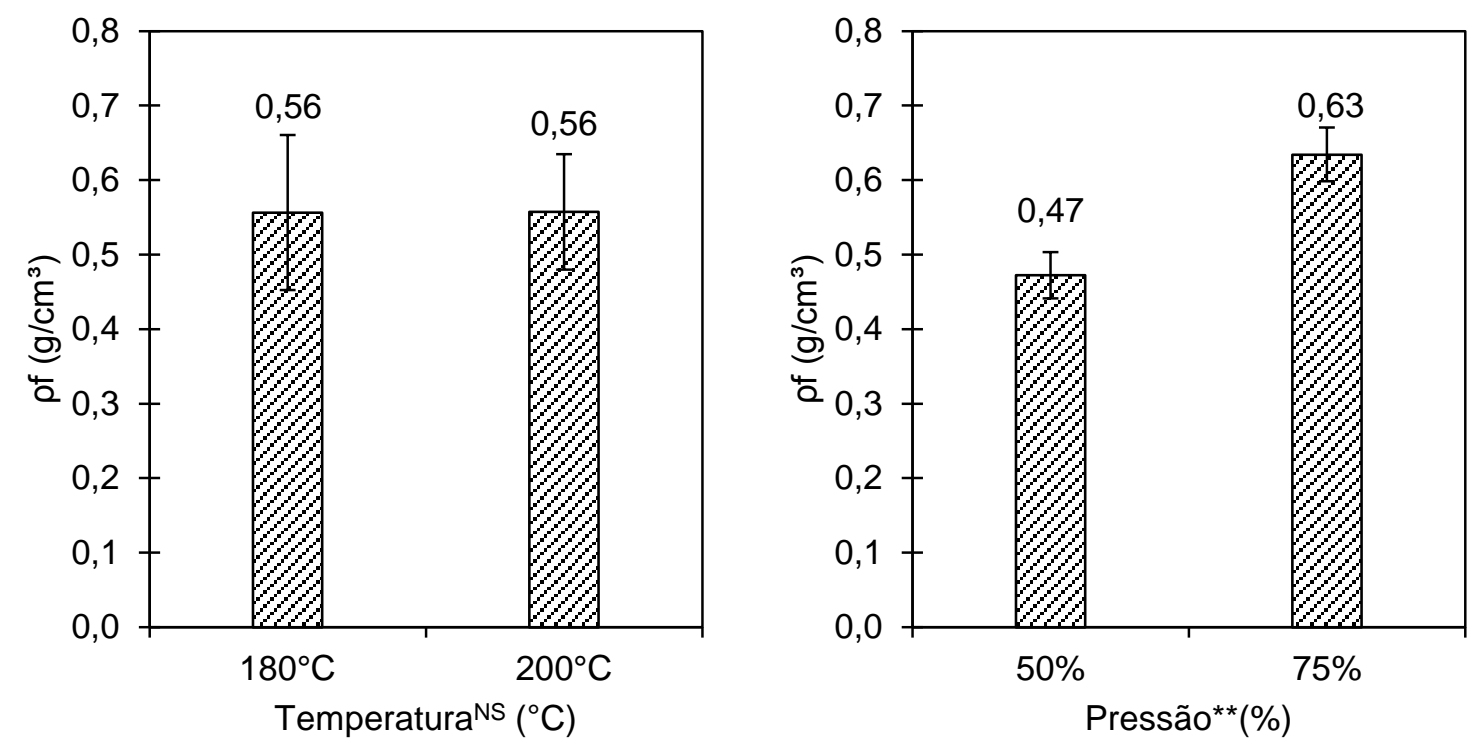

Figura 15 - Análise fatorial com o efeito dos fatores temperatura e pressão isolados na densidade final dos tratamentos termomecânicos

** fator significativo na análise fatorial a $5 \%$ de significância. ${ }^{N S}$ fator não significativo na análise fatorial a 5\% de significância. As barras acima das colunas indicam o desvio padrão.

Pelo fato da densificação ter ocorrido em apenas uma das faces da madeira, foi realizada a avaliação da densidade ao longo da espessura da madeira por densitometria de raio-x. Os resultados para esse teste são apresentados nas Figuras 16 e 17 (a densificação ocorreu no lado direito). A Tabela 7 mostra os valores da média, do máximo e do mínimo de cada tratamento. Os maiores valores ocorreram nos tratamentos 2 e 4, assim como a média. Nos valores mínimos praticamente não há diferença entre os tratamentos.

Tabela 7 - Resultados das médias, valores máximos e mínimos para a densitometria de raio-x dos quatro tratamentos termomecânicos e da testemunha

\begin{tabular}{cccc}
\hline Tratamento & Média & Máximo & Mínimo \\
\hline Testemunha & 0,42 & 0,58 & 0,30 \\
T1 $\left(180^{\circ} \mathrm{C} 50 \%\right)$ & 0,43 & 0,51 & 0,33 \\
T2 $\left(180^{\circ} \mathrm{C} 75 \%\right)$ & 0,50 & 0,68 & 0,34 \\
T3 $\left(200^{\circ} \mathrm{C} 50 \%\right)$ & 0,47 & 0,60 & 0,33 \\
T4 $\left(200^{\circ} \mathrm{C} 75 \%\right)$ & 0,57 & 0,85 & 0,35 \\
\hline
\end{tabular}



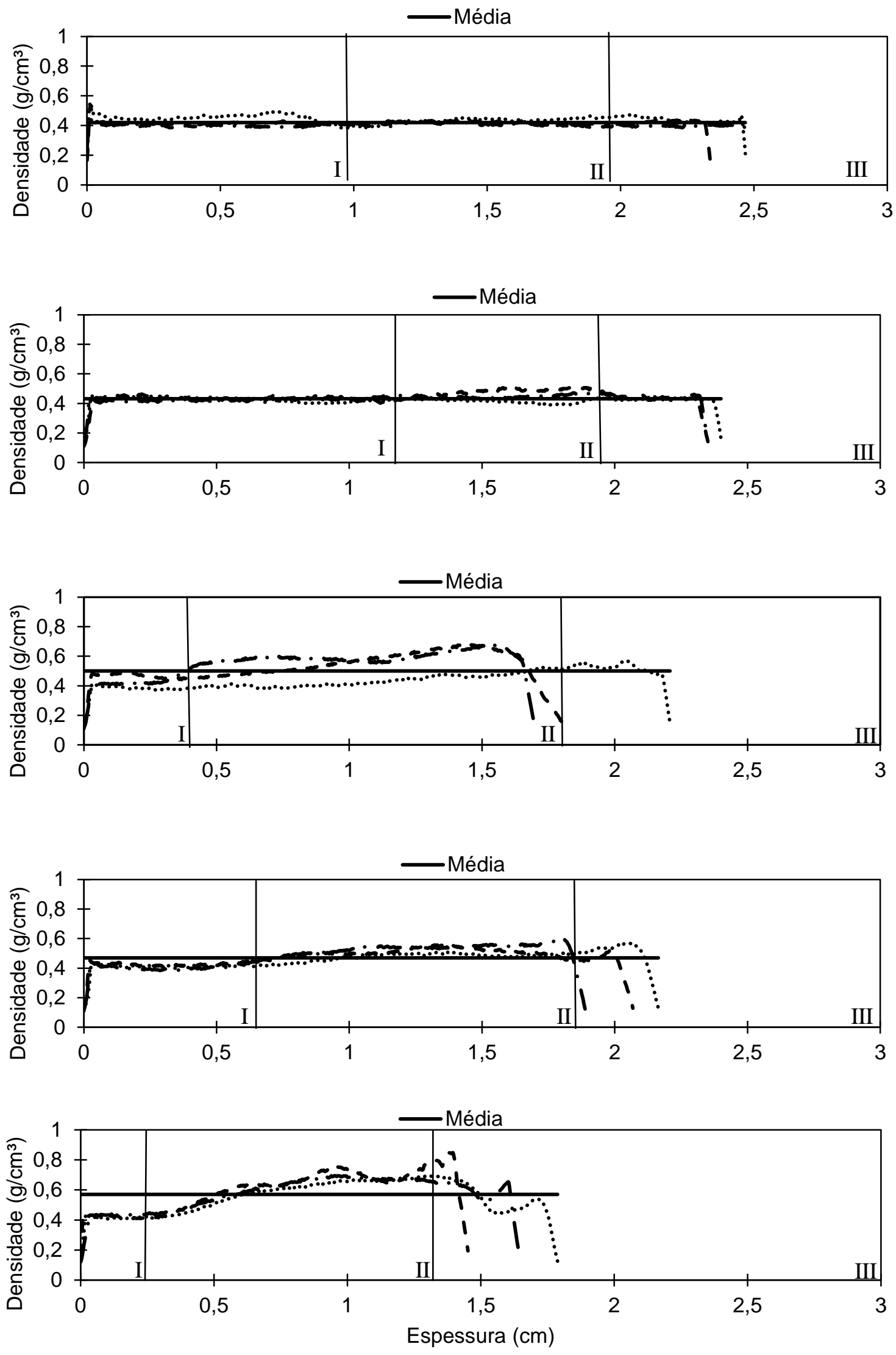

Figura 16 - Perfil da densidade da espessura dos quatro tratamentos e da testemunha dividido em três zonas de comportamento 

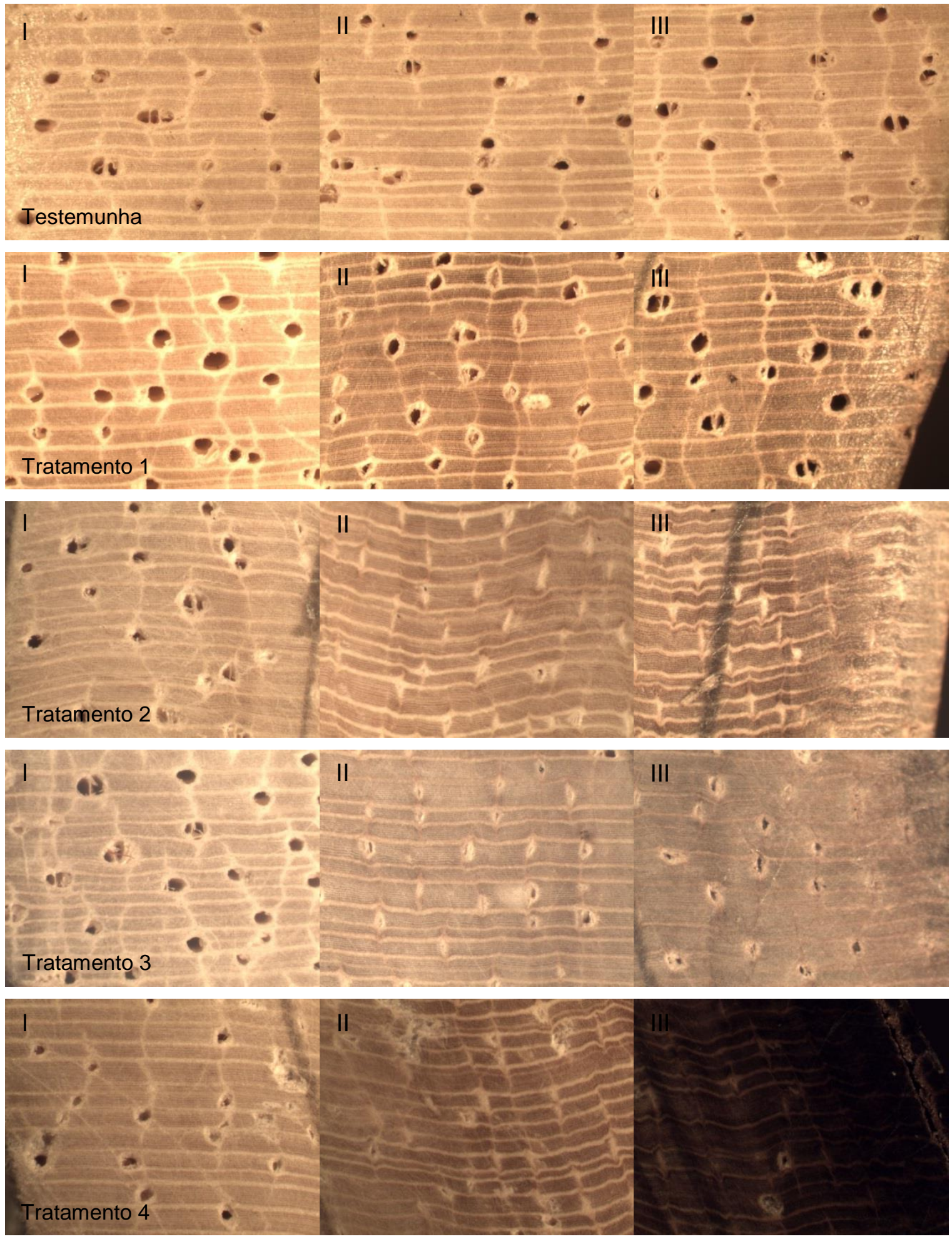

Figura 17 - Imagens da anatomia macroscópica das três zonas do perfil de densidade dos quatro tratamentos e da testemunha

$\mathrm{Na}$ Figura 16, os gráficos foram divididos em três partes para mostrar os diferentes perfis ao longo da espessura das amostras. Na testemunha não há muita diferença ao longo da espessura, apresentando um comportamento mais homogêneo, isso se explica pelo fato das amostras não terem passado por nenhum tipo de tratamento. 
No tratamento 1 , a média é praticamente igual à média apresentada pela testemunha, a área I mostra comportamento semelhante ao da testemunha, mostrando a superfície não densificada e não se distanciando muito da média. A área II é a parte crescente e intermediária, local onde apresenta as maiores densidades do corpo de prova e onde ocorre o maior distanciamento da média. A área III representa a superfície da madeira que esteve em contato com os pratos aquecidos da prensa e é onde se pode observar um comportamento decrescente quando comparado com a zona II. Na Figura 17 estão as imagens da anatomia macroscópica de cada área que ilustram como o tratamento interferiu na aparência dos raios e vasos, de modo a auxiliar na análise qualitativa.

Nas imagens macroscópicas do T1 é possível notar diferença da cor entre as zonas, sendo as áreas II e III mais amarronzadas e os vasos mais achatados. Mesmo a diferença não sendo tão significativa entre os valores das médias, máximos e mínimos do T0 e T1, através da análise de imagem acima nota-se que a temperatura e pressão afetaram a madeira.

No tratamento 2, as amostras têm um perfil mais heterogêneo, sendo que T1_15 possui dois pontos de declínio se assemelhando à letra $\mathrm{M}$, comportamento semelhante ao dos painéis. Devido à elevada pressão, a área I é reduzida e as linhas se distanciam mais da média. Pelas imagens, observa-se o maior achatamento dos vasos, assim como a distorção dos raios.

O tratamento 3 apesar de apresentar maior distância da média, se assemelha mais ao perfil apresentado pelo tratamento 1, tendo a média, máximo e mínimo bem próximos. Dessa forma, deduz-se que a pressão, assim como na densidade aparente, exerce maior influência nos resultados apresentados pela densitometria de raio-x.

O tratamento 4, por ser mais severo, apresentando a maior temperatura $\left(200^{\circ} \mathrm{C}\right)$ e maior pressão (75\%), alcançou a maior densidade. O gráfico de T4 se assemelha mais ao do T2. Os perfis dos três corpos de prova se distanciam muito da média mesmo na área I. Isso ocorre devido ao fato da elevada densificação que a madeira sofreu na área II e III, aumentando assim a média. As imagens da área II e III deixam mais clara a intensidade do tratamento. Na região II, os vasos já se encontram todos fechados e os raios muito distorcidos. Na área III é possível notar uma fissura na superfície e os vasos já são praticamente imperceptíveis.

De forma geral, nos tratamentos com maior pressão há uma redução da área I e maior distância da linha da média. Na região III, como observado anteriormente, há uma queda na densidade. Uma possível explicação é o fato de essa área representar a superfície densificada, em contato com os pratos aquecidos, que perde umidade de forma mais acelerada em comparação com as outras partes da madeira. A presença de água na madeira é essencial para um eficiente tratamento termomecânico ou termohidromecânico, ou seja, água é um excelente condutor 
térmico e a perda da umidade interfere negativamente no processo de densificação térmica, pois a falta de umidade dificulta a condução térmica e o processo de plasticização da madeira.

Outro fato interessante de ser notado é a alteração da cor da madeira ao longo dos tratamentos e das três áreas. A diferença entre a superfície densificada e não densificada fica clara com as imagens dos quatro tratamentos.

$\mathrm{Na}$ Figura 18, observam-se os valores do teor de umidade de equilíbrio da testemunha e dos quatro tratamentos. Como era esperado, a testemunha possui o maior valor de TUE, pois não foi submetida a nenhum tipo de tratamento. O teste de Dunnett (Tabela A.4 apêndice I) mostra que só houve diferença significativa a partir do T2. Sendo assim, o TUE do T1 foi estatisticamente igual ao da testemunha. Os demais tratamentos apresentaram diferença média de 14,92\% quando comparados à testemunha. Era esperado que a diferença fosse maior, devido ao tratamento térmico que tende a diminuir o teor de umidade de equilíbrio, como mostra Vasconcelos (2012), quando densificou amostras de Pinus $s p$. em ambas superfícies, obteve uma diferença média igual a 33\% maior da madeira tratada em relação a não tratada. Essa diferença de resultados mostra que a densificação quando ocorre em ambas as superfícies ou unilateral, interfere de forma significativa no TUE. No presente trabalho, talvez em consequência do tratamento ter ocorrido em apenas uma superfície, não foi possível observar um padrão no comportamento da madeira, ficando o T2 com o menor valor do TUE, mesmo sendo submetido a menor temperatura.

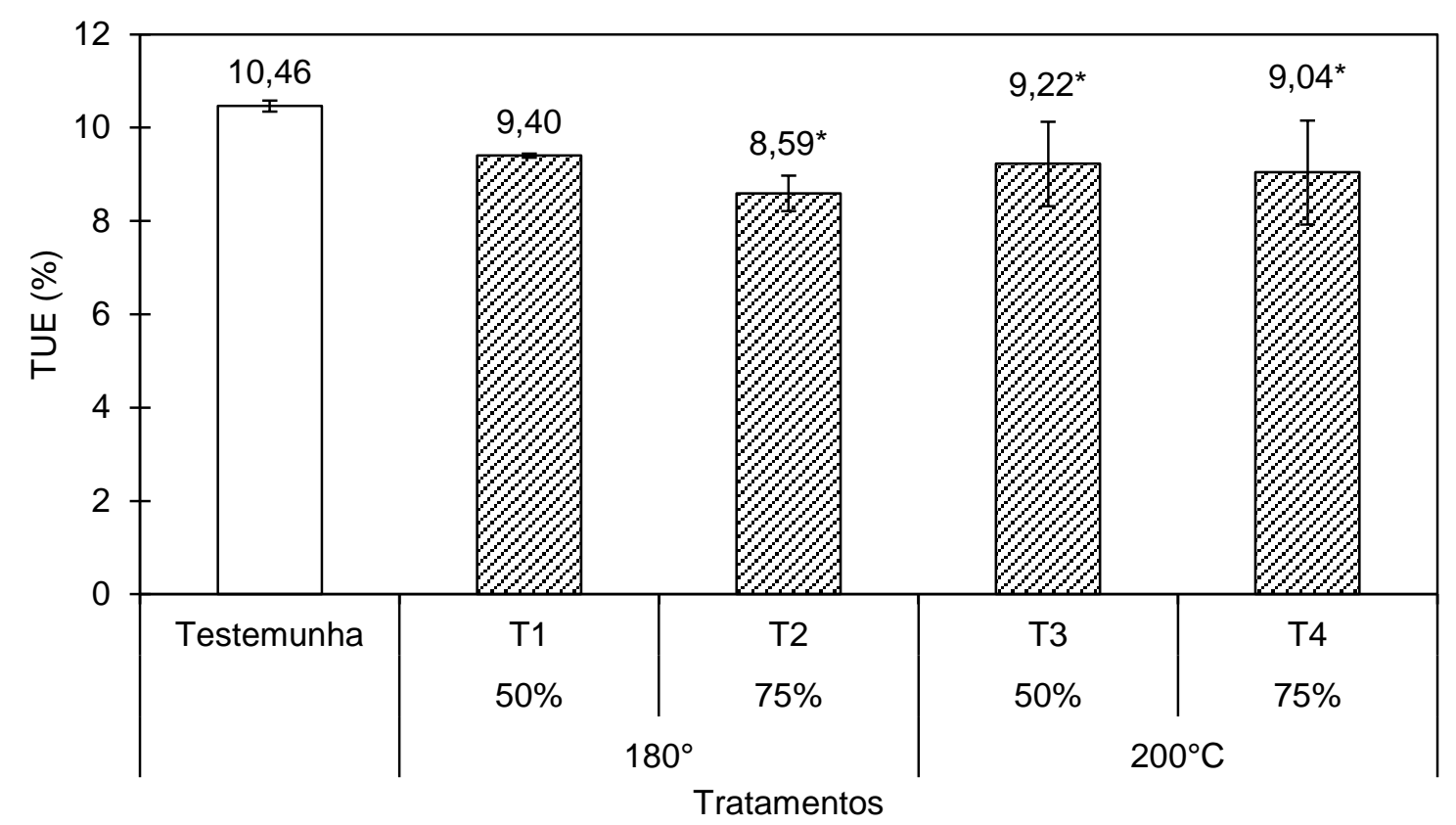

Figura 18 - Resultados do teor de umidade de equilíbrio (TUE) dos quatro tratamentos termomecânicos e a testemunha

*diferença significativa a 5\% de significância pelo teste de Dunnett 
A redução do TUE em madeiras tratadas termomecânicamente, segundo Del Menezzi e Tomaselli (2006), é muito vantajosa e indica que as madeiras são mais estáveis a variações de umidade, pois estão menos susceptíveis à adsorção de água. A principal causa da redução do TUE é a perda de polímeros higroscópicos, como a hemicelulose, que são mais sensíveis ao tratamento térmico (BOONSTRA; TJEERDSMA, 2006).

A análise fatorial (Tabela A.7 do apêndice), ilustrada na Figura 19, mostra que para o teor de umidade de equilíbrio não houve influência da variação da temperatura nem da variação da pressão nos resultados encontrados. Dessa forma assume-se que a aplicação da menor temperatura e da menor pressão são suficientes para reduzir o TUE.
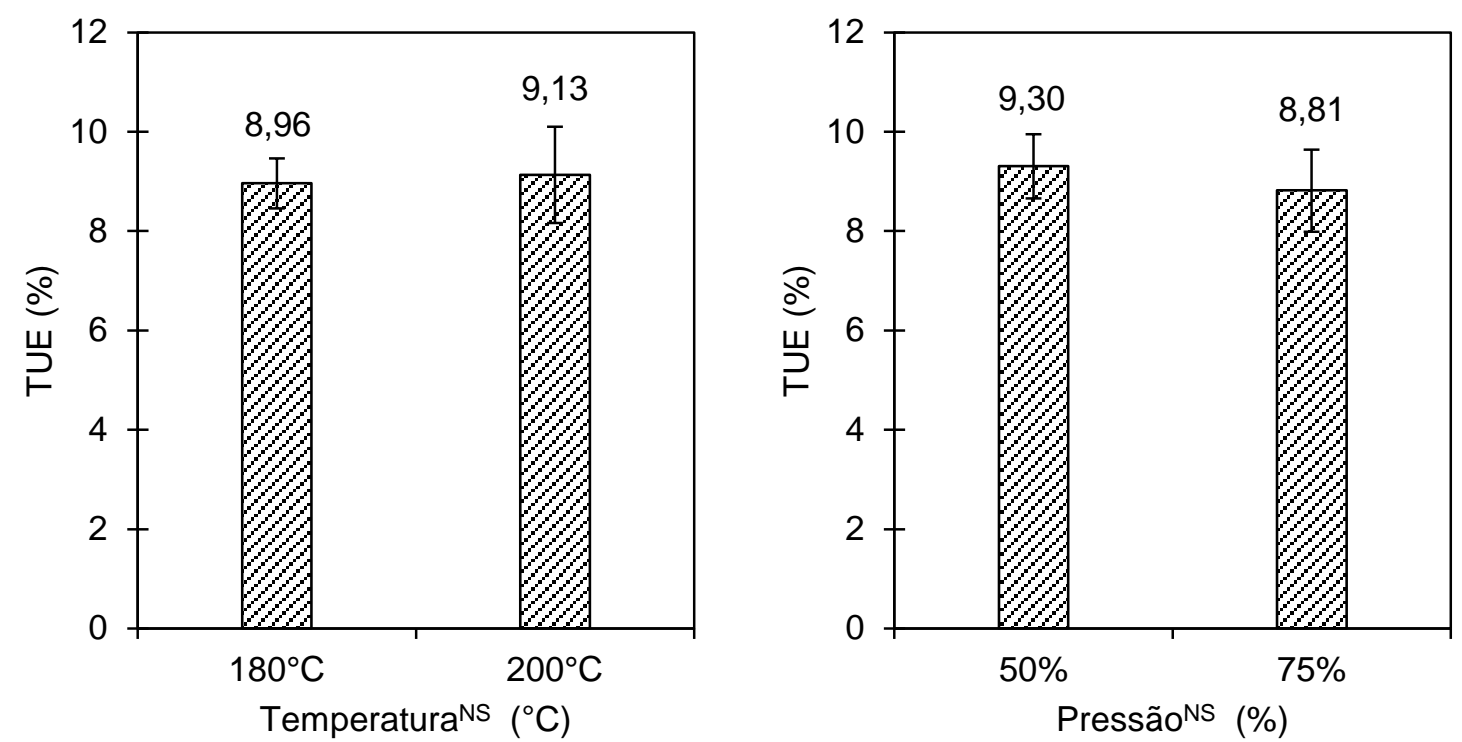

Figura 19 - Análise fatorial com efeito isolado dos fatores temperatura e pressão no TUE dos tratamentos termomecânicos

NS fator não significativo na análise fatorial a $5 \%$ de significância. As barras acima das colunas indicam o desvio padrão.

Em relação à estabilidade dimensional também foram analisadas variáveis como inchamento em espessura com as variáveis IE2H, IE24H (Figura 20), de uma forma geral houve um aumento nessas taxas. No IE2H T2 apresentou aumento superior a $1000 \%$ em relação à testemunha, tornando-se o único com diferença significativa em relação à testemunha pelo teste de Dunnett (Tabela A.4 do apêndice).

Para variável IE24H, os tratamentos T2 e T4 alcançaram os maiores valores, sendo o resultado médio aproximadamente 15,85 vezes maior que o da testemunha. Esses tratamentos, pelo teste de Dunnett se diferenciaram estatisticamente da testemunha, porém a mesma diferença não foi encontrada para T1 e T3. 
A análise fatorial (Tabela A.7 apêndice I) mostra o efeito significativo da pressão e da temperatura para os dois tempos do inchamento. Após $24 \mathrm{~h}$, o IE, com efeito isolado da temperatura, reduziu 23,59\% mostrando que o aumento desse fator Influência positivamente na maior resistência à variação climática. O trabalho de Del Menezzi (2004) com OSB tratados termicamente ratifica a afirmação acima, pois mostra que quanto mais severa a temperatura menor o inchamento definitivo do painel, indicando que o tratamento térmico ameniza as tensões internas da compressão, auxiliando na estabilidade dimensional.

口IE2H 口IE24H

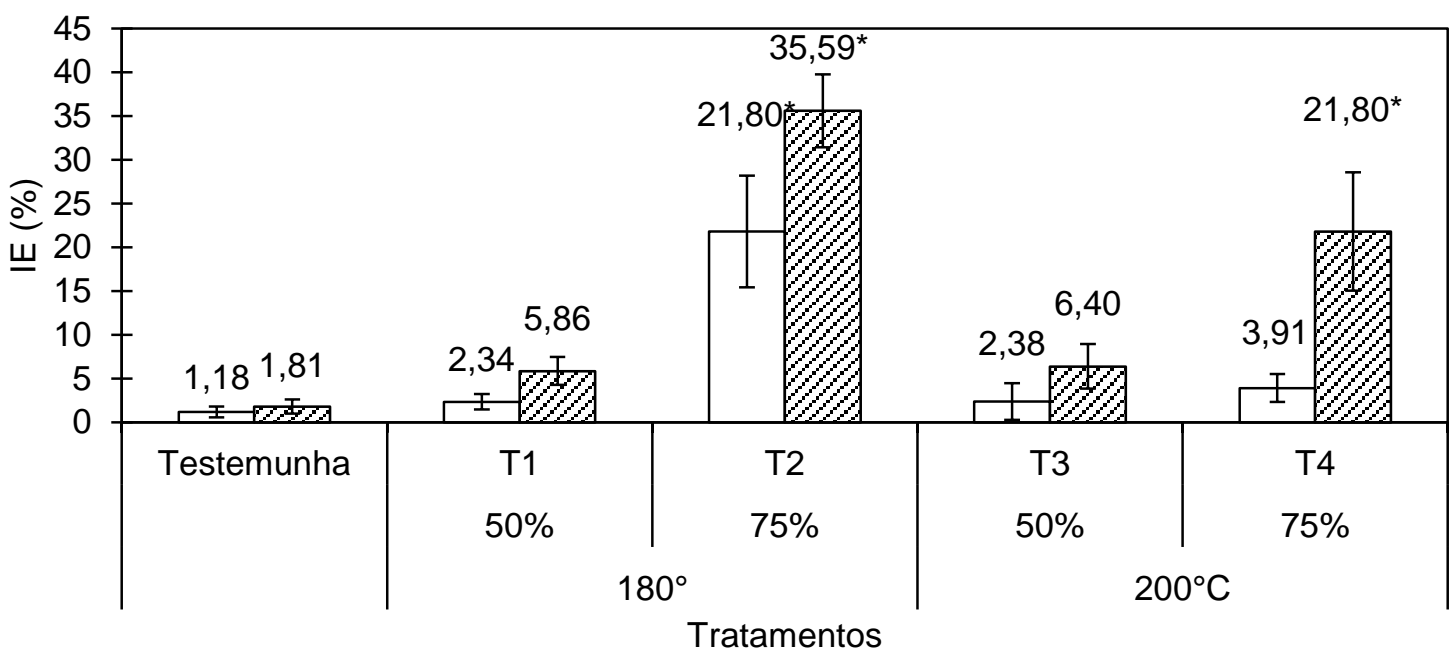

口IE2H øIE24H

ㅁIE2H IE24H
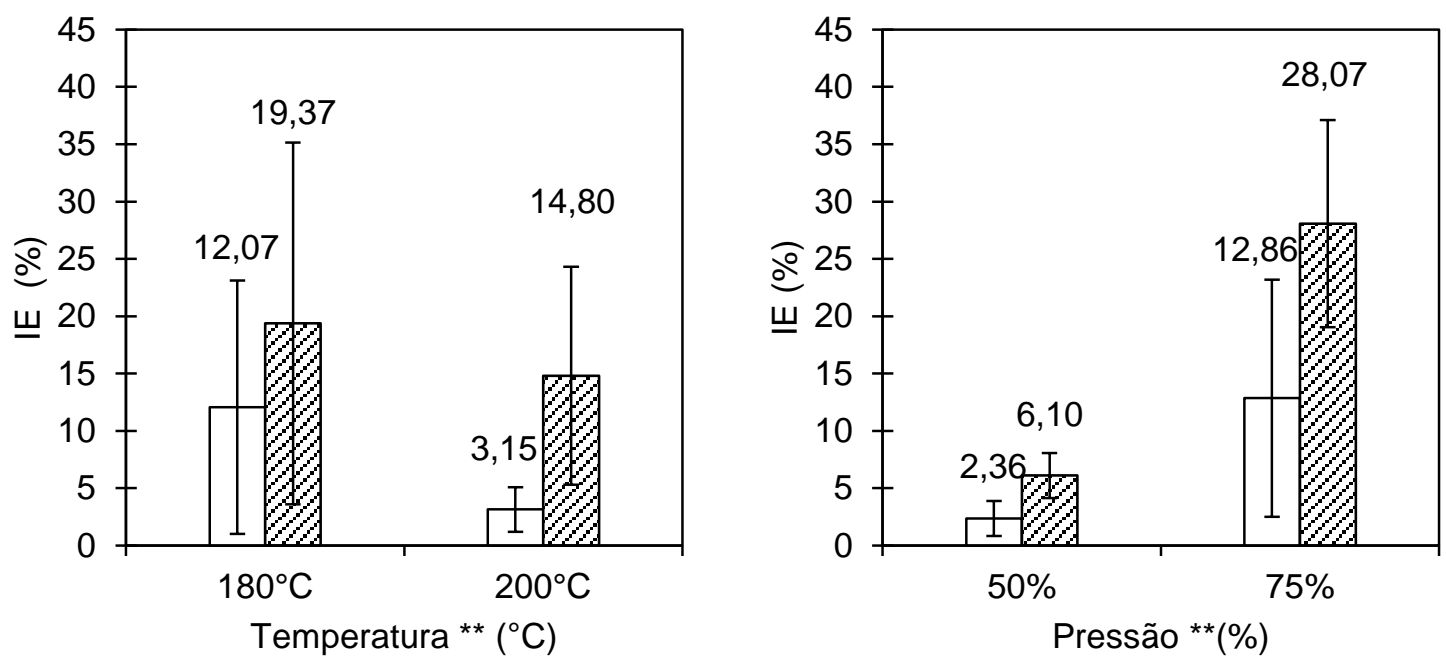

Figura 20 - Resultados do inchamento em espessura após duas e vinte e quatro horas para os quatro tratamentos termomecânicos e a testemunha e análise fatorial com efeito dos fatores temperatura e pressão isolados

* diferença significativa a $5 \%$ de significância pelo teste de Dunnett. ** fator significativo na análise fatorial a $5 \%$ de significância. As barras acima das colunas indicam o desvio padrão. 
No entanto, o mesmo efeito não pode ser observado no fator pressão, o qual o IE24H teve um aumento de $360 \%$ com o aumento da pressão. Dessa forma, para o $\mathrm{IE}$, a temperatura não conseguiu amenizar os efeitos negativos da pressão.

Na Figura 21 é apresentado o resultado da absorção de água. Em duas horas o único tratamento com valor significativamente maior que a testemunha foi o T2, com aumento de $81,60 \%$. Os demais tratamentos não se diferenciaram da testemunha (Tabela A.4 apêndice I) que absorveu $16,6 \%$. Para AB24H o comportamento descrito acima se repetiu, ou seja, T2 se manteve como o único tratamento a se diferenciar da testemunha com ganho de 50,38\%.

\section{$\square \mathrm{AB} 2 \mathrm{H} \square \mathrm{AB} 24 \mathrm{H}$}
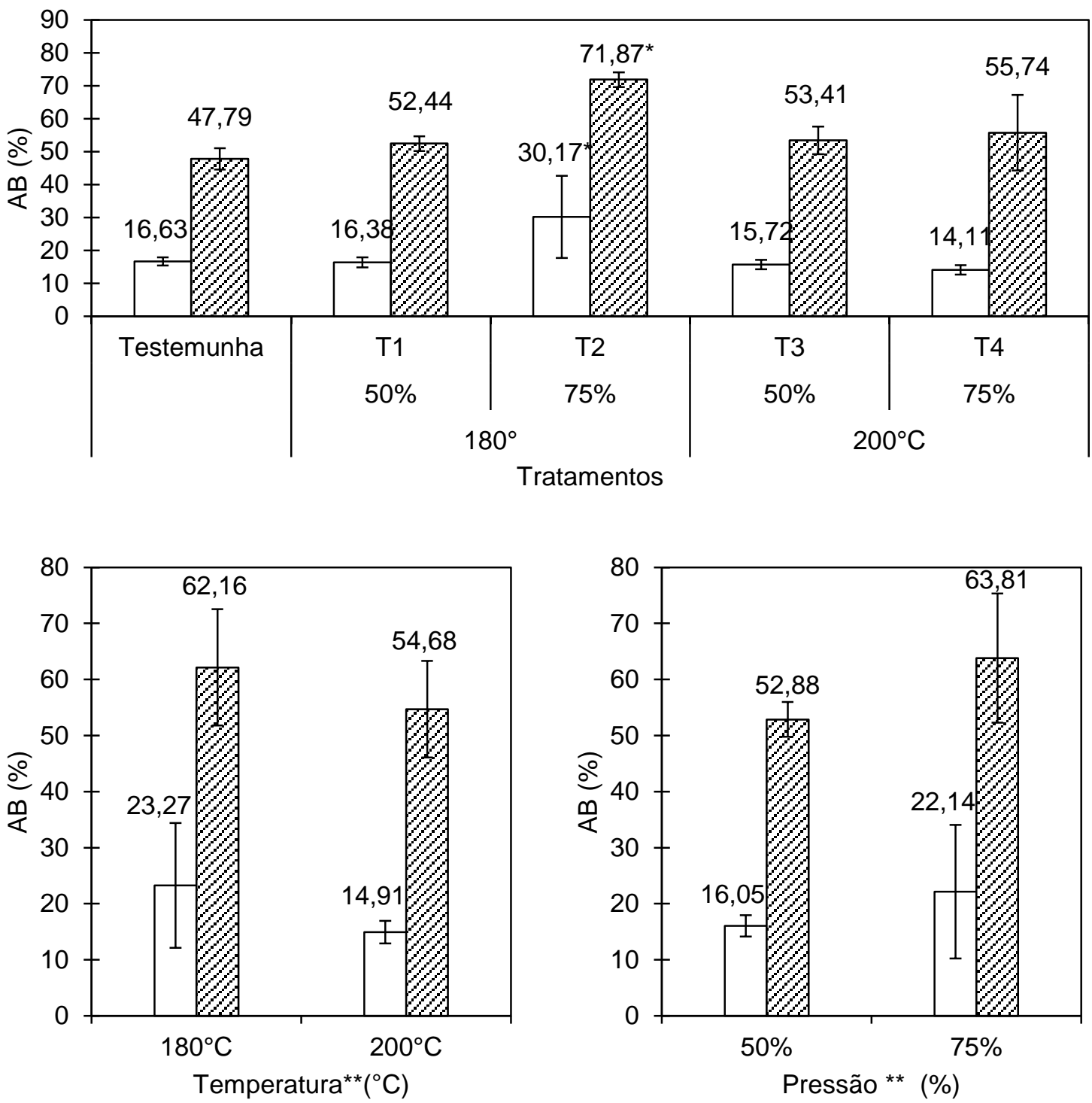

Figura 21 - Resultados da absorção em espessura após duas e 24 horas para os quatro tratamentos termomecânicos e a testemunha e análise fatorial com efeito dos fatores temperatura e pressão isolados

* diferença significativa a $5 \%$ de significância pelo teste de Dunnett. ** fator significativo na análise fatorial a $5 \%$ de significância. As barras acima das colunas indicam o desvio padrão. 
A absorção de água da madeira está muito relacionada com sua porosidade e a quantidade de espaços vazios. esperava-se que, com a aplicação da pressão, esses espaços vazios diminuíssem e ocorresse um decréscimo na taxa de $A B$. Esse aumento na absorção de água pode ser atribuído à expansão total da madeira durante a imersão em água, os vasos que estavam achatados foram reabertos e mais água foi absorvida.

Na Figura 21, o gráfico do efeito isolado da temperatura, a variável $A B 24 \mathrm{H}$, mostra que quando houve a elevação da temperatura ocorreu uma redução na absorção de água de 12,03\%. Já o aumento da pressão, na mesma variável, resulta em um aumento de $20,66 \%$. Novamente pode se constatar que o efeito da pressão superou a temperatura.

Grzeskiewicz et al., (2009), trabalhando com compensados, também observaram que a AB diminui com o aumento da temperatura. A testemunha teve $A B$ duas horas de $17,5 \%$ e os demais tratamentos $\left(160{ }^{\circ} \mathrm{C}, 190{ }^{\circ} \mathrm{C}\right.$ e $220^{\circ} \mathrm{C}$, pelo período de duas horas) apresentaram $17 \%, 12,7 \%$ e $11,4 \%$, respectivamente. $\mathrm{Na} A B 24$ horas, os valores também diminuíram com o aumento da temperatura. Na testemunha, o valor foi de $38,4 \%$ e nos tratamentos citados o valor foi diminuindo $(37,3 \%, 32 \%$ e $27,2 \%)$.

A TNRE está ilustrada na Figura 22 que mostra que o T2, juntamente com T4, foram os que se diferenciaram significativamente da testemunha (Tabela A.4 apêndice I).

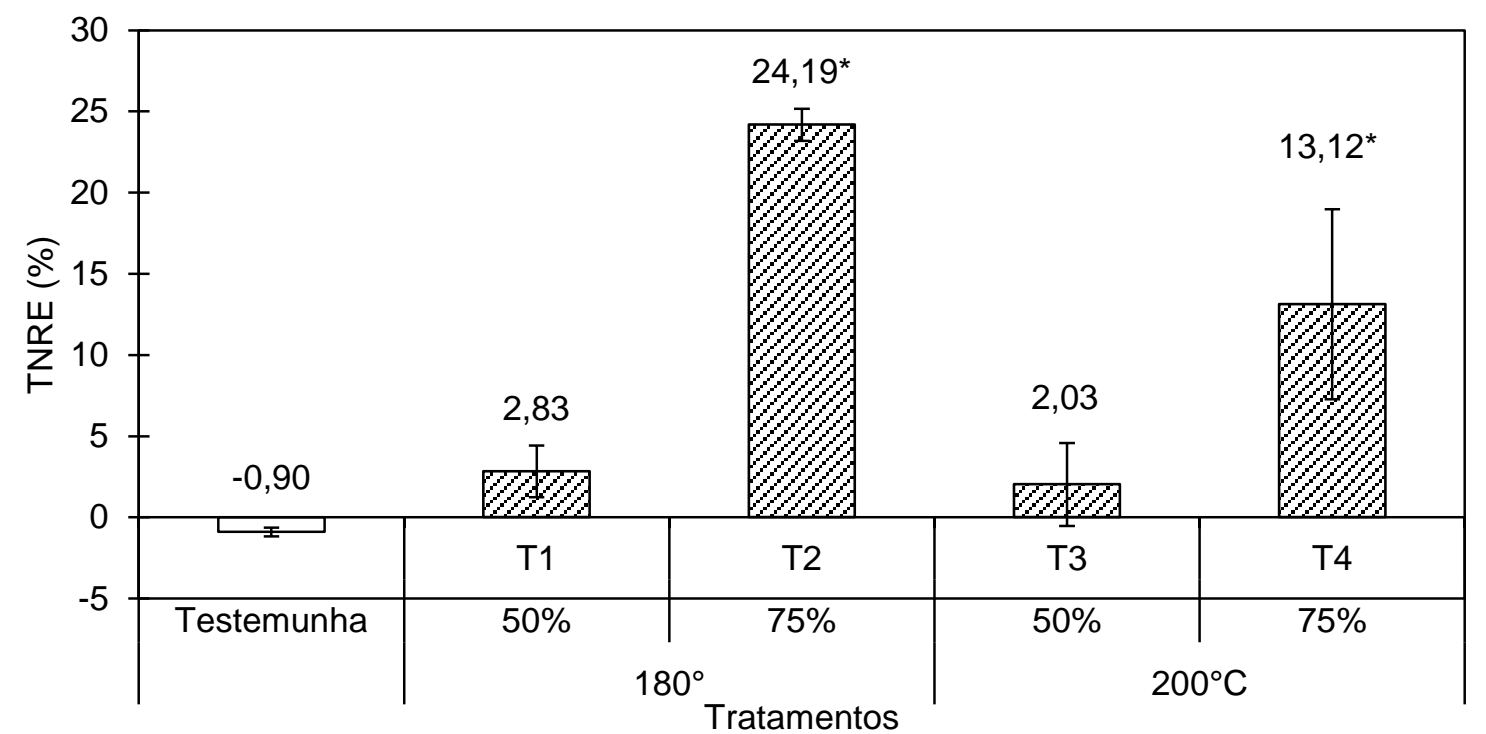

Figura 22 - Resultados da taxa de não retorno em espessura para os quatro tratamentos termomecânicos e a testemunha

* diferença significativa a $5 \%$ de significância pelo teste de Dunnett.

A TNRE mostra o inchamento definitivo da madeira, pois inclui a espessura com a liberação das tensões internas decorrente da compressão, por isso os tratamentos submetidos à maior pressão 
apresentaram maiores valores para o TNRE. Os tratamentos T1 e T3 apresentaram os menores valores $2,83 \%$ e $2,03 \%$ respectivamente.
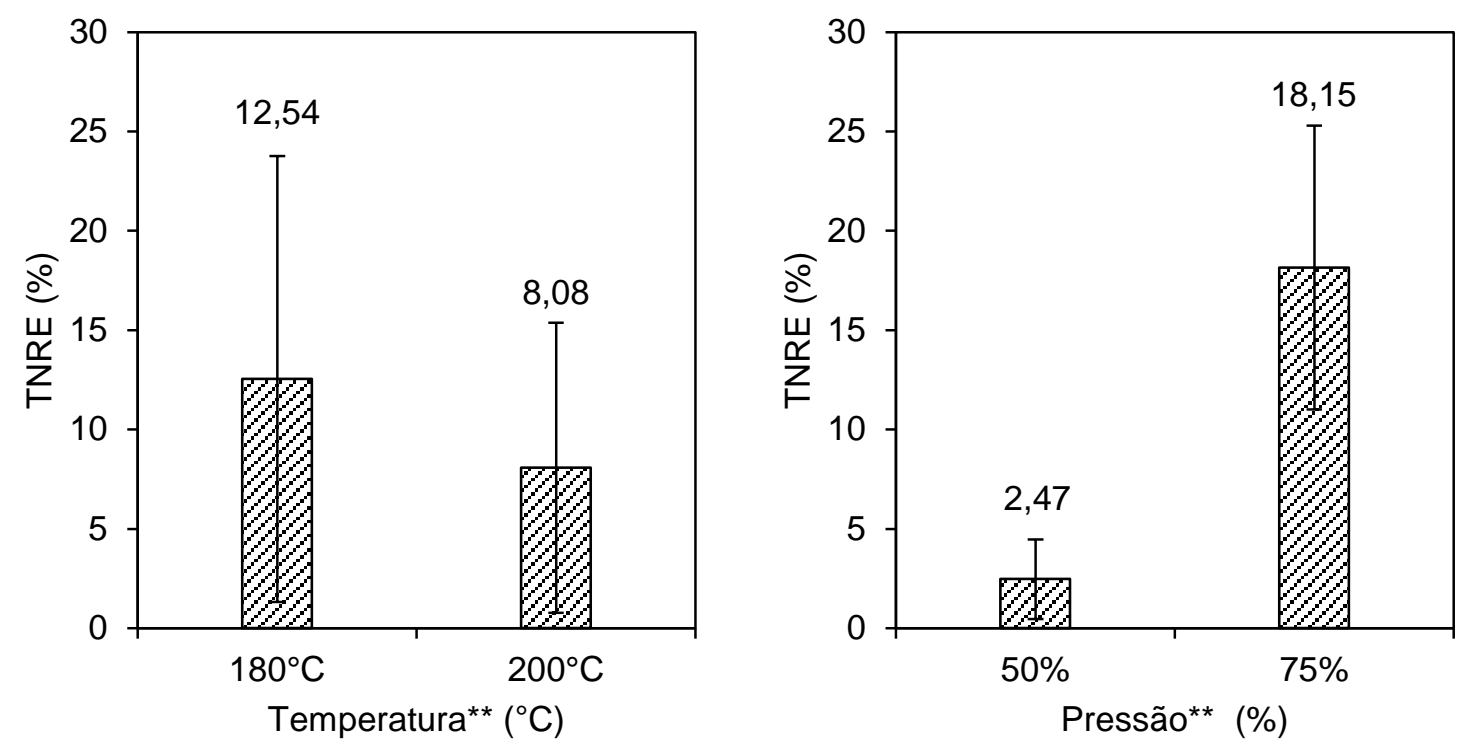

Figura 23 - Análise fatorial com efeito dos fatores temperatura e pressão isolados na taxa de não retorno em espessura nos tratamentos termomecânicos

** fator significativo na análise fatorial a $5 \%$ de significância. As barras acima das colunas indicam o desvio padrão.

A análise fatorial para TNRE mostrou a influência significativa para o fator pressão e temperatura (Figura 23 e Tabela A.7 do apêndice I). O aumento da temperatura diminui em 35,56\% o TNRE enquanto a elevação da pressão eleva a variável em $634,82 \%$, assim o efeito da pressão mais uma vez se sobressai ao da temperatura.

A taxa de retração (Figura 24) também apresenta T2 e T4 como os tratamentos com maior retratilidade, sendo os únicos com diferença significativa quando comparados com a testemunha. Os demais tratamentos obtiveram TR médio de 3,43\%.

Pela análise fatorial (Tabela A.7 apêndice I), obteve-se que apenas a pressão foi fator significativo para variável TR. A elevação da pressão de $50 \%$ para $75 \%$ resultou aumento de $114,28 \%$. 

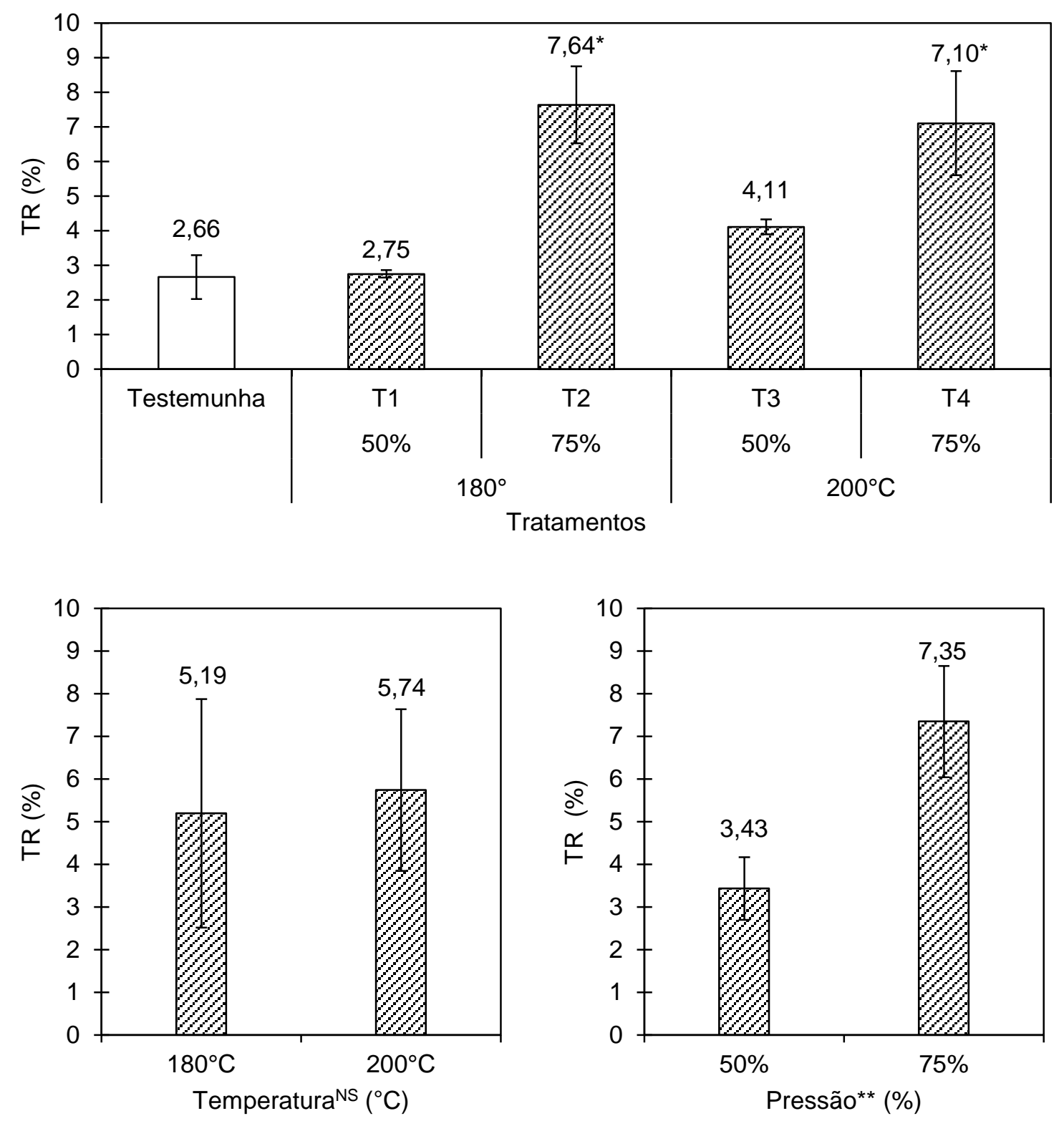

Figura 24 - Resultados da taxa de retração em espessura para os quatro tratamentos termomecânicos e a testemunha e análise fatorial com efeito dos fatores temperatura e pressão isolados

* diferença significativa a $5 \%$ de significância pelo teste de Dunnett. ${ }^{* *}$ fator significativo na análise fatorial a $5 \%$ de significância. ${ }^{N S}$ fator não significativo na análise fatorial a $5 \%$ de significância. As barras acima das colunas indicam o desvio padrão.

Na Figura 25, é possível notar a relação da TC com IE. T2, apesar de alcançar elevada taxa de compressão, também foi o que apresentou maior inchamento final em espessura, sendo que, após a imersão em água, a madeira recuperou o equivalente a $93,68 \%$ da compressão adquirida no tratamento. Novamente o T3 mostra a influência da temperatura na estabilidade dimensional, sendo considerado o melhor tratamento, pois, além da alta taxa de densificação, teve proporcionalmente a menor TNRE e o que menos recuperou a espessura durante o teste de inchamento, com $35,63 \%$. 


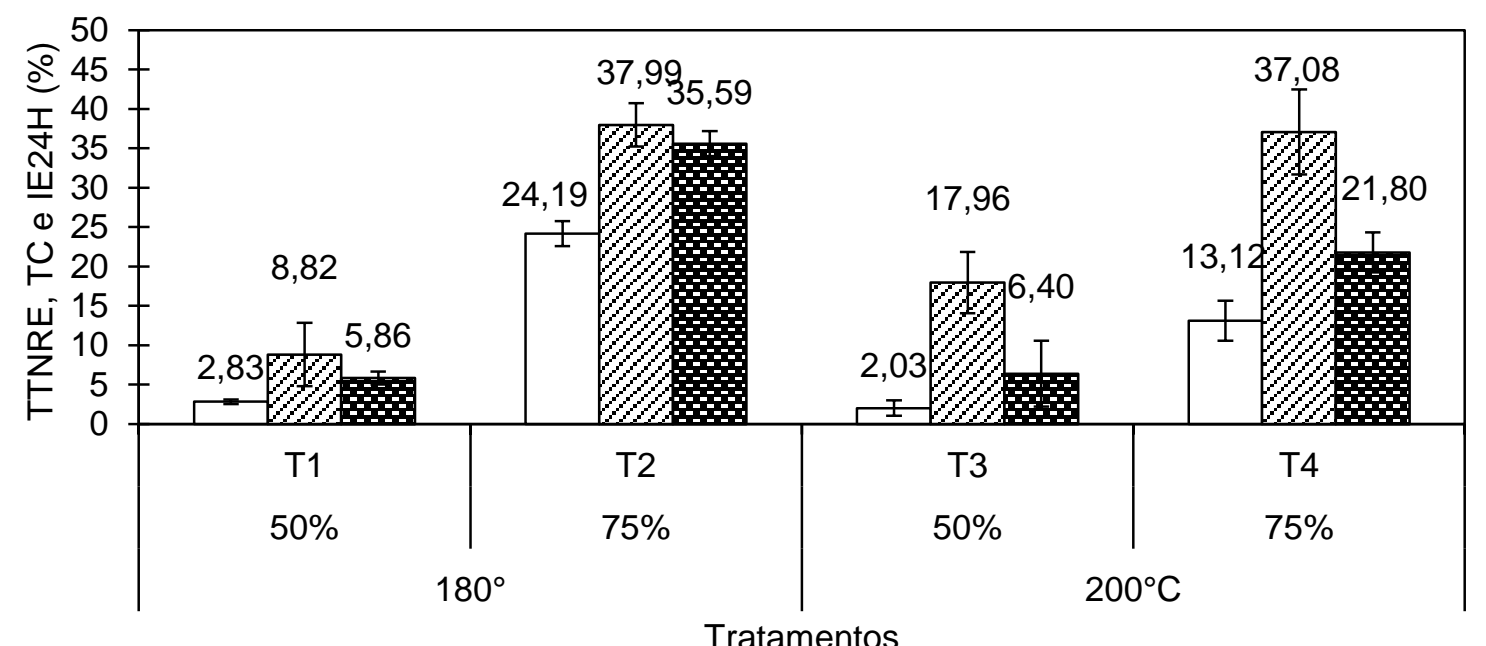

Figura 25 - Comparação entre a taxa de não retorno em espessura, taxa de compressão e inchamento em espessura dos quatro tratamentos termomecânicos analisados.

Dessa forma, as amostras submetidas à pressão de $75 \%$ passaram por fortes tensões internas que não conseguiram ser amenizadas nem pelas temperaturas nem durante o pós-tratamento de 30 min. Vasconcelos (2012), em seu trabalho utilizando um tempo de 15 min no pós-tratamento, também não obteve o resultado esperado. Considerando apenas o fator pressão, o valor de $50 \%$ é mais recomendado caso o objetivo seja a estabilidade dimensional da madeira.

Outro importante dado mostrado pela análise fatorial foi a interação entre os fatores pressão e temperatura. Na Figura 26, pode-se encontrar um padrão decrescente para a reta que representa a pressão de $75 \%$. Esse comportamento pode ser explicado pelo efeito da temperatura na estabilidade dimensional, ou seja, reduz o inchamento em espessura, a absorção de água, retratilidade e o efeito springback.

Embora ocorra essa melhoria, os resultados mais satisfatórios, em geral, permanecem com a menor pressão que, ao contrário da situação anterior, não apresenta um padrão. Há uma pequena diferença com a variação da temperatura, para algumas variáveis como IE24H, AB24H e TR a reta é crescente, tendo seu resultado mais expressivo no último caso. 

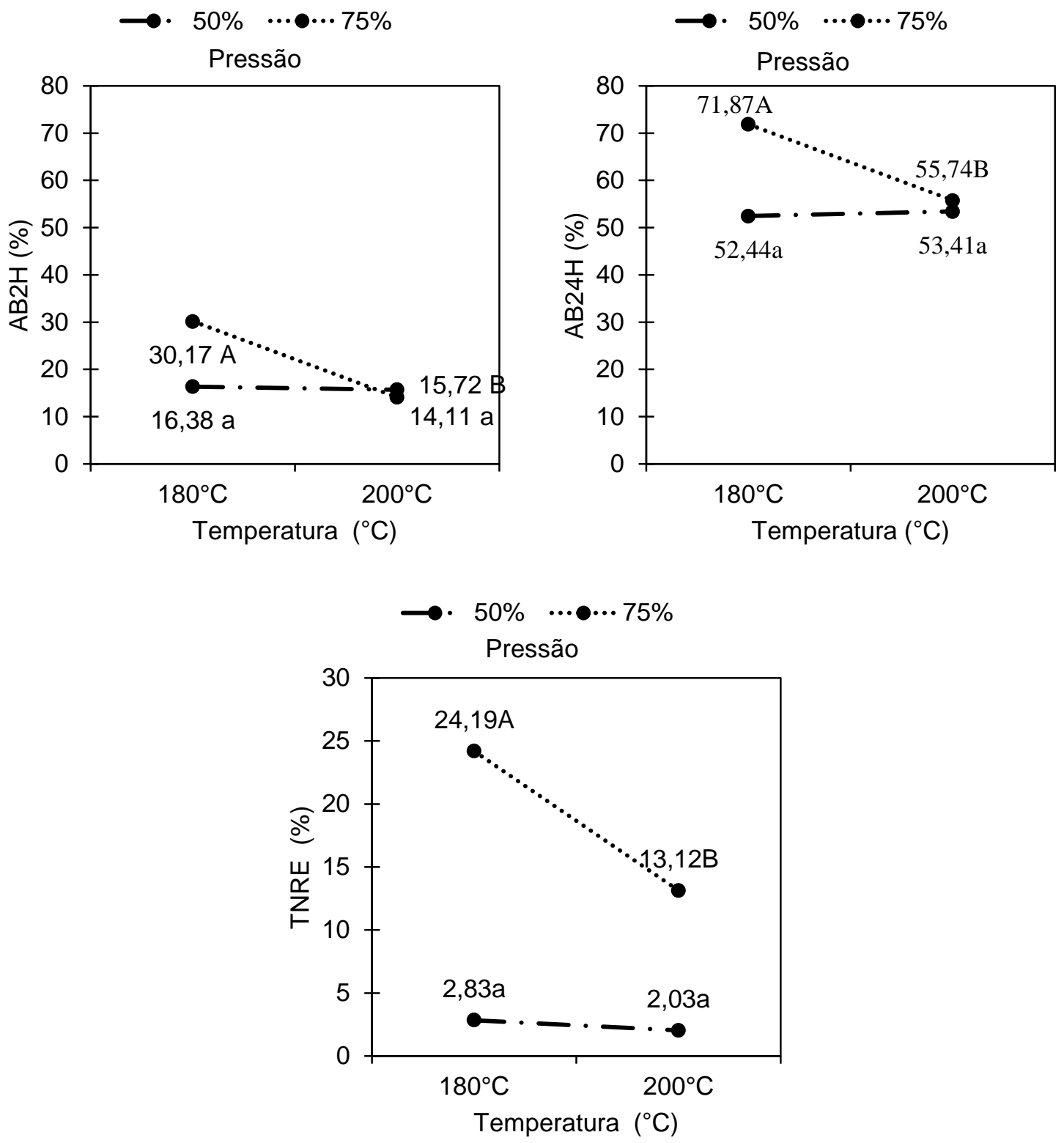

Figura 26 - Interação entre os fatores temperatura e pressão para AB2H, AB24H e TNRE dos quatros tratamentos termomecânicos analisados

Nota: Letras distintas maiúsculas e minúsculas indicam diferença significativa a $5 \%$ pela análise de variância.

\subsubsection{Efeito nas propriedades mecânicas}

O tratamento termomecânico superficial da madeira foi responsável por uma significativa melhora nas propriedades mecânicas. As figuras apresentadas a seguir mostram que em alguns ensaios o ganho foi mais relevante quando comparados com outros. Os ensaios realizados foram dureza Janka $\left(\mathfrak{f}_{\mathrm{H}, 9_{0}}\right)$, resistência à compressão paralela às fibras $\left(\mathfrak{f}_{\mathrm{c}, 0}\right)$, além da flexão estática: módulo de ruptura $\left(f_{M}\right)$ e módulo de elasticidade $\left(E_{m}\right)$.

O teste de dureza na Simarouba amara (Figura 27) apresentou ganho significativo nos tratamentos 2 e 4 cuja pressão era a mais elevada, sendo os ganhos bem elevados com valores de $99,32 \%$ e 78,21 \%. Os demais, T1 e T3, apresentaram valores iguais a 2967,82 $\mathrm{N}$ e 3361,51 
$\mathrm{N}$, respectivamente, não sendo esse ganho relevante estatisticamente e também não possuindo diferença significativa entre si (Tabela A.6 apêndice I).
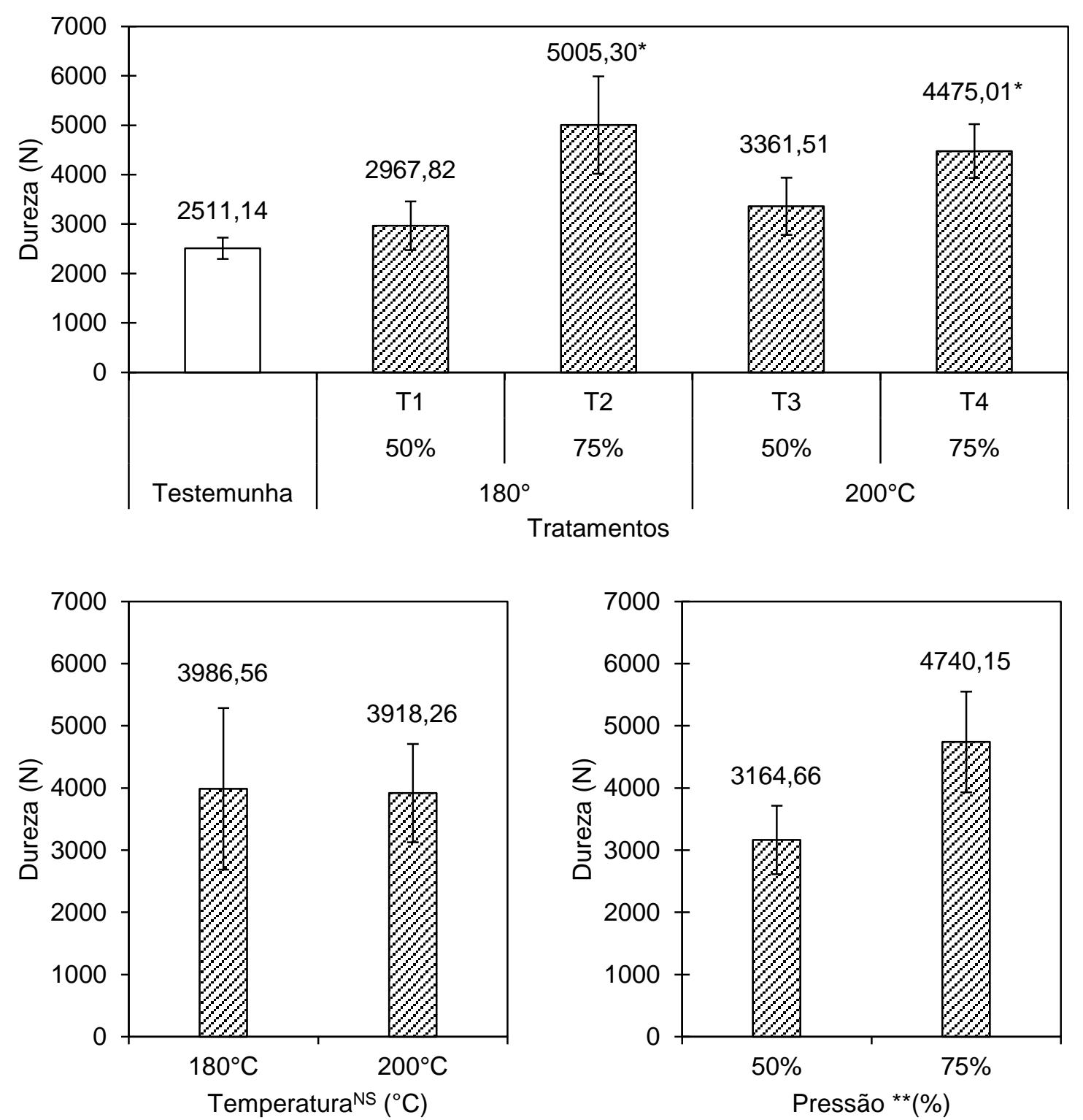

Figura 27 - Resultados da dureza para os quatro tratamentos termomecânicos e a testemunha e análise fatorial com efeito da temperatura e pressão isolados

* diferença significativa a $5 \%$ de significância pelo teste de Dunnett. ${ }^{* *}$ fator significativo na análise fatorial a $5 \%$ de significância. ${ }^{\text {NS }}$ fator não significativo na análise fatorial a $5 \%$ de significância. As barras acima das colunas indicam o desvio padrão.

Com a análise fatorial (Tabela A.9 apêndice I), fica clara a influência significativa do fator pressão, para a temperatura a mesma influência não foi significativa. Pode-se observar que o mesmo comportamento ocorreu para variável densidade aparente. Segundo Schilling et al., (1998) a densidade é um dos principais fatores usados na classificação da madeira em classes de qualidade por sua alta correlação com a resistência mecânica. De forma geral, o aumento nas propriedades mecânicas está relacionado ao aumento da densidade aparente, ou seja, são grandezas diretamente proporcionais. 
Em relação ao efeito da temperatura, apesar de não ter sido significativo, autores como Calonego (2009), em seu trabalho com Eucalyptus grandis, constatou que o aumento da temperatura de termorretificação entre $180^{\circ} \mathrm{C}$ e $220^{\circ} \mathrm{C}$ promoveu decréscimos significativos e na ordem de $12,1 \%$ e $20,7 \%$ na dureza Janka normal às fibras, quando comparada com a madeira controle. Pode-se inferir que o efeito da pressão anulou o efeito da temperatura na redução nas propriedades mecânicas, atingindo um dos objetivos propostos neste trabalho.

Arruda (2012) também verificou, a partir da análise fatorial, que a $\mathrm{f}_{\mathrm{H}, 90}$ não foi influenciada pelo aumento do tempo para dois minutos ou da temperatura para $180^{\circ} \mathrm{C}$. Isso mostra que situações mais severas de temperaturas não são necessárias para aumentar a dureza do material.

O efeito dos tratamentos 2,3 e 4 foi significativo estatisticamente (Tabela A.6 apêndice I) na resistência à compressão paralela com ganhos de $45,83 \%, 29,16 \%$ e $36,56 \%$, respectivamente. $O$ ganho do T1 $(8,34 \%)$ não foi significativo, como pode ser observado na Figura 28. Mais uma vez a análise fatorial (Figura 29) (Tabela A.9 apêndice I) mostra a influência da pressão nos resultados apresentados, quanto maior a pressão maior o ganho na propriedade. O efeito da temperatura, assim como no ensaio da dureza, não foi significativo, ou seja, para alcançar maior dureza ou maior $\mathrm{f}_{\mathrm{c}, 0}$ a madeira pode ser tratada em ambas as temperaturas.

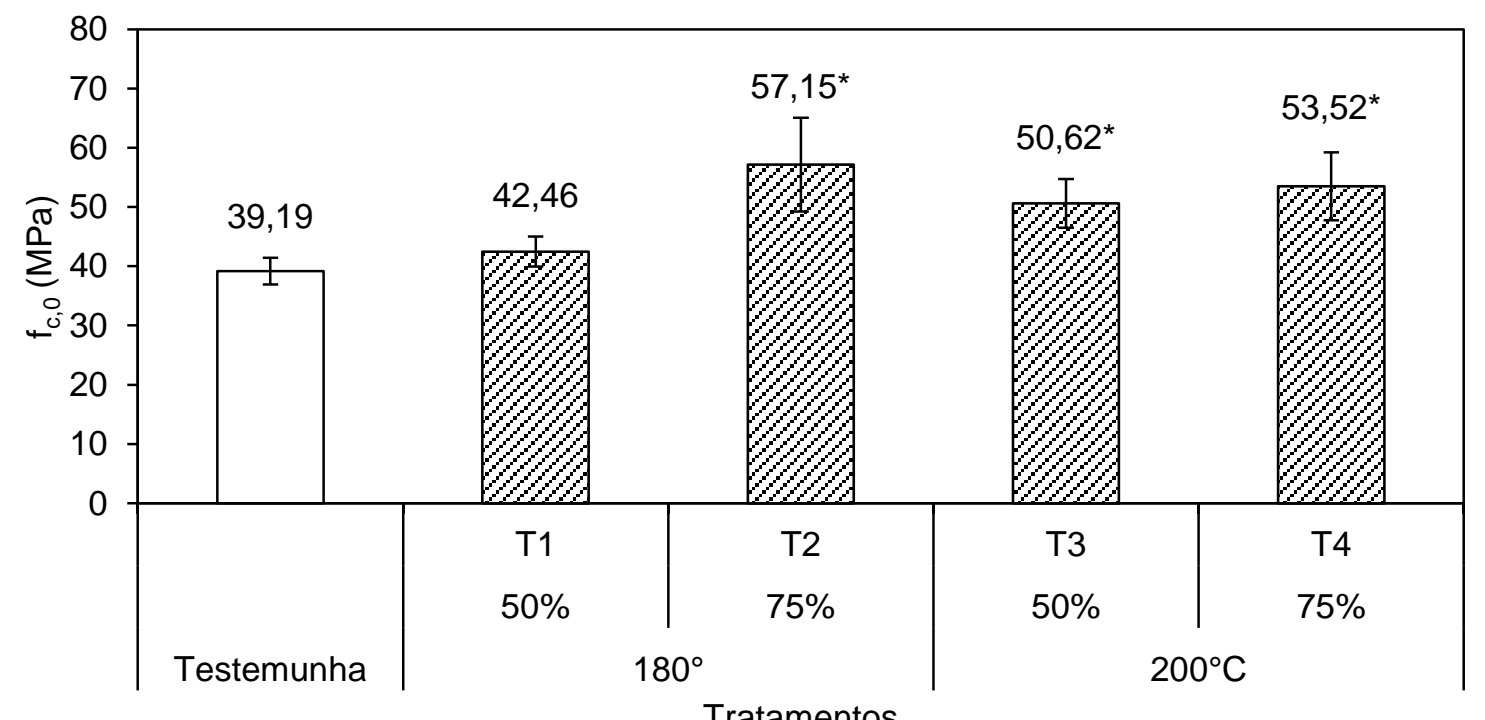

Figura 28 - Resultados da resistência à compressão paralela para os quatro tratamentos e a testemunha

* diferença significativa a 5\% de significância pelo teste de Dunnett. 

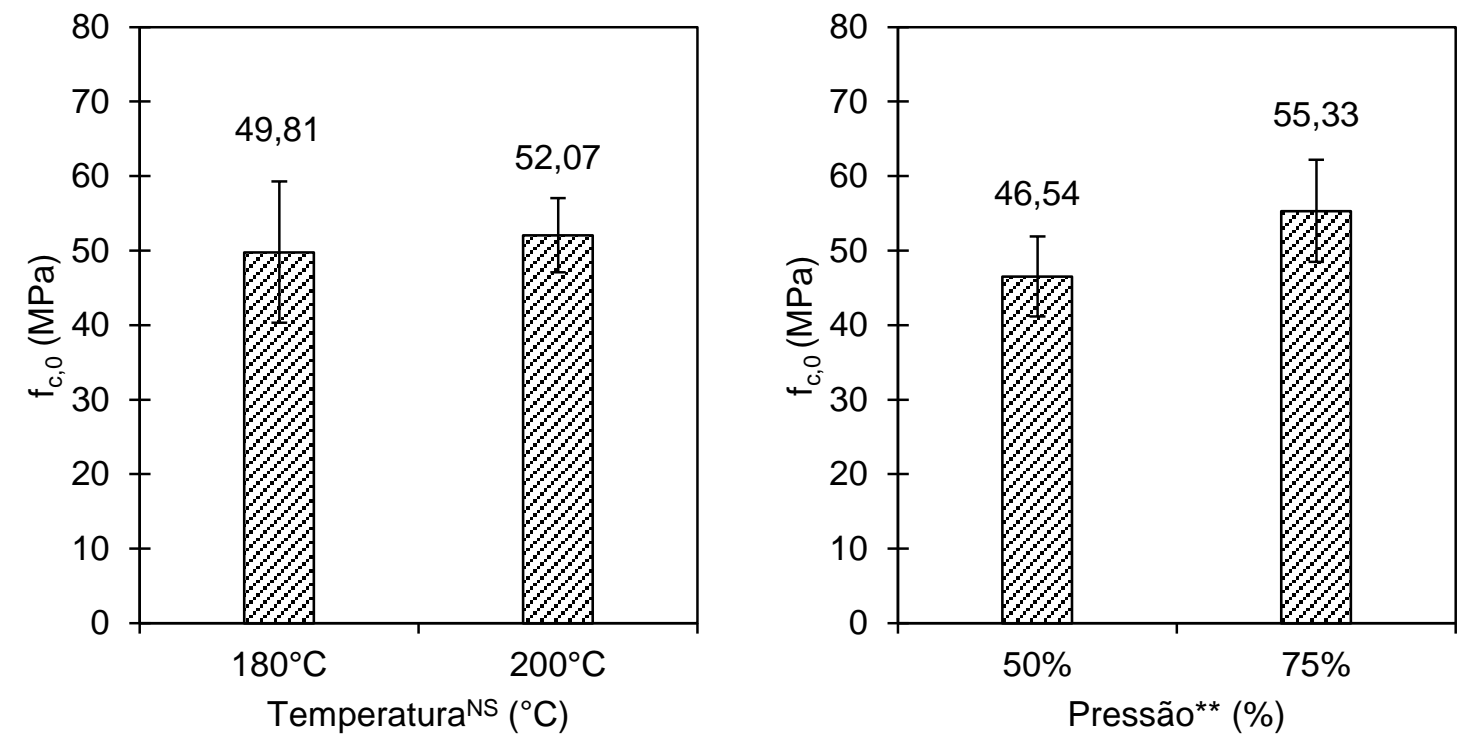

Figura 29 - Análise fatorial com efeito dos fatores temperatura e pressão isolados ** fator significativo na análise fatorial a $5 \%$ de significância. ${ }^{N S}$ fator não significativo na análise fatorial a 5\% de significância. As barras acima das colunas indicam o desvio padrão.

A partir dos resultados obtidos na resistência a compressão paralela às fibras, é possível à comparação com os dados da Tabela 8. Mesmo com o tratamento termomecânico, a madeira de marupá não alcançou valores semelhantes a madeiras mais densas como jatobá e cumaru, entretanto se tornou mais resistente que o eucalipto e se igualou, em relação a $f_{c, 0}$, ao pau-marfim, podendo competir também, dependendo das condições de uso, com cabreúva e amendoim.

Tabela 8 - Características físicas e mecânicas de espécies madeireiras utilizadas na produção de piso

\begin{tabular}{ccc}
\hline Espécies & Densidade $\mathbf{( g / \mathbf { c m } ^ { 3 } )}$ & $\begin{array}{c}\text { Resistencia à compressão paralela as } \\
\text { fibras (MPa) }\end{array}$ \\
\hline Ipê & 0,96 & 73,03 \\
Jatobá & 0,97 & 82,16 \\
Cumaru & 0,95 & 93,23 \\
Pau-marfim & 0,84 & 58,92 \\
Cabreúva & 0,95 & 71,08 \\
Amendoim & 0,77 & 71,08 \\
Eucalipto & 0,69 & 49,21 \\
Marupá* & 0,65 & 57,15 \\
\hline
\end{tabular}

Fonte: ANPM (2006) com modificações e dados do trabalho.

${ }^{*}$ Resultados observados para o tratamento $2\left(180^{\circ} \mathrm{C}\right.$ e $\left.75 \%\right)$, pois foi o que apresentou melhores resultados.

No ensaio de flexão estática, como explicado na metodologia, alguns corpos de prova foram testados para que a tração ocorresse no lado densificado e os demais no lado não densificado, como ilustra a Figura 30. Analisando a situação da tração na parte não densificada, o módulo de 
ruptura para todos os tratamentos teve um aumento variando entre $8,16 \%$ a $34,97 \%$, no entanto, somente para T2, T3 e T4 esse ganho foi significativo. O tratamento $2\left(180^{\circ} \mathrm{C}\right.$ e $\left.75 \%\right)$ foi o responsável pelo maior valor $(97,41 \mathrm{MPa})$ quando comparado com a testemunha.

Analisando a situação da $\mathrm{f}_{\mathrm{M}}$ do lado densificado, o mesmo padrão não pôde ser observado, tendo em vista que $\mathrm{T} 1$, T3 e T4 com $\mathrm{f}_{\mathrm{M}}$ igual a 67,98MPa, 67,67MPa e 66,37 MPa respectivamente, não se distinguiram da testemunha (72,14MPa). Assim, o único valor estatisticamente relevante foi 86,92 MPa no T2, esse representa um acréscimo de 20,49\%.

Tendo em vista os resultados apresentados, recomenda-se que a Simarouba amara deve ter seu uso de modo que a tração ocorra no lado não densificado, tendo em vista os melhores resultados apresentados. Para as duas situações apresentadas o T2 teve o maior ganho, sendo assim o mais resistente.
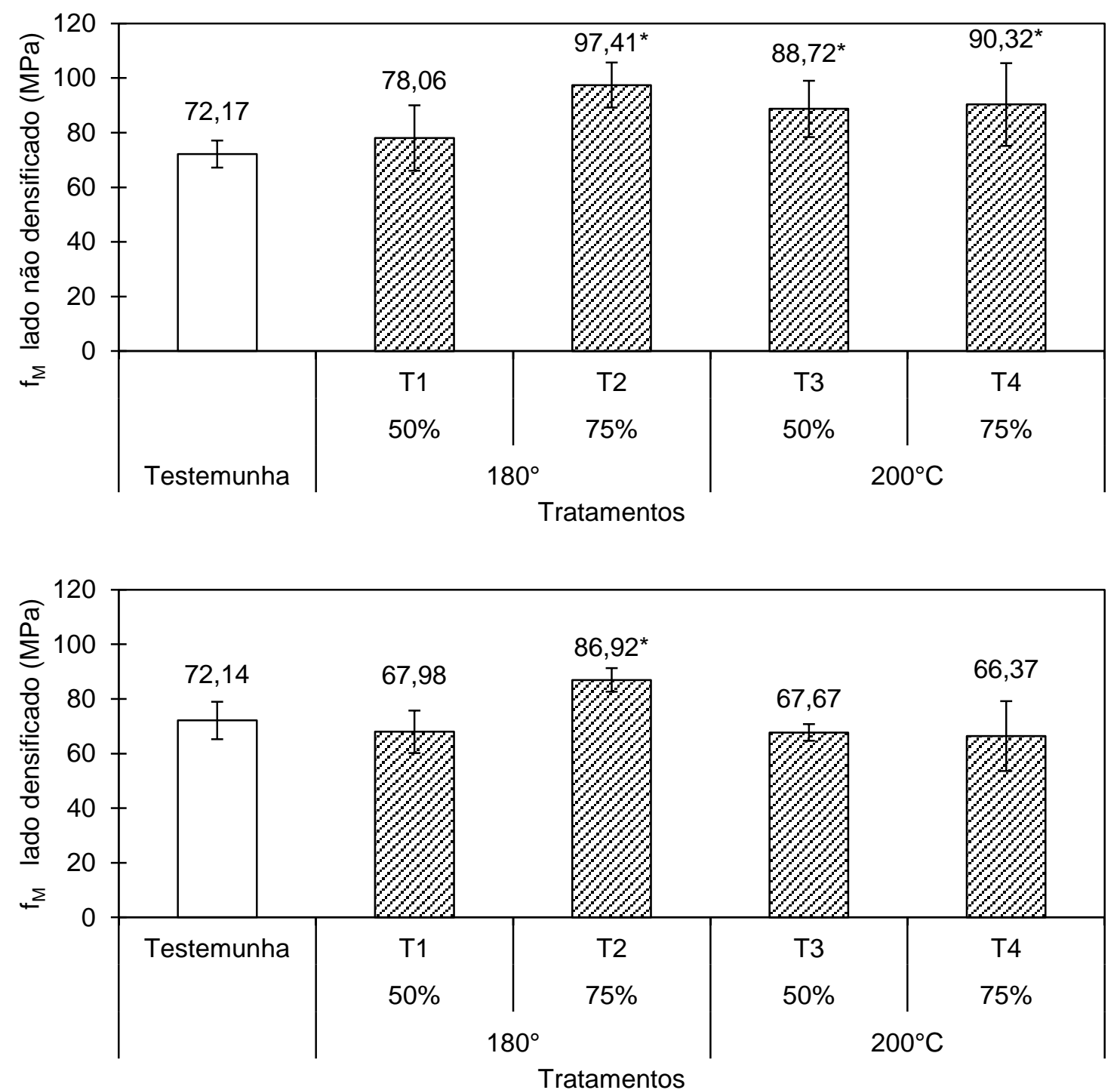

Figura 30 - Resultados do $\mathrm{f}_{\mathrm{M}}$ lado não densificado e lado densificado para os quatro tratamentos termomecânicos e a testemunha

* diferença significativa a 5\% de significância pelo teste de Dunnett. 
Os resultados acima são mais bem elucidados pela análise fatorial (Tabela A.9 do apêndice I) que mostra que apenas a pressão foi estatisticamente significante para $f_{M}$ na superfície não densificada e para $f_{M}$ na superfície densificada os dois fatores, pressão e temperatura, foram relevantes. Como explicado acima, é possível observar na Figura 31 (tração na superfície não densificada) que quanto maior a pressão maior o módulo de ruptura na flexão estática. Quando se passa da pressão $50 \%$ para $75 \%$ tem-se um ganho de $12,56 \%$.
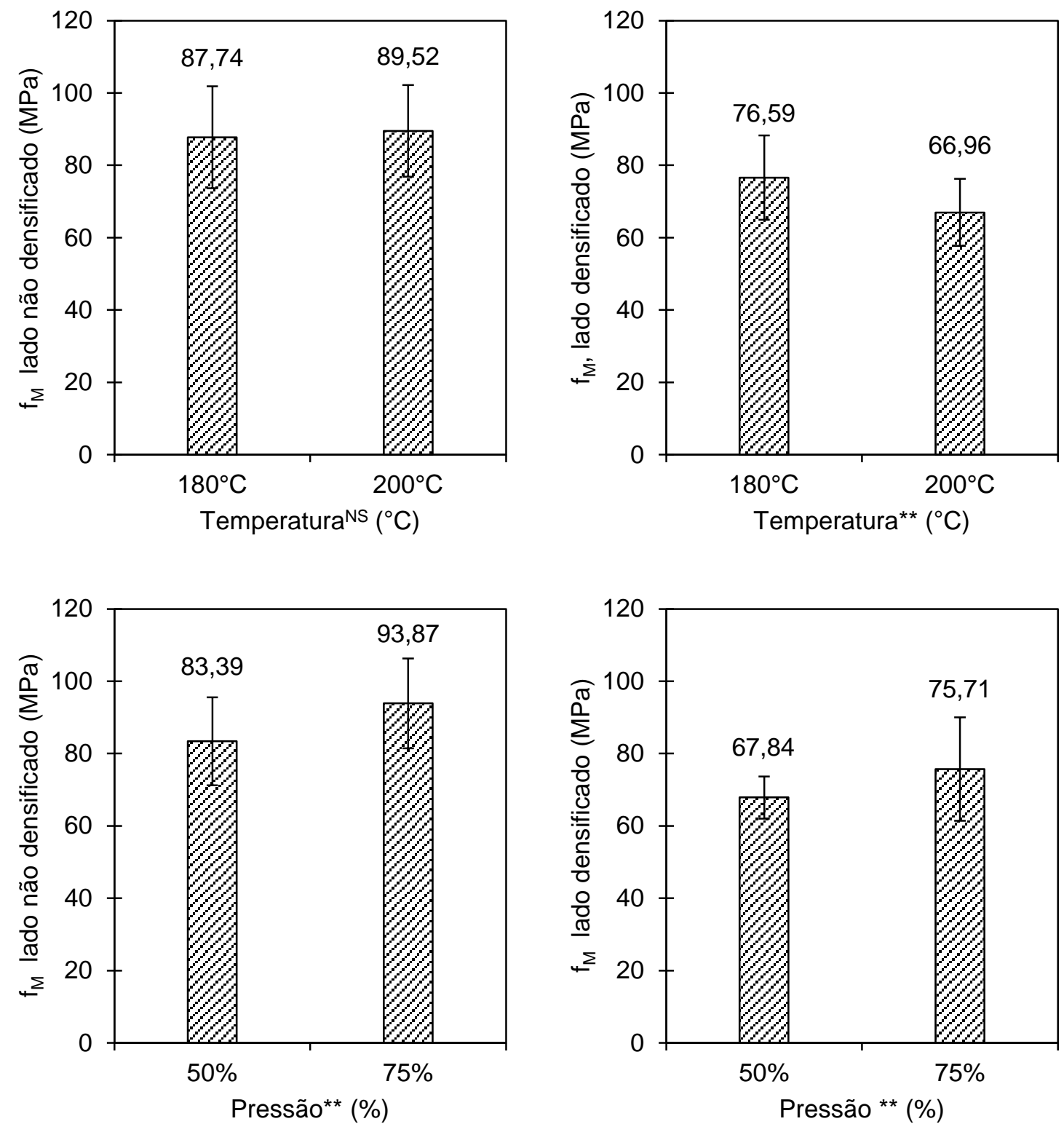

Figura 31 - Análise fatorial com efeito dos fatores temperatura e pressão isolados no $f_{M}$ dos tratamentos termomecânicos

* diferença significativa a $5 \%$ de significância pelo teste de Dunnett. ** fator significativo na análise fatorial a $5 \%$ de significância. ${ }^{N S}$ fator não significativo na análise fatorial a $5 \%$ de significância. As barras acima das colunas indicam o desvio padrão. 
$\mathrm{Na}$ análise do fator pressão da $\mathrm{f}_{\mathrm{M}}$ na superfície densificada, tem-se o mesmo comportamento, sendo que o aumento é menor $11,60 \%$, mas igualmente significativo. Já a temperatura, quando é elevada, observa-se um decréscimo significativo de $12,57 \%$ no módulo de ruptura no lado densificado. Situação semelhante é descrita na literatura por diversos autores como Esteves e Pereira (2009).

Segundo Bekhta e Niemz (2003), o módulo de ruptura na flexão estática em madeiras tratadas com altas temperaturas é a propriedade mecânica mais afetada nos tratamentos térmicos, sendo reduzido entre $44 \%$ e $50 \%$. No presente trabalho, em relação à superfície densificada, quando se analisa os dois fatores isolados é possível observar o maior efeito da temperatura quando comparado com a pressão, por isso os tratamentos com maior temperatura tiveram uma perda no módulo de ruptura. Já na menor temperatura com maior pressão, o efeito negativo da temperatura conseguiu ser anulado pela maior pressão, sendo, assim, a possível solução para mitigar o efeito negativo da temperatura seria a combinação de uma temperatura intermediária com elevada pressão.

A Figura 32 mostra as interações entre temperatura e pressão e ilustra de forma mais clara o que foi explicado anteriormente. $A f_{M}$ do lado não densificado mesmo tendo uma queda na pressão de $75 \%$ com a maior temperatura, esse efeito não é significativo. Já $f_{M}$ do lado densificado na pressão de $50 \%$ independentemente da temperatura o módulo de ruptura não sofre nenhuma alteração significativa e para a maior pressão a maior temperatura teve uma influência negativa, resultando na perda da resistência, ou seja, a condição mais severa não foi favorável para essa variável.

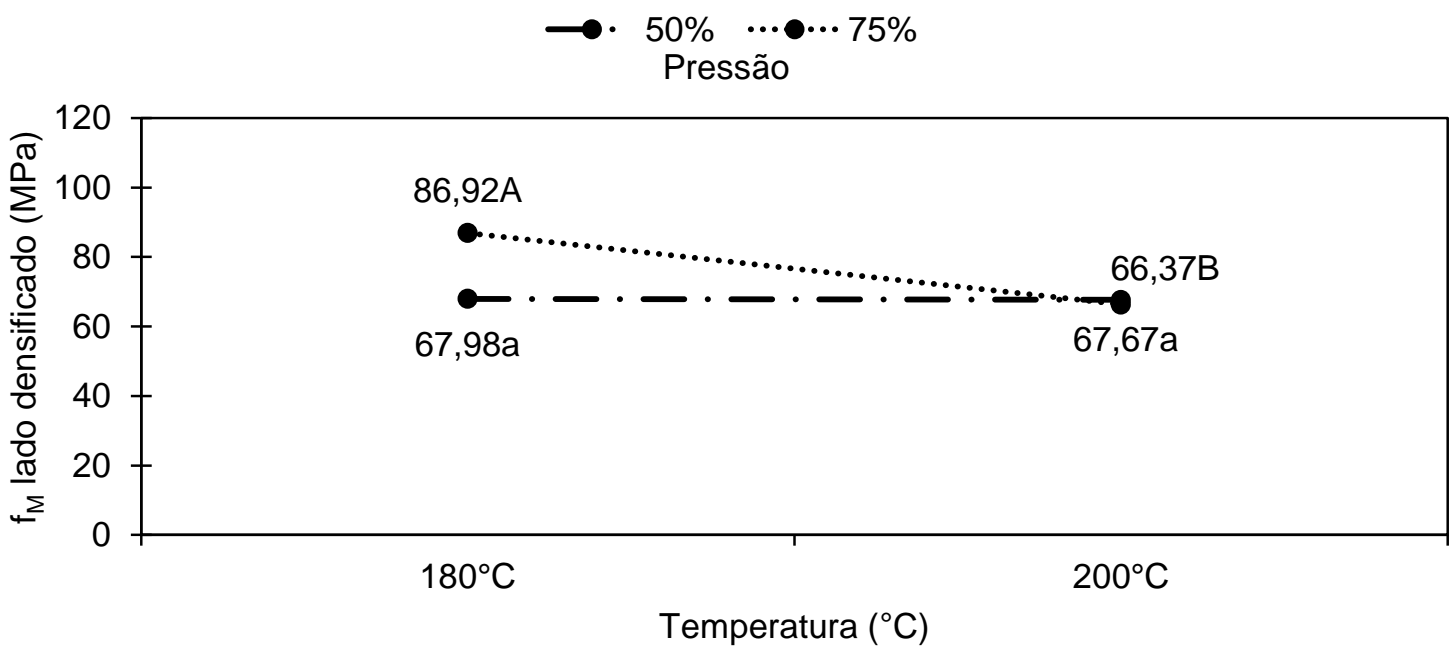

Figura 32 - Interação entre os fatores temperatura e pressão para $f_{M}$ lado densificado dos quatros tratamentos termomecânicos analisados

Nota: Letras distintas maiúsculas e minúsculas indicam diferença significativa a $5 \%$ pela análise de variância. 
Umas das hipóteses para explicar a diferença de comportamento entre as duas superfícies é o rearranjo ou a rearticulação dos componentes químicos presentes após o tratamento termomecânico da madeira e/ou a diferença da estrutura anatômica desses dois lados, quanto mais próximo da superfície densificada maior a incidência de colapsos ou rachaduras nas membranas celulares que prejudicam a resistência do material.

O ensaio de flexão também possibilitou o cálculo do módulo de elasticidade ilustrado pela Figura 33 que seguiu a mesma metodologia elucidada no módulo de ruptura (divisão entre lado densificado e não densificado).
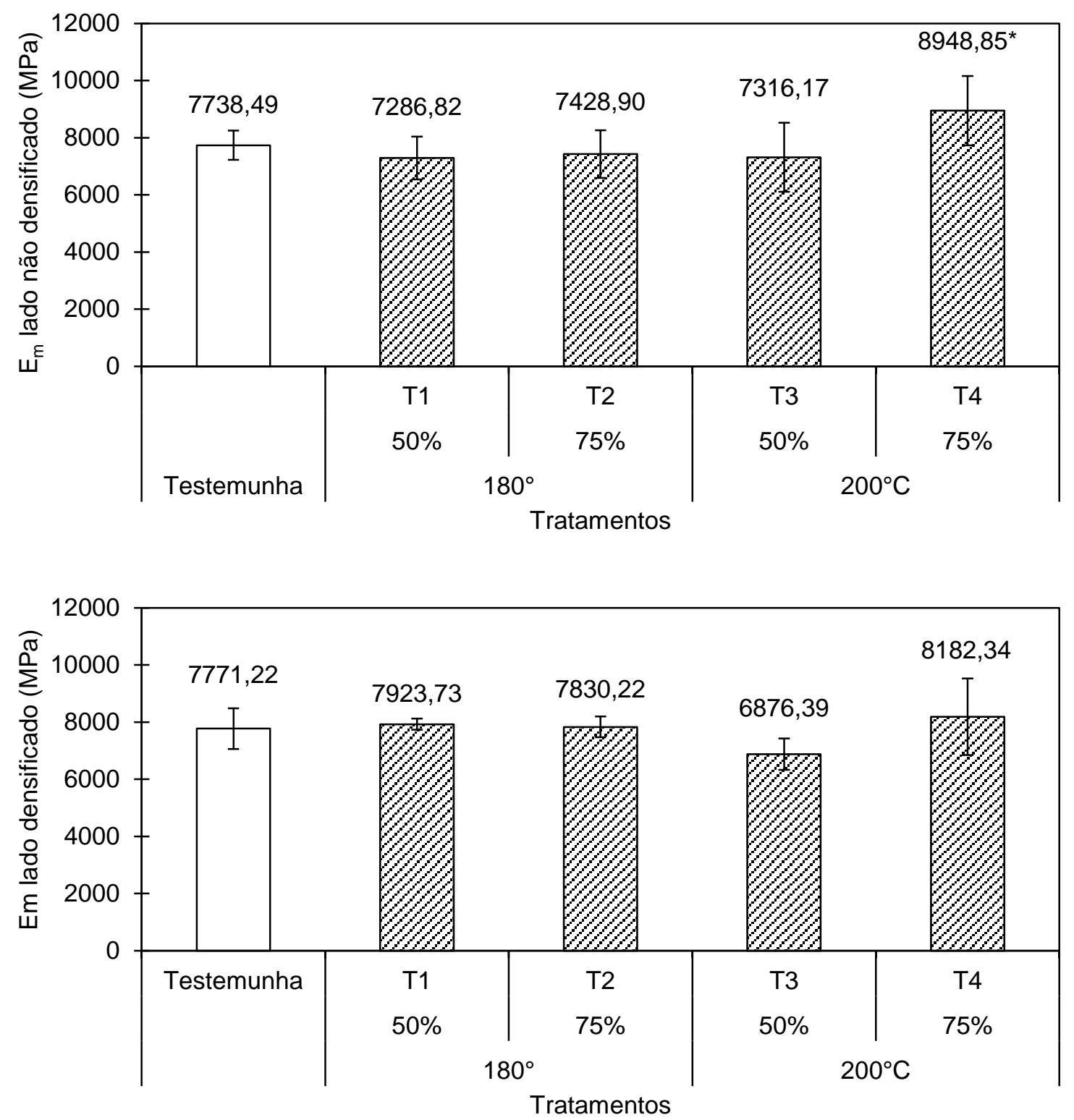

Figura 33 - Resultados do $E_{m}$ do lado não densificado e lado densificado para os quatro tratamentos termomecânicos e a testemunha

* Valor significativamente diferente da testemunha pelo teste de Dunnett. 
$O E_{m}$ no lado não densificado aumentou com a elevação da pressão para $75 \%$, os valores dos demais tratamentos não foram estatisticamente significativos. Dessa forma o único tratamento que apresentou diferença significativa foi o T4 elevando em 16,76\% ○ $E_{m}$ em relação à testemunha. Para se aumentar significativamente essa propriedade é necessário o uso das condições mais severas. Arruda (2012), trabalhando com compensados de amescla, obteve um aumento de $12,2 \%$ no tratamento mais severo, mostrando a interferência da elevação do aumento da temperatura e do tempo. A análise fatorial mostrada nas Figuras 34 e 35 confirma que com o aumento da temperatura e da pressão há um ganho nessa propriedade.

Na superfície densificada houve um aumento no T1, T2 e T4, sendo T3 o único que apresentou redução no módulo de elasticidade. Estatisticamente, nenhum tratamento foi significativo a $5 \%$, ou seja, nenhum ganho ou perda foi representativo. O mesmo comportamento também foi observado por Del Menezzi (2004) quando trabalhou com diferentes temperaturas em painéis de OSB. Apesar de haver redução nos valores de MOE, os tratamentos não afetaram significativamente as propriedades mecânicas.
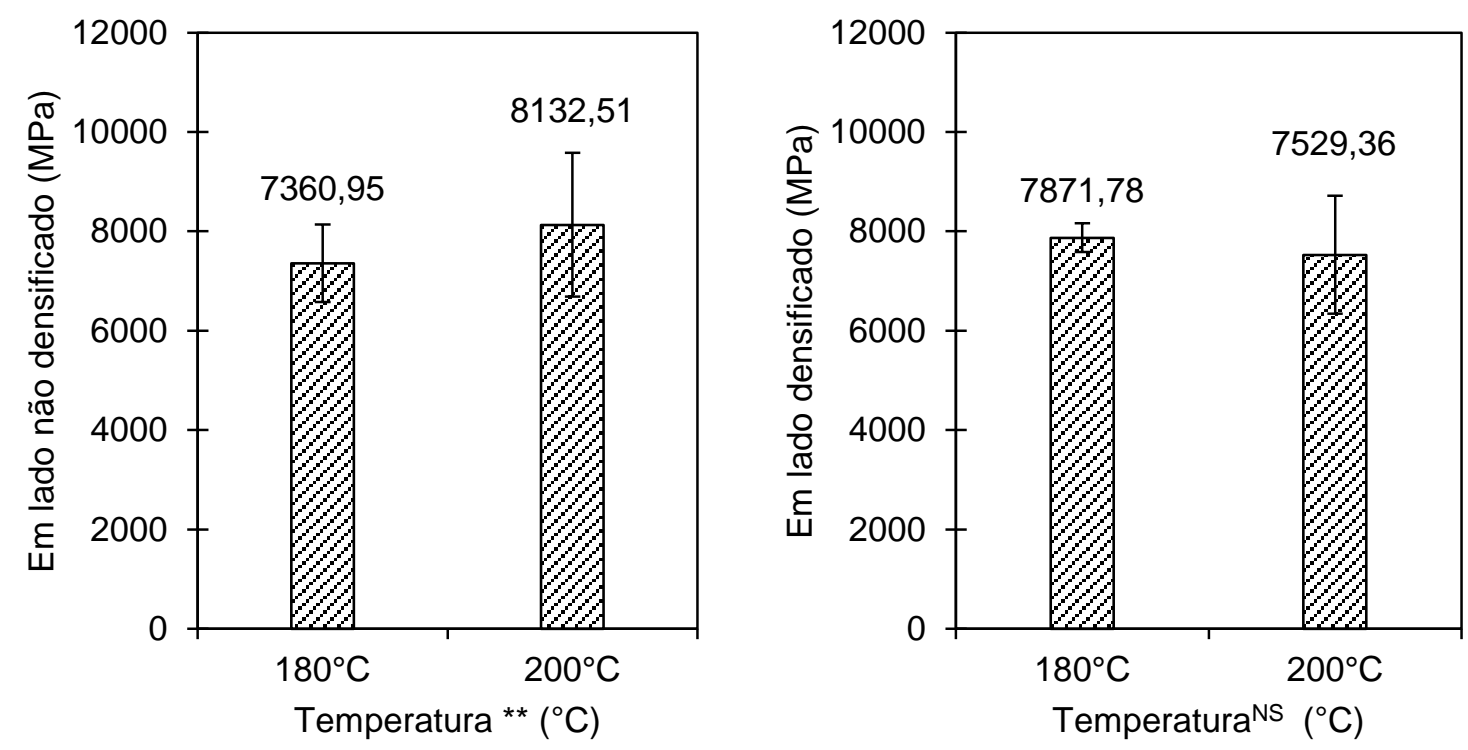

Figura 34 - Análise fatorial com efeito do fator temperatura isolados no $E_{m}$ do tratamento termomecânicos

** fator significativo na análise fatorial a $5 \%$ de significância. ${ }^{N S}$ fator não significativo pela análise fatorial a $5 \%$ de significância. As barras acima das colunas indicam o desvio padrão. 

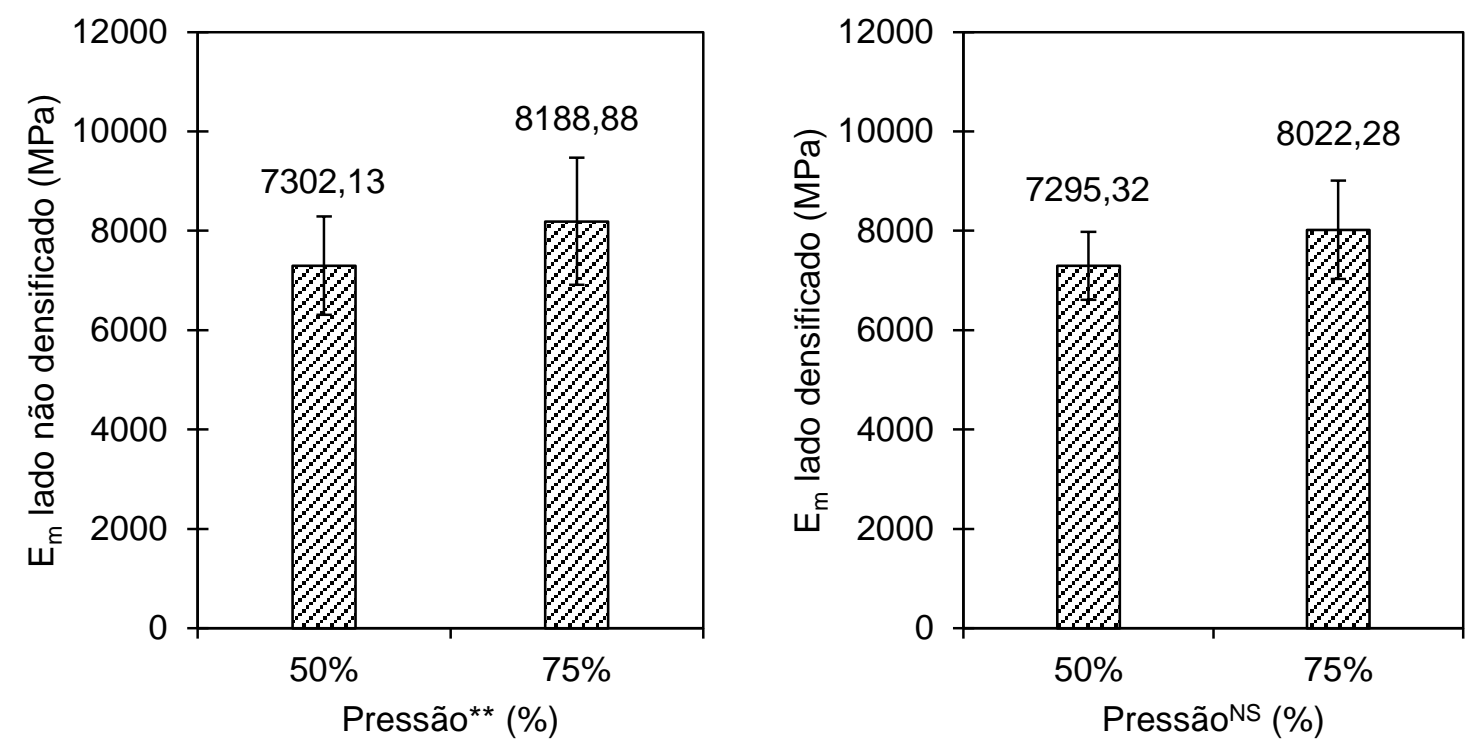

Figura 35 - Análise fatorial com efeito do fator pressão isolados no $E_{m}$ do tratamento termomecânicos

** fator significativo na análise fatorial a $5 \%$ de significância. ${ }^{N S}$ fator não significativo pela análise fatorial a $5 \%$ de significância. As barras acima das colunas indicam o desvio padrão.

Além dos ensaios destrutivos, foi realizado também o ensaio mecânico não destrutivo com auxílio do aparelho Stress Wave Timer que possibilitou verificar as variáveis: módulo de elasticidade dinâmico e velocidade. As Figuras 36 e 37 mostram o comportamento médio do módulo de elasticidade dinâmico ao longo dos tratamentos. De uma forma geral há um ganho no $E_{d}$, com exceção do T4 que apresenta uma perda não significativa. O único tratamento com ganho significativo foi o T2 $(22,85 \%)$.

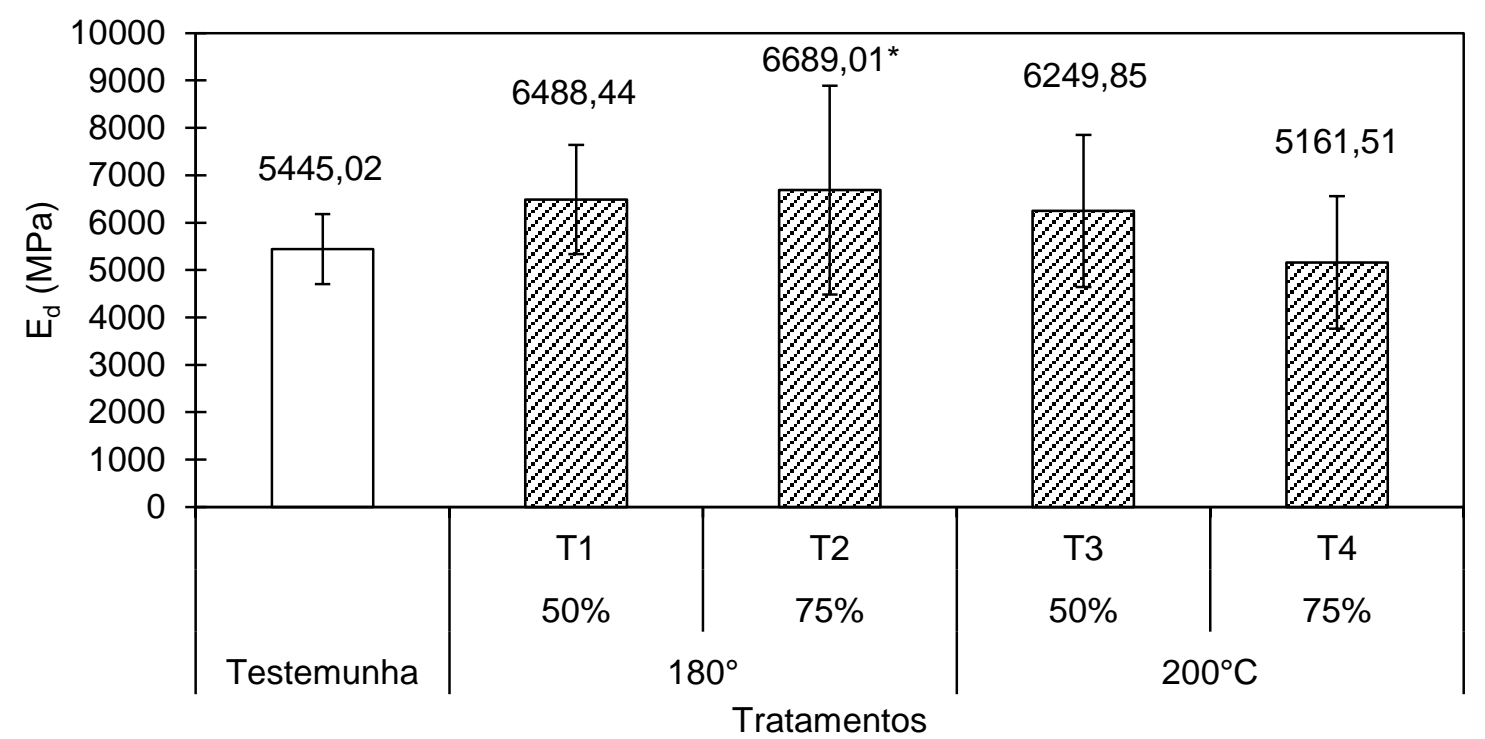

Figura 36 - Resultados da $E_{d}$ para os quatro tratamentos termomecânicos e a testemunha * diferença significativa a 5\% de significância pelo teste de Dunnett 

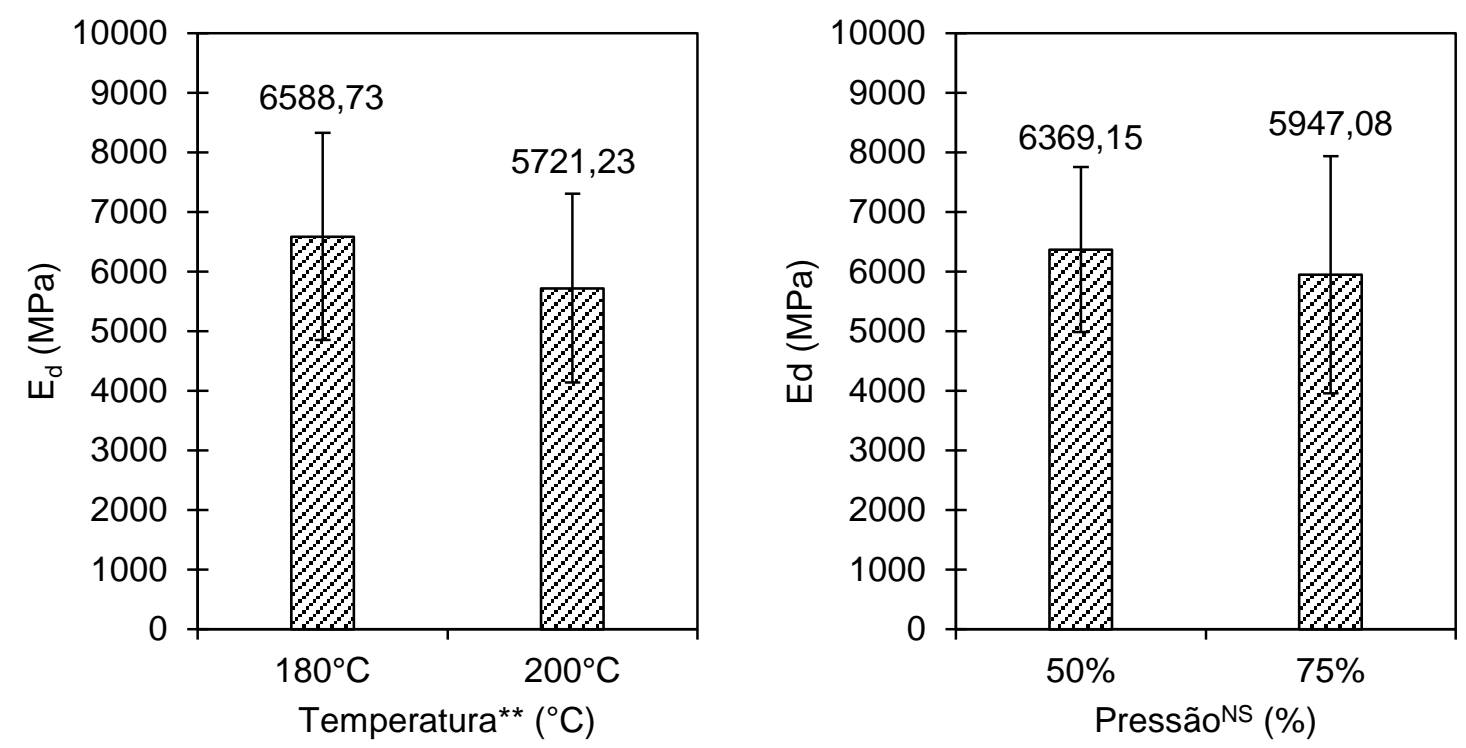

Figura 37 - Análise fatorial com efeito dos fatores temperatura e pressão isolados no $E_{d}$ dos tratamentos termomecânicos

** fator significativo na análise fatorial a $5 \%$ de significância. ${ }^{\text {NS }}$ fator não significativo a $5 \%$ de significância pela análise fatorial. As barras acima das colunas indicam o desvio padrão.

Pela análise estatística, foi possível notar que, assim como nas demais propriedades mecânicas, o aumento da temperatura acarreta na perda dessas propriedades. No caso do $E_{d} 0$ efeito da pressão não foi significativo e, portanto, não resultou no efeito esperado, que era a melhora do módulo de elasticidade dinâmico.

A partir do ensaio não destrutivo também foi possível calcular a velocidade de propagação da onda de tensão pelos CP. A Figura 38 traz o resultado para cada tratamento e para a testemunha.

Os tratamentos 2 e 4 pelo teste de Dunnett (Tabela A.6 apêndice I) tiveram redução significativa na velocidade em $10,46 \%$ e $23,19 \%$ respectivamente. Quando comparados com a testemunha (3513,00 MPa), os demais tratamentos não se diferenciaram estatisticamente. 

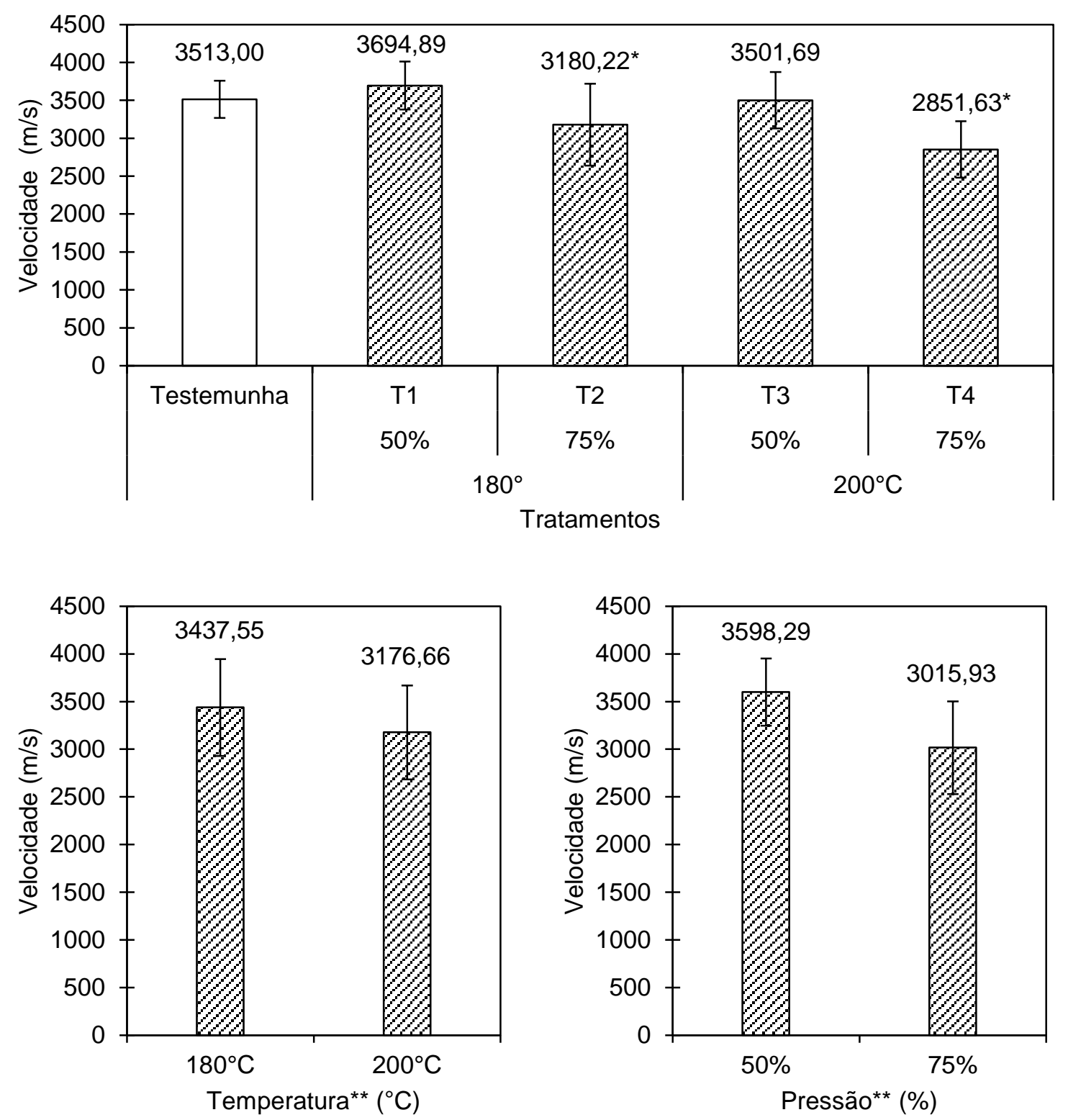

Figura 38 - Resultados da velocidade de propagação da onda para os quatro tratamentos termomecânicos e a testemunha e análise fatorial com efeito dos fatores temperatura e pressão isolados

* diferença significativa a $5 \%$ de significância pelo teste de Dunnett. ** fator significativo na análise fatorial a $5 \%$ de significância. As barras acima das colunas indicam o desvio padrão.

De acordo com a análise fatorial, as diferenças de temperatura e pressão são significativas (Tabela A.9 apêndice I). O aumento da pressão provoca, ao contrário do que se esperava, a diminuição da velocidade. Com a aplicação da pressão, esperava-se que houvesse uma redução dos espaços vazios internos e, consequentemente, a redução da descontinuidade do material, o que provocaria o aumento na velocidade. Tendo em vista isso, a provável explicação é que o aumento da pressão provocou colapsos celulares acarretando na descontinuidade interna, o que dificulta a propagação das ondas. 
Assim como a pressão, o aumento da temperatura também reduziu a velocidade: $83,81 \%$. Esse comportamento também não era esperado, tendo em vista que o teor de umidade é um dos fatores que mais afeta a velocidade de propagação da onda de tensão na madeira e a elevação da temperatura tende a diminuir o TUE e, consequentemente, aumenta a velocidade de propagação da onda como, observado por Del Menezzi et al., (2007) que relatam que há uma tendência da $v_{0}$, medida após o tratamento, ser superior em comparação aos valores observados antes do tratamento e após a climatização, ou seja, a temperatura influência de forma positiva na velocidade.

Em outros estudos, Del Menezzi et al., (2014) trabalharam com Simarouba amara tratada termicamente e concluíram através do teste $\mathrm{T}$ - pareado que no $\mathrm{T} 1\left(160^{\circ} \mathrm{C}\right.$ e $\left.180 \mathrm{~min}\right)$ a velocidade do stress wave não foi significativamente maior $(4,206 \mathrm{~m} / \mathrm{s} \times 4,319 \mathrm{~m} / \mathrm{s})$, sendo essa variação muito superior e significativa no T2 $\left(200^{\circ} \mathrm{C}\right.$ e $\left.70 \mathrm{~min}\right): 4216 \mathrm{~m} / \mathrm{s} \times 5,714 \mathrm{~m} / \mathrm{s}$. Os autores atribuíram as alterações de polímeros (cross-linking, degradação e cristalinidade) como as responsáveis pelas mudanças observadas no ensaio não destrutivo.

Embora esses estudos apontem conclusões distintas, há concordância de que o tratamento térmico ou termomecânico altera as propriedades da madeira e de painéis, o que ratifica os resultados aqui encontrados.

\subsubsection{Efeito nas propriedades de superfície}

A molhabilidade é um bom indicativo da qualidade da superfície da madeira e é analisada através do AC final. Quanto maior for o AC, mais hidrofóbica se tornou a madeira e menor a molhabilidade. A Figura 39 mostra os resultados desse teste. A testemunha possui a menor média do ângulo de contato entre os resultados. Isso ocorre devido ao fato de a Simarouba amara ser uma madeira leve, porosa e com facilidade de absorção de água.

Após o tratamento térmico, o ângulo de contato aumentou significativamente, como mostra o teste de Dunnett (Tabela A.5, apêndice I). $O$ aumento do ângulo de contato e a consequente redução na molhabilidade dos CPs indicam redução dos grupamentos hidroxílicos no material modificado termomecanicamente, gerando uma superfície parcialmente inativada. Além disso, é provável que o tratamento termomecânico tenha alterado a estrutura dos componentes da parede celular, principalmente das polioses, além da plasticização da lignina, resultando na redução da molhabilidade da madeira, conforme sugerido por Hakkou et al., (2005). 


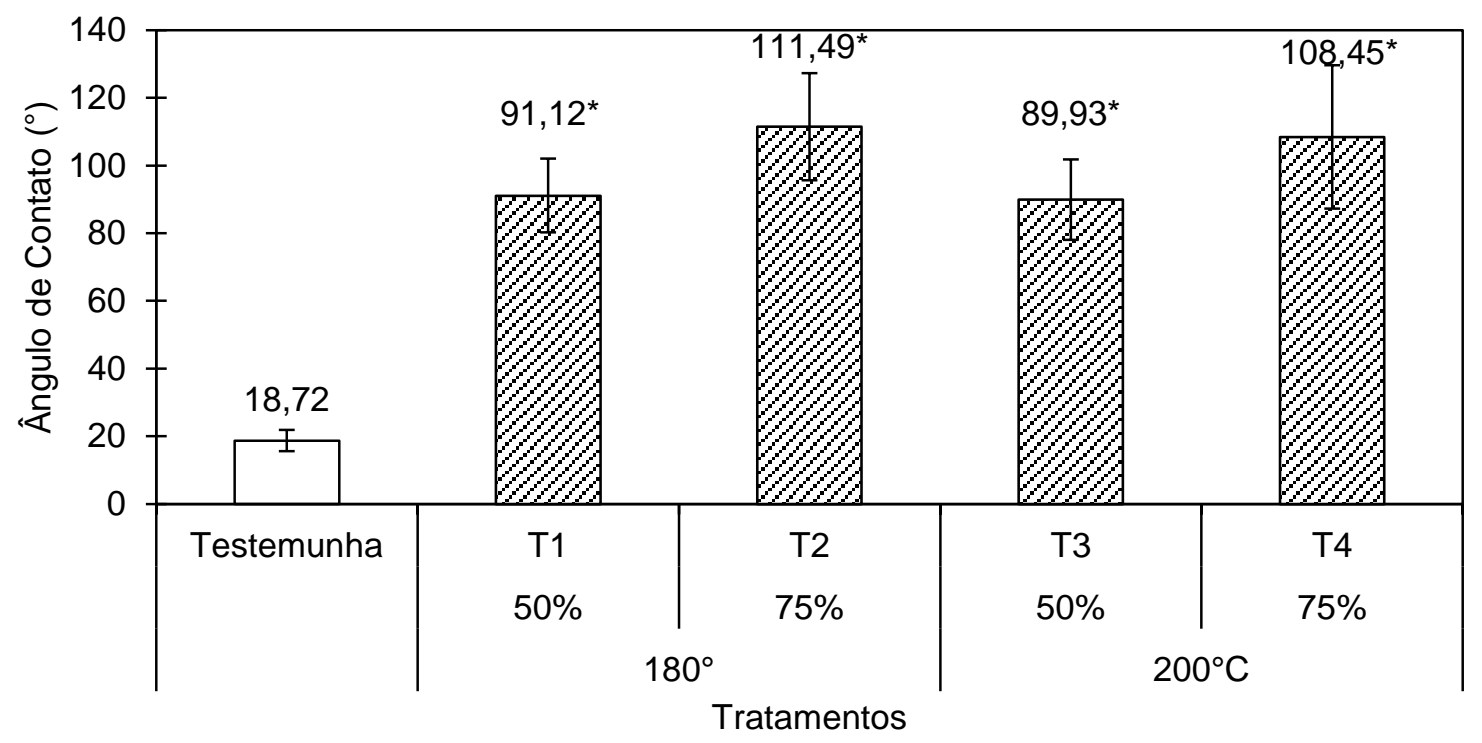

Figura 39 - Resultados do ângulo de contato para os quatro tratamentos termomecânicos e a testemunha

* diferença significativa a 5\% de significância pelo teste de Dunnett.

Essa alteração no comportamento da gota séssil pode ser atribuída também a vários outros fatores como alteração na anatomia (macro e microestrutura), teor de umidade, alteração nas propriedades físicas e defeitos, como afirma Piao et al., (2010).

Porém, nesse caso específico com base na análise fatorial (Tabela A.8, apêndice I) pode-se afirmar que a pressão foi um dos principais fatores que contribuíram para o aumento do ângulo de contato. Apesar de se acreditar na influência da temperatura no caráter hidrofóbico da madeira, como afirma Brisolari (2008), quando avaliou a molhabilidade e permeabilidade de Pinus elliottii tratada termicamente a 100 e $200^{\circ} \mathrm{C}$, esse não foi identificado como significativo no presente trabalho.

A Figura 40 apresenta a diferença significativa de $21,53 \%$ entre as pressões para a molhabilidade, mostrando que a maior pressão reduziu os espaços internos, deixando a madeira menos porosa. Nesse aspecto, pode-se observar que a pressão de $75 \%$ foi melhor na diminuição do ângulo de contato. Conhecendo o comportamento dessa variável, pode-se melhorar a relação entre a madeira e os produtos de acabamento, principalmente quando o uso final do material é piso. 

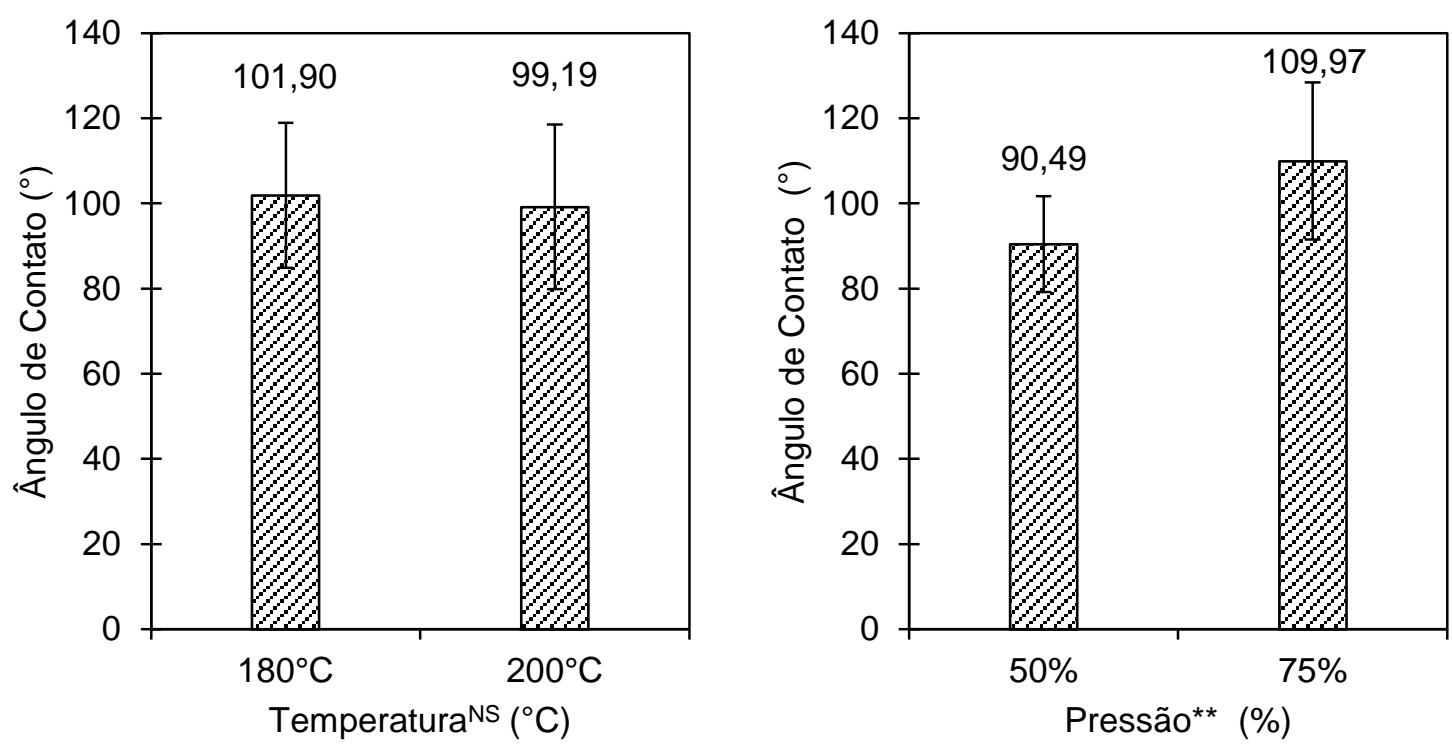

Figura 40 - Análise fatorial com efeito dos fatores temperatura e pressão isolados no ângulo de contato nos tratamentos termomecânicos

** fator significativo na análise fatorial a $5 \%$ de significância. As barras acima das colunas indicam o desvio padrão. ${ }^{N S}$ fator não significativo na análise fatorial a $5 \%$ de significância.

A abrasão é uma propriedade de superfície muito importante no estudo da viabilidade da madeira para piso. Essa propriedade pode ser definida como a capacidade que um revestimento tem de resistir à degradação causada por desgaste mecânico. Ao se realizar o teste de abrasão (Figura 41), foi possível o cálculo de duas variáveis: taxa de desgaste na Figura 42 e perda de massa Figura 43.

A menor taxa de desgaste foi observada na testemunha $(37,22 \%)$, enquanto no tratamento 3 o desgaste foi maior $(63,89 \%)$. Pelo teste de Dunnett apenas o T3 se diferenciou significativamente da testemunha, tendo uma taxa de desgaste $71,65 \%$ maior. Os demais tratamentos pelo teste de Dunnett (Tabela A.5. apêndice I) não alcançaram diferença significativa.

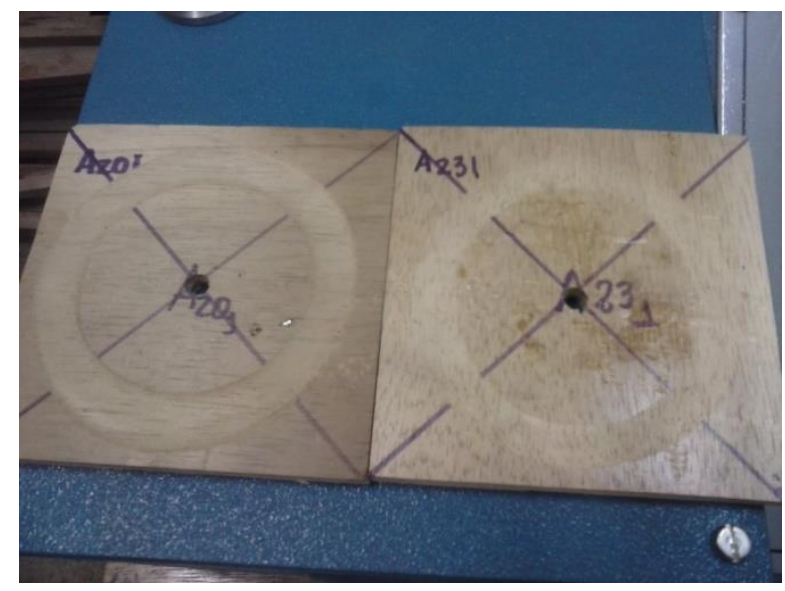

Figura 41 - Corpos de prova com o desgaste do teste de abrasão 

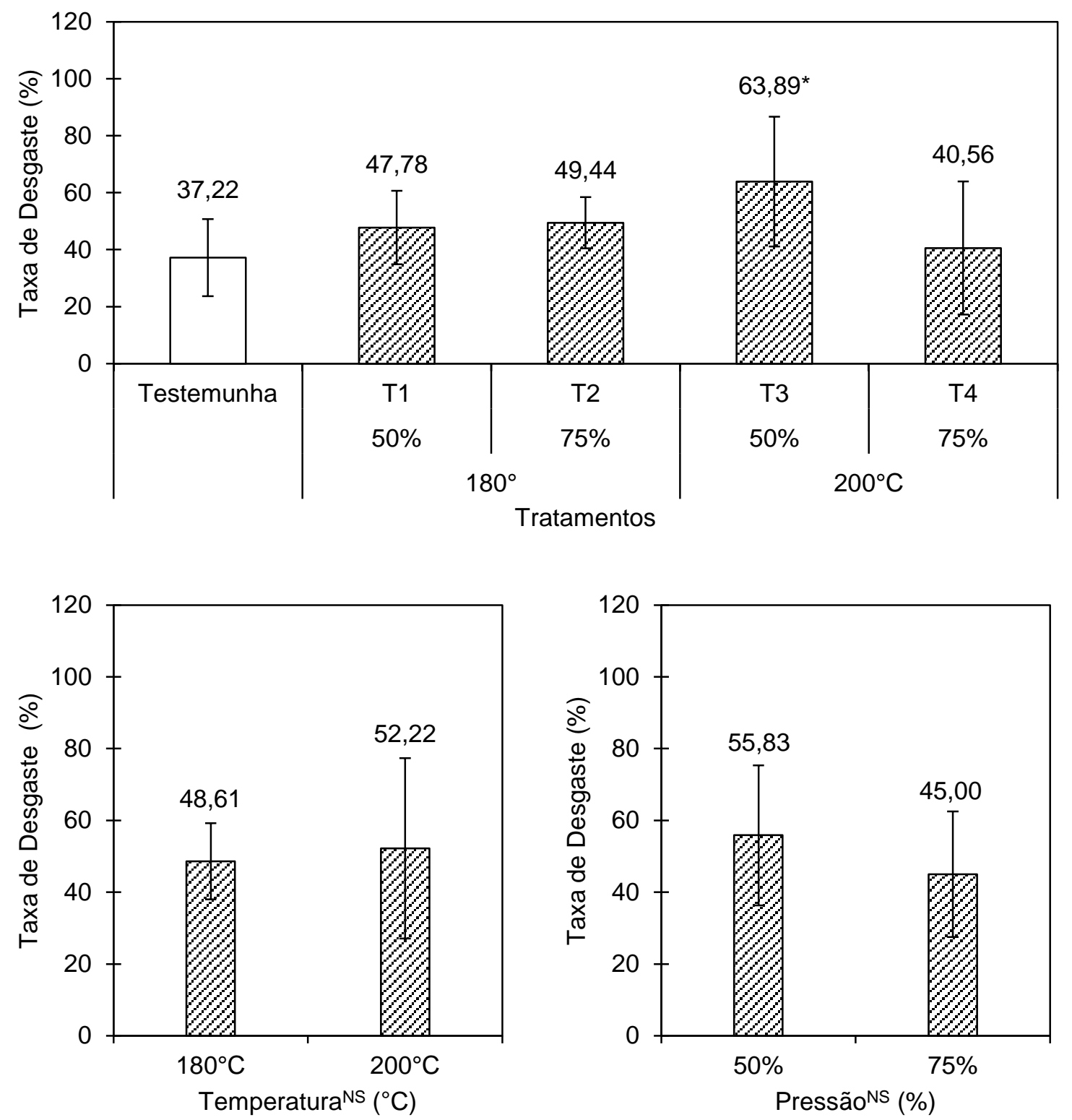

Figura 42 - Resultados da taxa de desgaste para os quatro tratamentos termomecânicos e a testemunha e análise fatorial com efeito da temperatura e pressão isolados *diferença significativa a $5 \%$ de significância pelo teste de Dunnett. ${ }^{N S}$ fator não significativo na análise fatorial a $5 \%$ de significância. As barras acima das colunas indicam o desvio padrão.

Lopes (2012) em seus estudos também detectou que a utilização do abrasímetro Taber para avaliar a resistência à abrasão de madeira sólida não se mostrou muito eficiente na configuração utilizada que é a recomendada pela NBR 14535:2000. O mesmo autor tentou correlacionar a resistência à abrasão com algumas propriedades (massa específica aparente, dureza e compressão). Entretanto, a correlação foi negativa e não significativa, inviabilizando a equação para estimar a resistência à abrasão em função de algumas dessas propriedades.

Acerca disso, verificou-se que, apesar de existir uma tendência das madeiras duras e densas a apresentarem alta resistência à abrasão, a taxa de desgaste não se comporta de forma linear ao longo das espécies. Algumas, de baixa dureza, apresentam taxa de desgaste similar às de alta 
dureza e vice-versa. Isso confirma outros autores que, apesar de utilizarem outras metodologias de teste de abrasão, concluíram que abrasão não se correlaciona bem com outras propriedades (NCUBE, 2008).

Em relação à perda de massa (Figura 43), o maior valor também ocorreu no T3 com 0,90\%, e T4 apresentou o menor valor $0,45 \%$. Pelo teste de Dunnett constatou-se que, comparados com a testemunha, nenhum tratamento teve diferença significativa.
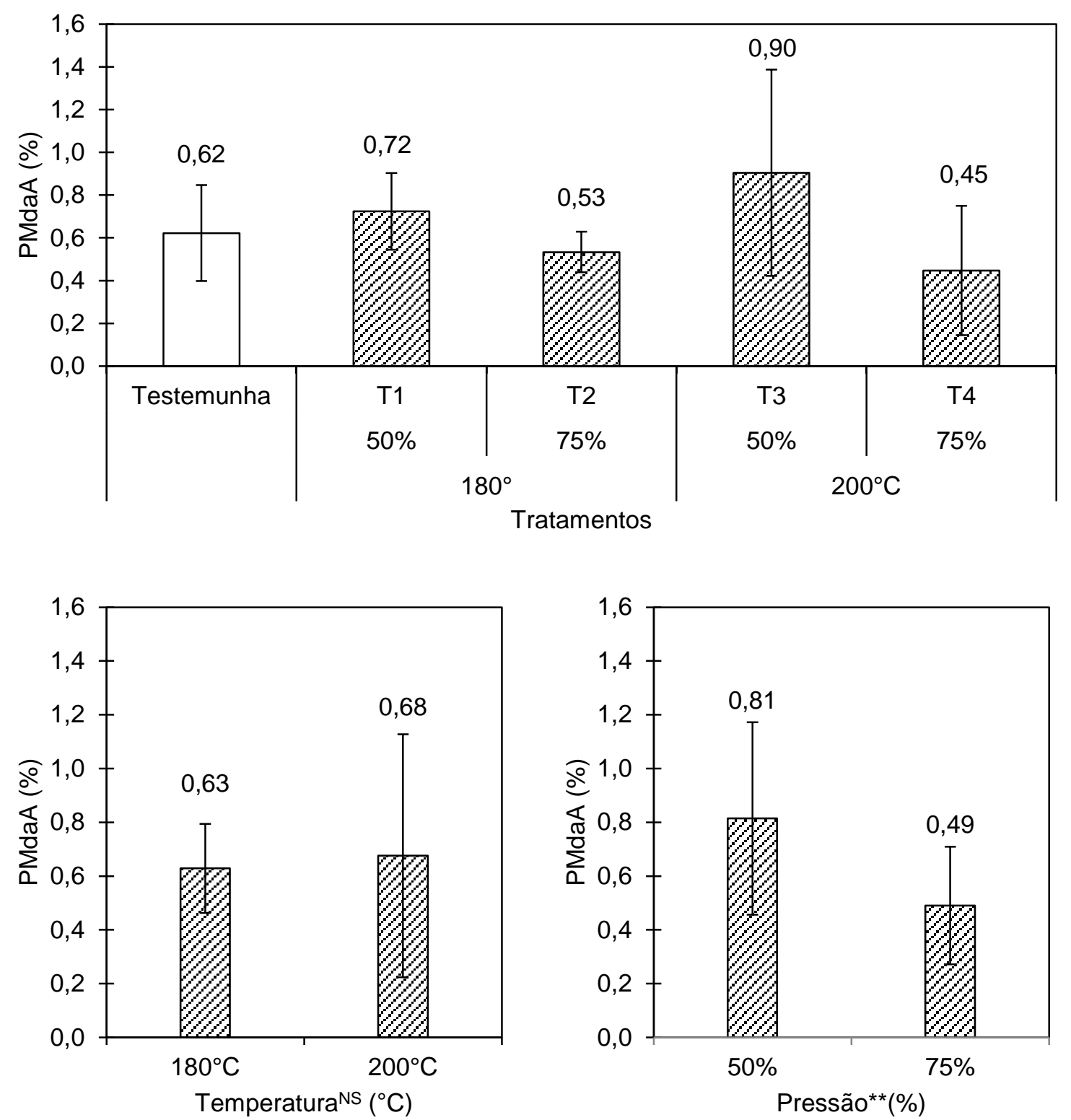

Figura 43 - Resultados da perda de massa para os quatro tratamentos termomecânicos e a testemunha e análise fatorial com efeito da temperatura e pressão isolados

** fator significativo na análise fatorial a $5 \%$ de significância. ${ }^{\text {NS }}$ fator não significativo na análise fatorial a $5 \%$ de significância. As barras acima das colunas indicam o desvio padrão.

A análise fatorial explica os resultados apresentados. A mudança na pressão foi relevante para a perda de massa. A diferença entre as pressões foi de $65,31 \%$, sendo que o aumento de pressão 
diminui a perda de massa. Esse efeito pode ser explicado pela alteração anatômica causada pelo tratamento que resulta em um material mais compactado, reduzindo assim a perda de massa em condições de atrito.

Considerando o fator estético da cor da madeira e o pretendido uso final, os resultados dos parâmetros colorimétricos para os quatro tratamentos e a testemunha foram satisfatórios. Pelos dados apresentados nas Figuras 44, 45,46, 47 e 48 é possível notar que os parâmetros mais afetados pelos tratamentos são: claridade $\left(L^{*}\right)$, parâmetro $a^{*}$ e ângulo de tinta $(h)$.

A hipótese acima levantada é confirmada pela análise estatística do teste de Dunnett (Tabela A.5 apêndice I) que fica mais clara por meio da Figura 44. Observa-se que para todos os parâmetros houve diferença estatística entre a média da testemunha e os tratamentos.

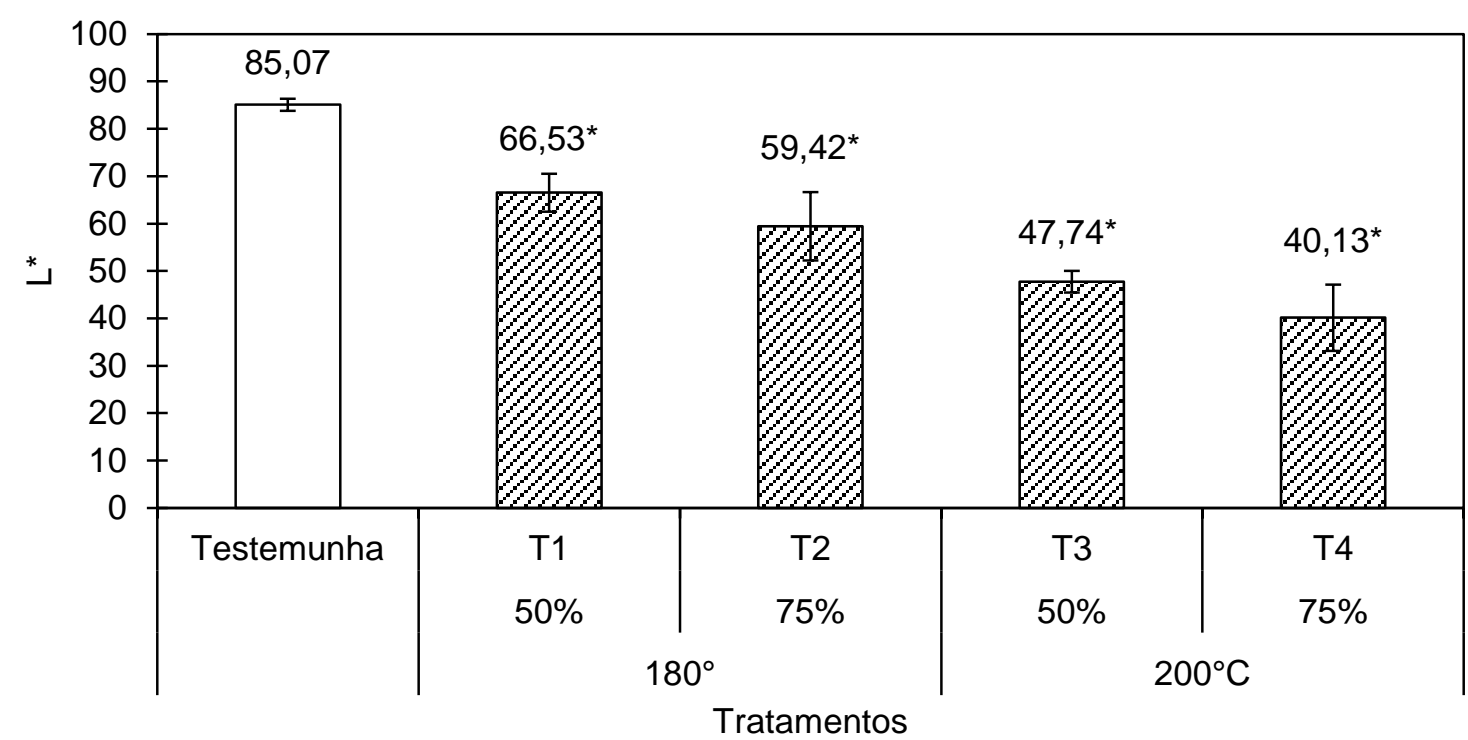

Figura 44 - Resultados da claridade $L^{*}$ para os quatro tratamentos termomecânicos e a testemunha

*diferença significativa a 5\% de significância pelo teste de Dunnett.

Analisando individualmente cada elemento, $0 L^{*}$, que expressa a claridade do material, variando de 0 (preto absoluto) a 100 (branco total), teve uma redução que variou de $21,79 \%$ a $52,82 \%$. A Figura 44 mostra um comportamento decrescente ao longo dos tratamentos sendo, T1 o que apresentou menor perda $(66,53)$ e T4 o de maior perda $(40,13)$.

Esse decréscimo na luminosidade é comum quando a madeira passa pelo processo de termorretificação, como é discutido por vários autores (ARRUDA,2012, OLIVEIRA, 2009, DEL MENEZZI, 2004). De acordo com Charrier et al., (2002) a oxidação de algumas substâncias resulta na perda de luminosidade na madeira e por conseguinte o menor valor do $L^{*}$. 
Zanuncio et al., (2014), estudando o efeito da termorretificação na madeira de Eucalyptus grandis com temperatura que variava de $140^{\circ} \mathrm{C}$ a $230^{\circ} \mathrm{C}$, obtiveram valores de $L^{*}$ entre 65,3 e 32,3 . Com isso foi possível verificar que com a intensificação da temperatura ocorre uma perda da claridade e que a temperatura mostrou-se mais efetiva na redução da claridade do que o tempo.

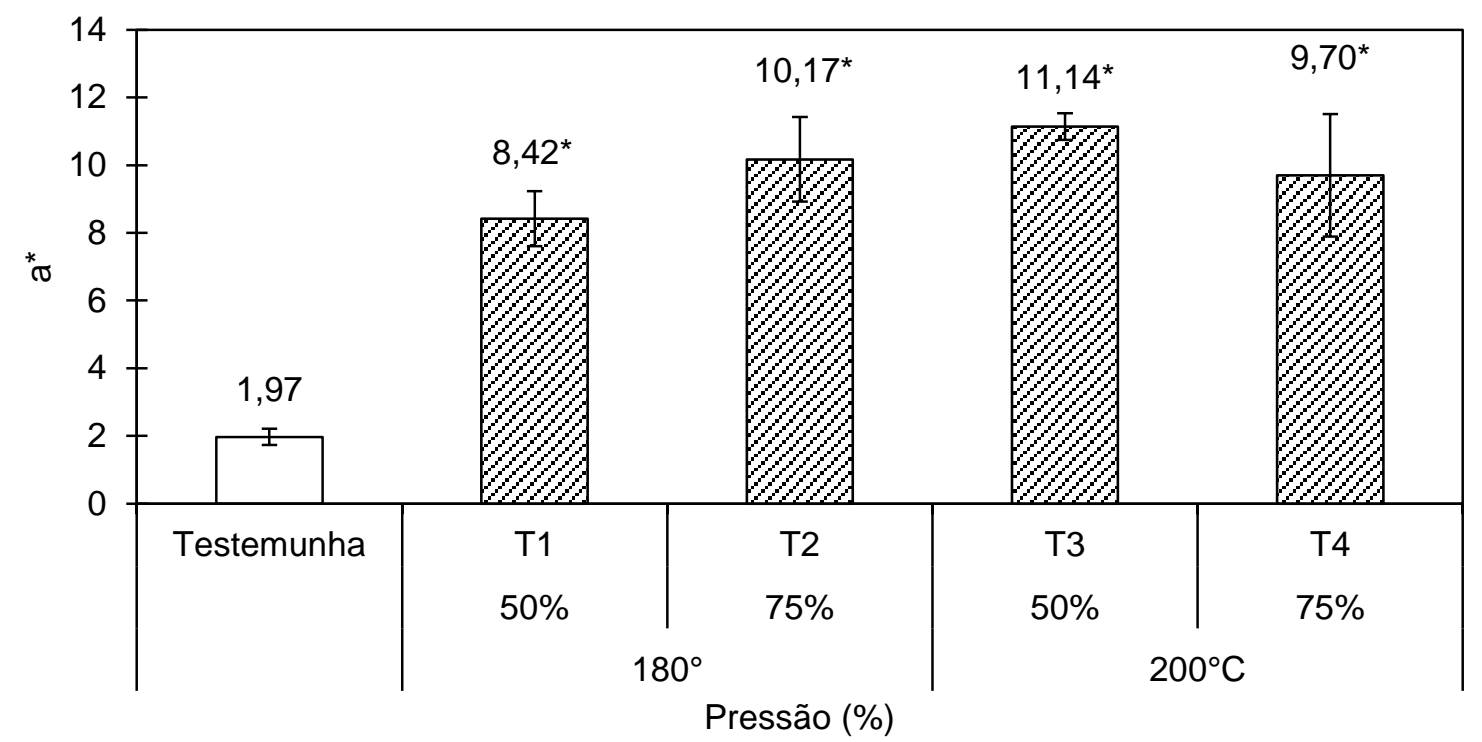

Figura 45 - Resultados do parâmetro a* para os quatro tratamentos termomecânicos e a testemunha

*diferença significativa a 5\% de significância pelo teste de Dunnett.

Para o parâmetro $a^{*}$ as alterações também foram bem visíveis, como mostra a Figura 45. O T1 foi o que apresentou menor aumento em relação à testemunha $(8,42)$ e T3 o que mais ganhou $(11,14)$. Entre os tratamentos, a maior diferença representou um ganho de $32,30 \%$, mas o ganho mais expressivo ocorreu na comparação com a testemunha que mostrou um acréscimo variando entre $327 \%$ a $465 \%$. O aumento do parâmetro a* representou um deslocamento positivo no eixo verde-vermelho, tornando a madeira mais avermelhada.

Já em relação ao parâmetro $b^{*}$, houve um aumento do pigmento amarelo nos tratamentos T1 e T2 e T3. Nas condições mais severas $\left(200^{\circ} \mathrm{C}\right.$ e $\left.75 \%\right)$, T4 apresentou a redução no eixo azul-amarelo, mostrando que a madeira se tornou mais azulada (Figura 46). Pincelli et al., (2012) relatam que os compostos cromóforos associados às ligninas e aos extrativos conferem a cor amarelada à madeira; entretanto, o tratamento térmico degrada estes compostos, reduzindo a matriz amarelo $\left(b^{*}\right)$. 


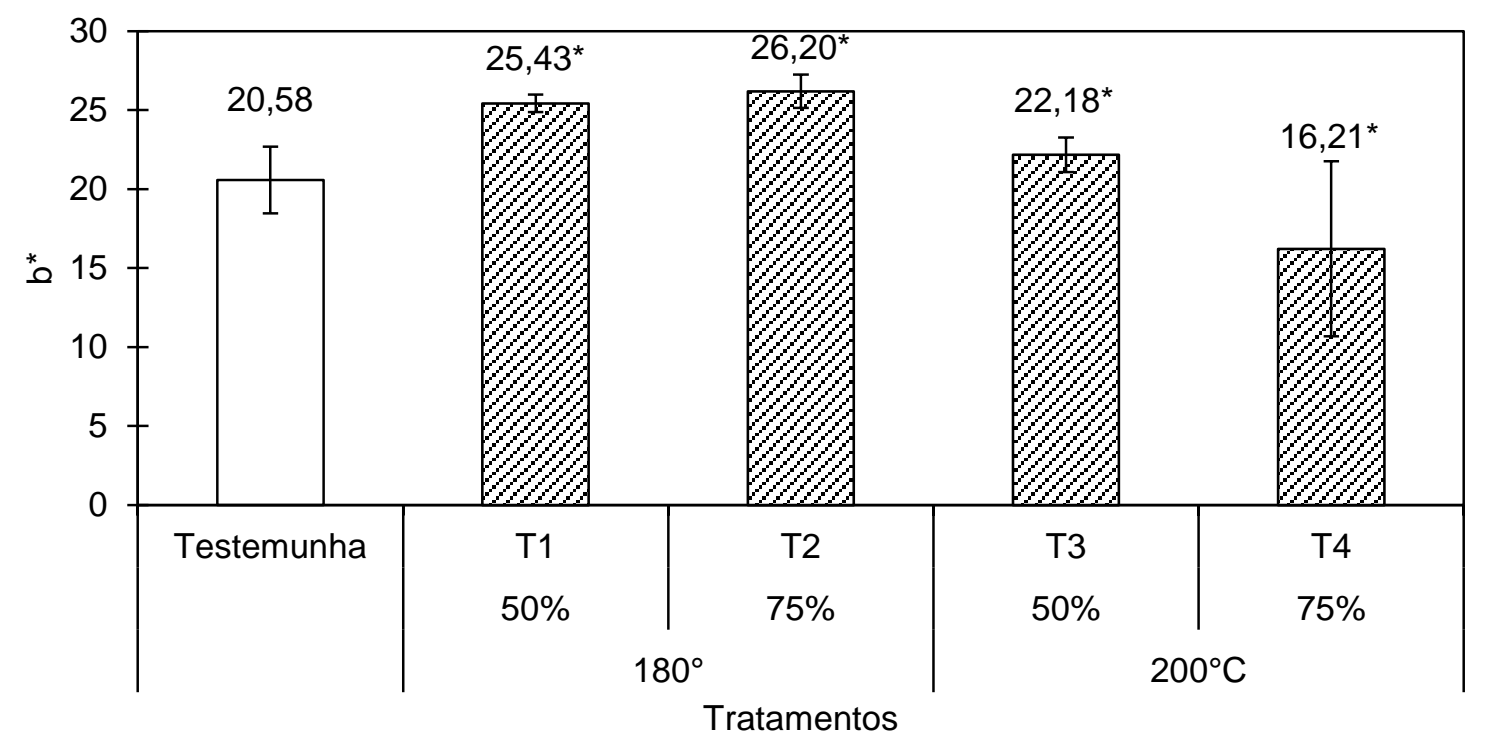

Figura 46 - Resultados do parâmetro b* para os quatro tratamentos termomecânicos e a testemunha

*diferença significativa a 5\% de significância pelo teste de Dunnett.

A saturação (Figura 47) apresentou o mesmo comportamento descrito acima: aumentou nos três primeiros tratamentos e reduziu nas condições mais severas. Zanuncio et al., (2014) observaram comportamento semelhante, pois em seus estudos os parâmetros $\mathrm{C} \mathrm{e} \mathrm{b}^{*}$ apresentaram o mesmo comportamento. Não houve redução a $140^{\circ} \mathrm{C}$, seguida de queda nas temperaturas de 170, $200 \mathrm{e}$ $230^{\circ} \mathrm{C}$. Os valores de saturação $(\mathrm{C})$ dependem da matriz vermelho $\left(a^{*}\right)$ e amarelo $\left(b^{*}\right)$. Na medida em que os valores de $b^{*}$ para madeira são em geral maiores que os de $a^{*}$, assume-se que a matriz amarelo $\left(b^{*}\right)$ tem mais influência sobre a saturação, o que explica o comportamento semelhante entre $b^{*}$ e $C$.

O ângulo de tinta (h) foi reduzido (Figura 48) ao longo dos tratamentos, sendo a menor redução observada no T1 15,34\% e a maior em T4 31\%. A redução do parâmetro h mostra que a madeira está escurecendo, assim como a redução de $L^{*}$, dessa forma são resultados complementares. 


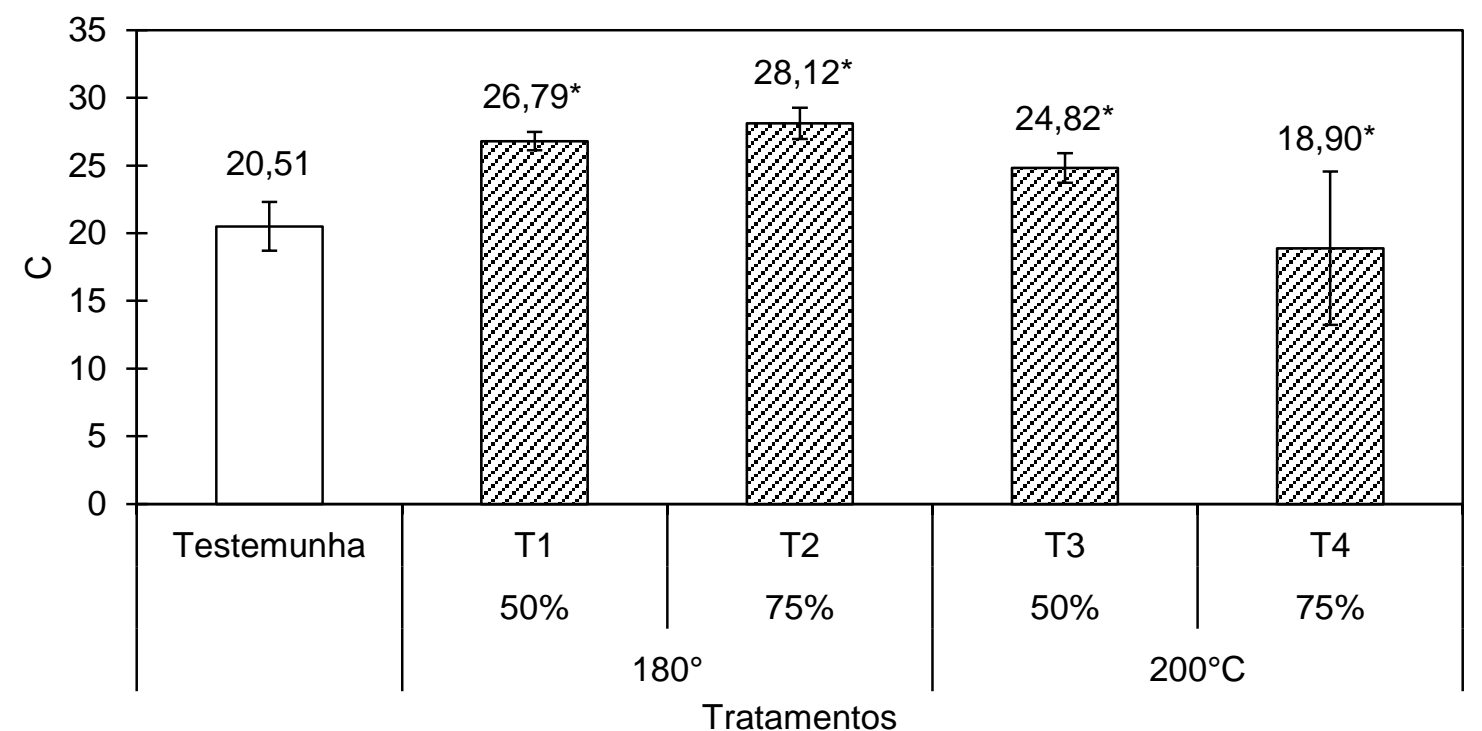

Figura 47 - Resultados do parâmetro C para os quatro tratamentos termomecânicos e a testemunha

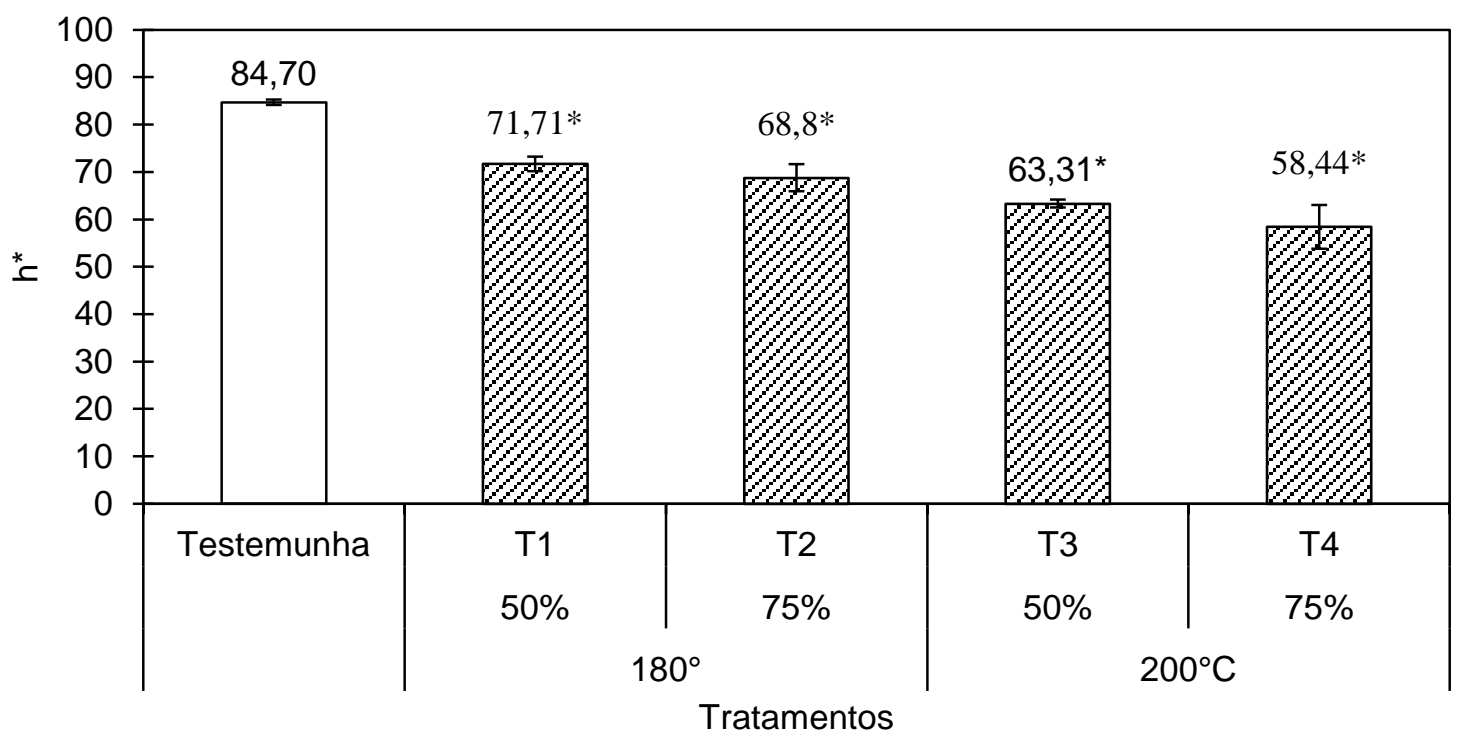

Figura 48 - Resultados do parâmetro $h^{\star}$ para os quatro tratamentos termomecânicos e a testemunha

*diferença significativa a 5\% de significância pelo teste de Dunnett.

As Figuras 49, 50 e 51 mostram os fatores influentes para mudança nas propriedades colorimétricas de acordo com a análise fatorial (Tabela A.8 do apêndice I). Para todos os parâmetros, a temperatura teve influência significativa, como já era esperado, e apenas para o $a^{*}$ o fator pressão não foi significativo.

Para a claridade, tanto o aumento na temperatura como na pressão são responsáveis pela redução da luminosidade na madeira sendo, que a temperatura reduz em 30,24\% e a pressão, $12,88 \%$, ou seja, pode se afirmar que a temperatura tem maior participação na perda da claridade quando comparada com a pressão. 

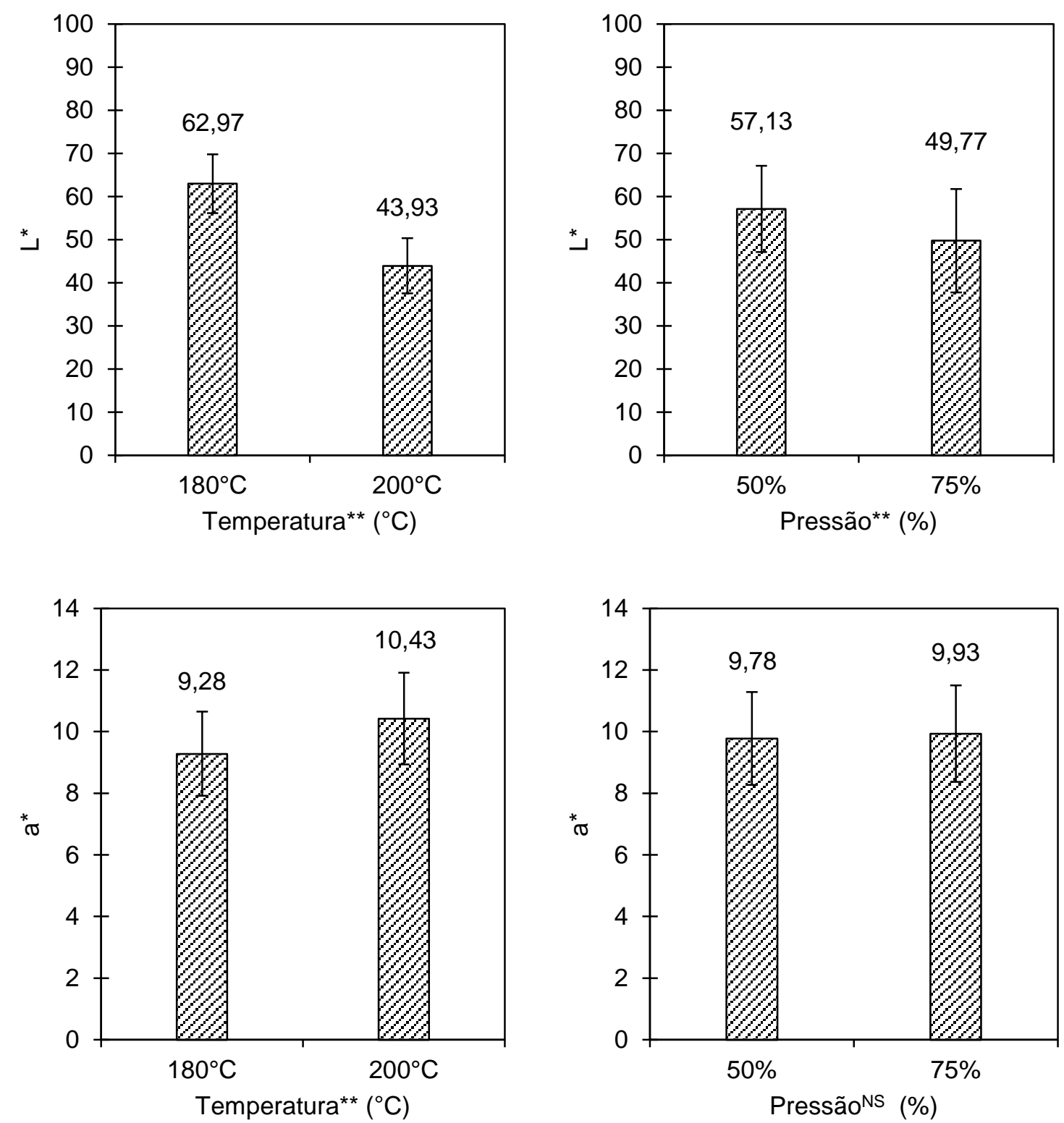

Figura 49 - Análise fatorial com efeito dos fatores temperatura e pressão isolados para os parâmetros $L^{*} e a^{*}$ dos tratamentos termomecânicos

** fator significativo na análise fatorial a $5 \%$ de significância. ${ }^{\text {NS }}$ fator não significativo na análise fatorial a 5\% de significância. As barras acima das colunas indicam o desvio padrão.

A variável $a^{*}$ é a única que é diretamente proporcional ao fator temperatura, sendo assim, quanto maior a temperatura maior a quantidade de pigmentos vermelho na madeira. As variáveis $b^{\star}, C^{*} e$ h apresentam comportamento semelhante ao descrito para o parâmetro $L^{*}$, ou seja, o aumento da pressão e temperatura causa uma perda nessas variáveis contribuindo, assim, para o escurecimento da madeira. Outro padrão observado foi a maior influência da temperatura em relação à pressão. 

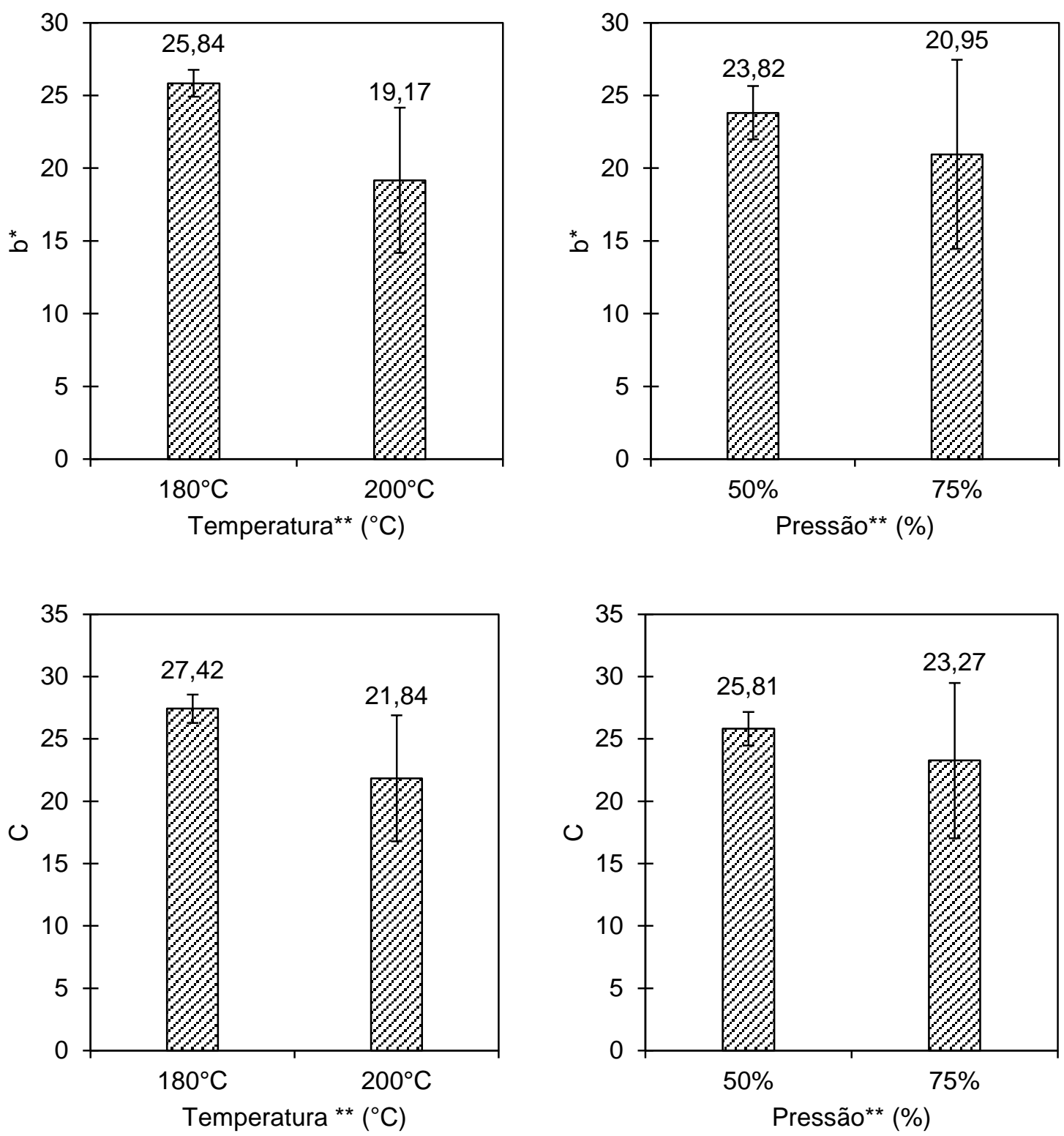

Figura 50 - Análise fatorial com efeito dos fatores temperatura e pressão isolados para o parâmetro $b^{*}$ e $C$ dos tratamentos termomecânicos

** fator significativo na análise fatorial a $5 \%$ de significância. As barras acima das colunas indicam o desvio padrão. 

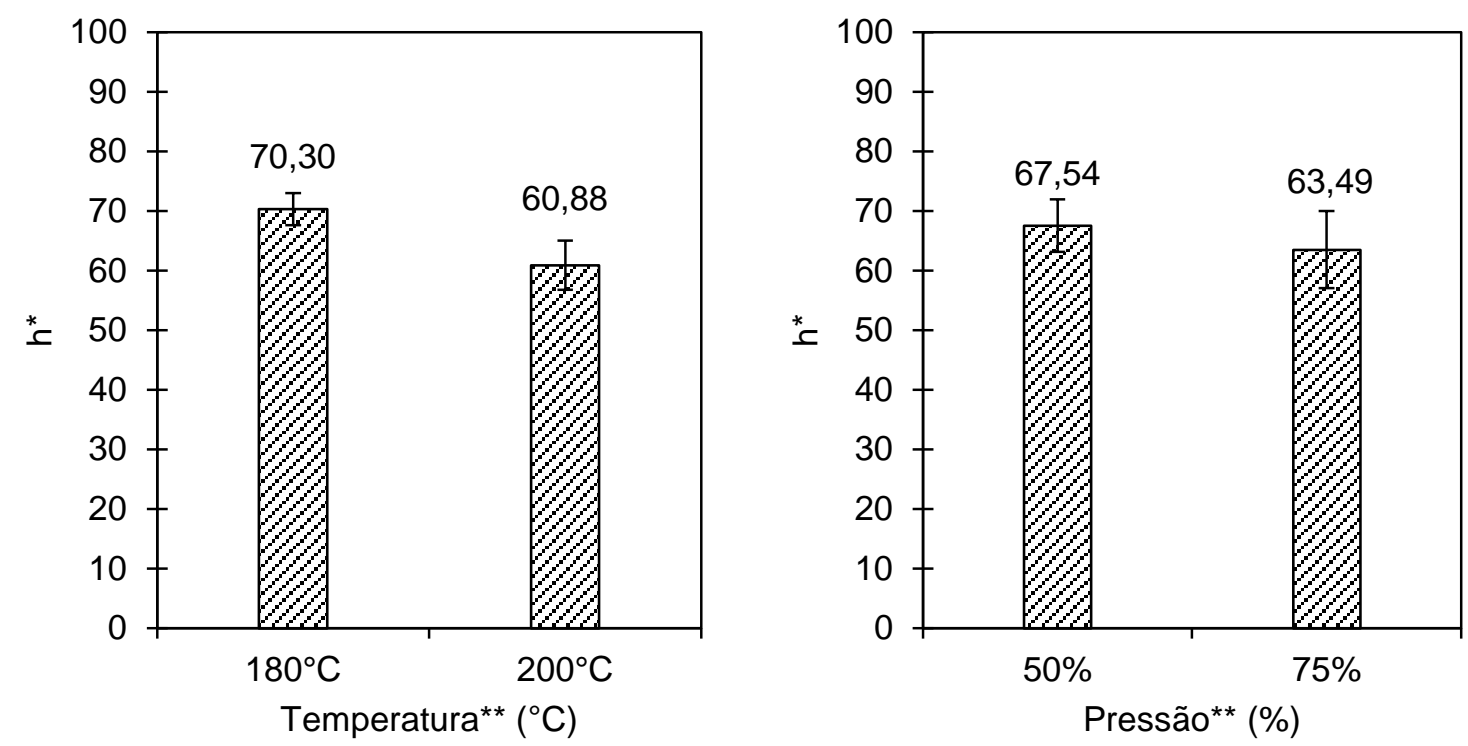

Figura 51 - Análise fatorial com efeito dos fatores temperatura e pressão isolados para o parâmetro $\mathrm{h}^{*}$ dos tratamentos termomecânicos

** fator significativo na análise fatorial a $5 \%$ de significância. As barras acima das colunas indicam o desvio padrão.

A variação de cor foi calculada pelo $\Delta E$ que é dado pelo somatório de $\Delta \mathrm{L}^{*}, \Delta \mathrm{a}^{*}$ e $\Delta \mathrm{b}^{*}$, sendo todas as variáveis elevadas ao quadrado. O resultado para variação de cor pode ser observado na Figura 52 e a variação dos parâmetros é mostrada na Tabela 9. O sinal negativo indica a redução e o positivo o ganho da variável em relação à testemunha. De acordo com a tabela de classificação proposta por Hikita et al., (2001) o $\Delta \mathrm{E}$ para todos os tratamentos foi muito significativo.

A variação de cor foi aumentando ao longo dos tratamentos, sendo o tratamento mais severo (T4) o que obteve maior alteração, 45,81 e o tratamento mais brando $\left(180^{\circ} \mathrm{C}\right.$ e $\left.50 \%\right)$ o que obteve menor alteração o que mostra que não é apenas a temperatura que influi nos resultados, a pressão também tem grande participação no $\Delta \mathrm{E}$. Gouveia (2008), em seu trabalho, também constatou o aumento do $\Delta \mathrm{E}$ para o Marupá quando tratado a $200^{\circ} \mathrm{C}$, a variação encontrada foi de 18,22 .

Tabela 9 - Resultados para as variações dos paramentos colorimétricos entre os tratamentos e a testemunha

\begin{tabular}{ccccccc}
\hline Tratamentos & \multicolumn{6}{c}{ Propriedades Colorimétricas } \\
\cline { 2 - 7 } & $\Delta \mathrm{L}^{*}$ & $\Delta \mathrm{a}^{*}$ & $\Delta \mathrm{b}^{*}$ & $\Delta \mathrm{C}$ & $\Delta \mathrm{h}^{*}$ & $\Delta \mathrm{E}$ \\
T1 $\left(180^{\circ} \mathrm{C} 50 \%\right)$ & $-18,54$ & 6,45 & 4,85 & 6,29 & $-12,99$ & 20,22 \\
T2 $\left(180^{\circ} \mathrm{C} 75 \%\right)$ & $-30,65$ & 8,20 & 5,62 & 7,48 & $-15,90$ & 32,22 \\
T3 $\left(200^{\circ} \mathrm{C} 50 \%\right)$ & $-37,33$ & 9,17 & 1,60 & 4,31 & $-21,39$ & 38,48 \\
T4 $\left(200^{\circ} \mathrm{C} 75 \%\right)$ & $-44,94$ & 7,73 & $-4,36$ & $-1,61$ & $-26,25$ & 45,81 \\
\hline
\end{tabular}




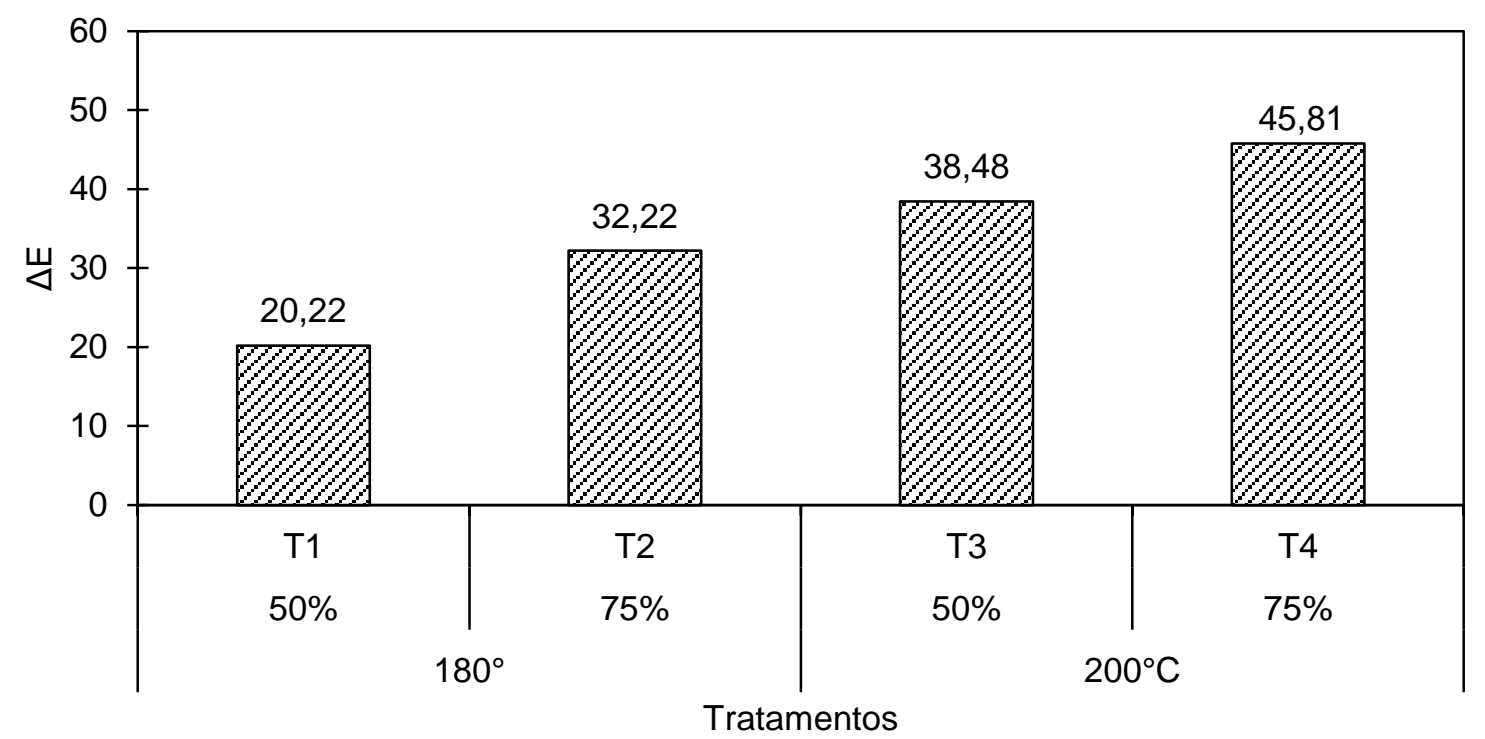

Figura 52 - Resultados para $\Delta \mathrm{E}$ nos quatros tratamentos termomecânicos

Utilizando a tabela de Camargos e Gonçalez (2001) considerando todos os parâmetros, concluiuse que a $S$. amara passou de branco acinzentado (Test.) para amarelo claro (T1), marrom oliva (T2), marrom claro (T3) e por fim marrom escuro (T4). Essa mudança de coloração (Figura 53) atinge um dos objetivos iniciais do trabalho e possibilita o ganho de valor agregado de madeiras claras, fazendo com que essas possam ser utilizadas no mercado para substituir madeiras mais procuradas como o cumaru, jatobá e ipê, que possuem coloração mais amarronzada.

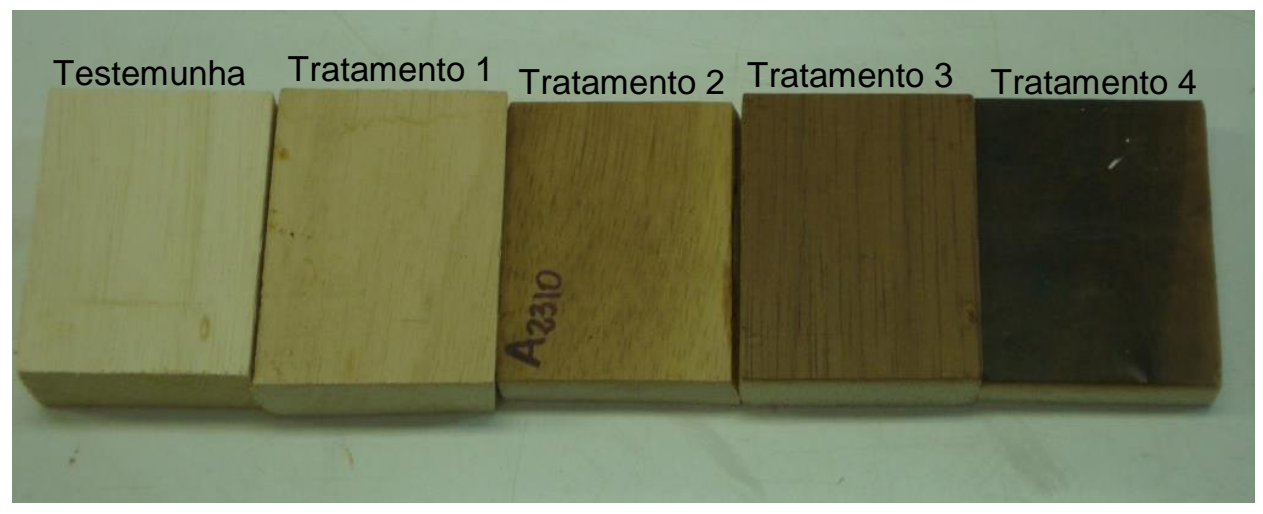

Figura 53 - Variação da cor entre os tratamentos e a testemunha

A fim de analisar o efeito isolado da temperatura e da pressão nas propriedades estudadas, a Tabela 10 traz um resumo dos resultados obtidos no presente trabalho. $O$ intuito dessa tabela resumo foi o de facilitar uma análise mais ampla e verificar qual a melhor combinação de temperatura e pressão de acordo com o objetivo de implementação do material desejado.

Observa-se que, das 28 propriedades avaliadas, 17 foram modificadas pela temperatura $(60,71 \%)$ e 23 afetadas pela pressão $(82,14 \%)$, ou seja, a pressão teve maior participação nas alterações que a madeira sofreu ao longo dos tratamentos. 
$\mathrm{O}$ uso da temperatura de $200^{\circ} \mathrm{C}$ implica melhoria na estabilidade dimensional e no escurecimento do marupá. Com relação às propriedades mecânicas, em 50\% o aumento da temperatura não interferiu na resistência, o que mostra que nesses casos o uso da pressão conseguiu anular ou mitigar os efeitos indesejados da temperatura na perda das propriedades mecânicas.

Já o aumento da pressão (75\%) afetou negativamente a estabilidade dimensional, sendo que o uso da pressão em apenas uma das superfícies e o pós tratamento não conseguiram erradicar as tensões internas sofridas pelo material. A maior pressão também contribuiu de forma positiva na alteração da cor da madeira e na redução da molhabilidade. Os ganhos nas propriedades mecânicas também são notáveis e estão intimamente relacionados ao aumento da densidade final juntamente com a TC e TD.

Tabela 10 - Tabela resumo com efeito da temperatura e da pressão do tratamento termomecânico nas propriedades físicas, superficiais e mecânicas

\begin{tabular}{|c|c|c|c|c|c|c|}
\hline \multirow{2}{*}{ Propriedade } & \multicolumn{3}{|c|}{ Temperatura $\left({ }^{\circ} \mathrm{C}\right)$} & \multicolumn{3}{|c|}{ Pressão } \\
\hline & Tendência & $180^{\circ} \mathrm{C}$ & $200^{\circ} \mathrm{C}$ & Tendência & $50 \%$ & $75 \%$ \\
\hline \multicolumn{7}{|l|}{ Físicas } \\
\hline PM & $\uparrow$ & $\mathrm{a}$ & $\mathrm{b}$ & $\uparrow$ & a & $b$ \\
\hline PMDAT & $\uparrow$ & a & $\mathrm{b}$ & $\uparrow$ & a & $b$ \\
\hline TC & $\uparrow$ & a & $\mathrm{b}$ & $\uparrow$ & a & $b$ \\
\hline TD & $\leftrightarrow$ & a & $a$ & $\uparrow$ & a & $b$ \\
\hline$\rho f$ & $\leftrightarrow$ & a & $a$ & $\uparrow$ & $\mathrm{a}$ & $b$ \\
\hline TUE & $\leftrightarrow$ & a & $a$ & $\leftrightarrow$ & a & a \\
\hline IE2H & $\downarrow$ & a & $b$ & $\uparrow$ & a & $b$ \\
\hline IE24H & $\downarrow$ & a & $b$ & $\uparrow$ & a & $b$ \\
\hline $\mathrm{AB2H}$ & $\downarrow$ & a & $\mathrm{b}$ & $\uparrow$ & a & $b$ \\
\hline AB24H & $\downarrow$ & a & $b$ & $\uparrow$ & a & $b$ \\
\hline TNRE & $\downarrow$ & a & $b$ & $\uparrow$ & a & $b$ \\
\hline TR & $\leftrightarrow$ & a & $a$ & $\uparrow$ & a & $b$ \\
\hline \multicolumn{7}{|l|}{ Superfície } \\
\hline ângulo de contato & $\leftrightarrow$ & a & $a$ & $\uparrow$ & $\mathrm{a}$ & $b$ \\
\hline PMdaA & $\leftrightarrow$ & a & $a$ & $\downarrow$ & a & $b$ \\
\hline Taxa de Desgaste & $\leftrightarrow$ & a & $\mathrm{a}$ & $\leftrightarrow$ & a & a \\
\hline$L^{*}$ & $\downarrow$ & a & $b$ & $\downarrow$ & a & $b$ \\
\hline$a^{*}$ & $\uparrow$ & a & $\mathrm{b}$ & $\leftrightarrow$ & a & a \\
\hline $\mathbf{b}^{*}$ & $\downarrow$ & a & $\mathrm{b}$ & $\uparrow$ & a & $b$ \\
\hline C & $\downarrow$ & a & $\mathrm{b}$ & $\downarrow$ & a & $b$ \\
\hline $\mathbf{h}^{*}$ & $\downarrow$ & a & $b$ & $\downarrow$ & a & $b$ \\
\hline \multicolumn{7}{|l|}{ Mecânicas } \\
\hline$f_{H, 90^{\circ}}$ & $\leftrightarrow$ & a & $a$ & $\uparrow$ & a & $b$ \\
\hline $\mathbf{f}_{\mathrm{c}, 0^{\circ}}$ & $\leftrightarrow$ & a & a & $\uparrow$ & a & $b$ \\
\hline $\begin{array}{l}\mathrm{f}_{\mathrm{M}} \text { lado não } \\
\text { densificado }\end{array}$ & $\leftrightarrow$ & a & $\mathrm{a}$ & $\uparrow$ & a & $b$ \\
\hline
\end{tabular}




\begin{tabular}{lcccccc}
\hline $\mathbf{f}_{\mathrm{M}}$ lado densificado & $\downarrow$ & $\mathrm{a}$ & $\mathrm{b}$ & $\uparrow$ & $\mathrm{a}$ & $\mathrm{b}$ \\
$\mathrm{E}_{\mathrm{m}}$ lado não & $\uparrow$ & $\mathrm{a}$ & $\mathrm{b}$ & $\uparrow$ & $\mathrm{a}$ & $\mathrm{b}$ \\
densificado & $\leftrightarrow$ & $\mathrm{a}$ & $\mathrm{a}$ & $\leftrightarrow$ & $\mathrm{a}$ & $\mathrm{a}$ \\
$\mathrm{E}_{\mathrm{m}}$ lado densificado & $\downarrow$ & $\mathrm{a}$ & $\mathrm{b}$ & $\leftrightarrow$ & $\mathrm{a}$ & $\mathrm{a}$ \\
$\mathrm{E}_{\mathrm{d}}$ & $\downarrow$ & $\mathrm{a}$ & $\mathrm{b}$ & $\downarrow$ & $\mathrm{a}$ & $\mathrm{b}$ \\
$\begin{array}{l}\text { Velocidade da } \\
\text { propagação da onda } \\
\text { de tensão }\end{array}$ & & & & & & \\
\hline
\end{tabular}

NOTA: (1) Tendência de acréscimo $(\uparrow)$, decréscimo $(\downarrow)$ ou sem tendência $(\leftrightarrow)$ na propriedade quando se aumenta a temperatura ou a pressão de tratamento. Letras iguais indicam ausência de diferença significativa.

Analisando os quatro tratamentos estudados no presente trabalho tem-se que o uso da maior pressão $(75 \%)$ combinado com $180^{\circ} \mathrm{C}$ é mais vantajoso, principalmente para as propriedades mecânicas, enquanto que a temperatura de $200^{\circ} \mathrm{C}$ e a pressão de $50 \%$ é melhor para a estabilidade dimensional.

Sendo assim, para a escolha do melhor tratamento deve-se levar em consideração o uso final do produto e suas principais exigências. No caso cuja finalidade seja resistência mecânica e maior densidade, o T3 tem maior preferência. Por outro lado, se a finalidade for a estabilidade dimensional, deve-se optar pelo uso do T2. 


\section{CONCLUSÕES}

A partir dos resultados apresentados neste trabalho, foi possível concluir que o tratamento termomecânico melhora algumas propriedades da madeira, destacando:

- A madeira se tornou mais densa, mais compacta e com menor teor de umidade de equilíbrio. Mesmo a compressão ocorrendo unilateralmente em decorrência da liberação das tensões de compressão, o inchamento em espessura, absorção de água, taxa de não retorno em espessura e taxa de retração foram maiores para o material tratado. Assim, o material submetido a menor pressão torna-se uma alternativa para usos externos por se mais resistente e mais denso que a madeira natural e ter a mesma estabilidade dimensional;

- Em relação às propriedades superficiais também houve uma melhora na aparência do material, pois a madeira reduziu sua molhabilidade e a superfície se tornou mais lisa e o efeito da temperatura foi satisfatório na alteração da cor do material, tornando-o visualmente mais competitivo no mercado de piso.

- O tratamento mecânico conseguiu amenizar os efeitos da temperatura na perda das propriedades mecânicas. Assim, as propriedades mecânicas melhoraram significativamente para todos os tratamentos, mas foi maior para os tratamentos com maior pressão.

- Dessa forma, a madeira se torna uma alternativa para o mercado de piso, sendo os tratamentos $2\left(180^{\circ} \mathrm{C}\right.$ e $\left.75 \%\right)$ e $3\left(200^{\circ} \mathrm{C}\right.$ e $\left.50 \%\right)$ os mais indicados. A combinação da maior temperatura e menor pressão $\left(200^{\circ} \mathrm{C}\right.$ e $\left.50 \%\right)$ se mostrou mais eficaz para uso que requer maior estabilidade dimensional e o uso da maior pressão e menor temperatura $\left(180^{\circ} \mathrm{C}\right.$ e $\left.75 \%\right)$ o mais indicado em demandas de maior resistência mecânica. 


\section{REFERÊNCIAS BIBLIOGRÁFICAS}

ALLEGRETTI, O.; BRUNETTI, M.; CUCCUI, I.; FERRARI, S.; NOCETTI, M.; TERZIEV, N. Thermo-Vaccuum modification of Spruce (Picea abies Karst,) and Fir (Abies alba Mill) wood. BioResources 7(3), 3656-3668, 2012.

ANDRADE A. de. A certificação como estratégia para a melhoria da qualidade de pisos de madeira. 2014. 128p. Tese (Doutorado em Ciências). Universidade de São Paulo Escola Superior de Agricultura "Luiz de Queiroz", Piracicaba. 128p. 2014.

AMERICAN SOCIETY FOR TESTING MATERIALS. ASTM D2395: Standard Test Methods for Specify Gravity for Wood and Wood-Based Materials. Pennsylvania, EUA, 2007.

AMERICAN SOCIETY FOR TESTING MATERIALS. ASTM D143-94 (reapproved 2005) Standard Test Methods for Small Clear Specimens of Timber. Annual Book of ASTM Standards vol. 4.10. 1994. 31p.

ASSOCIAÇÃO NACIONAL DOS PRODUTORES DE PISOS DE MADEIRA MACIÇA. Apostila do curso básico de madeira. Belém, 2006. 58p.

ASSOCIAÇÃO NACIONAL DOS PRODUTORES DE PISOS DE MADEIRA MACIÇA. Indicação de madeira para piso. Disponível em:<http://www.anpm.org.br/>. Acesso em: 07dez. 2014.

ARNOLD, M. Planing and sanding of Wood surfaces - effects on surface properties and coating performance. In: International Woodcoatings Congress, 7, Amsterdan, 2010. 15p.

ARRUDA, L. M.; GONÇALEZ, J. C; DEL MENEZZI, C. H. S.; MELO, R. R. Estudo preliminar das propriedades de compensados produzidos com lâminas de paricá (schizolobium amazonicum huber ex ducke) modificadas termomecânicamente. Ciência da Madeira, Pelotas, v. 02, n. 01, p. 29-42, 2011.

ARRUDA, L. M. Modificação Termomecânica da Madeira de amescla (Trattinnickia burseraefolia (Mart.) Willd.): Efeito sobre as Propriedades de Lâminas e Compensados. 2012. 108 p. Dissertação (Mestrado Engenharia Florestal) Universidade de Brasília, Brasília. 108 p, 2012.

BARRETO, C. C. K.; PASTORE, T. C. M. Resistência ao intemperismo de quatro madeiras tropicais: o efeito dos extrativos. Ciência Florestal, Santa Maria, v.19, n. 1, p. 23-30, jan./mar. 2009.

BEKHTA, P.; NIEMZ, P.; SEDLIACIK, J. Effect of Pre-Pressing of Veneer on the Glueability and Properties of Veneer-Based Products. European Journal of Wood and Wood Products, v. 70, n. 1-3, p. 99-106, 2012.

BEKHTA, P.; NIEMZ, P. Effect of High Temperature on the Change in Color, Dimensional Stability and Mechanical Properties of Spruce Wood. Holzforschung. v. 57. n. 5, p. 539-546, 2003.

BOONSTRA, M. J.; TJEERDSMA, B. Chemical Analysis of Heat Treated Softwoods. European Journal of Wood and Wood Products, v. 64, n. 3, p. 204-211, 2006.

BORGES, L. M.; QUIRINO, W. F. Higroscopicidade da madeira de Pinus caribaea var. hondurensis tratado termicamente. Revista Biomassa \& Energia, v.1, n.2 p. 173-182, 2004.

BRISOLARI, A. Estudo da molhabilidade em madeiras tropicais ou de reflorestamento por medidas de ângulo de contato e de permeabilidade. 2008. 98p.Dissertação (Mestrado em Ciência e Engenharia de Materiais) Universidade de São Paulo, Instituto de física de São Carlos, São Paulo, 98p. 2008. 
BRITO. J.O.; GARCIA, J.N.; BORTOLETTO JÚNIOR, G.; PESSOA, A.M.C.; DA SILVA, P.H.M. Densidade básica e retratibilidade da madeira de Eucalyptus grandis, submetida a diferentes temperaturas de termorretificação. Revista Cerne, v. 12, n. 2, p. 182-188, 2006.

BUSTOS, C.A.; ESCOBAR, W.G.; CLOUTIER, A.; FANG, C.H.; CARRASCO, P.V. Densification of wood veneers combined with oil-heat treatment. Part III: Cell wall mechanical properties determined by nanoindentation. BioResources 7(2), 1525-1532, 2011.

BYRNE, C.E.; NAGLE, D C. Carbonization of wood for advanced materials applications. Carbon, v.35, n.2, p.259-266, 1997.

CALONEGO, F.W. Efeito da termorretificação nas propriedades físicas, mecânicas e na resistência a fungos deterioradores da madeira de eucalyptus grandis hill ex maiden. 2009 Tese (Doutourado em Agronomia). Universidade Estadual Paulista Júlio de Mesquita Filho. Botucatu, 2009.

CAMARGOS, J. A. A.; GONÇALEZ J. C. A colorimetria aplicada como instrumento na elaboração de uma tabela de cores de madeira. Brasil Florestal, n 71, 2001.

CAMARGOS, J. A. A. Colorimetria quantitativa aplicada na elaboração de um catálogo de cores de madeiras tropicais. 1999. 75 p. Dissertação (Mestrado em Ciências Florestais). Universidade de Brasília, Brasília. 75p. 1999.

CAVALCANTE, L.C. Avaliação de novas espécies madeireiras na fabricação do cajón. 35p. 2006.Monografia (Graduação em Engenharia Florestal), Universidade de Brasília, Brasília. 35 p. 2006.

CHARRIER, B.; CHARRIER, F.; JANIN, G.; KAMDEM, D. P.; IRMOULI, M.; GONÇALEZ, J. C. Study of Industrial Boiling Process on Walnut Colour: Experimental Study under Industrial Conditions. European Journal of Wood Products, Heidelberg, v. 60, n. 4, p. 259-264, 2002.

CLOUTIER, A.; FANG, C.; MARIOTTI, N. Densification of Wood Veneers Under the Effect of Heat, Steam and Pressure. In: International Convention of Society of Wood Science and Technology, 51. 2008, Conception, Chile. Proceedings...Conception: Universidad del Bío-Bío, 2008.

COWIE, J.M.G. Polymers:Chemistry and Physics of Moderns Materials. Blackie Academic \& Professional, London (1991).

CRUZ, M.L.R.; FINGER, Z.; LOGSDON, N.B. Marupá : Descricao dendriologica e caracterização física. In: ENCONTRO BRASILEIRO EM MADEIRAS E EM ESTRUTURAS DE MADEIRA (X EBRAMEM), 2006, São Paulo. Anais ...São Paulo, 2006

DEL MENEZZI, C. H. S.; AMORIM, M.R.S.; COSTA, M.A.; GARCEZ, L.R.O. Evaluation of thermally modified wood by means of stress wave and ultrasound nondestructive methods. Materials Science, Medžiagotyra, v. 20, n. 1, 2014.

DEL MENEZZI, C.H.S; TOMASELLI, I.; SOUZA, M.R.; Avaliação não-destrutiva de painéis OSB modificados termicamente: parte 1- efeito do tratamento térmico sobre a velocidade de propagação de ondas de tensão. Scientia Florestalis, Piracicaba, n. 76, p. 67-75, dez. 2007

DEL MENEZZI, C. H. S.; TOMASELLI, I. Contact Thermal Post-Treatment of Oriented Strandboard to Improve Dimensional Stability: A preliminary Study. Holz als Roh-und Werkstoff, v. 64, n.3, p. 212-217, 2006.

DEL MENEZZI, C.H.S. Estabilização dimensional por meio do tratamento térmico e seus efeitos sobre as propriedades de painéis de partículas orientadas (OSB). 2004. 226p. Tese (Doutorado em Engenharia Florestal) Universidade Federal do Paraná, Curitiba, 2004.

DIROL, D.; GUYONNET, R. Durability by rectification process. In: International Research Group Wood Pre, Section 4-Processes, № IRG/WP 93-40015, 1993. 
ESTEVES, B. M.; DOMINGOS, I. J.; PEREIRA, H. M. Pine Wood Modification by Heat Treatment in Air. BioResources, v. 3, n. 1, p. 142-154, 2008.

ESTEVES, B. M.; PEREIRA, H. M. Wood Modification by Heat Treatment: A Review. BioResources, v. 4, n. 1, p. 370-404, 2009.

FRANKE, I.L. Principais usos e serviços de árvores e arbustos promissores que ocorrem em pastagens no Estado do Acre. Embrapa, Comunicado Técnico, 1999, 106: 1-6.

GARDNER, A.M. AVIEL, S. ARGON, Y. Rapid degradation of an unassembled immunoglobulin light chain is mediated by a serine protease and occurs in pre-Golgi compartment. J. Biol. Chem, 268, p. 25940-25947. 1993.

GOUVEIA, F. N. Aplicação de tratamentos térmicos para estabilização colorimétrica de madeiras tropicais. 2008, 131p.Tese (Doutorado em Ciências Florestais), Departamento de Engenharia Florestal, Universidade de Brasília,Brasília, 131p, 2008.

GRZESKIEWICZ, M.; BORYSIUK, P.; JASKÓLOWSKI, W. Physical and Mechanical Properties and Burning Behavior of Beech Plywood Made of Thermally Modified Veneers. In: International Panel Products Symposium. 2009, Nantes, France. Proceedings... 2009. p.1-36.

HAKKOU, M.; PÉTRISSANS, M.; ZOULALIAN, A.; GÉRARDIN, P. Investigation of Wood Wettabilitiy Changes During Heat Treatment on the Basis of Chemical Analysis. Polymer Degradation and Stability, v. 89, n. 1, p. 1-5, 2005.

HEGER, F.; GROUX, M.; GIRARDET, F.; WELZBACHER, C. R.; RAPP, A. O.; NAVI, P. Mechanical and Durability Performance of THM Densified Wood In: Workshop COST Action E22 „Environmental Optimisation of Wood Protection. 2004, Lisboa, Portugal. Proceedings... 2004. p. 1-10.

INOUE, M.; NORIMOTO, M.; TANAHASHI, M.; ROWELL, R.M. Steam or Heat Fixation of Compressed Wood. Wood and Fiber Science, v. 25, n. 3, p. 224-235, 1993.

JANKOWSKY, I. P. Fundamentos da Secagem de Madeiras. Documentos Florestais, Piracicaba, SP, 1990. p.1-13.

JONES, D.; HILL, C. A. S. Wood modification - a brief overview of the technology. In: International Workshop on Bonding of Modified Wood, 5., 2007, Slovenia. Anais... Slovenia: Bled, 2007.

KAMKE, F. A.; SIZEMORE, H. Viscoelastic thermal compression of wood. USA Patent $n$. 7404422, 2005

KOLLMANN, F. P.; KUENZI, E. W.; STAMM, A. J. Principles of Wood Science and Technology: Part II - Wood Based Materials. New York: Springer-Verlag Berlin, 1975.

KULTIKOVA, E. Structure and Properties Relationships of Densified Wood. 1999. 133 f. Master Thesis (Master of Science in Wood Science and Forest Products) - Faculty of the Virginia Polytechnic Institute and State University, Virginia Tech, Blacksburg, Virginia, 1999.

KUTNAR, A.; KAMKE, F. A. Compression of Wood Under Saturated Steam, Superheated Steam, and Transient Conditions at $150^{\circ} \mathrm{C}, 160^{\circ} \mathrm{C}$ and $170{ }^{\circ} \mathrm{C}$. Wood Science and Technology, v. 46, n. 1-3, p. 73-88, 2012.

KUTNAR, A.; KAMKE, F. A.; SERNEK, M. Density Profile and Morphology of Viscoelastic Thermal Compressed Wood. Wood Science and Technology, v. 43, n. 1-2, p. 57-68, 2009.

KUTNAR, A.; SERNEK, M. Densification of Wood. Zbornik gozdarstva in lesarstva, v. 82, p. 5362, 2007 
LONGWOOD, F.R. Present and potential commercial timbers of the Caribbean: with special reference to the West Indies, the Guianas, and British Honduras. Washington, D.C.: United States Department of Agriculture, 1962. 167 p. (USDA. Agriculture Handbook, 207).

LOPES, J.O.; GARCIA, R.A.; LATORRAA, J.V.F. NASCIMENTO, A.M. Alteração da Cor da Madeira de Teca por Tratamento Térmico. Floresta e Ambiente, v.21, n.4, 2014.

LOPES, M.D.M. Resistência à abrasão de onze espécies florestais. 2012. 48p. Monografia (Graduação em Engenharia Florestal), Universidade de Brasília, Brasília 48p, 2012.

LOUREIRO, A.A.; SILVA, M.F. da; ALENCAR, J. da C. Essências madeireiras da Amazônia. Manaus: INPA, v. 1. 315p. 1977.

MODES, K. S. Efeito da retificação térmica nas propriedades físico- mecânicas e biológica das madeiras de Pinus taeda e Eucalyptus grandis. 2010. 99p. Dissertação (Mestrado em Engenharia Florestal) - Universidade Federal de Santa Maria, Centro de Ciências Rurais, Programa de Pós-Graduação em Engenharia Florestal. 99p, 2010.

MENDES, R.F., Efeito do tratamento térmico sobre as propriedades de painéis OBS. 2010. 115p Dissertação (Mestrado em Ciências), Universidade de São Paulo, Escola Superior Luiz de Quiroz. Piracicaba, 115p 2010.

MONGABAY.The Amazon: The World's Largest Rainforest. Available on: <http://rainforests.mongabay.com/amazon/>. Accessed on: 20 sep. 2013.

NAVI, P., GIRARDET, F. Effect of thermo-hydro-mechanical treatment on the structure and properties of wood. Holzforschung. v. 54. n. .3, p.287-293. 2000

NARAYANAMURTI, D.; KAUL, R.K. Heat Stabilized Compressed Wood from Indian Hardwoods and Factors Affecting Improvement in Properties. Holz als Roh-und Werkstoff, v. 24, n. 11, p. 556-559, 1966.

NCUBE, E. Use of a simple abrasive-wear resistance test device to assess the suitability of selected hardwoods for wood flooring. Department of Forest and Wood Science, University of Stellenbosch, Private Bag X1, Matieland 7602, South Africa. Scientific Research and Essay v.3 (5), p. 168-173, May, 2008

OLIVEIRA, R. M.; Utilização de técnicas de caracterização de superfícies em madeiras tratadas termicamente. Tese (Doutorado em Ciências), Instituto de Física, Universidade de São Paulo, 123p, 2009.

PAULA, J.E.; ALVES, J.L.H. 897 madeiras nativas do Brasil: anatomia - dendrologia dendrometria - produção - uso. Porto Alegre: Cinco Continentes, 2007. 438p.

PESSOA, A.M.C.;FILHO, E.B.; BRITO, J. O. Avaliação da madeira termorretificada de Eucalyptus grandis submetida ao ataque de cupim de madeira seca Cryptotermes brevis. Scientis Florestalis, v. 1, n. 72, p. 11-16, 2006.

PIAO, C.; WINANDY, J. E.; SHUPE, T. F. From Hidrophilicity to Hydrophobicity: A Critical Review: Part 1. Wettability and Surface Behavior. Wood and Fiber Science, v. 42, n. 4, p. 490-510, 2010.

PINCELLI, A.L.P.S.M.; MOURA, L.F.de.; BRITO, J.O. Effect of thermal rectification on colors of eucalyptus saligna and Pinus caribaea Woods. Maderas. Ciencia y tecnología, v.14 n.2, 2012

PINTO, A.M.; RIBEIRO, R.J.; ALENCAR, J.C.; BARBOSA, A.P.. Fenologia de Simarouba amara Aubl. na Reserva Florestal Adolpho Ducke, Manaus, AM. Acta Amazonica, 2005, 35: 347 - 352.

REMADE - Revista da Madeira, Ed. N ${ }^{\circ} 100$ - novembro de 2006. Disponível em > http://www.remade.com.br/br/revistadamadeira materia.php?num=977\&subject=E\%20mais\&title= 
Associa\%E7\%E30\%20Nacional\%20dos\%20Produtores\%20de\%20Pisos\%20de\%20Madeira\%20\%20ANPM.> Acesso em 21 de dezembro de 2014.

ROUSSET, P. Choix et validation experimentale d'un modele de pyrolyse pour le bois traite par haute temperature: de la micro-particule au bois massif. Tese (Spécialité : Sciences forestières et du bois), École Nationale du Génie Rural des Eaux et des Forêts, 203 p. 2004.

SANTANA, M.A.E.; OKINO, E.Y.A. Chemical composition of 36 Brazilian Amazon forest wood species. Holzforschung, Berlin. v. 61, p. 469- 477. 2007

SANTOS, C.M.T. Efeito do tratamento termomecânico sobre as propriedades da madeira de pinus caribae var. Hondurensis. Dissertação (Mestrado em Ciências Florestais). Departamento de Engenharia Florestal, Universidade de Brasília, Brasília,114p, 2011.

SCHILLING, A.C.; SCHNEIDER, P. R.; HASELEIN, C. R.; FINGER, C. A. G. Influência de diferentes intensidades de desrama sobre a porcentagem de lenho tardio e quantidade de nós da madeira de primeiro esbaste de Pinus elliottii Engelman. Ciência Florestal, Santa Maria, v.8, n.1, p.115-127, 1998.

SILVA, M.R. da. Efeito do tratamento térmico nas propriedades químicas, físicas e mecânicas em elementos estruturais de Eucalipto citriodora e Pinus taeda. Tese (Doutorado Ciências e Engenharia de Materiais), Universidade de São Carlos, 223p, 2012.

SILVA, M.R. da; MACHADO, G. de, O.; JUNIOR, C.C. Efeito do tratamento térmico nas propriedades mecânicas de Pinus elliotti. In: ENCONTRO BRASILEIRO EM MADEIRA, 11., 2008, Londrina. Anais...Londrina: UEL - EBRAMEN, 2008.

SILVA, F.D.; BITTENCOURT, R.M. Estudo do desgaste à abrasão do eucalipto, madeira laminada e bambu gigante laminado utilizados como elemento de piso. In. ENCONTRO BRASILEIRO EM MADEIRAS E EM ESTRUTURAS DE MADEIRAS, 8., 2002, Uberlândia. Anais... Uberlândia: UFU.2002.

SILVA, A.B.; SOUZA, J. Madeiras amazônicas para uso adequado em assoalho. In: CONGRESSO BRAILEIRO EM MADEIRA E ESTRUTURA DE MADEIRA, 4., 1992, São Carlos, SP. Anais... São Carlos: LAMEM-EESCUSP, 1992. v.3, p.167-178.

SLOOTEN, H.J. van der; SOUZA, M.R. de. Avaliação das espécies madeireiras da Amazônia selecionadas para a manufatura de instrumentos musicais. Manaus: INPA, 1993. 123 p.

SOUZA, M.H.; MAGLIANO, M.M.; CAMARGOS, J.A.A, SOUZA, M.R. Madeiras tropicais brasileiras. Brasília: IBAMA-LPF, 1997. 152p.

STAMM, A.J. Wood and cellulose science. New York: Ronald Press, 1964. 549p.

STANGERLIN, D.M. Monitoramento de propriedades de madeiras da Amazônia submetidas ao ataque de fugos apodrecedores. 2012. 259p. Tese (Doutorado em Ciências Florestais) Universidade de Brasília, Brasília, 2012

SUNDQVIST, B. Color Changes and Acid Formation in Wood During Heating. 2004. 154 f. Thesis (Doctoral) - Division of Wood Material Science, Lulea University of Technology, Skellefta, Sweden, 2004.

UNSAL, O.; KARTAL, Z.; CANDAN, Z.; ARANGO, R.; CLAUSEN, C.A. Green decay and térmite resistance, water absorption and swelling of thermally compressed wood panels. Inter. Biodeter. Biodegr., v. 63, p. 548-552, 2009

ULKER, O.; IMIRZI, O.; BURDURLU, E. The effect of densification temperature on some physical and mechanical properties of scots pine (Pinus sylvestris L.). BioResources 7(4), 5581-5592, 2012 
VASCONCELOS, R.G. Efeito do tratamento termomecânico sobre propriedades da madeira do Gênero Pinus sp. Monografia (Graduação em Engenharia Florestal), Universidade de Brasília, Brasília 69p, 2012.

VAZ, S.S. Resistência biológica de painéis compensados de trattinnickia burseraefolia (mart.) willd. produzidos com lâminas modificadas termomecanicamente. Monografia (Graduação em Engenharia Florestal), Universidade de Brasília, Brasília, 23p, 2013.

VITAL, B.R.; ANDRADE, P.I.L.; CARNEIRO, A. de, C.O.C.; CABRAL, C.P.T.; CARVALHO, A.M.M. Estabilidade dimensional e resistência à tração perpendicular de painéis fabricados com partículas termorretificadas oriundas de embalagens de Pinus sp. Revista Árvore, vol.38, n.5., Viçosa, 2014.

WANG, J. Initiating evaluation of thermal-oil treatment for post-MPE pine. Forintek Canada Corp., Vancouver, BC, Canada, 2007.

WEILAND, J.J.; GUYONNET, R. Study of chemical modifications and fungi degradation of thermally modified wood using DRIFT spectroscopy. Holz als Roh-Werkstoff, v. 61, n. 2, p. 216220. 2003

WELZBACHER, C. R.; WEHSENER, J.; RAPP, A. O.; HALLER, P. Thermo-Mechanical Densification Combined with Thermal Modification of Norway spruce (Picea abies Karst) in Industrial Scale - Dimensional Stability and Durability Aspects. Holz als Roh-und Werkstoff, v. 66, p. 39-49, 2007.

WELZBACHER, C. R.; RAPP, O. Study of chemical modification and fungi degradation of thermally modified wood using DRIFT spectroscopy. Holz Roh-Werkst, 61, 216-220, 2002.

ZANGIÁCOMO, A.L.; LAHR, F.A.R. Emprego de espécies tropicais alternativas na produção de elementos estruturais de madeira laminada colada. Cadernos de Engenharia de Estruturas, São Carlos, v. 9, n. 40, p. 103-131, 2007.

ZANUNCIO, A.J. V; FARIAS E. DE S. F.; SILVEIRA, T. A. Termorretificação e colorimetria da madeira de Eucalyptus grandis. Floresta e Ambiente, vol 21, n.1, 2014. 
APÊNDICE I - ESTATÍSTICA DESCRITIVA E ANÁLISES DE VARIÂNCIA PARA AS PROPRIEDADES AVALIADAS 


\section{A - Estatística Descritiva para as propriedades avaliadas nos}

\section{tratamentos}

Tabela A 1 - Estatística descritiva das propriedades físicas dos tratamentos analisados.

\begin{tabular}{|c|c|c|c|c|}
\hline Variável & Tratamento & Média & Desvio Padrão & Repetições \\
\hline \multirow{5}{*}{ PM } & Testemunha & - & - & - \\
\hline & $\mathrm{T} 1\left(180^{\circ} \mathrm{C} 50 \%\right)$ & 5,4946 & 0,60643 & 6 \\
\hline & $\mathrm{T} 2\left(180^{\circ} \mathrm{C} 75 \%\right)$ & 7,9768 & 0,51002 & 6 \\
\hline & T3 $\left(200^{\circ} \mathrm{C} 50 \%\right)$ & 8,2663 & 0,51002 & 6 \\
\hline & $\mathrm{T} 4\left(200^{\circ} \mathrm{C} 75 \%\right)$ & 9,8113 & 0,33051 & 6 \\
\hline \multirow{5}{*}{ PMDAT } & Testemunha & - & - & - \\
\hline & $\mathrm{T} 1\left(180^{\circ} \mathrm{C} 50 \%\right)$ & 1,4316 & 0,60643 & 6 \\
\hline & $\mathrm{T} 2\left(180^{\circ} \mathrm{C} 75 \%\right)$ & 2,9385 & 0,51002 & 6 \\
\hline & T3 $\left(200^{\circ} \mathrm{C} 50 \%\right)$ & 3,1726 & 0,51002 & 6 \\
\hline & $\mathrm{T} 4\left(200^{\circ} \mathrm{C} 75 \%\right)$ & 4,2515 & 0,33051 & 6 \\
\hline \multirow{5}{*}{ TD } & Testemunha & - & - & - \\
\hline & $\mathrm{T} 1\left(180^{\circ} \mathrm{C} 50 \%\right)$ & 3,8036 & 2,21545 & 6 \\
\hline & $\mathrm{T} 2\left(180^{\circ} \mathrm{C} 75 \%\right)$ & 48,6309 & 6,47669 & 6 \\
\hline & T3 $\left(200^{\circ} \mathrm{C} 50 \%\right)$ & 12,0172 & 5,23581 & 6 \\
\hline & $\mathrm{T} 4\left(200^{\circ} \mathrm{C} 75 \%\right)$ & 44,1456 & 11,41950 & 6 \\
\hline \multirow{5}{*}{ TC } & Testemunha & - & - & - \\
\hline & $\mathrm{T} 1\left(180^{\circ} \mathrm{C} 50 \%\right)$ & 8,8217 & 4,03870 & 6 \\
\hline & $\mathrm{T} 2\left(180^{\circ} \mathrm{C} 75 \%\right)$ & 37,9872 & 2,74593 & 6 \\
\hline & T3 $\left(200^{\circ} \mathrm{C} 50 \%\right)$ & 17,9567 & 3,88058 & 6 \\
\hline & $\mathrm{T} 4\left(200^{\circ} \mathrm{C} 75 \%\right)$ & 37,0770 & 5,38964 & 6 \\
\hline \multirow{5}{*}{$\rho f$} & Testemunha & 0,4419 & 0,17120 & 6 \\
\hline & $\mathrm{T} 1\left(180^{\circ} \mathrm{C} 50 \%\right)$ & 0,4498 & 0,00952 & 6 \\
\hline & $\mathrm{T} 2\left(180^{\circ} \mathrm{C} 75 \%\right)$ & 0,6454 & 0,02772 & 6 \\
\hline & $\mathrm{T} 3\left(200^{\circ} \mathrm{C} 50 \%\right)$ & 0,4913 & 0,02990 & 6 \\
\hline & $\mathrm{T} 4\left(200^{\circ} \mathrm{C} 75 \%\right)$ & 0,6235 & 0,42610 & 6 \\
\hline \multirow{5}{*}{ TUE } & Testemunha & 10,4631 & 0,12087 & 6 \\
\hline & $\mathrm{T} 1\left(180^{\circ} \mathrm{C} 50 \%\right)$ & 9,4018 & 0,04669 & 6 \\
\hline & $\mathrm{T} 2\left(180^{\circ} \mathrm{C} 75 \%\right)$ & 8,5891 & 0,38176 & 6 \\
\hline & T3 $\left(200^{\circ} \mathrm{C} 50 \%\right)$ & 9,2227 & 0,90369 & 6 \\
\hline & $\mathrm{T} 4\left(200^{\circ} \mathrm{C} 75 \%\right)$ & 9,0403 & 1,11495 & 6 \\
\hline \multirow{5}{*}{ IE2H } & Testemunha & 1,1757 & 0,61834 & 6 \\
\hline & $\mathrm{T} 1\left(180^{\circ} \mathrm{C} 50 \%\right)$ & 2,3376 & 0,88537 & 6 \\
\hline & T2 (180 $\mathrm{C} 75 \%)$ & 21,7974 & 6,38493 & 6 \\
\hline & T3 $\left(200^{\circ} \mathrm{C} 50 \%\right)$ & 2,3817 & 2,08989 & 6 \\
\hline & $\mathrm{T} 4\left(200^{\circ} \mathrm{C} 75 \%\right)$ & 3,9128 & 1,60912 & 6 \\
\hline
\end{tabular}

Tabela A 1 - Estatística descritiva das propriedades físicas dos tratamentos analisados. 


\begin{tabular}{|c|c|c|c|c|}
\hline Variável & Tratamento & Média & Desvio Padrão & Repetições \\
\hline \multirow{5}{*}{ IE24H } & Testemunha & 1,8118 & 0,82418 & 6 \\
\hline & $\mathrm{T} 1\left(180^{\circ} \mathrm{C} 50 \%\right)$ & 5,8594 & 1,59132 & 6 \\
\hline & $\mathrm{T} 2\left(180^{\circ} \mathrm{C} 75 \%\right)$ & 35,5892 & 4,17703 & 6 \\
\hline & T3 $\left(200^{\circ} \mathrm{C} 50 \%\right)$ & 6,3982 & 2,53610 & 6 \\
\hline & $\mathrm{T} 4\left(200^{\circ} \mathrm{C} 75 \%\right)$ & 21,8038 & 6,77376 & 6 \\
\hline \multirow{5}{*}{$\mathrm{AB} 2 \mathrm{H}$} & Testemunha & 16,6325 & 1,23921 & 6 \\
\hline & $\mathrm{T} 1\left(180^{\circ} \mathrm{C} 50 \%\right)$ & 16,3785 & 1,55026 & 6 \\
\hline & $\mathrm{T} 2\left(180^{\circ} \mathrm{C} 75 \%\right)$ & 30,1707 & 12,49070 & 6 \\
\hline & T3 $\left(200^{\circ} \mathrm{C} 50 \%\right)$ & 15,7169 & 2,31265 & 6 \\
\hline & $\mathrm{T} 4\left(200^{\circ} \mathrm{C} 75 \%\right)$ & 14,1112 & 1,43805 & 6 \\
\hline \multirow{5}{*}{$\mathrm{AB} 24 \mathrm{H}$} & Testemunha & 47,7863 & 3,27287 & 6 \\
\hline & $\mathrm{T} 1\left(180^{\circ} \mathrm{C} 50 \%\right)$ & 52,4430 & 2,24478 & 6 \\
\hline & T2 $\left(180^{\circ} \mathrm{C} 75 \%\right)$ & 71,8730 & 2,25546 & 6 \\
\hline & T3 $\left(200^{\circ} \mathrm{C} 50 \%\right)$ & 53,4059 & 4,17688 & 6 \\
\hline & $\mathrm{T} 4\left(200^{\circ} \mathrm{C} 75 \%\right)$ & 55,7397 & 11,46718 & 6 \\
\hline \multirow{5}{*}{ TR } & Testemunha & 2,6592 & 0,63118 & 6 \\
\hline & $\mathrm{T} 1\left(180^{\circ} \mathrm{C} 50 \%\right)$ & 2,7521 & 0,10590 & 6 \\
\hline & $\mathrm{T} 2\left(180^{\circ} \mathrm{C} 75 \%\right)$ & 7,6360 & 1,11047 & 6 \\
\hline & T3 $\left(200^{\circ} \mathrm{C} 50 \%\right)$ & 4,1105 & 0,21911 & 6 \\
\hline & $\mathrm{T} 4\left(200^{\circ} \mathrm{C} 75 \%\right)$ & 7,1033 & 1,50270 & 6 \\
\hline \multirow{5}{*}{ TNRE } & Testemunha & $-0,8998$ & 0,28110 & 6 \\
\hline & $\mathrm{T} 1\left(180^{\circ} \mathrm{C} 50 \%\right)$ & 2,8349 & 1,58121 & 6 \\
\hline & $\mathrm{T} 2\left(180^{\circ} \mathrm{C} 75 \%\right)$ & 24,1861 & 0,99220 & 6 \\
\hline & T3 $\left(200^{\circ} \mathrm{C} 50 \%\right)$ & 2,0268 & 2,55350 & 6 \\
\hline & $\mathrm{T} 4\left(200^{\circ} \mathrm{C} 75 \%\right)$ & 13,1218 & 5,85639 & 6 \\
\hline
\end{tabular}


Tabela A 2 - Estatística descritiva das propriedades da superfície dos tratamentos analisados

\begin{tabular}{|c|c|c|c|c|}
\hline Variável & Tratamento & Média & Desvio Padrão & Repetições \\
\hline \multirow{5}{*}{ Ângulo de Contato } & Testemunha & 18,7238 & 3,14436 & 6 \\
\hline & $\mathrm{T} 1\left(180^{\circ} \mathrm{C} 50 \%\right)$ & 91,1190 & 10,90256 & 6 \\
\hline & T2 $\left(180^{\circ} \mathrm{C} 75 \%\right)$ & 111,4861 & 15,81167 & 6 \\
\hline & T3 $\left(200^{\circ} \mathrm{C} 50 \%\right)$ & 89,9311 & 11,84425 & 6 \\
\hline & $\mathrm{T} 4\left(200^{\circ} \mathrm{C} 75 \%\right)$ & 108,4467 & 21,16890 & 6 \\
\hline \multirow{5}{*}{ Taxa de Desgaste } & Testemunha & 37,2222 & 13,52638 & 6 \\
\hline & $\mathrm{T} 1\left(180^{\circ} \mathrm{C} 50 \%\right)$ & 47,7778 & 12,89559 & 6 \\
\hline & $\mathrm{T} 2\left(180^{\circ} \mathrm{C} 75 \%\right)$ & 49,4444 & 8,98559 & 6 \\
\hline & T3 $\left(200^{\circ} \mathrm{C} 50 \%\right)$ & 63,8889 & 22,74659 & 6 \\
\hline & $\mathrm{T} 4\left(200^{\circ} \mathrm{C} 75 \%\right)$ & 40,5556 & 23,37298 & 6 \\
\hline \multirow{5}{*}{ PMdaA } & Testemunha & 0,6224 & 0,22375 & 6 \\
\hline & $\mathrm{T} 1\left(180^{\circ} \mathrm{C} 50 \%\right)$ & 0,7241 & 0,17910 & 6 \\
\hline & T2 $\left(180^{\circ} \mathrm{C} 75 \%\right)$ & 0,5335 & 0,09504 & 6 \\
\hline & T3 $\left(200^{\circ} \mathrm{C} 50 \%\right)$ & 0,9047 & 0,48224 & 6 \\
\hline & $\mathrm{T} 4\left(200^{\circ} \mathrm{C} 75 \%\right)$ & 0,4468 & 0,30269 & 6 \\
\hline \multirow{5}{*}{$L^{*}$} & Testemunha & 85,0697 & 1,24940 & 6 \\
\hline & $\mathrm{T} 1\left(180^{\circ} \mathrm{C} 50 \%\right)$ & 66,5260 & 4,02209 & 6 \\
\hline & T2 $\left(180^{\circ} \mathrm{C} 75 \%\right)$ & 59,4182 & 7,23794 & 6 \\
\hline & T3 $\left(200^{\circ} \mathrm{C} 50 \%\right)$ & 47,7352 & 2,30515 & 6 \\
\hline & $\mathrm{T} 4\left(200^{\circ} \mathrm{C} 75 \%\right)$ & 40,1315 & 6,96793 & 6 \\
\hline \multirow{5}{*}{$a^{*}$} & Testemunha & 1,9717 & 0,23870 & 6 \\
\hline & $\mathrm{T} 1\left(180^{\circ} \mathrm{C} 50 \%\right)$ & 8,4173 & 0,81229 & 6 \\
\hline & T2 $\left(180^{\circ} \mathrm{C} 75 \%\right)$ & 10,1728 & 1,24471 & 6 \\
\hline & T3 $\left(200^{\circ} \mathrm{C} 50 \%\right)$ & 11,1392 & 0,39856 & 6 \\
\hline & $\mathrm{T} 4\left(200^{\circ} \mathrm{C} 75 \%\right)$ & 9,7005 & 1,81246 & 6 \\
\hline \multirow{5}{*}{$b^{*}$} & Testemunha & 20,5767 & 2,11449 & 6 \\
\hline & $\mathrm{T} 1\left(180^{\circ} \mathrm{C} 50 \%\right)$ & 25,4277 & 0,54594 & 6 \\
\hline & $\mathrm{T} 2\left(180^{\circ} \mathrm{C} 75 \%\right)$ & 26,1991 & 1,31990 & 6 \\
\hline & T3 $\left(200^{\circ} \mathrm{C} 50 \%\right)$ & 22,1763 & 1,08997 & 6 \\
\hline & $\mathrm{T} 4\left(200^{\circ} \mathrm{C} 75 \%\right)$ & 16,2138 & 5,53591 & 6 \\
\hline \multirow{5}{*}{$\mathrm{C}^{*}$} & Testemunha & 20,5082 & 1,79154 & 6 \\
\hline & $\mathrm{T} 1\left(180^{\circ} \mathrm{C} 50 \%\right)$ & 26,7947 & 0,67023 & 6 \\
\hline & T2 $\left(180^{\circ} \mathrm{C} 75 \%\right)$ & 28,1463 & 1,08156 & 6 \\
\hline & T3 $\left(200^{\circ} \mathrm{C} 50 \%\right)$ & 24,8185 & 1,10420 & 6 \\
\hline & $\mathrm{T} 4\left(200^{\circ} \mathrm{C} 75 \%\right)$ & 18,9015 & 5,66951 & 6 \\
\hline \multirow{5}{*}{$h^{*}$} & Testemunha & 84,6965 & 0,58054 & 6 \\
\hline & $\mathrm{T} 1\left(180^{\circ} \mathrm{C} 50 \%\right)$ & 71,7057 & 1,53229 & 6 \\
\hline & T2 $\left(180^{\circ} \mathrm{C} 75 \%\right)$ & 68,7970 & 2,85538 & 6 \\
\hline & T3 $\left(200^{\circ} \mathrm{C} 50 \%\right)$ & 63,3103 & 0,83188 & 6 \\
\hline & $\mathrm{T} 4\left(200^{\circ} \mathrm{C} 75 \%\right)$ & 58,4449 & 4,63593 & 6 \\
\hline
\end{tabular}


Tabela A 3 - Estatística descritiva das propriedades mecânicas dos tratamentos analisados

\begin{tabular}{|c|c|c|c|c|}
\hline Propriedades & Tratamento & Média & Desvio Padrão & Repetições \\
\hline \multirow{5}{*}{$f_{H, 90^{\circ}}$} & Testemunha & 2511,135 & 216,59838 & 6 \\
\hline & $\mathrm{T} 1\left(180^{\circ} \mathrm{C} 50 \%\right)$ & 2967,8167 & 493,62064 & 6 \\
\hline & $\mathrm{T} 2\left(180^{\circ} \mathrm{C} 75 \%\right)$ & 5005,2967 & 985,41232 & 6 \\
\hline & T3 $\left(200^{\circ} \mathrm{C} 50 \%\right)$ & 3361,505 & 577,94734 & 6 \\
\hline & $\mathrm{T} 4\left(200^{\circ} \mathrm{C} 75 \%\right)$ & 4475,0067 & 545,38197 & 6 \\
\hline \multirow{5}{*}{$f_{c, 0^{\circ}}$} & Testemunha & 39,1879 & 2,2316 & 6 \\
\hline & $\mathrm{T} 1\left(180^{\circ} \mathrm{C} 50 \%\right)$ & 42,4586 & 2,52076 & 6 \\
\hline & $\mathrm{T} 2\left(180^{\circ} \mathrm{C} 75 \%\right)$ & 57,1534 & 7,9336 & 6 \\
\hline & T3 $\left(200^{\circ} \mathrm{C} 50 \%\right)$ & 50,6238 & 4,10616 & 6 \\
\hline & $\mathrm{T} 4\left(200^{\circ} \mathrm{C} 75 \%\right)$ & 53,5164 & 5,73478 & 6 \\
\hline \multirow{5}{*}{$\begin{array}{l}f_{m} \text { lado não } \\
\text { densificado }\end{array}$} & Testemunha & 72,174 & 4,96394 & 12 \\
\hline & $\mathrm{T} 1\left(180^{\circ} \mathrm{C} 50 \%\right)$ & 78,0627 & 11,95421 & 12 \\
\hline & T2 $\left(180^{\circ} \mathrm{C} 75 \%\right)$ & 97,4083 & 8,22894 & 12 \\
\hline & T3 $\left(200^{\circ} \mathrm{C} 50 \%\right)$ & 88,7238 & 10,32402 & 12 \\
\hline & $\mathrm{T} 4\left(200^{\circ} \mathrm{C} 75 \%\right)$ & 90,3233 & 4,96394 & 12 \\
\hline \multirow{5}{*}{$\begin{array}{c}f_{m} \text { lado } \\
\text { densificado }\end{array}$} & Testemunha & 72,1355 & 6,87274 & 12 \\
\hline & $\mathrm{T} 1\left(180^{\circ} \mathrm{C} 50 \%\right)$ & 67,981 & 7,76034 & 12 \\
\hline & $\mathrm{T} 2\left(180^{\circ} \mathrm{C} 75 \%\right)$ & 86,923 & 4,33768 & 12 \\
\hline & T3 $\left(200^{\circ} \mathrm{C} 50 \%\right)$ & 67,6743 & 3,0452 & 12 \\
\hline & $\mathrm{T} 4\left(200^{\circ} \mathrm{C} 75 \%\right)$ & 66,3674 & 12,78483 & 12 \\
\hline \multirow{5}{*}{$\begin{array}{l}\mathrm{E}_{\mathrm{m}} \text { lado não } \\
\text { densificado }\end{array}$} & Testemunha & 7738,485 & 512,33751 & 6 \\
\hline & $\mathrm{T} 1\left(180^{\circ} \mathrm{C} 50 \%\right)$ & 7286,823 & 750,53455 & 6 \\
\hline & $\mathrm{T} 2\left(180^{\circ} \mathrm{C} 75 \%\right)$ & 7428,9003 & 833,11001 & 6 \\
\hline & T3 $\left(200^{\circ} \mathrm{C} 50 \%\right)$ & 7316,1707 & 1203,53995 & 6 \\
\hline & $\mathrm{T} 4\left(200^{\circ} \mathrm{C} 75 \%\right)$ & 8948,8527 & 1212,87086 & 6 \\
\hline \multirow{5}{*}{$\begin{array}{c}\mathrm{E}_{\mathrm{m}} \text { lado } \\
\text { densificado }\end{array}$} & Testemunha & 7771,2155 & 708,99058 & 6 \\
\hline & $\mathrm{T} 1\left(180^{\circ} \mathrm{C} 50 \%\right)$ & 7923,729 & 195,32075 & 6 \\
\hline & $\mathrm{T} 2\left(180^{\circ} \mathrm{C} 75 \%\right)$ & 7830,2192 & 362,80147 & 6 \\
\hline & T3 $\left(200^{\circ} \mathrm{C} 50 \%\right)$ & 6876,3875 & 547,68435 & 6 \\
\hline & $\mathrm{T} 4\left(200^{\circ} \mathrm{C} 75 \%\right)$ & 8182,3388 & 1340,09846 & 6 \\
\hline
\end{tabular}

Continua 
Tabela A 3 - Estatística descritiva das propriedades mecânicas dos tratamentos analisados

\begin{tabular}{|c|c|c|c|c|}
\hline Propriedades & Tratamento & Média & Desvio Padrão & Repetições \\
\hline \multirow{5}{*}{ Velocidade } & Testemunha & 3513,0046 & 244,07233 & 18 \\
\cline { 2 - 5 } & $\mathrm{T} 1\left(180^{\circ} \mathrm{C} 50 \%\right)$ & 3694,8865 & 315,66393 & 18 \\
\cline { 2 - 5 } & $\mathrm{T} 2\left(180^{\circ} \mathrm{C} 75 \%\right)$ & 3180,2197 & 539,62746 & 18 \\
\cline { 2 - 5 } & $\mathrm{T} 3\left(200^{\circ} \mathrm{C} 50 \%\right)$ & 3501,6895 & 370,26319 & 18 \\
\cline { 2 - 5 } & $\mathrm{T} 4\left(200^{\circ} \mathrm{C} 75 \%\right)$ & 2851,6308 & 371,89586 & 18 \\
\hline \multirow{5}{*}{$\mathrm{E}_{\mathrm{d}}$} & $\mathrm{Testemunha}$ & 5445,0242 & 739,02158 & 18 \\
\cline { 2 - 5 } & $\mathrm{T} 1\left(180^{\circ} \mathrm{C} 50 \%\right)$ & 6488,4406 & 1149,76643 & 18 \\
\cline { 2 - 5 } & $\mathrm{T} 2\left(180^{\circ} \mathrm{C} 75 \%\right)$ & 6689,0127 & 2203,25945 & 18 \\
\cline { 2 - 5 } & $\mathrm{T} 3\left(200^{\circ} \mathrm{C} 50 \%\right)$ & 6249,8529 & 1605,15930 & 18 \\
\cline { 2 - 5 } & $\mathrm{T} 4\left(200^{\circ} \mathrm{C} 75 \%\right)$ & 5161,5063 & 1398,80186 & 18 \\
\hline
\end{tabular}

Tabela A 4 - Análise de variância a 5\% de significância com teste post-hoc de Dunnett para as propriedades físicas.

Anova

\begin{tabular}{|c|c|c|c|c|c|c|}
\hline \multicolumn{2}{|c|}{ Propriedade } & SQT & gl & SQM & $\mathrm{F}$ & Sig. \\
\hline$\rho f$ & $\begin{array}{c}\text { Entre os Grupos } \\
\text { Dentro dos Grupos } \\
\text { Total }\end{array}$ & $\begin{array}{l}0,217 \\
0,018 \\
0,235\end{array}$ & $\begin{array}{c}4,000 \\
23,000 \\
27,000\end{array}$ & $\begin{array}{l}0,054 \\
0,001\end{array}$ & 69,389 & 0,000 \\
\hline TUE & $\begin{array}{c}\text { Entre os Grupos } \\
\text { Dentro dos Grupos } \\
\text { Total }\end{array}$ & $\begin{array}{l}11,592 \\
11,109 \\
22,702\end{array}$ & $\begin{array}{l}4,000 \\
24,000 \\
28,000\end{array}$ & $\begin{array}{l}2,898 \\
0,463\end{array}$ & 6,261 & 0,001 \\
\hline IE2h & $\begin{array}{c}\text { Entre os Grupos } \\
\text { Dentro dos Grupos } \\
\text { Total }\end{array}$ & $\begin{array}{c}1819,062 \\
244,453 \\
2063,514\end{array}$ & $\begin{array}{c}4,000 \\
25,000 \\
29,000\end{array}$ & $\begin{array}{c}454,765 \\
9,778\end{array}$ & 46,509 & 0,000 \\
\hline IE24H & $\begin{array}{c}\text { Entre os Grupos } \\
\text { Dentro dos Grupos } \\
\text { Total }\end{array}$ & $\begin{array}{c}4272,764 \\
340,994 \\
4613,759\end{array}$ & $\begin{array}{c}4,000 \\
23,000 \\
27,000\end{array}$ & $\begin{array}{c}1068,191 \\
14,826\end{array}$ & 72,049 & 0,000 \\
\hline $\mathrm{AB} 2 \mathrm{H}$ & $\begin{array}{c}\text { Entre os Grupos } \\
\text { Dentro dos Grupos } \\
\text { Total }\end{array}$ & $\begin{array}{c}1026,893 \\
836,864 \\
1863,757\end{array}$ & $\begin{array}{c}4,000 \\
25,000 \\
29,000\end{array}$ & $\begin{array}{c}256,723 \\
33,475\end{array}$ & 7,669 & 0,000 \\
\hline AB24H & $\begin{array}{c}\text { Entre os Grupos } \\
\text { Dentro dos Grupos } \\
\text { Total }\end{array}$ & $\begin{array}{c}2022,968 \\
831,455 \\
2854,423\end{array}$ & $\begin{array}{c}4,000 \\
24,000 \\
28,000\end{array}$ & $\begin{array}{c}505,742 \\
34,644\end{array}$ & 14,598 & 0,000 \\
\hline TNRE & $\begin{array}{c}\text { Entre os Grupos } \\
\text { Dentro dos Grupos } \\
\text { Total }\end{array}$ & $\begin{array}{c}2280,798 \\
214,402 \\
2495,200\end{array}$ & $\begin{array}{c}4,000 \\
23,000 \\
27,000\end{array}$ & $\begin{array}{c}570,199 \\
9,322\end{array}$ & 61,168 & 0,000 \\
\hline TR & $\begin{array}{c}\text { Entre os Grupos } \\
\text { Dentro dos Grupos } \\
\text { Total }\end{array}$ & $\begin{array}{c}122,809 \\
18,452 \\
141,260\end{array}$ & $\begin{array}{c}4,000 \\
22,000 \\
26,000\end{array}$ & $\begin{array}{c}30,702 \\
0,839\end{array}$ & 36,606 & 0,000 \\
\hline
\end{tabular}


Teste de Dunnett a 5\% de significância

\begin{tabular}{|c|c|c|c|c|c|}
\hline Propriedade & (I) Tratamento & (J) Tratamento & Diferença média $(\mathrm{I})$ - $(\mathrm{J})$ & $\begin{array}{c}\text { Erro } \\
\text { Padrão }\end{array}$ & Sig. \\
\hline \multirow[t]{4}{*}{ r } & 1,0 & 5,0 & 0,014 & 0,018 & 0,830 \\
\hline & 2,0 & 5,0 & ,20981 & 0,017 & 0,000 \\
\hline & 3,0 & 5,0 & ,05571 & 0,017 & 0,011 \\
\hline & 4,0 & 5,0 & ,18794 & 0,017 & 0,000 \\
\hline \multirow{4}{*}{ TUE } & 1,0 & 5,0 & $-1,061$ & 0,412 & 0,055 \\
\hline & 2,0 & 5,0 & $-1,874^{*}$ & 0,393 & 0,000 \\
\hline & 3,0 & 5,0 & $-1,240^{*}$ & 0,393 & 0,015 \\
\hline & 4,0 & 5,0 & $-1,423^{*}$ & 0,393 & 0,005 \\
\hline \multirow{4}{*}{ IE2H } & 1,0 & 5,0 & 1,162 & 1,805 & 0,916 \\
\hline & 2,0 & 5,0 & 20,622 & 1,805 & 0,000 \\
\hline & 3,0 & 5,0 & 1,206 & 1,805 & 0,905 \\
\hline & 4,0 & 5,0 & 2,737 & 1,805 & 0,379 \\
\hline \multirow{4}{*}{ IE24H } & 1,00 & 5,00 & 4,048 & 2,223 & 0,238 \\
\hline & 2,00 & 5,00 & $33,777^{*}$ & 2,332 & 0,000 \\
\hline & 3,00 & 5,00 & 4,586 & 2,332 & 0,185 \\
\hline & 4,00 & 5,00 & 19,992 & 2,223 & 0,000 \\
\hline \multirow{4}{*}{$\mathrm{AB} 2 \mathrm{H}$} & 1,0 & 5,0 & $-0,254$ & 3,340 & 1,000 \\
\hline & 2,0 & 5,0 & 13,53825 & 3,340 & 0,002 \\
\hline & 3,0 & 5,0 & $-0,916$ & 3,340 & 0,996 \\
\hline & 4,0 & 5,0 & $-2,521$ & 3,340 & 0,864 \\
\hline \multirow{4}{*}{ AB24H } & 1,0 & 5,0 & 4,657 & 3,398 & 0,470 \\
\hline & 2,0 & 5,0 & $24,087^{*}$ & 3,398 & 0,000 \\
\hline & 3,0 & 5,0 & 5,620 & 3,564 & 0,349 \\
\hline & 4,0 & 5,0 & 7,953 & 3,398 & 0,089 \\
\hline \multirow{4}{*}{ TNRE } & 1,0 & 5,0 & 3,735 & 1,763 & 0,140 \\
\hline & 2,0 & 5,0 & $25,086^{*}$ & 1,849 & 0,000 \\
\hline & 3,0 & 5,0 & 2,927 & 1,849 & 0,350 \\
\hline & 4,0 & 5,0 & $14,022^{*}$ & 1,763 & 0,000 \\
\hline \multirow{4}{*}{ TR } & 1,0 & 5,0 & 0,093 & 0,555 & 0,999 \\
\hline & 2,0 & 5,0 & $4,977^{\star}$ & 0,555 & 0,000 \\
\hline & 3,0 & 5,0 & 1,451 & 0,555 & 0,053 \\
\hline & 4,0 & 5,0 & 4,444 & 0,529 & 0,000 \\
\hline
\end{tabular}


Tabela A 5 - Análise de variância a 5\% de significância com teste post-hoc de Dunnett para as propriedades de superfície.

\begin{tabular}{|c|c|c|c|c|c|c|}
\hline \multicolumn{2}{|c|}{ Variável } & SQT & $\mathrm{gl}$ & SQM & $\mathrm{F}$ & Sig. \\
\hline $\begin{array}{l}\text { Ângulo de } \\
\text { Contato }\end{array}$ & $\begin{array}{c}\text { Entre os Grupos } \\
\text { Dentro dos Grupos } \\
\text { Total }\end{array}$ & $\begin{array}{r}93831,357 \\
16184,389 \\
110015,746\end{array}$ & $\begin{array}{l}4,000 \\
81,000 \\
85,000\end{array}$ & $\begin{array}{c}23457,839 \\
199,807\end{array}$ & 117,402 & 0,000 \\
\hline PMdaA & $\begin{array}{c}\text { Entre os Grupos } \\
\text { Dentro dos Grupos } \\
\text { Total }\end{array}$ & $\begin{array}{l}0,756 \\
2,064 \\
2,820\end{array}$ & $\begin{array}{l}4,000 \\
25,000 \\
29,000\end{array}$ & $\begin{array}{l}0,189 \\
0,083\end{array}$ & 2,288 & 0,088 \\
\hline $\begin{array}{l}\text { Taxa de } \\
\text { Desgaste }\end{array}$ & $\begin{array}{c}\text { Entre os Grupos } \\
\text { Dentro dos Grupos } \\
\text { Total }\end{array}$ & $\begin{array}{c}2555,556 \\
7468,519 \\
10024,074 \\
\end{array}$ & $\begin{array}{l}4,000 \\
25,000 \\
29,000\end{array}$ & $\begin{array}{l}638,889 \\
298,741\end{array}$ & 2,139 & 0,106 \\
\hline$L^{*}$ & $\begin{array}{c}\text { Entre os Grupos } \\
\text { Dentro dos Grupos } \\
\text { Total }\end{array}$ & $\begin{array}{c}72980,890 \\
7315,509 \\
80296,399 \\
\end{array}$ & $\begin{array}{c}4,000 \\
295,000 \\
299,000 \\
\end{array}$ & $\begin{array}{c}18245,222 \\
24,798\end{array}$ & 735,744 & 0,000 \\
\hline$a^{*}$ & $\begin{array}{c}\text { Entre os Grupos } \\
\text { Dentro dos Grupos } \\
\text { Total }\end{array}$ & $\begin{array}{c}3126,343 \\
330,390 \\
3456,733\end{array}$ & $\begin{array}{c}4,000 \\
290,000 \\
294,000\end{array}$ & $\begin{array}{c}781,586 \\
1,139\end{array}$ & 686,037 & 0,000 \\
\hline$b^{*}$ & $\begin{array}{c}\text { Entre os Grupos } \\
\text { Dentro dos Grupos } \\
\text { Total }\end{array}$ & $\begin{array}{l}3803,338 \\
2180,006 \\
5983,344\end{array}$ & $\begin{array}{c}4,000 \\
279,000 \\
283,000\end{array}$ & $\begin{array}{c}950,834 \\
7,814\end{array}$ & 121,689 & 0,000 \\
\hline C & $\begin{array}{c}\text { Entre os Grupos } \\
\text { Dentro dos Grupos } \\
\text { Total }\end{array}$ & $\begin{array}{l}3599,972 \\
2224,589 \\
5824,561\end{array}$ & $\begin{array}{c}4,000 \\
279,000 \\
283,000\end{array}$ & $\begin{array}{c}899,993 \\
7,973\end{array}$ & 112,874 & 0,000 \\
\hline$h^{*}$ & $\begin{array}{c}\text { Entre os Grupos } \\
\text { Dentro dos Grupos } \\
\text { Total }\end{array}$ & $\begin{array}{c}23646,128 \\
1893,499 \\
25539,627\end{array}$ & $\begin{array}{c}4,000 \\
289,000 \\
293,000\end{array}$ & $\begin{array}{c}5911,532 \\
6,552\end{array}$ & 902,262 & 0,000 \\
\hline
\end{tabular}


Teste de Dunnett a 5\% de significância

\begin{tabular}{|c|c|c|c|c|c|}
\hline Propriedade & (I) Tratamento & (J) Tratamento & Diferença média (I) - (J) & $\begin{array}{c}\text { Erro } \\
\text { Padrão }\end{array}$ & Sig. \\
\hline \multirow{4}{*}{$\begin{array}{l}\text { Ângulo de } \\
\text { Contato }\end{array}$} & 1 & 5 & $72,388^{*}$ & 4,998 & 0,000 \\
\hline & 2 & 5 & $92,762^{*}$ & 4,857 & 0,000 \\
\hline & 3 & 5 & $71,207^{*}$ & 4,857 & 0,000 \\
\hline & 4 & 5 & $89,723^{*}$ & 4,857 & 0,000 \\
\hline \multirow{4}{*}{ PMdaA } & 1 & 5 & 0,102 & 0,166 & 0,928 \\
\hline & 2 & 5 & $-0,089$ & 0,166 & 0,954 \\
\hline & 3 & 5 & 0,282 & 0,166 & 0,284 \\
\hline & 4 & 5 & $-0,176$ & 0,166 & 0,674 \\
\hline \multirow{4}{*}{$\begin{array}{l}\text { Taxa de } \\
\text { Desgaste }\end{array}$} & 1 & 5 & 10,556 & 9,979 & 0,675 \\
\hline & 2 & 5 & 12,222 & 9,979 & 0,561 \\
\hline & 3 & 5 & $26,667^{*}$ & 9,979 & 0,043 \\
\hline & 4 & 5 & 00003 & 9,979 & 0,991 \\
\hline \multirow{4}{*}{$L^{*}$} & 1 & 5 & $-26,251^{*}$ & 0,909 & 0,000 \\
\hline & 2 & 5 & $-25,651^{*}$ & 0,909 & 0,000 \\
\hline & 3 & 5 & $-37,334^{*}$ & 0,909 & 0,000 \\
\hline & 4 & 5 & $-44,938^{*}$ & 0,909 & 0,000 \\
\hline \multirow{4}{*}{$a^{*}$} & 1 & 5 & $6,445^{\star}$ & 0,197 & 0,000 \\
\hline & 2 & 5 & $8,201^{*}$ & 0,198 & 0,000 \\
\hline & 3 & 5 & $9,167^{*}$ & 0,197 & 0,000 \\
\hline & 4 & 5 & $7,728^{*}$ & 0,197 & 0,000 \\
\hline \multirow{4}{*}{$b^{*}$} & 1 & 5 & $4,850^{*}$ & 0,530 & 0,000 \\
\hline & 2 & 5 & $5,732^{*}$ & 0,546 & 0,000 \\
\hline & 3 & 5 & $1,599^{*}$ & 0,532 & 0,010 \\
\hline & 4 & 5 & $-4,362^{*}$ & 0,530 & 0,000 \\
\hline \multirow{4}{*}{$\mathrm{C}$} & 1 & 5 & $6,286^{*}$ & 0,538 & 0,000 \\
\hline & 2 & 5 & $7,614^{*}$ & 0,551 & 0,000 \\
\hline & 3 & 5 & $4,310^{*}$ & 0,540 & 0,000 \\
\hline & 4 & 5 & $-1,606^{*}$ & 0,538 & 0,011 \\
\hline \multirow{4}{*}{$h^{*}$} & 1 & 5 & $-12,990^{*}$ & 0,467 & 0,000 \\
\hline & 2 & 5 & $-15,899^{*}$ & 0,476 & 0,000 \\
\hline & 3 & 5 & $-21,386^{*}$ & 0,469 & 0,000 \\
\hline & 4 & 5 & $-26,251^{*}$ & 0,469 & 0,000 \\
\hline
\end{tabular}


Tabela A 6 - Análise de variância a 5\% de significância com teste post-hoc de Dunnett para as propriedades de mecânicas.

\begin{tabular}{|c|c|c|c|c|c|c|}
\hline \multicolumn{2}{|c|}{ Variável } & SQT & gl & SQM & $\mathrm{F}$ & Sig. \\
\hline \multirow{3}{*}{$\mathrm{f}_{\mathrm{H}, 90^{\circ}}$} & Entre os Grupos & 26172483,676 & 4 & 6543120,919 & 17,282 & 0,000 \\
\hline & Dentro dos Grupos & 9465391,305 & 25 & 378615,652 & & \\
\hline & Total & 35637874,981 & 29 & & & \\
\hline \multirow{3}{*}{$f_{c, 0^{\circ}}$} & Entre os Grupos & 1366,383 & 4 & 341,596 & 13,771 & 0,000 \\
\hline & Dentro dos Grupos & 620,123 & 25 & 24,805 & & \\
\hline & Total & 1986,507 & 29 & & & \\
\hline \multirow{3}{*}{$\begin{array}{l}\mathrm{f}_{\mathrm{M}} \text { lado não } \\
\text { densificado }\end{array}$} & Entre os Grupos & 4898,765 & 4 & 1224,691 & 10,736 & 0,000 \\
\hline & Dentro dos Grupos & 6273,871 & 55 & 114,070 & & \\
\hline & Total & 11172,636 & 59 & & & \\
\hline \multirow{3}{*}{$\begin{array}{c}f_{M} \text { lado } \\
\text { densificado }\end{array}$} & Entre os Grupos & 1493,812 & 4 & 373,453 & 5,855 & 0,002 \\
\hline & Dentro dos Grupos & 1466,901 & 23 & 63,778 & & \\
\hline & Total & 2960,713 & 27 & & & \\
\hline \multirow{3}{*}{$\begin{array}{l}E_{m} \text { lado não } \\
\text { densificado }\end{array}$} & Entre os Grupos & 23104033,041 & 4 & 5776008,260 & 6,462 & 0,000 \\
\hline & Dentro dos Grupos & 48270408,743 & 54 & 893896,458 & & \\
\hline & Total & 71374441,784 & 58 & & & \\
\hline \multirow{3}{*}{$\begin{array}{c}\mathrm{E}_{\mathrm{m}} \text { lado } \\
\text { densificado }\end{array}$} & Entre os Grupos & 5781158,658 & 4 & 1445289,665 & 2,332 & 0,088 \\
\hline & Dentro dos Grupos & 13633398,521 & 22 & 619699,933 & & \\
\hline & Total & 19414557,179 & 26 & & & \\
\hline \multirow{3}{*}{ Velocidade } & Entre os Grupos & 8022769,758 & 4 & 2005692,439 & 13,817 & 0,000 \\
\hline & Dentro dos Grupos & 12338841,030 & 85 & 145162,836 & & \\
\hline & Total & 20361610,788 & 89 & & & \\
\hline \multirow{3}{*}{$E_{d}$} & Entre os Grupos & 30237473,883 & 4 & 7559368,471 & 3,864 & 0,006 \\
\hline & Dentro dos Grupos & 164316564,178 & 84 & 1956149,574 & & \\
\hline & Total & 194554038,061 & 88 & & & \\
\hline
\end{tabular}


Teste de Dunnett a 5\% de significância

\begin{tabular}{|c|c|c|c|c|c|}
\hline Variável & (I) Tratamento & (J) Tratamento & Diferença média $(\mathrm{I})$ - $(\mathrm{J})$ & $\begin{array}{c}\text { Erro } \\
\text { Padrão }\end{array}$ & Sig. \\
\hline \multirow{4}{*}{$\mathrm{f}_{\mathrm{H}, 90^{\circ}}$} & 1 & 5 & 456,682 & 355,254 & 0,520 \\
\hline & 2 & 5 & $2494,16167^{*}$ & 355,254 & 0,000 \\
\hline & 3 & 5 & 850,370 & 355,254 & 0,078 \\
\hline & 4 & 5 & $1963,87167^{*}$ & 355,254 & 0,000 \\
\hline \multirow{4}{*}{$\mathrm{f}_{\mathrm{c}, 0^{\circ}}$} & 1 & 5 & 3,271 & 2,875 & 0,620 \\
\hline & 2 & 5 & $17,96550^{*}$ & 2,875 & 0,000 \\
\hline & 3 & 5 & $11,43586^{*}$ & 2,875 & 0,002 \\
\hline & 4 & 5 & $14,32844^{*}$ & 2,875 & 0,000 \\
\hline \multirow{4}{*}{$\begin{array}{l}\mathrm{f}_{\mathrm{M}} \text { lado não } \\
\text { densificado }\end{array}$} & 1 & 5 & 5,889 & 4,360 & 0,470 \\
\hline & 2 & 5 & $25,23434^{*}$ & 4,360 & 0,000 \\
\hline & 3 & 5 & $16,54985^{*}$ & 4,360 & 0,001 \\
\hline & 4 & 5 & $18,14930^{*}$ & 4,360 & 0,000 \\
\hline \multirow{4}{*}{$\begin{array}{c}\mathrm{f}_{\mathrm{M}} \text { lado } \\
\text { densificado }\end{array}$} & 1 & 5 & $-4,15453$ & 4,61080 & 0,784 \\
\hline & 2 & 5 & $14,78750^{*}$ & 4,83584 & 0,019 \\
\hline & 3 & 5 & $-4,46116$ & 4,83584 & 0,771 \\
\hline & 4 & 5 & $-5,76805$ & 4,61080 & 0,551 \\
\hline \multirow{4}{*}{$\begin{array}{c}\mathrm{E}_{\mathrm{m}} \text { lado } \\
\text { não } \\
\text { densificado }\end{array}$} & 1 & 5 & $-451,66205$ & 394,65768 & 0,613 \\
\hline & 2 & 5 & $-309,58476$ & 385,98283 & 0,840 \\
\hline & 3 & 5 & $-422,31430$ & 385,98283 & 0,648 \\
\hline & 4 & 5 & $1210,36771^{*}$ & 385,98283 & 0,010 \\
\hline \multirow{4}{*}{$\begin{array}{c}\mathrm{E}_{\mathrm{m}} \text { lado } \\
\text { densificado }\end{array}$} & 1 & 5 & 152,51350 & 508,14201 & 0,995 \\
\hline & 2 & 5 & 59,00361 & 476,67946 & 1,000 \\
\hline & 3 & 5 & $-894,82802$ & 454,49603 & 0,187 \\
\hline & 4 & 5 & 411,12327 & 454,49603 & 0,786 \\
\hline \multirow{4}{*}{ Velocidade } & 1 & 5 & 181,882 & 127,001 & 0,415 \\
\hline & 2 & 5 & $-332,78483^{*}$ & 127,001 & 0,036 \\
\hline & 3 & 5 & $-11,315$ & 127,001 & 1,000 \\
\hline & 4 & 5 & $-661,37376^{*}$ & 127,001 & 0,000 \\
\hline \multirow{4}{*}{$E_{d}$} & 1 & 5 & 1043,416 & 466,208 & 0,091 \\
\hline & 2 & 5 & $1243,98846^{*}$ & 466,208 & 0,032 \\
\hline & 3 & 5 & 517,796 & 473,014 & 0,646 \\
\hline & 4 & 5 & $-262,296$ & 466,208 & 0,947 \\
\hline
\end{tabular}


Tabela A 7 - Análise fatorial a 5\% de significância para as propriedades físicas dos tratamentos analisados

\begin{tabular}{|c|c|c|c|c|c|c|}
\hline Fonte de Variação & Variável & $\begin{array}{l}\text { Soma dos } \\
\text { Quadrados }\end{array}$ & $\begin{array}{l}\text { Graus de } \\
\text { Liberdade }\end{array}$ & $\begin{array}{c}\text { Quadrado } \\
\text { Médio }\end{array}$ & F Calc & Significância \\
\hline \multirow{12}{*}{ Temperatura (Te) } & PM & 31,826 & 1 & 31,826 & 101,431 & 0,000 \\
\hline & PMDAT & 13,324 & 1 & 13,324 & 21,655 & 0,000 \\
\hline & TC & 101,472 & 1 & 101,472 & 5,973 & 0,024 \\
\hline & TD & 20,850 & 1 & 20,850 & 0,383 & 0,543 \\
\hline & TUE & 0,106 & 1 & 0,106 & 0,182 & 0,674 \\
\hline & $\rho f$ & 0,001 & 1 & 0,001 & 0,591 & 0,452 \\
\hline & $\mathrm{IE} 2 \mathrm{H}$ & 477,425 & 1 & 477,425 & 39,369 & 0,000 \\
\hline & IE24H & 239,279 & 1 & 239,279 & 12,758 & 0,002 \\
\hline & $\mathrm{AB} 2 \mathrm{H}$ & 419,392 & 1 & 419,392 & 10,116 & 0,005 \\
\hline & $\mathrm{AB} 24 \mathrm{H}$ & 328,774 & 1 & 328,774 & 8,030 & 0,011 \\
\hline & TNRE & 192,210 & 1 & 192,210 & 16,167 & 0,001 \\
\hline & TR & 0,889 & 1 & 0,889 & 0,919 & 0,351 \\
\hline \multirow{12}{*}{ Pressão (P) } & PM & 24,329 & 1 & 24,329 & 77,537 & 0,000 \\
\hline & PMDAT & 9,552 & 1 & 9,552 & 15,524 & 0,001 \\
\hline & $\mathrm{TC}$ & 3497,275 & 1 & 3497,275 & 205,848 & 0,000 \\
\hline & TD & 8883,272 & 1 & 8883,272 & 163,343 & 0,000 \\
\hline & TUE & 1,415 & 1 & 1,415 & 2,436 & 0,135 \\
\hline & $\rho f$ & 0,154 & 1 & 0,154 & 164,343 & 0,000 \\
\hline & $\mathrm{IE} 2 \mathrm{H}$ & 660,925 & 1 & 660,925 & 54,500 & 0,000 \\
\hline & $\mathrm{IE} 24 \mathrm{H}$ & 2778,004 & 1 & 2778,004 & 148,117 & 0,000 \\
\hline & $\mathrm{AB} 2 \mathrm{H}$ & 222,765 & 1 & 222,765 & 5,373 & 0,031 \\
\hline & $\mathrm{AB} 24 \mathrm{H}$ & 676,662 & 1 & 676,662 & 16,527 & 0,001 \\
\hline & TNRE & 1435,566 & 1 & 1435,566 & 120,745 & 0,000 \\
\hline & TR & 80,924 & 1 & 80,924 & 83,579 & 0,000 \\
\hline \multirow{12}{*}{ Te $\times \mathrm{P}$} & PM & 1,318 & 1 & 1,318 & 4,200 & 0,054 \\
\hline & PMDAT & 0,262 & 1 & 0,262 & 0,425 & 0,522 \\
\hline & $\mathrm{TC}$ & 151,359 & 1 & 151,359 & 8,909 & 0,007 \\
\hline & TD & 241,890 & 1 & 241,890 & 4,448 & 0,048 \\
\hline & TUE & 0,568 & 1 & 0,568 & 0,977 & 0,335 \\
\hline & $\rho f$ & 0,006 & 1 & 0,006 & 6,143 & 0,023 \\
\hline & IE2H & 482,156 & 1 & 482,156 & 39,759 & 0,000 \\
\hline & IE24H & 279,793 & 1 & 279,793 & 14,918 & 0,001 \\
\hline & $\mathrm{AB} 2 \mathrm{H}$ & 355,644 & 1 & 355,644 & 8,578 & 0,008 \\
\hline & $\mathrm{AB} 24 \mathrm{H}$ & 417,542 & 1 & 417,542 & 10,198 & 0,005 \\
\hline & TNRE & 143,441 & 1 & 143,441 & 12,065 & 0,003 \\
\hline & TR & 4,665 & 1 & 4,665 & 4,818 & 0,042 \\
\hline
\end{tabular}

Continua 
Tabela A 7 - Análise fatorial a 5\% de significância para as propriedades físicas dos tratamentos analisados

\begin{tabular}{|c|c|c|c|c|c|c|}
\hline Fonte de Variação & Variável & $\begin{array}{l}\text { Soma dos } \\
\text { Quadrados }\end{array}$ & $\begin{array}{l}\text { Graus de } \\
\text { Liberdade }\end{array}$ & $\begin{array}{l}\text { Quadrado } \\
\text { Médio }\end{array}$ & $\begin{array}{c}F \\
\text { Calc }\end{array}$ & Significância \\
\hline \multirow{12}{*}{ Erro } & PM & 6,275 & 20 & 0,314 & & \\
\hline & PMDAT & 11,690 & 19 & 0,615 & & \\
\hline & $\mathrm{TC}$ & 339,792 & 20 & 16,990 & & \\
\hline & TD & 1087,682 & 20 & 54,384 & & \\
\hline & TUE & 11,036 & 19 & 0,581 & & \\
\hline & $\rho f$ & 0,018 & 19 & 0,001 & & \\
\hline & $\mathrm{IE} 2 \mathrm{H}$ & 242,541 & 20 & 12,127 & & \\
\hline & IE24H & 337,598 & 18 & 18,755 & & \\
\hline & $\mathrm{AB} 2 \mathrm{H}$ & 829,186 & 20 & 41,459 & & \\
\hline & $\mathrm{AB} 24 \mathrm{H}$ & 777,896 & 19 & 40,942 & & \\
\hline & TNRE & 214,007 & 18 & 11,889 & & \\
\hline & TR & 16,460 & 17 & 0,968 & & \\
\hline \multirow{11}{*}{ Total } & PM & 1556,752 & 24 & & & \\
\hline & PMDAT & 242,592 & 23 & & & \\
\hline & TC & 19647,805 & 24 & & & \\
\hline & TD & 27923,768 & 24 & & & \\
\hline & TUE & 1896,342 & 23 & & & \\
\hline & $\rho f$ & 7,309 & 23 & & & \\
\hline & IE24H & 9933,684 & 22 & & & \\
\hline & $\mathrm{AB} 2 \mathrm{H}$ & 10577,244 & 24 & & & \\
\hline & $\mathrm{AB} 24 \mathrm{H}$ & 81176,393 & 23 & & & \\
\hline & TNRE & 4240,683 & 22 & & & \\
\hline & TR & 733,094 & 21 & & & \\
\hline
\end{tabular}


Tabela A 8 - Análise fatorial a 5\% de significância para as propriedades da superfície dos tratamentos analisados

\begin{tabular}{|c|c|c|c|c|c|c|}
\hline $\begin{array}{l}\text { Fonte de } \\
\text { Variação }\end{array}$ & Variável & $\begin{array}{c}\text { Soma dos } \\
\text { Quadrado } \\
\text { s }\end{array}$ & $\begin{array}{c}\text { Graus de } \\
\text { Liberdad } \\
e\end{array}$ & $\begin{array}{l}\text { Quadrado } \\
\text { Médio }\end{array}$ & F Calc & $\begin{array}{c}\text { Significânci } \\
\text { a }\end{array}$ \\
\hline \multirow{8}{*}{ Temperatura (Te) } & $\begin{array}{c}\text { Ângulo de } \\
\text { Contato }\end{array}$ & 77,717 & 1 & 77,717 & 0,320 & 0,574 \\
\hline & Taxa de Desgaste & 78,241 & 1 & 78,241 & 0,239 & 0,630 \\
\hline & PMdaA & 0,013 & 1 & 0,013 & 0,146 & 0,707 \\
\hline & $L^{*}$ & 21748,440 & 1 & $\begin{array}{c}21748,44 \\
0 \\
\end{array}$ & $\begin{array}{c}710,55 \\
5 \\
\end{array}$ & 0,000 \\
\hline & $a^{*}$ & 74,946 & 1 & 74,946 & 53,378 & 0,000 \\
\hline & $b^{*}$ & 2576,230 & 1 & 2576,230 & $\begin{array}{c}300,91 \\
5\end{array}$ & 0,000 \\
\hline & C & 1830,069 & 1 & 1830,069 & $\begin{array}{c}203,86 \\
8 \\
\end{array}$ & 0,000 \\
\hline & $\mathrm{h}^{*}$ & 5136,704 & 1 & 5136,704 & $\begin{array}{c}630,56 \\
8 \\
\end{array}$ & 0,000 \\
\hline \multirow{8}{*}{ Pressão (P) } & $\begin{array}{c}\text { Ângulo de } \\
\text { Contato }\end{array}$ & 6599,633 & 1 & 6599,633 & 27,162 & 0,000 \\
\hline & Taxa de Desgaste & 704,167 & 1 & 704,167 & 2,149 & 0,158 \\
\hline & PMdaA & 0,631 & 1 & 0,631 & 6,957 & 0,016 \\
\hline & $L^{*}$ & 3246,423 & 1 & 3246,423 & $\begin{array}{c}106,06 \\
6 \\
\end{array}$ & 0,000 \\
\hline & $a^{*}$ & 1,486 & 1 & 1,486 & 1,058 & 0,305 \\
\hline & $b^{*}$ & 373,263 & 1 & 373,263 & 43,599 & 0,000 \\
\hline & $\mathrm{C}$ & 302,937 & 1 & 302,937 & 33,747 & 0,000 \\
\hline & $\mathrm{h}^{*}$ & 883,297 & 1 & 883,297 & $\begin{array}{c}108,43 \\
1 \\
\end{array}$ & 0,000 \\
\hline \multirow{8}{*}{ Te $\times \mathrm{P}$} & $\begin{array}{l}\text { Ângulo de } \\
\text { Contato }\end{array}$ & 15,075 & 1 & 15,075 & 0,062 & 0,804 \\
\hline & Taxa de Desgaste & 937,500 & 1 & 937,500 & 2,861 & 0,106 \\
\hline & PMdaA & 0,107 & 1 & 0,107 & 1,182 & 0,290 \\
\hline & $L^{*}$ & 3,688 & 1 & 3,688 & 0,120 & 0,729 \\
\hline & $a^{*}$ & 151,090 & 1 & 151,090 & $\begin{array}{c}107,61 \\
0\end{array}$ & 0,000 \\
\hline & $b^{*}$ & 677,447 & 1 & 677,447 & 79,129 & 0,000 \\
\hline & $\mathrm{C}$ & 55,958 & 1 & 55,958 & 6,869 & 0,009 \\
\hline & $\mathrm{h}^{*}$ & 767,905 & 1 & 767,905 & 85,544 & 0,000 \\
\hline
\end{tabular}

Continua

Tabela A 8 - Análise fatorial a 5\% de significância para as propriedades da superfície dos tratamentos analisados

\begin{tabular}{|c|c|c|c|c|c|c|}
\hline \multirow{2}{*}{ Fonte de Variação } & Variável & $\begin{array}{c}\text { Soma dos } \\
\text { Quadrados }\end{array}$ & $\begin{array}{c}\text { Graus de } \\
\text { Liberdade }\end{array}$ & $\begin{array}{c}\text { Quadrado } \\
\text { Médio }\end{array}$ & $\begin{array}{c}F \\
\text { Calc }\end{array}$ & Significância \\
\hline \multirow{3}{*}{ Erro } & Ângulo de Contato & 16036,084 & 66 & 242,971 & & \\
\cline { 2 - 8 } & Taxa de Desgaste & 6553,704 & 20 & 327,685 & & \\
\cline { 2 - 8 } & PMdaA & 1,814 & 20 & 0,091 & & \\
\hline
\end{tabular}




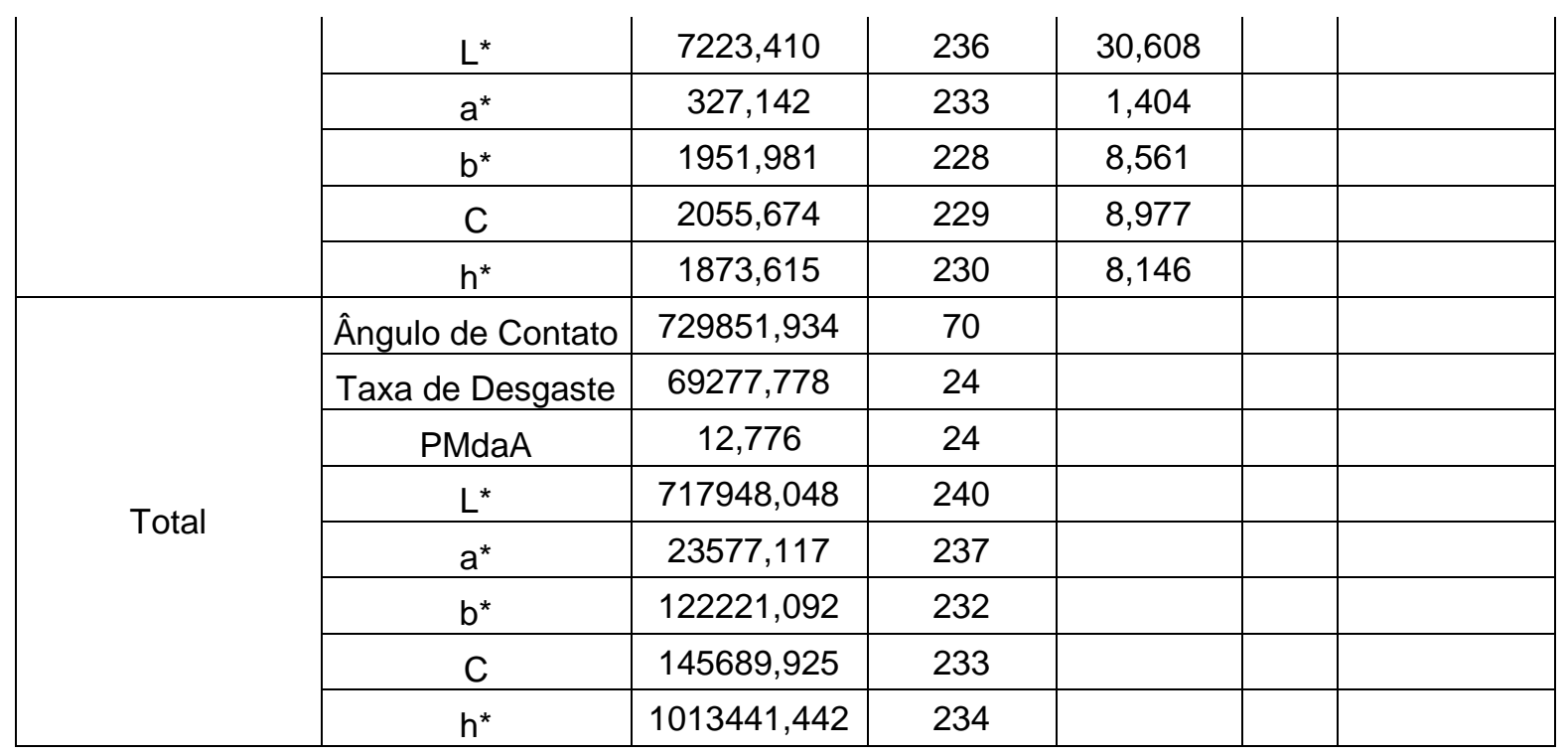

Tabela A 9 - Análise fatorial a 5\% de significância para as propriedades mecânicas dos tratamentos analisados

\begin{tabular}{|c|c|c|c|c|c|c|}
\hline $\begin{array}{l}\text { Fonte de } \\
\text { Variação }\end{array}$ & Variável & $\begin{array}{l}\text { Soma dos } \\
\text { Quadrados }\end{array}$ & $\begin{array}{c}\text { Graus } \\
\text { de } \\
\text { Liberdad } \\
e \\
\end{array}$ & $\begin{array}{l}\text { Quadrado } \\
\text { Médio }\end{array}$ & $\begin{array}{c}\mathrm{F} \\
\text { Calc }\end{array}$ & $\begin{array}{c}\text { Significânci } \\
\text { a }\end{array}$ \\
\hline \multirow{8}{*}{ Temperatura } & $f_{H, 90^{\circ}}$ & 27990,023 & 1 & 27990,023 & 0,061 & 0,808 \\
\hline & $\mathrm{f}_{\mathrm{c}, 0^{\circ}}$ & 30,756 & 1 & 30,756 & 1,033 & 0,321 \\
\hline & $\begin{array}{l}\mathrm{f}_{\mathrm{M}} \text { lado não } \\
\text { densificado }\end{array}$ & 38,365 & 1 & 38,365 & 0,281 & 0,599 \\
\hline & $\begin{array}{l}E_{m} \text { lado não } \\
\text { densificado }\end{array}$ & $\begin{array}{c}7040971,35 \\
8\end{array}$ & 1 & $\begin{array}{c}7040971,35 \\
8\end{array}$ & 6,671 & 0,013 \\
\hline & $\mathrm{f}_{\mathrm{M}}$ lado densificado & 593,496 & 1 & 593,496 & 8,680 & 0,009 \\
\hline & $\mathrm{E}_{\mathrm{m}}$ lado densificado & 617021,401 & 1 & 617021,401 & 0,943 & 0,345 \\
\hline & Velocidade & $\begin{array}{c}1225172,59 \\
8 \\
\end{array}$ & 1 & $\begin{array}{c}1225172,59 \\
8 \\
\end{array}$ & 7,356 & 0,008 \\
\hline & $E_{d}$ & $\begin{array}{c}13832478,5 \\
55\end{array}$ & 1 & $\begin{array}{c}13832478,5 \\
55\end{array}$ & 5,146 & 0,027 \\
\hline \multirow{8}{*}{ Pressão } & $\mathrm{f}_{\mathrm{H}, 90^{\circ}}$ & $\begin{array}{c}14893028,1 \\
96 \\
\end{array}$ & 1 & $\begin{array}{c}14893028,1 \\
96 \\
\end{array}$ & $\begin{array}{c}32,26 \\
8 \\
\end{array}$ & 0,000 \\
\hline & $\mathrm{f}_{\mathrm{c}, \mathrm{O}^{\circ}}$ & 463,975 & 1 & 463,975 & $\begin{array}{c}15,59 \\
0\end{array}$ & 0,001 \\
\hline & $\begin{array}{l}\mathrm{f}_{\mathrm{M}} \text { lado não } \\
\text { densificado }\end{array}$ & 1316,083 & 1 & 1316,083 & 9,647 & 0,003 \\
\hline & $\begin{array}{l}E_{m} \text { lado não } \\
\text { densificado }\end{array}$ & $\begin{array}{c}9239326,94 \\
4 \\
\end{array}$ & 1 & $\begin{array}{c}9239326,94 \\
4 \\
\end{array}$ & 8,754 & 0,005 \\
\hline & $\mathrm{f}_{\mathrm{M}}$ lado densificado & 424,088 & 1 & 424,088 & 6,202 & 0,023 \\
\hline & $\mathrm{E}_{\mathrm{m}}$ lado densificado & $\begin{array}{c}1876613,81 \\
9 \\
\end{array}$ & 1 & $\begin{array}{c}1876613,81 \\
9 \\
\end{array}$ & 2,869 & 0,109 \\
\hline & Velocidade & $\begin{array}{c}6104634,86 \\
8 \\
\end{array}$ & 1 & $\begin{array}{c}6104634,86 \\
8 \\
\end{array}$ & $\begin{array}{c}36,65 \\
1 \\
\end{array}$ & 0,000 \\
\hline & $E_{d}$ & $\begin{array}{c}3495246,11 \\
0 \\
\end{array}$ & 1 & $\begin{array}{c}3495246,11 \\
0 \\
\end{array}$ & 1,300 & 0,258 \\
\hline
\end{tabular}


Tabela A 9 - Análise fatorial a 5\% de significância para as propriedades mecânicas dos tratamentos analisados

\begin{tabular}{|c|c|c|c|c|c|c|}
\hline $\begin{array}{l}\text { Fonte de } \\
\text { Variação }\end{array}$ & Propriedade & $\begin{array}{l}\text { Soma dos } \\
\text { Quadrados }\end{array}$ & $\begin{array}{c}\text { Graus } \\
\text { de } \\
\text { Liberdad } \\
e\end{array}$ & $\begin{array}{l}\text { Quadrado } \\
\text { Médio }\end{array}$ & $\begin{array}{c}\mathrm{F} \\
\text { Calc }\end{array}$ & $\begin{array}{l}\text { Significânc } \\
\text { ia }\end{array}$ \\
\hline \multirow{8}{*}{ Te $\times P$} & $\mathrm{f}_{\mathrm{H}, 90^{\circ}}$ & 1280603,941 & 1 & $\begin{array}{c}1280603,9 \\
41 \\
\end{array}$ & $\begin{array}{c}2,77 \\
5 \\
\end{array}$ & 0,111 \\
\hline & $f_{c, 0^{\circ}}$ & 208,939 & 1 & 208,939 & $\begin{array}{c}7,02 \\
1\end{array}$ & 0,015 \\
\hline & $\begin{array}{l}f_{M} \text { lado não } \\
\text { densificado }\end{array}$ & 944,777 & 1 & 944,777 & $\begin{array}{c}6,92 \\
5\end{array}$ & 0,012 \\
\hline & $\begin{array}{l}\mathrm{E}_{\mathrm{m}} \text { lado não } \\
\text { densificado }\end{array}$ & 6517580,506 & 1 & $\begin{array}{c}6517580,5 \\
06 \\
\end{array}$ & $\begin{array}{c}6,17 \\
5\end{array}$ & 0,017 \\
\hline & $\mathrm{f}_{\mathrm{M}}$ lado densificado & 559,117 & 1 & 559,117 & $\begin{array}{c}8,17 \\
7\end{array}$ & 0,010 \\
\hline & $\mathrm{E}_{\mathrm{m}}$ lado densificado & 2500202,086 & 1 & $\begin{array}{c}2500202,0 \\
86 \\
\end{array}$ & $\begin{array}{c}3,82 \\
2 \\
\end{array}$ & 0,067 \\
\hline & Velocidade & 82489,372 & 1 & 82489,372 & $\begin{array}{c}0,49 \\
5\end{array}$ & 0,484 \\
\hline & $E_{d}$ & 7367554,833 & 1 & $\begin{array}{c}7367554,8 \\
33 \\
\end{array}$ & $\begin{array}{c}2,74 \\
1\end{array}$ & 0,102 \\
\hline \multirow{8}{*}{ Erro } & $\mathrm{f}_{\mathrm{H}, 90^{\circ}}$ & 9230817,012 & 20 & $\begin{array}{c}461540,85 \\
1 \\
\end{array}$ & & \\
\hline & $f_{c, 0}$ & 595,223 & 20 & 29,761 & & \\
\hline & $\begin{array}{l}f_{M} \text { lado não } \\
\text { densificado }\end{array}$ & 6002,823 & 44 & 136,428 & & \\
\hline & $\begin{array}{l}E_{m} \text { lado não } \\
\text { densificado }\end{array}$ & 45383021,823 & 43 & $\begin{array}{c}1055419,1 \\
12\end{array}$ & & \\
\hline & $f_{M}$ lado densificado & 1230,728 & 18 & 68,374 & & \\
\hline & $\mathrm{E}_{\mathrm{m}}$ lado densificado & 11120060,321 & 17 & $\begin{array}{c}654121,19 \\
5 \\
\end{array}$ & & \\
\hline & Velocidade & 11326128,898 & 68 & $\begin{array}{c}166560,71 \\
9\end{array}$ & & \\
\hline & $E_{d}$ & $\begin{array}{c}180104820,64 \\
9 \\
\end{array}$ & 67 & $\begin{array}{c}2688131,6 \\
51 \\
\end{array}$ & & \\
\hline \multirow{8}{*}{ Total } & $\mathrm{f}_{\mathrm{H}, 90^{\circ}}$ & $\begin{array}{c}400348803,13 \\
3 \\
\end{array}$ & 24 & & & \\
\hline & $f_{c, 0^{\circ}}$ & 63571,359 & 24 & & & \\
\hline & $\begin{array}{l}f_{M} \text { lado não } \\
\text { densificado }\end{array}$ & 385351,307 & 48 & & & \\
\hline & $\begin{array}{l}\mathrm{E}_{\mathrm{m}} \text { lado não } \\
\text { densificado }\end{array}$ & $\begin{array}{c}2895021245,2 \\
48 \\
\end{array}$ & 47 & & & \\
\hline & $f_{M}$ lado densificado & 116064,117 & 22 & & & \\
\hline & $E_{m}$ lado densificado & $\begin{array}{c}806199146,71 \\
9 \\
\end{array}$ & 72 & & & \\
\hline & Velocidade & $\begin{array}{c}2899265761,0 \\
43 \\
\end{array}$ & 71 & & & \\
\hline & $E_{d}$ & $\begin{array}{c}1254235892,0 \\
58 \\
\end{array}$ & 21 & & & \\
\hline
\end{tabular}

